\title{
Shear Behaviour of Oil Sand Fine Tailings in simple shear and triaxial devices
}

\author{
A thesis submitted to \\ the Faculty of Graduate and Postdoctoral Affairs \\ in Partial Fulfillment of the requirements for the degree of \\ Master of Applied Science in Civil Engineering \\ By \\ Mahsa Gholami \\ Department of Civil and Environmental Engineering \\ Carleton University
}

Ottawa-Carleton Institute of Civil and Environmental Engineering

December 2014

(C) 2014 Mahsa Gholami 


\section{Dedication}

This thesis is dedicated to my family who makes me to believe angels are existed in this world, and love and life meanings are completed with them.

This is dedicated to:

My father, Mahmood Gholami,

Who taught me life alphabet with his unlimited kindness

My mother, Mahnaz Ghashghaie,

Who taught me love alphabet with her big heart and her unconditional love

My sister, Mandana Gholami and Maryam Gholami,

Who their presence warms my heart and brings me happiness

My brother's soul, Mohsen Gholami,

Who taught me how to be strong.

"And you shall love the Lord your God with all your heart and with all your soul and with all your mind and with all your strength.' The second is this: You shall love your neighbour as yourself.' There is no other commandment greater than these. "-Mark 12:30-31 


\section{Acknowledgements}

I would like to express my sincere gratitude to my supervisor Professor Paul H. Simms for his endless and kind support, guidance, patience, and understanding which made this research to be completed. I learned a lot from you not only as a supervisor but also as a nice individual. I am really hopeful to pursue my Ph.D. studies under your supervision one day.

I would like to appreciate technical staffs, Stanley Conley, Pierre Trudel, Jason Arnott, Benjamin Griffin, Kenneth Akhiwu, Marie Tudoret and Payal Chadha (Graduate administrator) in Department of Civil and Environmental Engineering at Carleton University for their unlimited support and time. Recalling those days that I was working in the lab with a great support and help from great people like you makes me happy and encourages me to come back one day to continue my studies.

Financial support by COSIA (Canada's Oil Sands Innovation Alliance) and NSERC (National Research Council of Canada) and Essential In-kind support by Shell Canada in terms of tailings are highly appreciated.

I would like to thank Dr. Siva Sivathayalan for providing the access to the simple shear device in the advanced geotechnical lab at Carleton University. I am also grateful to Professors Sai Vanapalli, Mohammad Rayhani, Mamadou Fall, and Oh Won Taek for improving my knowledge by their useful courses.

I would like to appreciate the graduate fellows Thayaparan Theenathayarl, Abdulghader Abdulrahman, Mandy Witteman, Shabnam Mizani and Sahar Soleimani for their time and friendly help during this research.

And finally I would like to thank my family, Mahmood Gholami, Mahnaz Ghashghaie, and Mandana Gholami for their endless support, help, and understanding which made my journey in Canada smoother. 


\section{Contents}

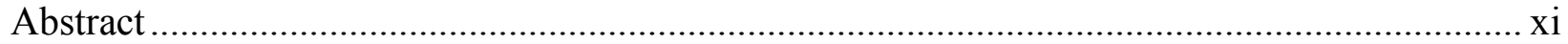

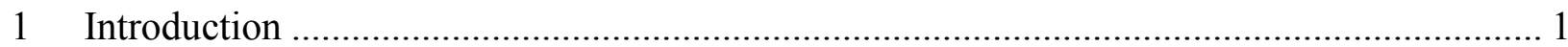

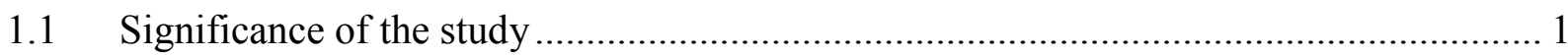

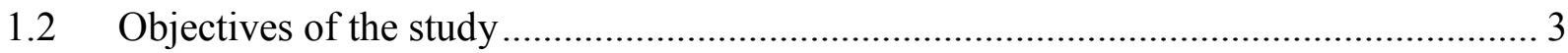

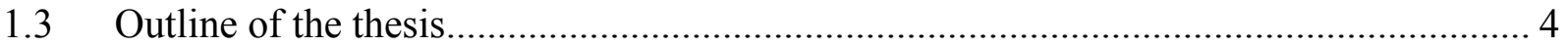

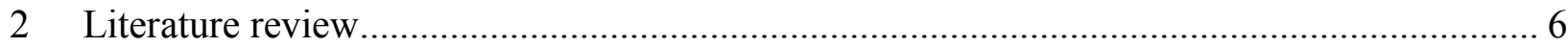

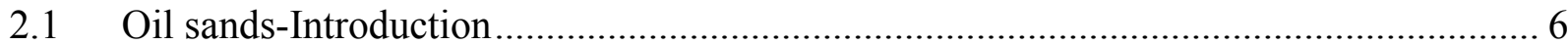

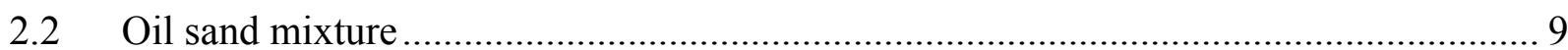

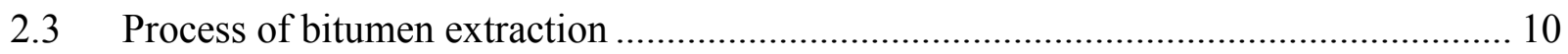

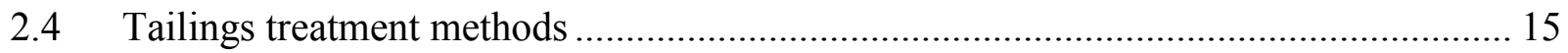

2.4.1 Chemical amendment........................................................................... 17

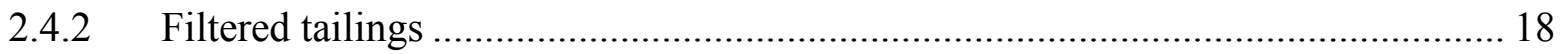

2.4.3 Composite/Consolidated Tailings ...................................................................... 18

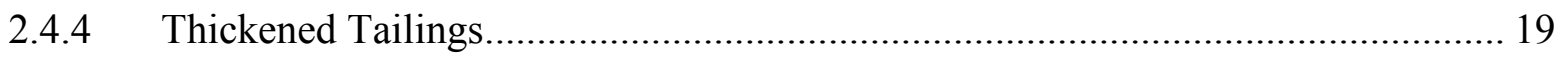

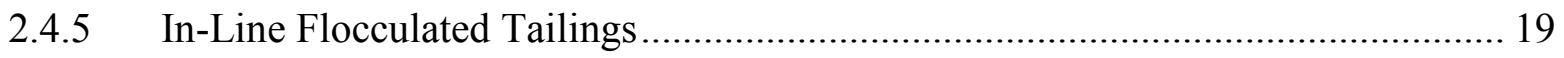

2.4.6 In-line Thickening with Thin Lift Dewatering ............................................ 21

2.4.7 In-line Thickening with Accelerated Dewatering (rim ditching) ....................... 21

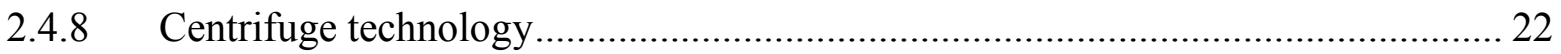

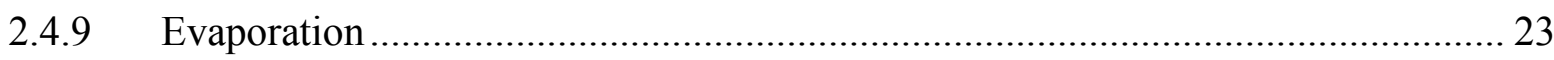

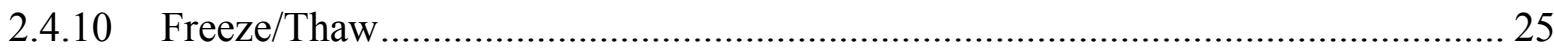

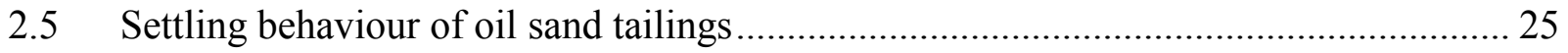

2.5.1 Segregated tailings vs. non-segregated tailings ........................................... 25

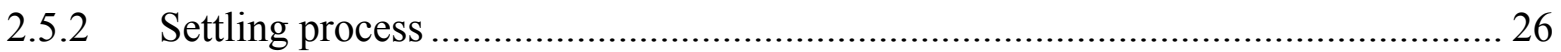

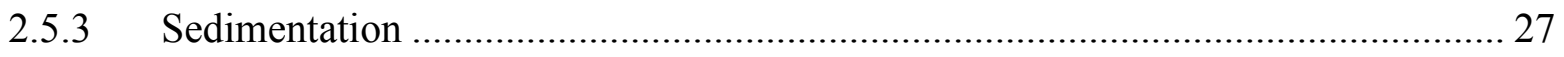

2.5.4 Compression behaviour of tailings .............................................................. 29

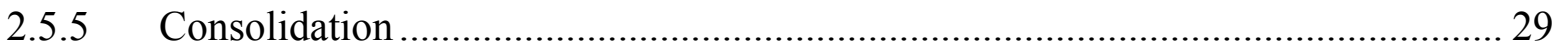

2.5.6 Finite strain consolidation model..................................................................... 31

2.6 Previous experiments on constitutive relationships determination ............................ 34

2.6.1 Self-weight consolidation test......................................................................... 34

2.6.2 Hydraulic consolidation test .................................................................. 35 


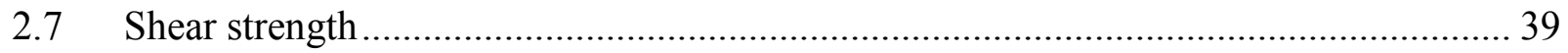

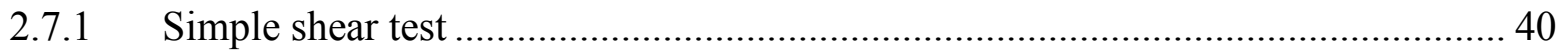

2.7.2 Undrained monotonic behaviour of sands ........................................................... 44

2.7.3 Parameters affecting monotonic response of sands ................................................ 45

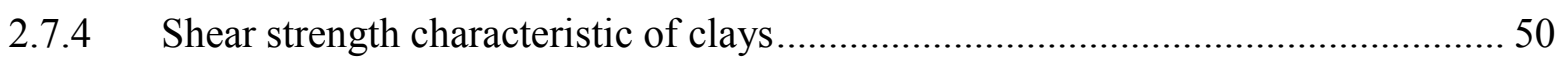

2.7.5 Parameters affecting shear strength of hard rock mine tailings .............................. 54

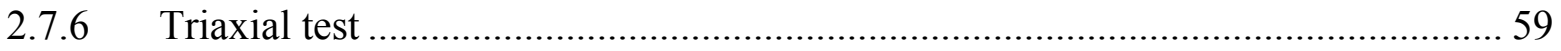

2.7.7 Comparison of shearing apparatus and triaxial device …….................................... 61

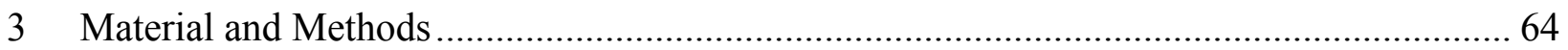

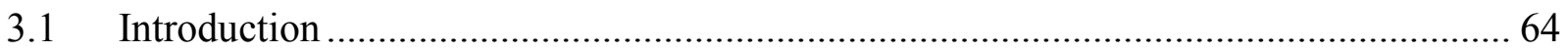

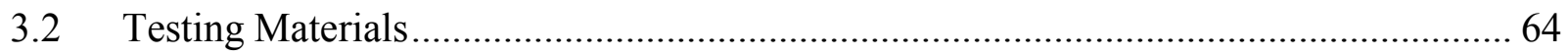

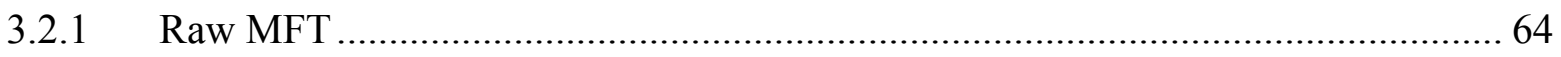

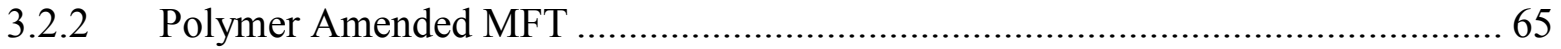

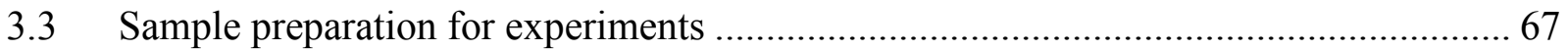

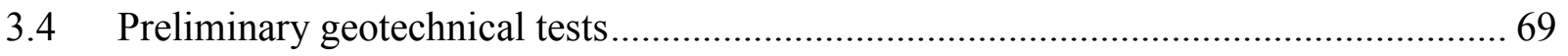

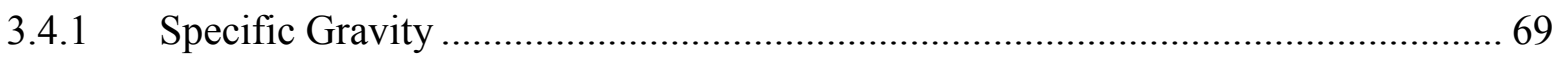

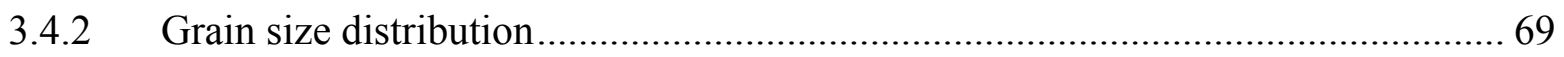

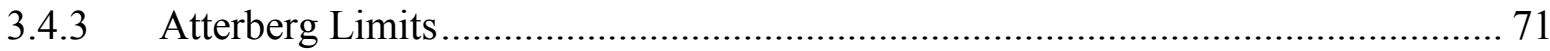

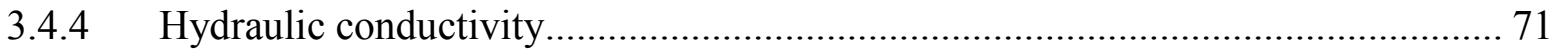

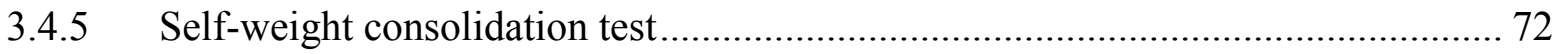

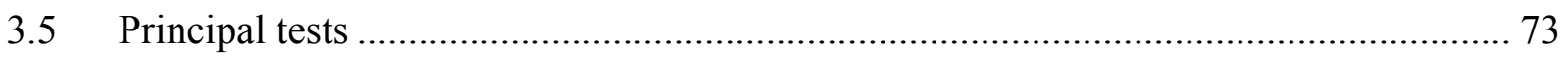

4 Results of consolidation, simple shear, and triaxial tests .................................................. 83

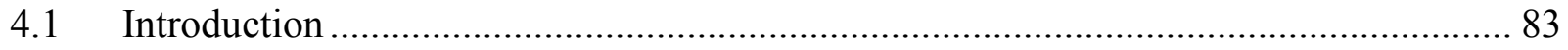

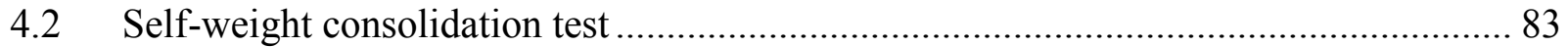

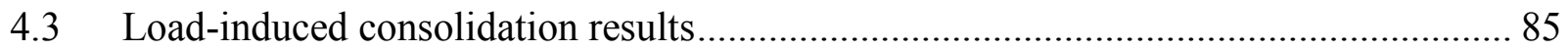

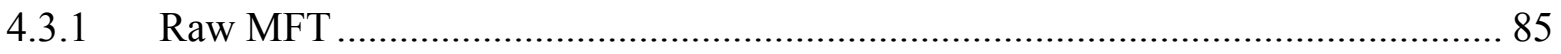

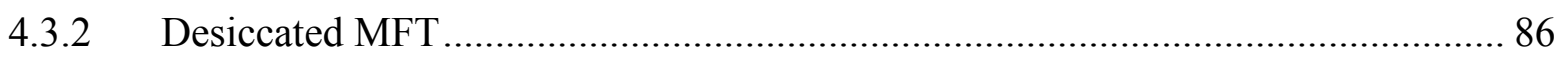

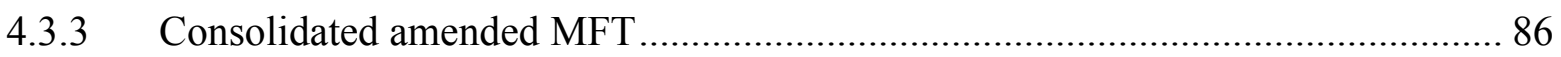

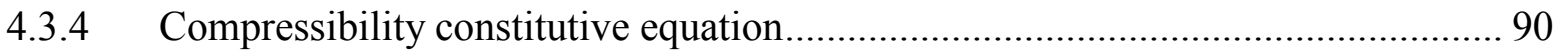

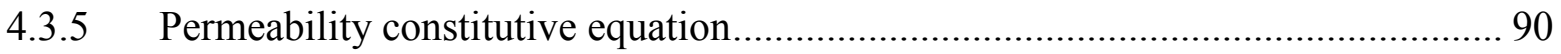

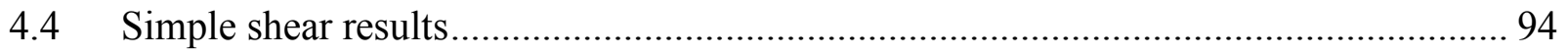

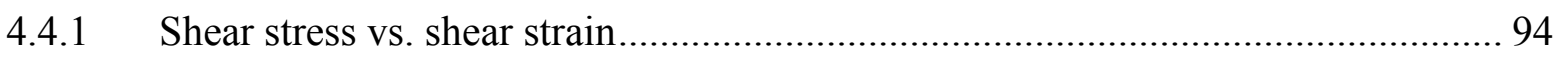




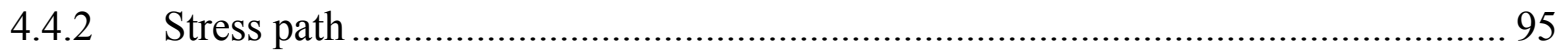

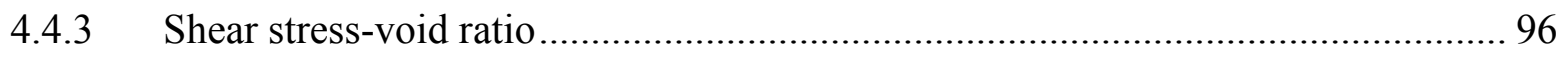

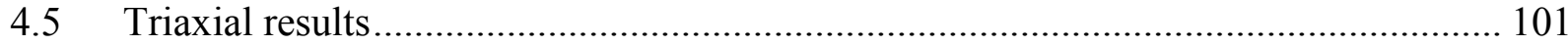

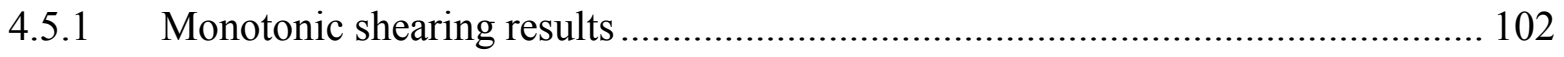

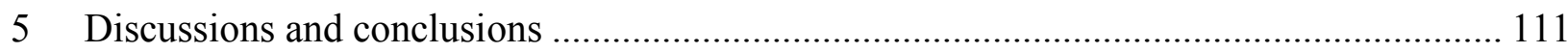

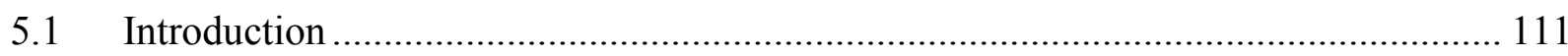

5.1.1 Compressibility constitutive relationship ............................................... 111

5.1.2 Permeability constitutive relationship......................................................... 112

5.2 Comparison of simple shear results .............................................................. 114

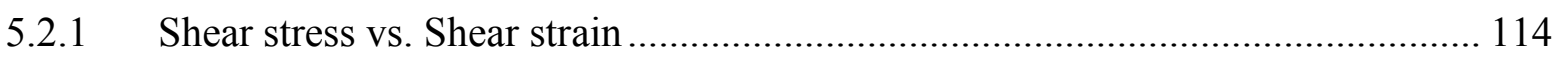

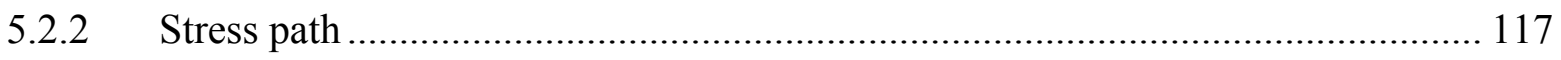

5.3 Comparison of triaxial results ...................................................................... 119

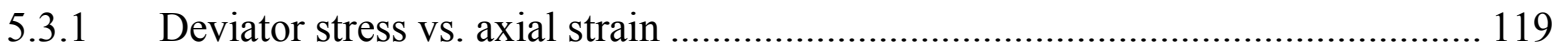

5.4 Comparison of tariaxial and simple shear results................................................. 122

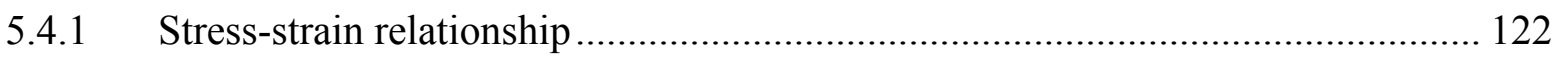

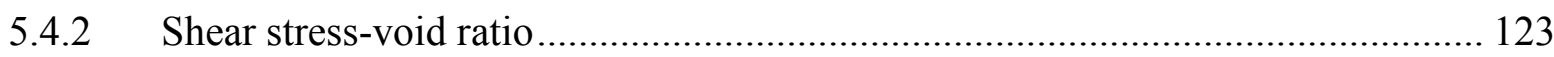

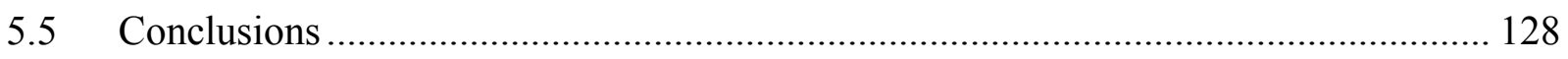

5.6 Recommendations for future study ............................................................ 128

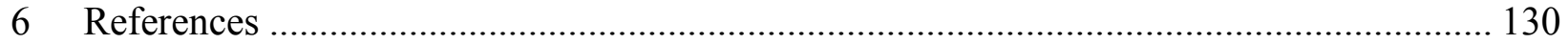

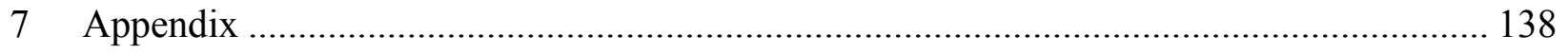

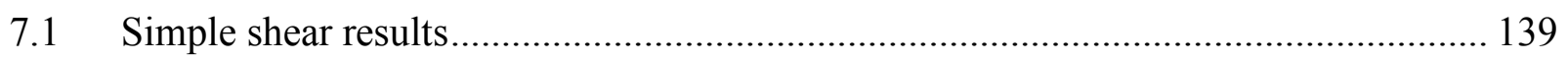

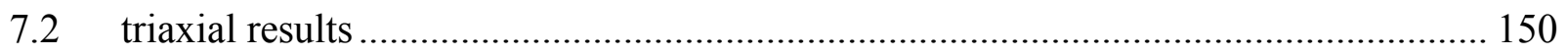




\section{$\underline{\text { List of Figures }}$}

Figure 1-1.Deposition of centrifuged tailings in an impoundment (Syncrude 2008) .....................................2

Figure 1-2. Fluid fine tailings (Left), produced lower water content tailings using in-line flocculation technique (Shell 2009)

Figure 1-3. Rapid mixing of polymer occurs in a $17 \mathrm{ft}$ pipeline (shell) (Mizani et al. 2013) ............................. 3

Figure 2-1. Distribution of oil sand resources in Canada.............................................................................. 7

Figure 2-2.Ternary diagram for oil sand tailings characterization (Azam and Scott 2005) ............................. 9

Figure 2-3. Mining and Extraction of Bitumen from Oil Sands (Masliyah, 2009) ..........................................11

Figure 2-4.Steam assisted gravity drainage for in situ Bitumen extraction ................................................... 12

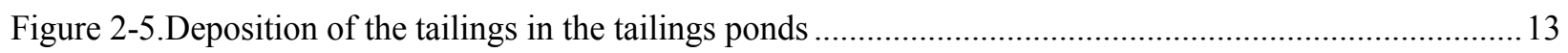

Figure 2-6.Tailings segregation after depositing in the tailings pond (ERCB 2011)...................................... 13

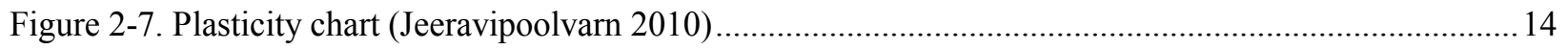

Figure 2-8. Field ILTT history matching compressibility relationship compared ........................................ 15

Figure 2-9. Field history matching hydraulic conductivity relationship (Jeeravipoolvarn 2010).................... 15

Figure 2-10.Composite tailings process (Matthews et al. 2000) ................................................................... 19

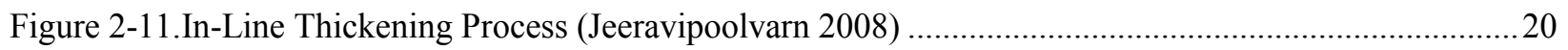

Figure 2-12.Stages of adding chemical amendments (Jeeravipoolvarn 2008) .............................................2 21

Figure 2-13. Implementing accelerated dewatering technique in a big scale by Syncrude (Lahaie 2008) .........22

Figure 2-14.MFT centrifuge technique to produce cake and centrate (Devenny, 2010) .................................23

Figure 2-15.Factors affecting drying of a freshly deposited layer (Simms and Grabinsky, 2004) ...................24

Figure 2-16. The general characteristics of sedimentation of a clay-water mixture (Imai 1981) .....................28

Figure 2-17.Compressibility path followed by soil element during progress of consolidation (solid lines,

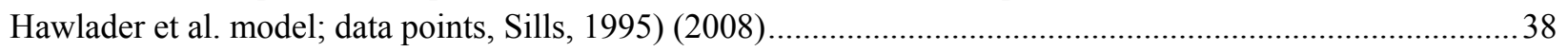

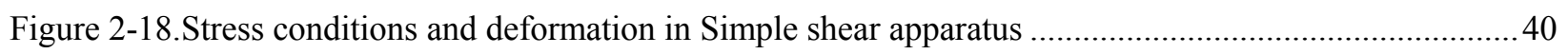

Figure 2-19.Specimen confinement in Simple shear test (Kim 2009) ........................................................ 41

Figure 2-20.NGI simple shear apparatus (Kjellman 1951) ...................................................................... 42 
Figure 2-22.The Cambridge University simple shear device- (a) vertical section, (b) side elevation (Roscoe $1953)$ .43

Figure 2-23.a) Simple shear and Pure Shear. b) Stress distribution in a Simple shear Airey et al. (1985).........44

Figure 2-24.Undrained monotonic response of sand at different relative density- a) Stress vs.strain, b) Stress path (after Vaid and Chern 1985).

Figure 2-25.Effect of fabric on undrained Simple shear response, a) after Vaid et al. (1995), b) Vaid and Sivathayalan (2000) .46

Figure 2-26.Comparison of undrained monotonic behaviour of Fraser Delta sand at different loading modes (Vaid and Sivathayalan 1996).

Figure 2-27. The correlation of Brittleness Index and contractiveness tendency (Vaid and Sivathayalan 1996) 48

Figure 2-28.Behavior of loosest deposited Frazer River sand in (a) Monotonic triaxial compression loading, and (b) Monotonic extension loading (Vaid et al. 2001).

Figure 2-29. Simple shear test results for soft clays (Kaolinite specimens). (Bro et al. 2013) .50

Figure 2-30.Comparison of DST tests on remoulded and undisturbed specimens of plastic Drammen clay (Hanzawa et al. 2007). .51

Figure 2-31.Normalised behaviour using idealised triaxial compression test data for homogeneous clay and direct simple shear test data for normally consolidated Maine organic clay (Ladd and Foot, 1974).................53

Figure 2-32.Monotonic response of a gold tailings over a range of void ratio (Al-Tarhouni et al. 2011) ..........55

Figure 2-33.Comparison of two samples of similar post-consolidation void ratio (ec), with one of the tests connected to a water reservoir to increase degree of saturation: (a) normalized shear stress versus shear strain; (b) excess pore pressure ratio versus shear strain; (c) stress path. .56

Figure 2-34.Comparison of monotonic response of constant volume tests on synthetic silts under same void ratio (ec $=0.66 \pm 0.01)$ but different degrees of saturation (Daliri 2013).

Figure 2-35. The effect of OCR derived by desiccation and mechanical method on monotonic response of thickened gold tailings (Kim et al. 2011)... .58

Figure 2-36.Typical results of conventional triaxial 60

Figure 2-37.Specimen stress state during triaxial compression (GDS 2013) 61

Figure 3-1.Mixer to prepare polymer and amended MFT .66

Figure 3-2.Comparison of different dosage of polymer for preparing flocculated MFT (Jig test)...... .67 
Figure 3-3.Preparation of amended MFT with self-weigth consolidation only .....

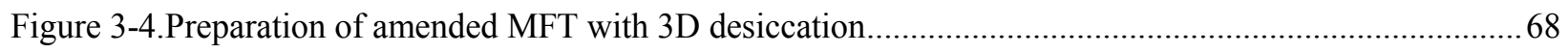

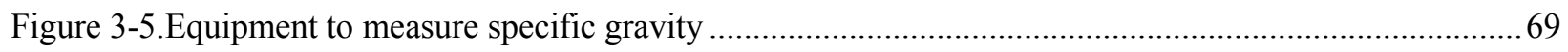

Figure 3-6.Particle size distribution of raw MFT (Bajwa and Simms 2013) ................................................. 70

Figure 3-7.Particle size distribution of amended MFT (polymer dosage of 700 g/T) (Bajwa and Simms 2013)

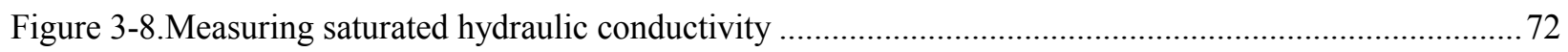

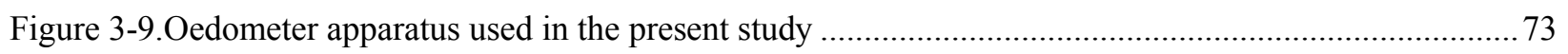

Figure 3-10.The rigid ring and other parts required for sample set up in Oedometer device .......................... 74

Figure 3-11.The membrane to restrict any lateral movement in NGI device................................................ 76

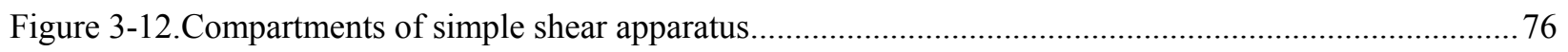

Figure 3-13.Configuration of simple shear apparatus used in the study (Al-Tarhuni 2008) .......................... 77

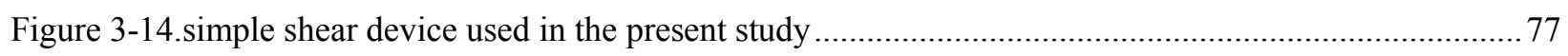

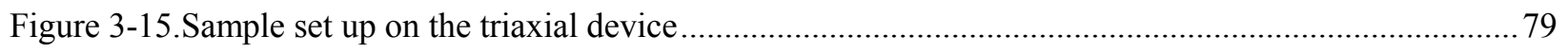

Figure 3-16.Conventional triaxial device used for consolidation and shearing behaviour analysis .................. 80

Figure 4-1.Moveable rings to track self-weight consolidation ................................................................. 84

Figure 4-2.Void ratio change with respect to depth during self-weight consolidation ...................................... 85

Figure 4-3.Behaviour of Raw MFT during consolidation. a) Displacement, b) Settlement, c) Void ratio changes

Figure 4-4.Behaviour of desiccated amended MFT during consolidation. a) Displacement, b) Settlement, c) Void ratio changes .

Figure 4-5.Behaviour of consolidated amended MFT during consolidation. a) Displacement, b) Settlement, c) Void ratio changes .

Figure 4-6.Compressibility behaviour- a) Raw MFT, b) Desiccated amended MFT, c) consolidated amended MFT.

Figure 4-7.Calculated permeability at the end of consolidation- a) Raw MFT, b) Consolidated amended MFT, c) Desiccated amended MFT .93

Figure 4-8.A sample within the simple shear device before and after shearing .94 
Figure 4-9.Comparison of Raw MFT behaviour during shearing- a) shear stress vs. shear strain, b) Normalized shear stress vs. shear strain, c) Normalized pore water pressure, d) stress path

Figure 4-10.Comparison of consolidated amended MFT behaviour during shearing- a) shear stress vs. shear strain, b) Normalized shear stress vs. shear strain, c) Normalized pore water pressure, d) stress path ...... .98

Figure 4-11.Comparison of desiccated MFT behaviour during shearing- a) shear stress vs. shear strain, b) Normalized shear stress vs. shear strain, c) Normalized pore water pressure, d) stress path.

Figure 4-12. Shear strength-void ratio relationship ....... 100

Figure 4-13. Figure 4-14.Sample within triaxial apparatus from left to right-before consolidation-after consolidation- after shearing..... 102

Figure 4-15.Comparison of consolidated amended MFT behaviour during shearing a) Deviator stress vs. strain, b) Normalized stress, c) Normalized pore water pressure (top) d) Stress path (top) 105

Figure 4-16.Comparison of consolidated amended MFT behaviour during shearing a) Deviator stress vs. strain, b) Normalized stress, c) Normalized pore water pressure (bottom) d) Stress path (Bottom) 106

Figure 4-17.Comparison of desiccated amended MFT behaviour during shearing a) Deviator stress vs. strain, b) Normalized stress, c) Normalized pore water pressure (Top) d) Stress path (Top)... 107

Figure 4-18.Comparison of desiccated amended MFT behaviour during shearing a) Deviator stress vs. strain, b) Normalized stress, c) Normalized pore water pressure (Bottom) d) Stress path (Bottom)....... 108

Figure 4-19. Shear strength-void ratio relationship 110

Figure 5-1 Combined compressibility behaviour of all samples 113

Figure 5-2 Combined permeability results. 113

Figure 5-3. Simple shear results comparison between consolidated amended MFT and raw MFT at effective stress level of a) $25 \mathrm{kPa}, \mathrm{b}) 50 \mathrm{kPa}$, c) $75 \mathrm{kPa}$, d) $100 \mathrm{kPa}$. 117

Figure 5-4. Shear strength-void ratio relationship

Figure 5-5.Stress Path comparison- a) Raw MFT and polymer amended MFT, b) Raw MFT and desiccated amended MFT, c) Polymer amended desiccated MFT 118

Figure 5-6. Simple shear test results for soft clays (Kaolinite specimens) (Bro et al. 2013). 119

Figure 5-7. Comparison of triaxial results at effective stress level of a) $25 \mathrm{kPa}, \mathrm{b}) 50 \mathrm{kPa}$, c) $75 \mathrm{kPa}$, d) $100 \mathrm{kPa}$

Figure 5-8-Su-sensitivity of oil sands fine tailings.

Figure 5-9. Stress-Strain comparison in simple shear and triaxial -Desiccated amended MFT 124 
Figure 5-12- Comparison of element test shear strength to field vane data - lines best fits to data presented in Beier et al. (2013). 127

Figure 7-1.Raw MFT behaviour during shearing (25 kPa)- a) shear stress vs. shear strain, b) Normalized shear stress vs. shear strain, c) Normalized pore water pressure, d) stress path.....

Figure 7-2.Raw MFT behaviour during shearing (50 kPa)- a) shear stress vs. shear strain, b) Normalized shear stress vs. shear strain, c) Normalized pore water pressure, d) stress path. 140

Figure 7-3.Raw MFT behaviour during shearing (75 kPa)- a) shear stress vs. shear strain, b) Normalized shear stress vs. shear strain, c) Normalized pore water pressure, d) stress path.

Figure 7-4.Raw MFT behaviour during shearing (100 kPa)- a) shear stress vs. shear strain, b) Normalized shear stress vs. shear strain, c) Normalized pore water pressure, d) stress path 142

Figure 7-5.Consolidated amended MFT behaviour during shearing (25 kPa)- a) shear stress vs. shear strain, b) Normalized shear stress vs. shear strain, c) Normalized pore water pressure, d) stress path. 143

Figure 7-6. Consolidated amended MFT behaviour during shearing (50 kPa)- a) shear stress vs. shear strain, b) Normalized shear stress vs. shear strain, c) Normalized pore water pressure, d) stress path.

Figure 7-7. Consolidated amended MFT behaviour during shearing (75 kPa)- a) shear stress vs. shear strain, b) Normalized shear stress vs. shear strain, c) Normalized pore water pressure, d) stress path. 145

Figure 7-8. Consolidated amended MFT behaviour during shearing $(100 \mathrm{kPa}) \mathrm{g}$ - a) shear stress vs. shear strain, b) Normalized shear stress vs. shear strain, c) Normalized pore water pressure, d) stress path ...... 146

Figure 7-9.Desiccated MFT behaviour during shearing ( $25 \mathrm{kPa}$ )- a) shear stress vs. shear strain, b) Normalized shear stress vs. shear strain, c) Normalized pore water pressure, d) stress path

Figure 7-10.Desiccated MFT behaviour during shearing(50 kPa)- a) shear stress vs. shear strain, b) Normalized shear stress vs. shear strain, c) Normalized pore water pressure, d) stress path 148

Figure 7-11.Desiccated MFT behaviour during shearing (75 kPa)- a) shear stress vs. shear strain, b) Normalized shear stress vs. shear strain, c) Normalized pore water pressure, d) stress path.

Figure 7-12. consolidated amended MFT behaviour during shearing(25 kPa)- a) Deviator stress vs. shear strain, b) Pore water pressure-Bottom c) Pore water pressure-Top, d) stress path (bottom) 150

Figure 7-13.Consolidated amended MFT behaviour during shearing(50 kPa)- a) Deviator stress vs. shear strain, b) Pore water pressure-Bottom c) Pore water pressure-Top, d) stress path (bottom) 151

Figure 7-14.Consolidated amended MFT behaviour during shearing(75 kPa)- a) Deviator stress vs. shear strain, b) Pore water pressure-Bottom c) Pore water pressure-Top, d) stress path (bottom) 152 
Figure 7-15.Consolidated amended MFT behaviour during shearing(100 kPa)- a) Deviator stress vs. shear strain, b) Pore water pressure-Bottom c) Pore water pressure-Top, d) stress path (bottom)

Figure 7-16.Desiccated MFT behaviour during shearing(25 kPa)- a) Deviator stress vs. shear strain, b) Pore water pressure-Bottom c) Pore water pressure-Top, d) stress path (bottom). 154

Figure 7-17.Desiccated MFT behaviour during shearing(50 kPa)- a) Deviator stress vs. shear strain, b) Pore water pressure-Bottom c) Pore water pressure-Top, d) stress path (bottom) 155

Figure 7-18.Desiccated MFT behaviour during shearing(75 kPa)- a) Deviator stress vs. shear strain, b) Pore water pressure-Bottom c) Pore water pressure-Top, d) stress path (Bottom) 156

Figure 7-19.Desiccated MFT behaviour during shearing(100 kPa)- a) Deviator stress vs. shear strain, b) Pore water pressure-Bottom c) Pore water pressure-Top, d) stress path (Bottom) 157 


\section{$\underline{\text { List of Tables }}$}

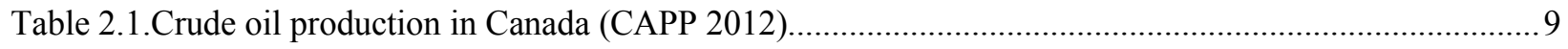

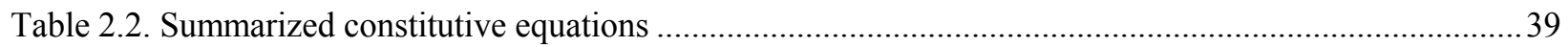

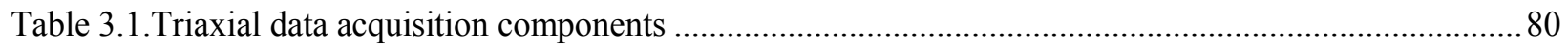

Table 4.1.Water Content and Solid Content distribution after shearing in the triaxial apparatus-consolidated

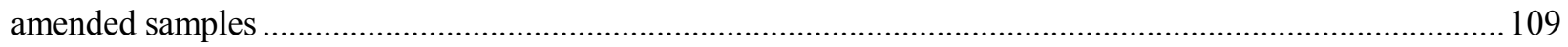

Table 4.2.Water Content and Solid Content distribution after shearing in the triaxial apparatus-Desiccated

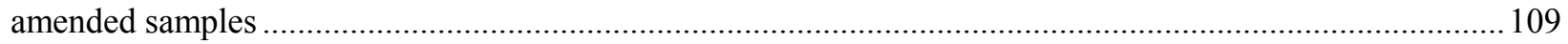

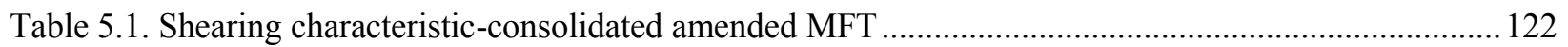

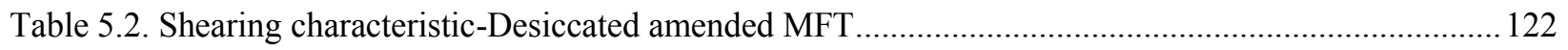

Table 5.3.Comparison of Shear stress values-Consolidated amended samples ............................................ 126

Table 5.4.Comparison of Shear stress values-Desiccated amended samples................................................ 126 


\begin{abstract}
Oil Sand Fine Tailings are difficult to manage due to their poor consolidation characteristics. Once reaching about 35\% solids content, at which they are termed mature fine tailings (MFT), they do not appreciably consolidate any further. This is due to low hydraulic conductivity associated with the dispersion of clay particles generated during the bitumen extraction process. On the other hand, MFT at 35\% solids content do not possess any substantial strength, and therefore the tailings have to be stored in dammed impoundments with substantial footprints, that cannot be reclaimed. Regulations have been therefore recently implemented (Directive 074) that require oil sand operators to improve shear strength of deposited tailings to be at least $5 \mathrm{kPa}$ within a year after deposition.
\end{abstract}

To meet the regulatory requirements, many technologies have been explored that use a polymer in order to drive clay particle flocculation and improve dewatering which results in shear strength improvement. Such technologies include centrifugation, in-line flocculation, thickening, and recombining fine tailings with sand tailings. However, most of the tracking of strength behaviour of deposits of polymer amended fine tailings has been using undrained strength measurements using field vane or cone penetration testing. This thesis attempts to analyze strength behaviour by using element tests (simple shear and triaxial), the first such attempt in the public domain to the author's knowledge.

Results of shear strength analysis showed that simple shear gave a consistent normalized shear strength (shear strength over effective vertical consolidation stress) across all stress levels. Qualitatively, the behaviour is similar to other soft soils tested using simple shear. Polymeramended MFT showed a higher strength when compared against reconstituted MFT samples on a void ratio basis, but not on an effective stress basis. The shear strength increased towards a constant value, but the samples did not achieve a true steady state, and pore-water pressures increased continuously throughout the tests. Samples desiccated before rewetting and consolidation did show a somewhat stronger response.

Triaxial tests yielded comparable strength to simple shear when evaluated on an equivalent void ratio basis. The tests, however, showed significant heterogeneity in density and even in pore- 
water pressure response from the top to the bottom of the sample. This arises due to variable density with depth produced by self-weight consolidation. 


\section{Introduction}

\subsection{Significance of the study}

In oil sands surface mine, the tailings that come directly from the extraction plant, named whole tailings, consist of water, a combination of coarse (sand) and fine particles (silt and clay) as well as small portion of residual bitumen. The solid content of whole tailings after extraction is in the range of $45-55 \%$. In conventional deposition, the whole tailings are pumped to dammed disposal areas. Coarse particles settle relatively rapidly to form beaches, while fine particles and bitumen accumulate to form a floating layer called fluid fine tailings with a solid content of about $8 \%$. Over some years, fluid fine tailings undergo hindered settlement and the excess water drains in order to create Mature Fine Tailings (MFT), which have a solid content of about 35\%. At this density, the tailings posses low strength $(<1 \mathrm{kPa})$ and are fair from being trafficable, hence impossible or at least very difficult to reclaim, Also, the low hydraulic conductivity and thixotropic behaviour of the tailings impedes further dewatering over a reasonable time period.

Therefore, the Alberta government recently enacted regulations (Directive 074) in which operators have been forced to accelerate exploration of new technologies as alternative(s) to conventional deposition such that undrained shear strength of fine tailings should be at least 5 $\mathrm{kPa}$ within a year.

Several tailings technologies accelerate dewatering through the use of a polymer: Thickening, inline flocculation, centrifugation. These technologies have or are being trialed in the oil sands industry up to the pilot scale. These techniques are described in details in chapter 2. Figure 1-1 illustrates an example of consolidated tailings production using centrifuge technique. Examples 
of the deposits produced by centrifugation and in-line flocculation are shown in (Figure 1-2 and Figure 1-3).

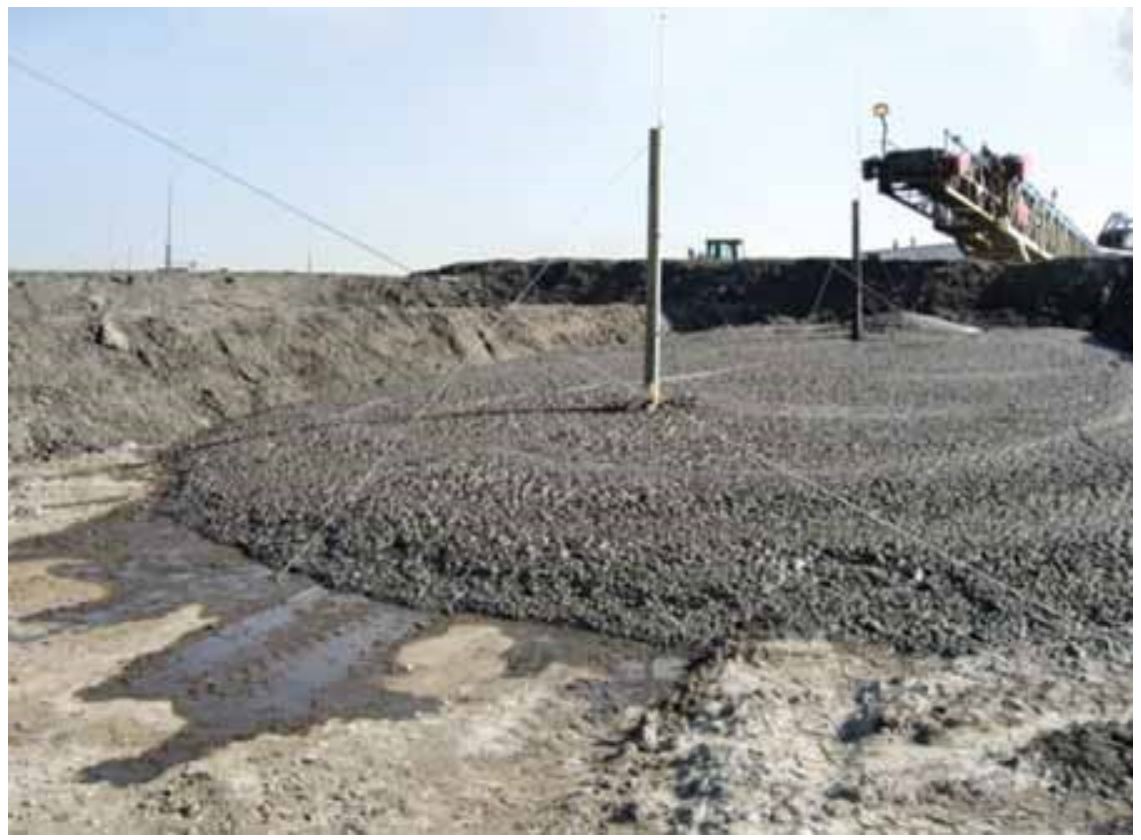

Figure 1-1.Deposition of centrifuged tailings in an impoundment (Syncrude 2008)
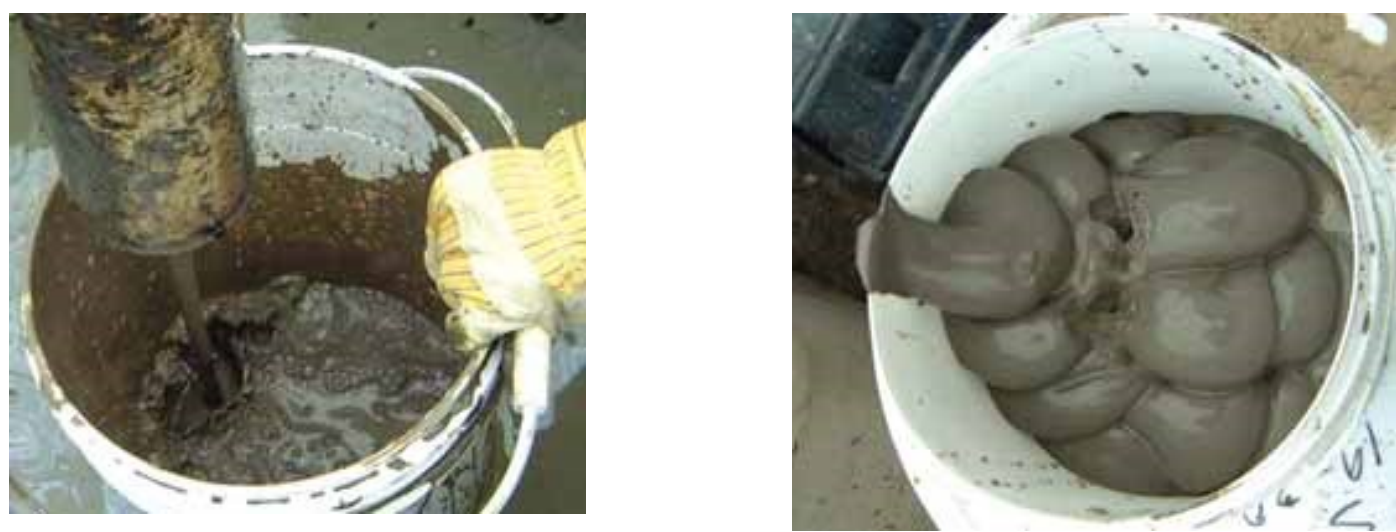

Figure 1-2. Fluid fine tailings (Left), produced lower water content tailings using in-line flocculation technique (Shell 2009) 

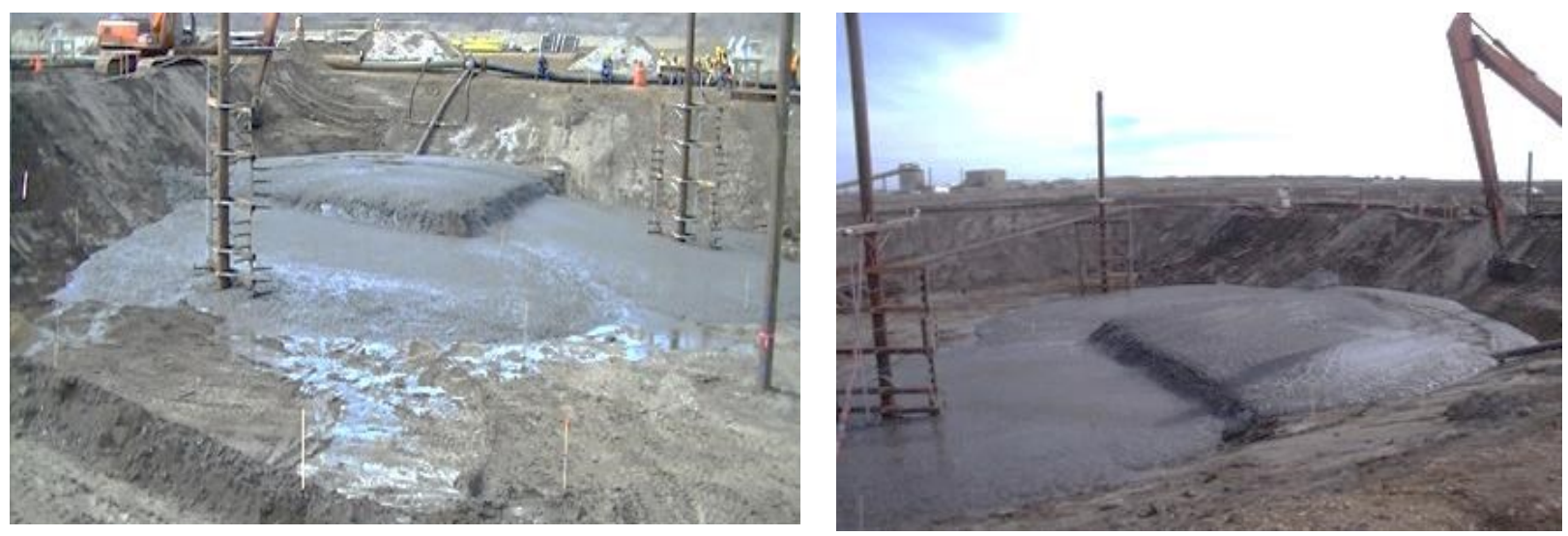

Figure 1-3. Rapid mixing of polymer occurs in a $17 \mathrm{ft}$ pipeline (shell) (Mizani et al. 2013)

Generally, each introduced approachis effective to some extent by improving dewatering of MFT, which in turn accelerates consolidation and improves shear strength attainment. At larger scale, it decreases large impoundment footprint area and shortens the time to reclamation. However, there has been no completely acceptable solution to date, probably due to lack of technical or economic feasibility.

\subsection{Objectives of the study}

This study investigates the shear strength behaviour and compressibility of polymer amended MFT at laboratory scale. This is done using oedomter, simple shear and triaxial tests. The novelty of this study rests primarily in the use of element tests to characterize polymer amended MFT. Element tests will provide richer detail on the shear behaviour of these materials, which until now have been mainly characterized using field vane tests. The information from the element tests will be useful, for example to assess whether polymer ameneded MFT are sensitive, as claimed by some works in the literature (e.g., Beier et al. 2013). Additionally, the influence of desiccation that may occur during thin-lift deposition, or near the surface of deep deposits, on strength behaviour of subsequently buried tailings, is also investigated.

The following objectives are followed for conducting this study:

1. Generate polymer amended MFT in the laboratory that mimics field samples in its primary characteristics (Atterberg limits, dewaterability, rheology). This is also helpful in investigating the influence of polymer on improving geotechnical properties of raw MFT. 
2. Design protocols to facilitate self-weight (SW) consolidation and desiccation of samples, and allowed them to be transferred to triaxial and simple shear tests with minimal disturbance.

3. Control Desiccation to generate samples with a consistent water content to be used for consolidation and shearing tests. This is important to answer this question: "How desiccation contributes to shear strength gain".

4. Conduct consolidation tests to find void ratio-effective stress (compressibility) and void ratio-hydraulic conductivity relationships

5. Conduct triaxial and simple shear tests to investigate shear behaviour

\subsection{Outline of the thesis}

This thesis has written in 5 chapters. A summary introduction of each chapter is presented as below:

The first chapter describes the significance of the present study and its objectives.

Chapter 2 starts with an explanation of oil sand tailings and different treatment techniques to improve geotechnical behaviour of MFT with special focus on hydraulic conductivity, consolidation and shear strength. This is followed by description of settling behaviour of tailings and related phenomena including sedimentation and consolidation. Also, finite strain consolidation and its application are reviewed. Shear strength behaviour of materials such as sand, clay, and mine tailings and the parameters affecting the shear strength are described. Furthermore, information on shear strength measurement using simple shear and triaxial apparatus are given.

Chapter 3 describes the testing material and sample preparation for raw MFT and polymer amended MFT in the laboratory scale. The preliminary geotechnical tests to determine general properties of both raw MFT and amended MFT are presented. A full description of main experiments including oedometer test, simple shear test, and triaxial test are addressed in order to characterize consolidation and shear strength of the materials.

In Chapter 4, results of consolidation tests, simple shear tests, and triaxial tests are presented and discussed in details. The results include displacement and void ratio changes during 
consolidation and stress-strain relationship, pore water pressure build up and stress path during shearing phase.

Chapter 5 summarizes all observations and conclusions from the present study. A comparison was made between the results of simple shear tests and triaxial tests to analyze any change in behaviour of polymer amended MFT that may arise at different testing methodologies. Also, the influence of desiccation on shear strength gain has addressed. At the end, recommendations for further study are given. 


\section{Literature review}

\subsection{Oil sands-Introduction}

Canada holds the world's third largest reserves of crude oil after Saudi Arabia and Venezuela, with the total in situ and mineable remaining established reserves of 27.1 billion cubic metres equivalent to 174 billion barrels (ERCB 2009). Of that number, 169 billion barrels are located in the oil sands, which makes it a strategic resource of energy for both Canada and North America.

Canada's oil sands are found in three main deposits namely, the Athabasca, Peace River and Cold Lake deposits in Alberta and Saskatchewan, underlying a land mass of 142,200 square kilometres $(\mathrm{km} 2)$. (Figure 2-1). The Athabasca deposit is the largest known reservoir of crude bitumen in the world and the largest of three major deposits. The general information of each deposit is given as follow (Government of Alberta 2012).

\section{Athabasca deposit}

At 40,000 square kilometres, this is the largest and most accessible reserve. It also contains the most bitumen. About $20 \%$ of the oil sands near Fort McMurray are close enough to the surface to be mined. In situ techniques are needed for other deeper deposits. This area also includes deposits in the Wabasca region. 


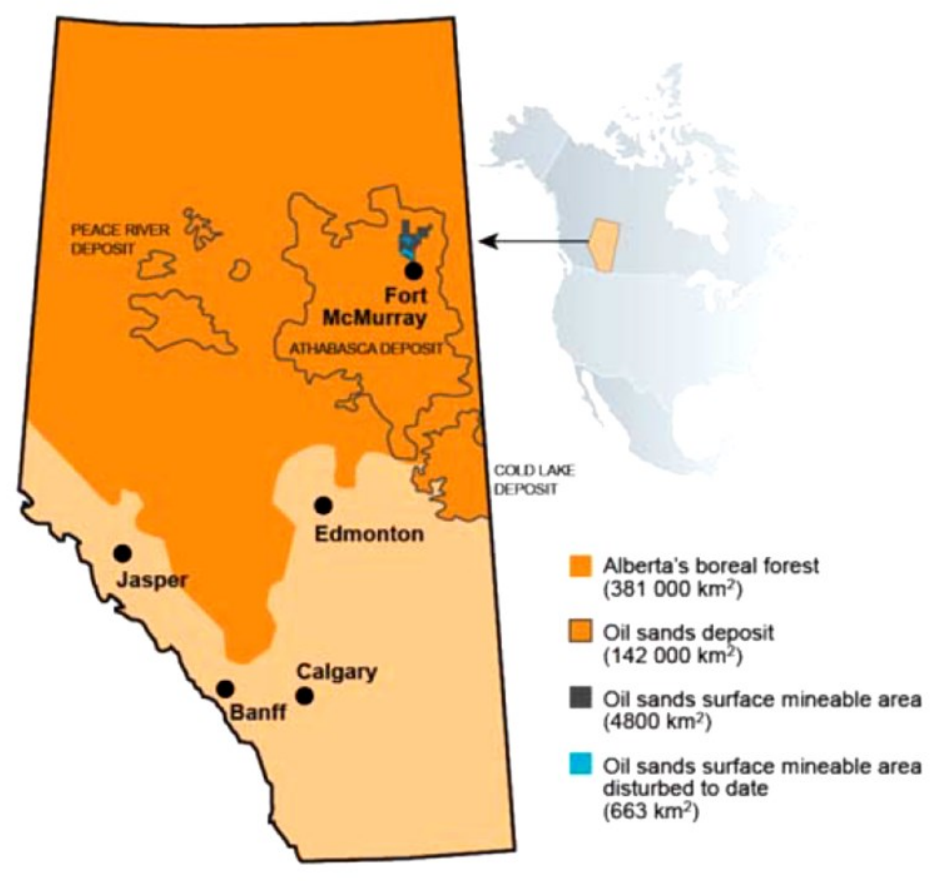

Figure 2-1. Distribution of oil sand resources in Canada

\section{Cold Lake deposit}

At 22,000 square kilometres, this area has Alberta's second largest reserve of bitumen held in deep deposits ranging from 300 to 600 metres below the surface. Presently, some of these deposits are being recovered using in situ technology.

\section{Peace River deposit}

At 8,000 square kilometres, this is the smallest of Alberta's oil sands areas. These deep deposits (ranging from 300 to 770 meters below the surface) are being recovered with in situ methods.

The Government of Alberta (2012) published statistical data of land use and reclamation information for the year 2011 as follow:

\section{Land use (2011)}

- Total oil sands area: $142,200 \mathrm{~km}^{2}$

- Surface mineable area: $4,800 \mathrm{~km}^{2}$ 
- Size of Canada's boreal forest: 3,099,996 km²

- Percentage of Canada's boreal forest within mineable area: $0.20 \%$

- Conservation Areas protected in oil sands region (Lower Athabasca Region): 20,000 km²

\section{Reclamation (2011)}

- Area cleared or disturbed by mining: $761 \mathrm{~km}^{2}$

- Area under active reclamation: $74 \mathrm{~km}^{2}$

- Area certified as reclaimed and returned to the Crown:104 hectares

- Total surface area of all tailings ponds: $182 \mathrm{~km}^{2}$

- Total surface area of all fluid tailings: $77 \mathrm{~km}^{2}$

- Amount held in the Mine Financial Security Fund as of September 31, 2011: $\$ 936,596,075$

The Canadian Association of Petroleum Producers (CAPP 2012) annually publishes a long-term outlook for Canadian crude oil production. The results of investigation conducted in 2012 to forecast the crude oil production in Canada until 2030 are given in Table 2.1. In this table oil production of Eastern Canada mainly sourced from offshore Atlantic is compared with that in Western Canada. The forecast shows that the Eastern Canada oil production is reducing from 0.27 billion barrel per day (b/d) in 2011 to $0.09 \mathrm{~b} / \mathrm{d}$ in 2030, while Western Canada experiences a marked increase (almost twofold) in oil production to meet the energy demands at the same period of time. 
Table 2.1.Crude oil production in Canada (CAPP 2012)

\begin{tabular}{|l|l|l|l|l|l|}
\hline Million b/d & 2011 & 2015 & 2020 & 2025 & 2030 \\
\hline $\begin{array}{l}\text { Total Canadian } \\
\text { (including oil sands) }\end{array}$ & 3.0 & 3.8 & 4.7 & 5.6 & 6.2 \\
\hline Eastern Canada & 0.3 & 0.2 & 0.2 & 0.2 & 0.1 \\
\hline Western Canada (Total) & 2.7 & 3.6 & 4.5 & 5.4 & 6.1 \\
\hline \multicolumn{1}{|l|}{ Conventional } & 1.1 & 1.3 & 1.3 & 1.2 & 1.1 \\
\hline Oil sands & 1.6 & 2.3 & 3.2 & 4.2 & 5.0 \\
\hline
\end{tabular}

\subsection{Oil sand mixture}

Oil sand is a natural mixture of sand and clay (80-85\%), water (3-4\%) and bitumen (10-15\%). Bitumen is a viscous form of hydrocarbon that should be heated or diluted with lighter hydrocarbons to reduce the viscosity and improve the ease of flow.

Produced waste tailings exhibits wide distribution of grain size from sands to clays. In order to analyze the engineering behaviour of tailings as the solid content and fine content changes, a ternary diagram with three apexes of water, sand and fines was introduced by Azam and Scott (2005). The characteristics boundaries and zones of oil sand tailings in the ternary diagram is shown in Figure 2-2. The concept behind the diagram is that segregation of fine and coarse particles depends on cumulative effects of solid content, grain size distribution and mineralogy of fine particles. Description of each boundary is given in the following.

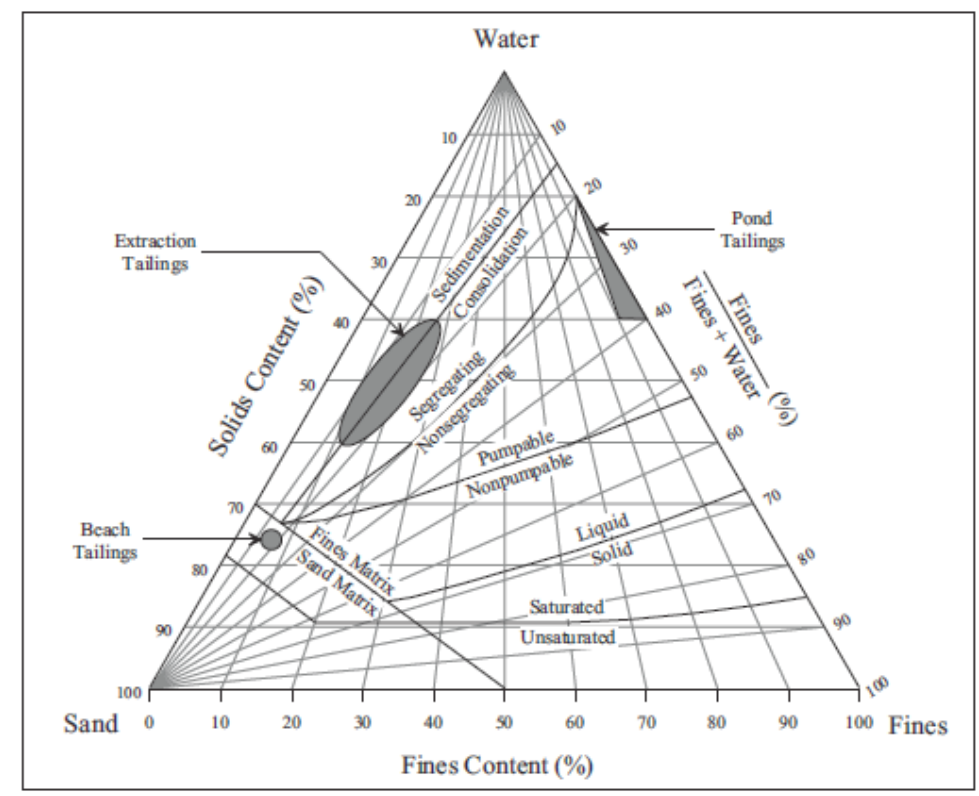

Figure 2-2.Ternary diagram for oil sand tailings characterization (Azam and Scott 2005) 
The matrix boundary defines sand matrix below the line and fine matrix above the line. In the fine matrix, the fine particles are closely in touch while coarse grains are suspended within the matrix.

The sedimentation-consolidation boundary distinguishes the sedimentation area and the consolidation region. Sedimentation defines as the onset of settling process with no measurable effective stress. Contrary, particles are in close contact during consolidation process and therefore the effective stress can be transmitted by solid grains.

Above the segregating-non-segregating boundary, coarse particles segregate or settle in the slurry whereas there is no considerable settlement below the line. Producing non-segregated tailings is possible by increasing solid content or adding some binding agents.

The pumpable-nonpumple boundary depends on rheological characteristics of the slurry including viscosity and shear strength. It is known that by increasing solid content of slurry more energy is lost during pumping. Therefore, the economics of disposal system should take into account as well. Considering the diagram, a limiting value of solid content for a pumpable slurry is $68 \%$ if it has a fine content of $10 \%-20 \%$.

The liquid-solid boundary is illustrated by plotting equal undrained shear strength which is close to liquid limit of slurries $(2.5 \mathrm{kPa})$. Several authors believe that this boundary is highly affected by grain size distribution as well as physic-chemistry interaction. The higher water content and fine content, the higher interaction between solid particles and liquid.

The saturated-unsaturated boundary shows the shrinkage limit for fine particles in the fine matrix and maximum void ratio of sands in the sand matrix.

\subsection{Process of bitumen extraction}

Depending on depth of deposited reserves, oil sands are recovered using two main methods: mining and in situ. In situ method has lower environmental impacts compared to mining approach. Only 20 per cent of the oil sands are shallow enough to be recoverable through surface mining and only in an area north of Fort McMurray along the Athabasca River Valley. 
Figure 2-3 shows extraction of oil sand from bitumen in the mining method. In this approach, the oil sand ore is mined by shovels and then transported by trucks to crushers in order to pursue extraction process. Crushing the ore into small pieces is followed by filtering and mixing with hot water to produce slurry for bitumen extraction plant. There is a separation vessel in the extraction plant within the bitumen froth is produced on top while sand and water is located at bottom. A solvent is added and the froth is treated to produce the final product of bitumen. However, both primary and secondary upgrading processes are needed to convert the bitumen into a synthetic crude oil. The crude oil should also go through refining process before commercial use.

Injecting steam or air, combustion or other sources of heat into the reservoir as well as solvents are all possible methods to extract bitumen from sand. In 1926, the method introduced by Clark called Clark Hot Water Extraction (CHWE) process which applies hot water, steam, and caustic $(\mathrm{NaOH})$ is the most common to separate oil sand from bitumen in the surface mining of the Athabasca deposit. However, producers have used CHWE in different ways. $\mathrm{NaoH}$ is used as $\mathrm{PH}$ adjusting additive aiding to efficient bitumen separation. Dispersed nature of clays in tailings caused by sodium ions, however, inhibits rapid dewatering processes through sedimentation and consolidation.

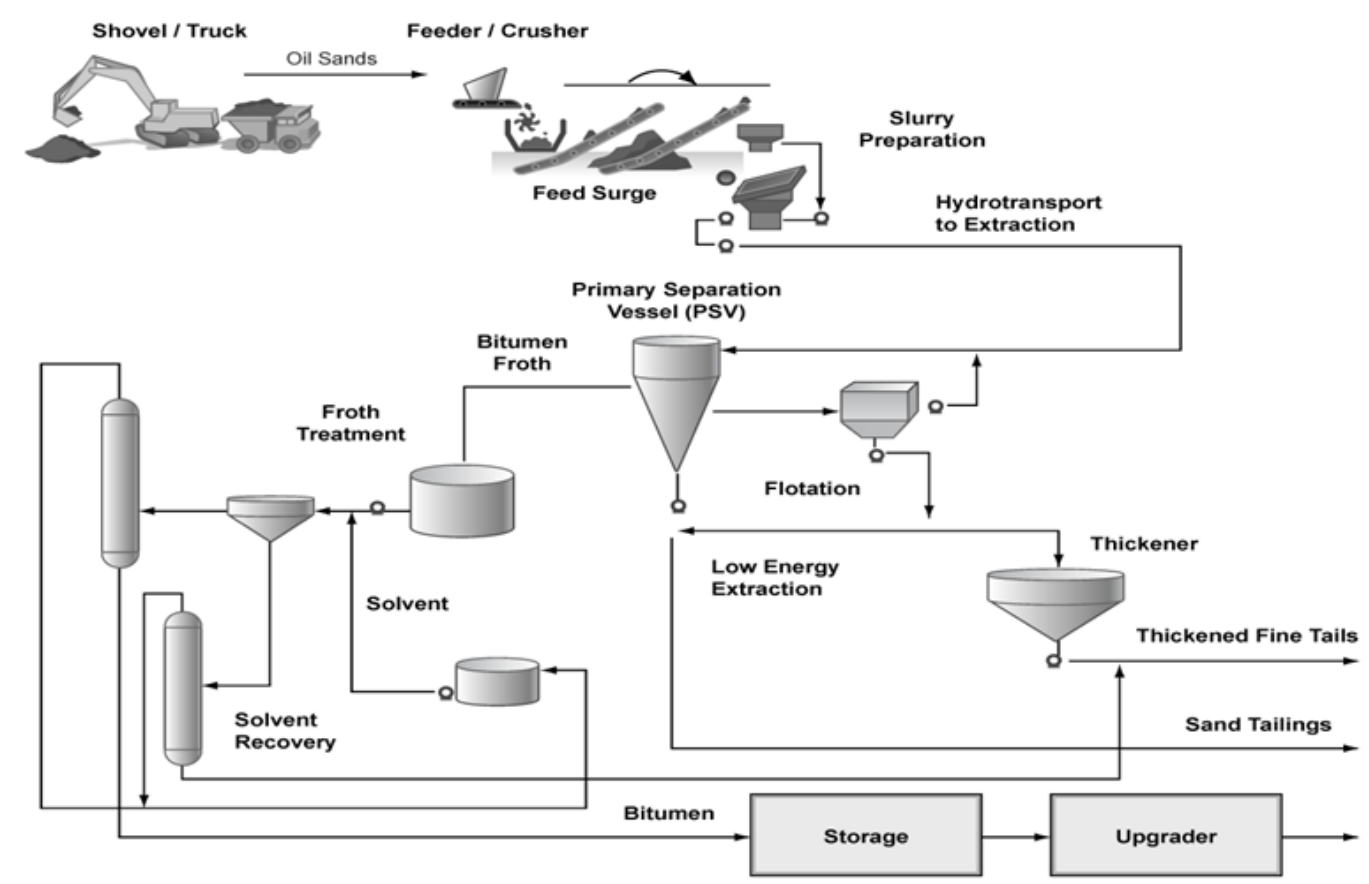

Figure 2-3. Mining and Extraction of Bitumen from Oil Sands (Masliyah, 2009) 
$80 \%$ of the oil sands reserves in Canada are too deep to be mined and need to be recovered in situ. Cyclic Steam Stimulation (CSS) was the first method for in situ extraction of oil sands. In CSS approach one well was used for both bitumen recovery and steam injection. In 1978, Dr. Roger Butler, introduced the concept of Steam Assisted Gravity Drainage (SAGD) which was an advanced form of CSS method. SAGD approach is summarized in Figure 2-4. In this method, a pair of horizontal wells located 4 to 6 meters above the other is drilled into the oil reservoir. Water is converted into a steam and is injected to the upper well to heat the oil and reduce its viscosity. The produced oil is then flows to the bottom well by gravity. The resulting oil and condensed steam is then piped out for further treatment and separation. The water is also recycled for new steam in next cycle as the steam injection and oil production should be continuous and simultaneous.

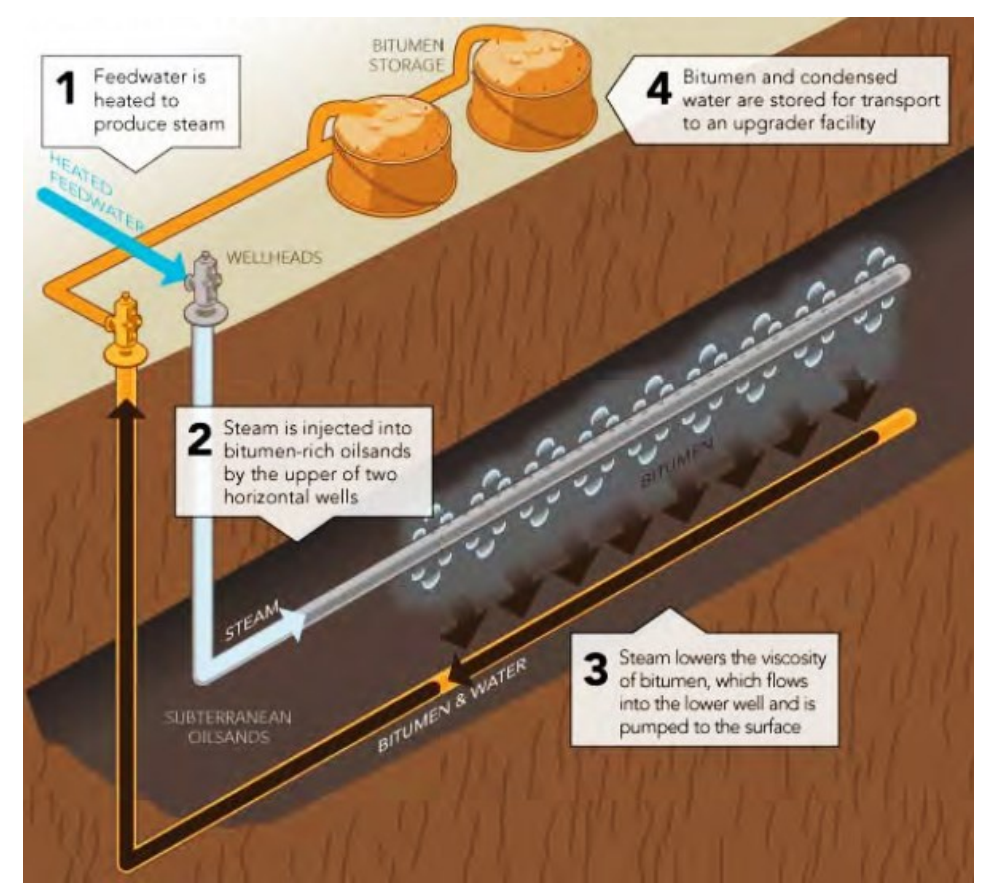

Figure 2-4.Steam assisted gravity drainage for in situ Bitumen extraction

Tailings are produced from surface mining only. The tailings coming directly from extraction plant, named whole tailings, consist of water, a combination of coarse (sand) and fine particles (silt and clay) as well as small portion of residual bitumen. Coarse materials defined as particles with a size greater than $44 \mu$ while fine particles refer to size less than $44 \mu$. The solid content of whole tailings after extraction varied in the range of $45-55 \%$. Once the whole tailings are 
pumped to the tailings ponds (Figure 2-5), coarse particles settle to form beaches in the settling basin.

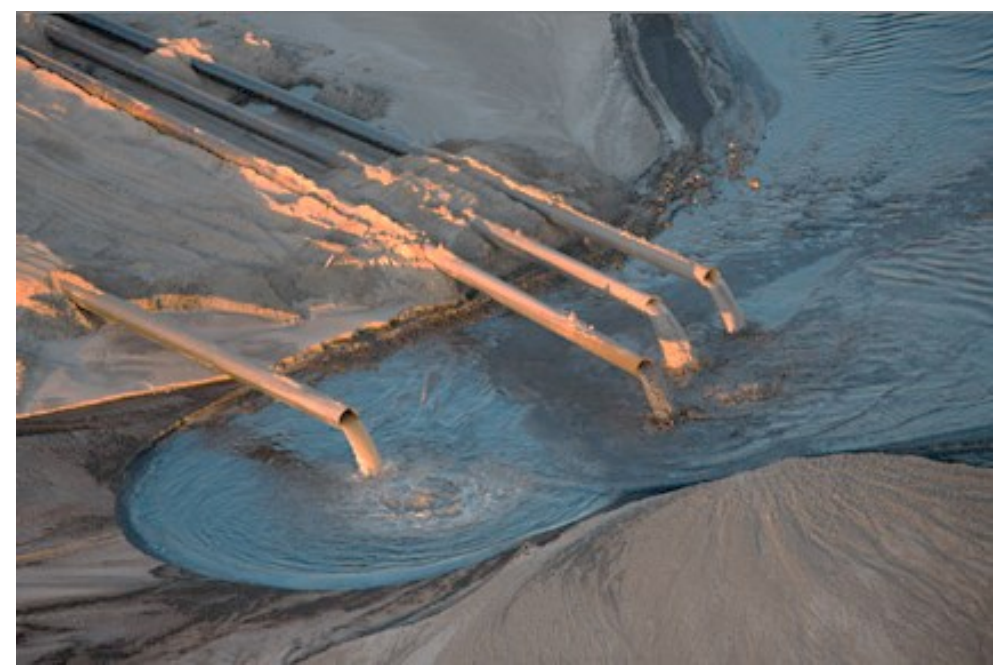

Figure 2-5.Deposition of the tailings in the tailings ponds

On the other hand, fine particles and bitumen accumulate to form a floating layer called fluid fine tailings with solid content of about $8 \%$. Over a few years, fluid fine tailings undergoes a hindered settlement and the excess water drains in order to create Mature Fine Tailings (MFT) which is comprised of $70 \%$ water and $30 \%$ silt and clay. MFT are a great concern as the further settlement and self-weight consolidation rates are extremely slow and therefore excess water release takes several years. The schematic segregation of tailings after deposition in the tailings pond is shown in Figure 2-6.

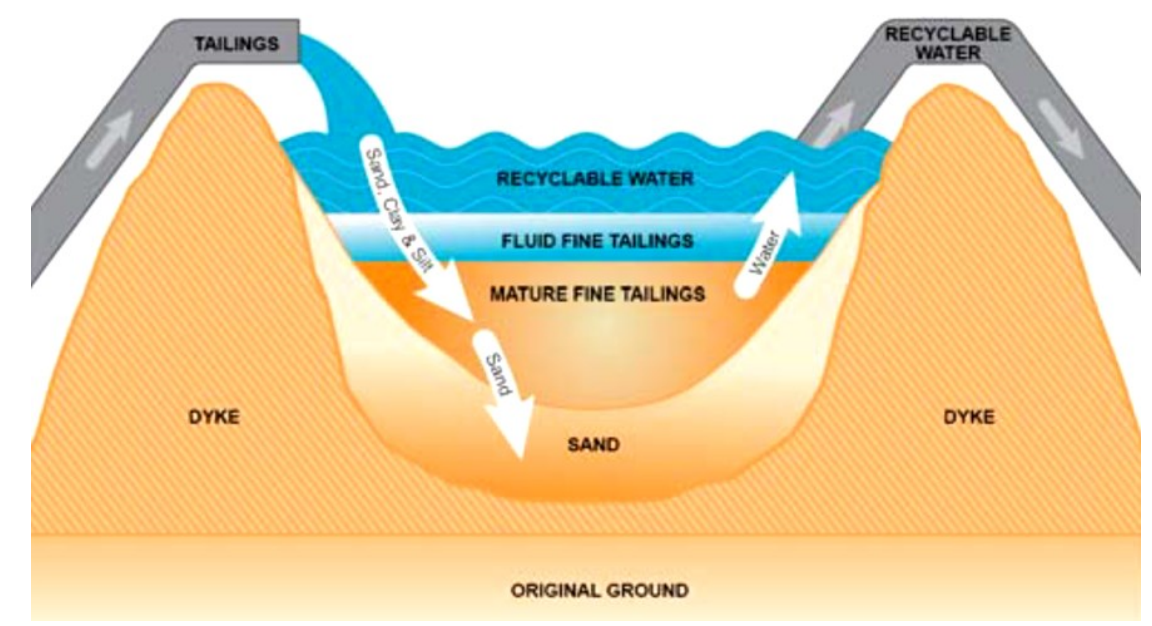

Figure 2-6.Tailings segregation after depositing in the tailings pond (ERCB 2011) 
The slow dewatering of MFT is due to both low hydraulic conductivity and the building of the thixotropic strength. Some basic geotechnical properties of MFT are summarized as follows (Sobkowicz 2012):

- The mean particle size of the fine tailings is between $5 \mu \mathrm{m}$ and $10 \mu \mathrm{m}$.

- $\quad$ The average solid content of MFT is about $33 \%$, equivalent to an average void ratio of 5 .

- The hydraulic conductivity of the MFT is in the range of $10^{-6}$ to $10^{-9} \mathrm{~m} / \mathrm{s}$ for the void ratio above 5

- The liquid limit and plastic limit range from 40 to $75 \%$ and 10 to $20 \%$ respectively.

- $\quad$ MFT shear strengths are typically much less than $1 \mathrm{kPa}$ (i.e. it acts as a fluid).

The plasticity chart for field samples and laboratory specimens are shown in Figure 2-7. An example of void ratio-effective stress relationship and void ratio-permeability relationship for raw MFT samples are also illustrated in Figure 2-8 and Figure 2-9 respectively. These graphs also show data for "ILTT", an in-line flocculated oil sand fine tailings from cyclone overflow before deposition (Jeeravipoolvarn 2010).

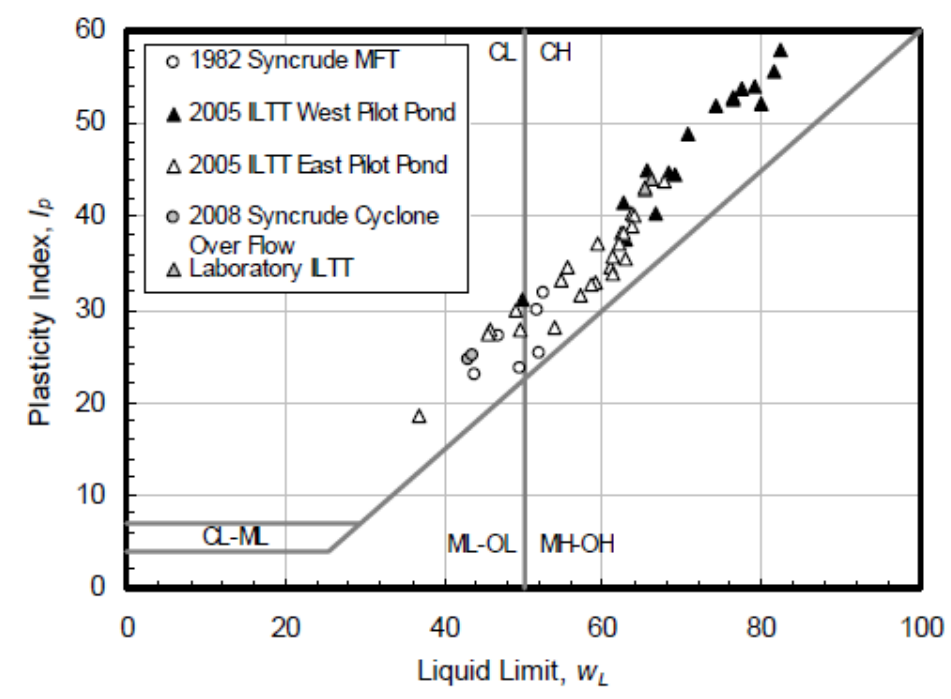

Figure 2-7. Plasticity chart (Jeeravipoolvarn 2010) 


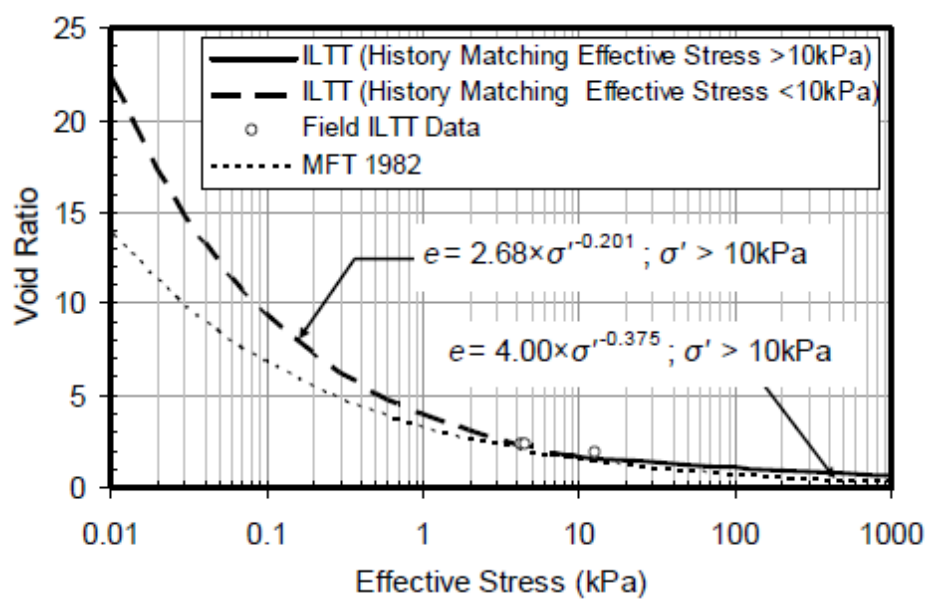

Figure 2-8. Field ILTT history matching compressibility relationship compared with field data and MFT compressibility (Jeeravipoolvarn 2010)

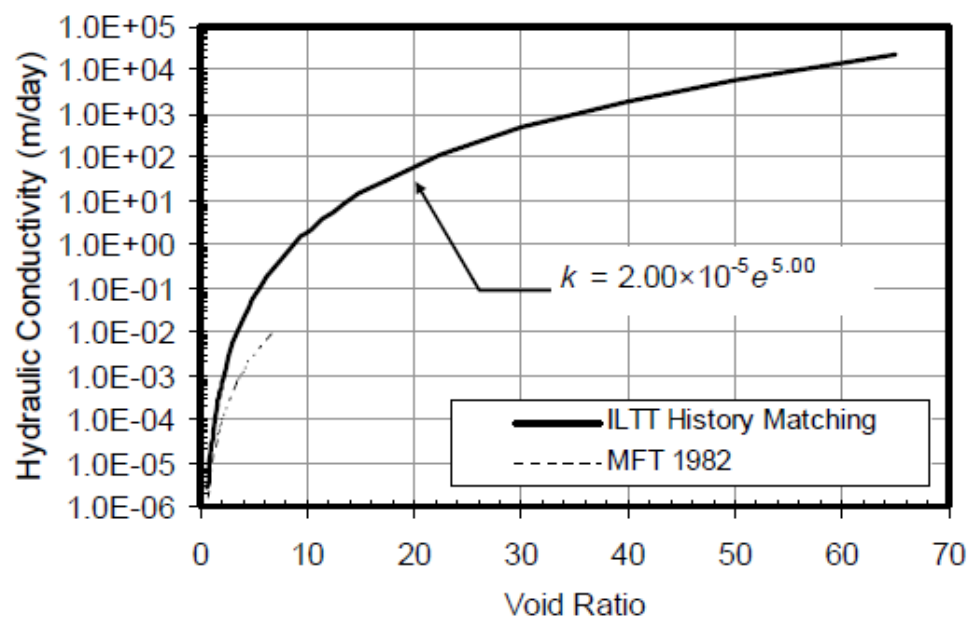

Figure 2-9. Field history matching hydraulic conductivity relationship (Jeeravipoolvarn 2010)

\subsection{Tailings treatment methods}

Oil sand characterization, treatment and management have been analyzed by many researchers and operators since last decades. In order to find possible solutions to address tailings treatment methodology, it is important to consider different approaches as Powter (2012) declared "we frame and approach a research problem in one of two ways - as a liquid that requires removal of solids or as a solid that requires removal of liquid".

The slow rate of dewatering through natural phenomena such as sedimentation and consolidation is more challenging particularly for MFT which is made up of fine dispersed clay particles. MFT 
reaches a solid content of 30-35\% after a few years and therefore larger ponds are needed for long term storage. As a result, large impoundment footprints caused by large volume of accumulated MFT should be reduced using tailings treatment methods. These methods try to accelerate transformation of tailings to reclaimed land and make them technically and economically suitable in future. Therefore, it is essential to characterize oil sand for better management of field tailings. This includes different aspects of geotechnical behaviour such as consolidation and shear strength characteristics.

Due to Directive 074 regulation legislated by Energy Resources Conservation Board (ERCB 2009), oil sand operators have to meet some requirements to improve strength of deposits and technically accelerate dewatering process using an appropriate technology. This is facilitated by reduction of fluid tailings and the formation of trafficable deposits. Fluid tailings defined as any fluid discard from bitumen extraction facilities containing more than 1 mass per cent suspended solids and having less than an undrained shear strength of $5 \mathrm{kPa}$. The regulation is briefly described as follow:

- Gaining undrained shear strength of $5 \mathrm{kPa}$ within one year

- Removing previous deposited tailings that does not meet the $5 \mathrm{kPa}$ requirement

- Ready for reclamation within five years after active deposition and having the progressive reclamation plan in a suitable time frame. Regarding the strength, stability and structure of trafficable surface a minimum undrained shear strength of $10 \mathrm{kPa}$ is required.

In 2011, the government of Alberta published a report in which different technologies and approaches applied by the three main companies (Suncor, Shell, Syncrude) was described (Government of Alberta 2011). Each introduced approach tries to improve dewatering of MFT which in turn accelerates consolidation and improves shear strength attainment. At larger scale, it decreases large impoundment footprint area and shortens the reclamation plan. However, there has been no completely acceptable solution to date, probably due to lack of technical or economic feasibility. The following section introduces different dewatering techniques to improve geotechnical behaviour of MFT. 


\subsubsection{Chemical amendment}

Chemical amendment technique has become more applicable in recent years. This method involves in adding a cementing agent, flocculant, or coagulant- to MFT. Flocculation refers to the process that polymeric materials (flocculant) create aggregates by forming bridges between individual suspended particles or neutralizing particles charges. Bridging, which is the most common flocculation mechanism, is considered to adsorption of segments of a polymer chain on surfaces of group of particles. Similar to coagulants, flocculants can be either cationic, anionic or non-ionic. Generally, a cationic flocculent adsorbs on negatively charged suspension while anionic flocculent reacts on particles with positive charge surface. However, anionic flocculants aggregate clay minerals (Kaolinite and Illite) which are electronegative through bridging.

Flocculation efficiency is highly influenced by ionic type, molecular weight, charge density, dosage of the flocculant (polymers), mineralogical composition and particle size of solid particles, pH and chemical composition of the solutions (Sworska et al. 2000, Azam 2011).

Depending on the flocculation mechanism, flocculants are divided into three groups including mineral flocculants, natural flocculants and synthetic flocculants. Polyacrylamide is a non-ionic polymer which is the most applicable synthetic flocculants. Polyacrylamides which have the highest molecular weight among the synthesized industrial chemicals are used as a suspending agent by flocculating solids in the liquid. Polyacrylamide has been widely applied as an amendment for oil sand tailings by bridging the fine particles and forming agglomerates.

Coagulants bring the particles together to form a continuous mass by changing the surface characteristics or surface charge. In other words, repulsive negative charges around the particles are neutralized by coagulants. Coagulants are either polymers or metallic salts such as Aluminium Sulfate. Polymers are usually long-chain molecules which can be cationic, anionic or non-ionic. Considering the fact that any further densification, settling or mixing processes breaks down the polymer bonds, coagulant aids can be used to add density to flocs with slow rate of settling. 


\subsubsection{Filtered tailings}

Due to recent regulations, limitation of tailings pond space and water availability, operators are looking for some alternative methods to conventional deposition techniques. Filtered tailings is one of these alternatives provides dry and stackable tailings disposal. Filtered tailings is divided into two distinguished categories, namely filtered coarse tailings and filtered thickened fine tailings. Cyclone Underflow Tailings (CUT) of the slurry from the extraction plant which is consist of coarse particles, is filtered, dried and compacted to form tailings stack. Remobilization of deposited tailings is prohibited by compaction. Unlike the conventional deposition method, a retention dam or tailings pond are not essential since the coarse filtered tailings are dried before deposition. Nonetheless, applicability of this method is reduced when the fine particles are more than 4\% (Xu et al. 2008). In other words, filterability of coarse particles is affected by amount of fine particles. Cyclone Overflow Tailings (COT) is referred to fine particles of slurry in the extraction plant and is treated for settling improvement.

\subsubsection{Composite/Consolidated Tailings}

A sustainable management of oil sand tailings needs a considerable geotechnical attention. This requires either reducing the volume of produced fine particles through extraction process or using some novel techniques to generate non-segregating tailings. Composite/Consolidated Tailings (CT) refers to mixing a tailings consists of coarse particles (CUT) and fine particles (MFT) with a chemical coagulant which is typically gypsum. As a result of this treatment, a nonsegregated and more homogeneous slurry with solid concentration of up to $60 \%$ is produced. This improves trafficability of slurry during transportation, discharge and deposition (Matthews et al. 2000). In addition, CT provides another benefit with respect to release of free-solid particles water suitable for recycling. The outline of CT process is shown in Figure 2-10. 


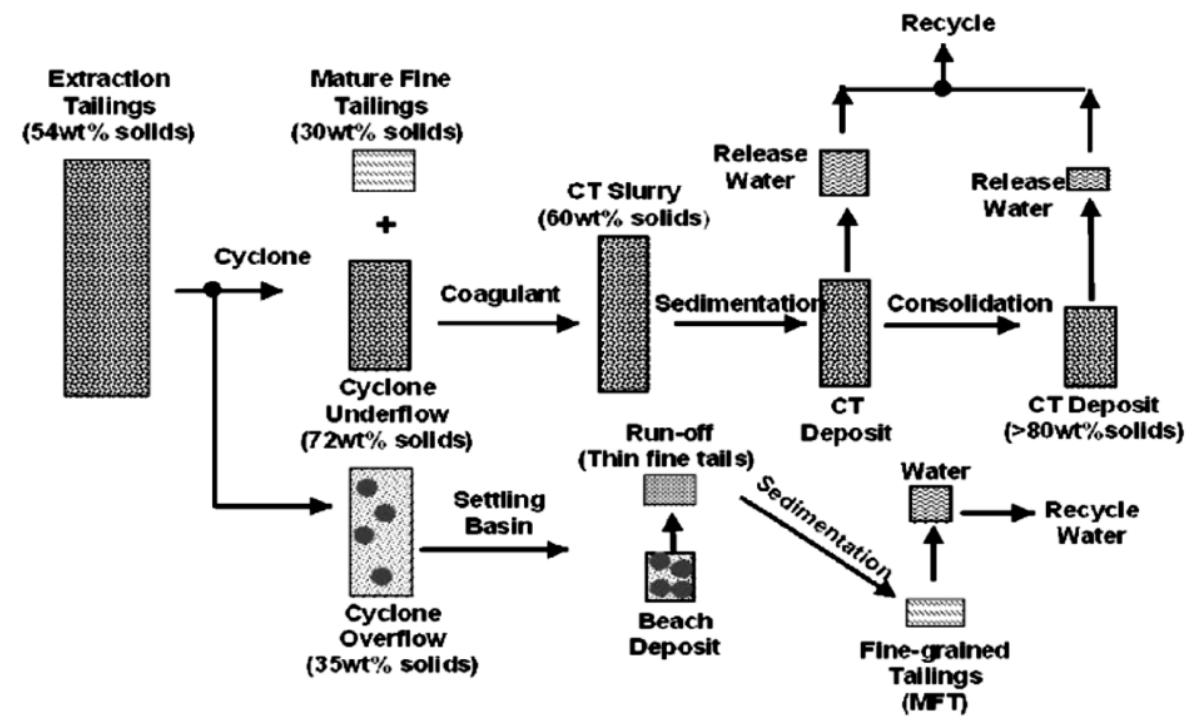

Figure 2-10.Composite tailings process (Matthews et al. 2000)

\subsubsection{Thickened Tailings}

Thickened Tailings (TT) is a technology focusing on improving settling and sedimentation behaviour of high fine content tailings by accelerating water release. In other words, segregation of fine particles should be prevented or considerably reduced at lower solid content by adding a binding agent. This is facilitated by adding some chemical amendments such as flocculants and/or coagulants in the thickener to increase the density. Feed thickener, COF, has the weight solid of $10 \%-20 \%$ and sand to fine ratio (SFR) of approximately $0.3: 1$ to $0.8: 1$. The cyclone under flow also contains coarse particles with a solid content of 50\%. Application of amendments is usually in conjunction with rake mechanism in thickeners to improve MFT densification. Therefore, the solid content could increase and achieve up to 55\% (Sobkowicz 2012). Resulted material can be deposited in the ponds but with lower land disturbance compared to slurries. Released water also can be reused in the extraction plant as it has very low solid content (less than 1\%). Generally, thickened tailings occupies less volume and also contains more coarse particles compared to composite tailings. Availability of more coarse particles is helpful for dyke construction (Jeeravipoolvarn, 2010).

\subsubsection{In-Line Flocculated Tailings}

In-Line Flocculated Tailings (ILFT) involves injection and in-line mixing of chemical amendments such as flocculants or coagulants into COT or harvested MFT. Dewatering rate in 
ILFT is more tangible compared to MFT and therefore undrained shear strength is higher. The schematic of ILFT process is illustrated in Figure 2-11. It should be note that number and order of stages for adding amendments are important determinants for the procedure efficiency. Yuan and Shaw (2007) examined different approaches and concluded a single coagulant, a single floculant or the combination of coagulant-flocculant cannot increase the solid content considerably. However, the combination of flocculation-coagulation-flocculation (FCF) showed a tangible increase in solid content (Figure 2-12). In fact, the best combination of amendments is that produces huge flocs helping in faster initial settling rate of aggregated clay minerals and cleaner supernatant water with low solid content.

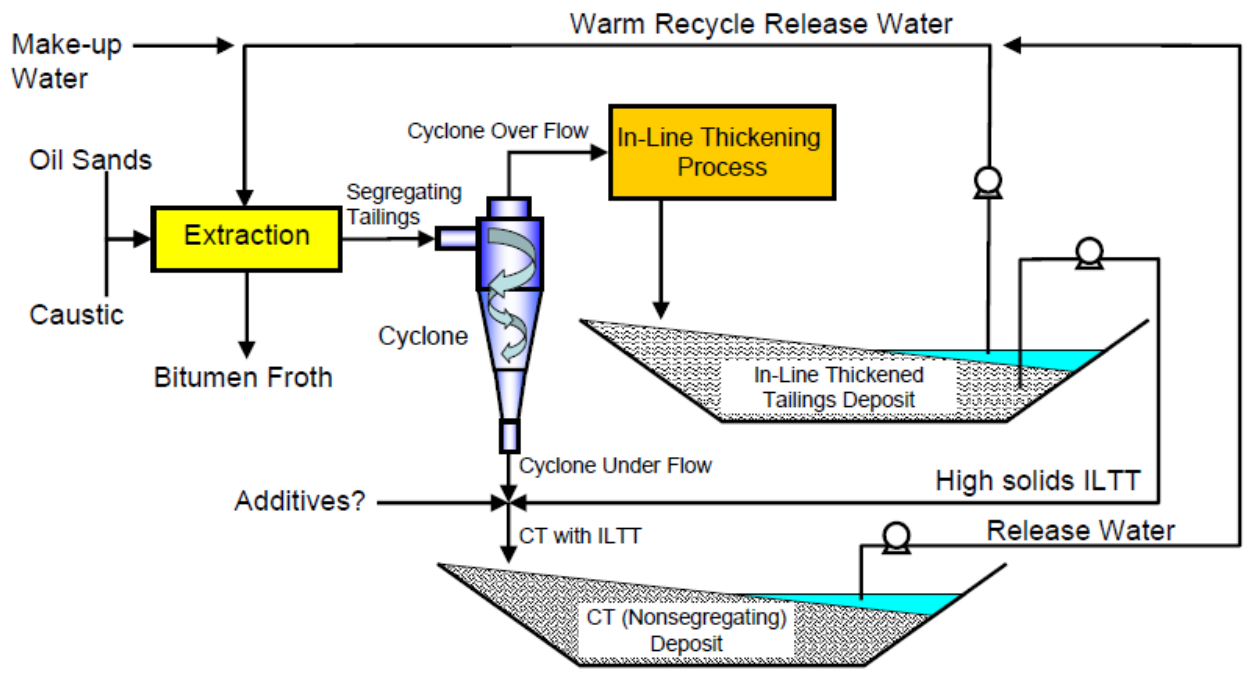

Figure 2-11.In-Line Thickening Process (Jeeravipoolvarn 2008) 


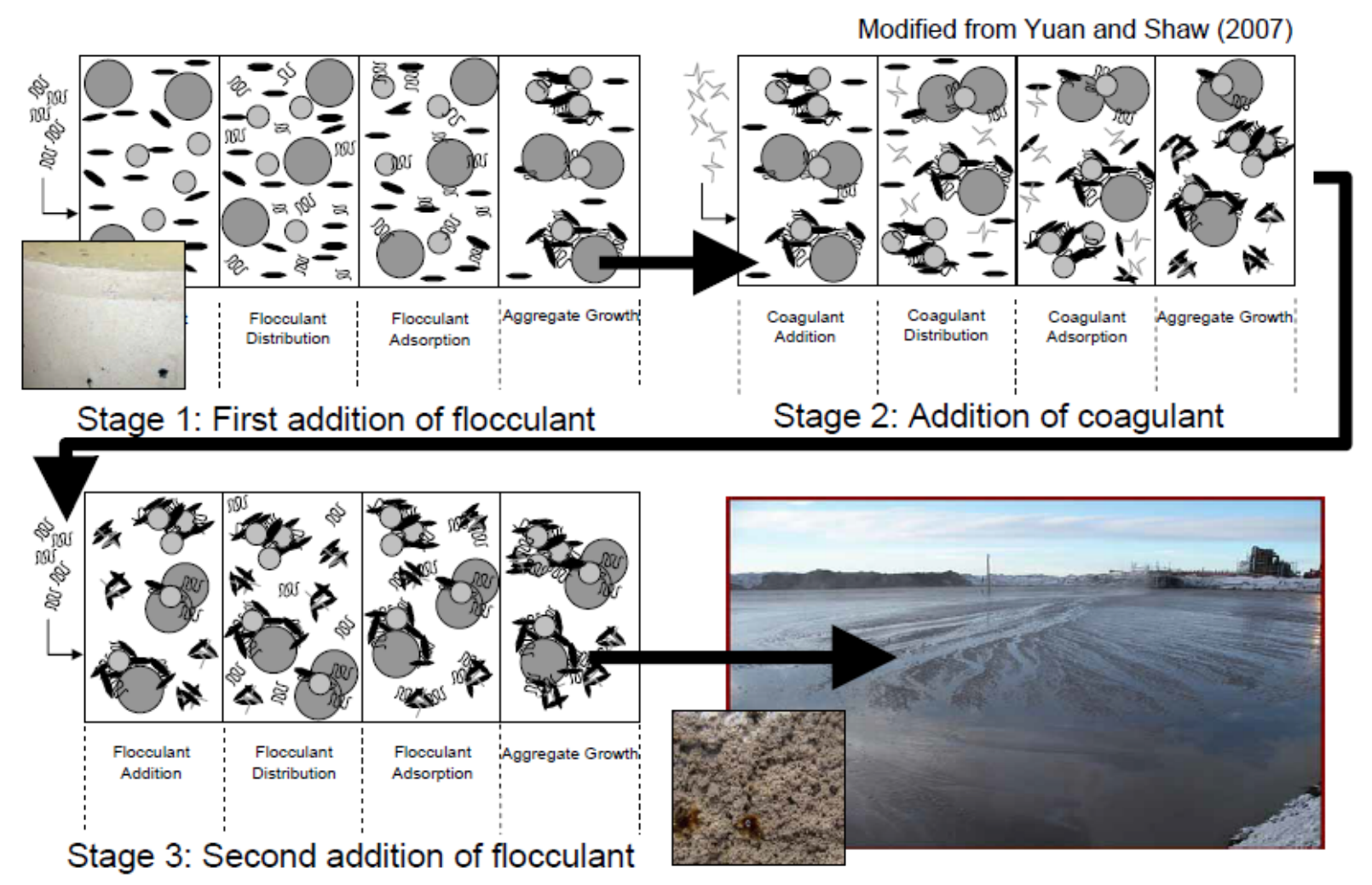

Figure 2-12.Stages of adding chemical amendments (Jeeravipoolvarn 2008)

\subsubsection{In-line Thickening with Thin Lift Dewatering}

This treatment technology has been applied in Suncor site where anionic flocculant is added to MFT, followed by deposition of thin layer with thickness of 10-30 cm (Sobkowicz 2012). Deposition of thin layer is then pursued by dewatering to reach a solid content of $60 \%$ and allowing atmospheric drying for further desiccation to end up with desired solid content. Once one or two layers achieved design solid content, the material is removed from surface and carried to waste dumps. This technology still faces with some challenges and it is of interest to find out the optimum water content of each layer (or solid content) before deposition of fresh layer and the number of layers which can be deposited in this manner to meet both geotechnical stability requirements and practical applicability.

\subsubsection{In-line Thickening with Accelerated Dewatering (rim ditching)}

This method relies on In-line flocculation of MFT followed by deposition in containment area and accelerating dewatering process by rim ditching and evaporation. In order to densify tailings 
deposit in this technique, the rate of evaporation should be higher than rate of water release. As a result, crust is formed on the surface. However, ditching network contributes for further desiccation of tailings with depth. Crack initiation and crack propagation also play significant roles in dewatering and densification of deposits.

MFT accelerating dewatering technology has been applied by Syncrude and water removal was managed by virtue of decant structure and rim ditching. Figure 2-13 shows the rim ditching technique in a big scale. Results showed that MFT volume can be reduced up to 50\% after 3-5 years and make it more suitable for reclamation plan (Lahaie 2008)

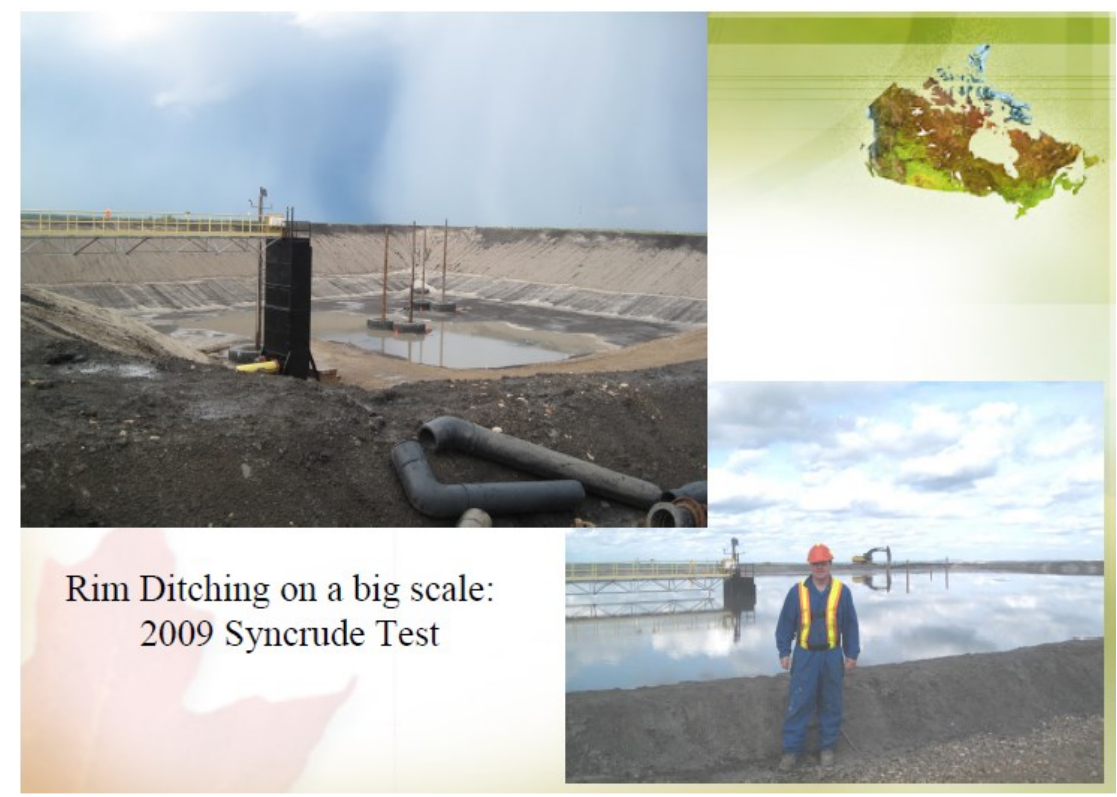

Figure 2-13. Implementing accelerated dewatering technique in a big scale by Syncrude (Lahaie 2008)

\subsubsection{Centrifuge technology}

Centrifuge technology implements centrifuge force which is up to thousand times higher than gravity force to extract fluid from MFT and yield dry stackable tailings. As a result of this process, the overflow stream contains water, bitumen and lower fine particles content. Nonetheless, the mere application of centrifuge was not cost-effective in the early studies. Therefore, operators have tried to use some chemical amendments in addition to centrifuge force in order to improve the outcomes. Syncrude is an example which has applied centrifuge technique as an option for oil sand tailings treatment and introduced this method in two steps (Lahaie 2008). In the first step. MFT is dewatered using a horizontal solid bowl scroll centrifuge 
as well as flocculant (Figure 2-14). This step yields two different streams; centrate and cake. Centrate contains particles free water $(0.5 \%-1 \%$ solid content $)$ which is suitable for recycling and reusing in the extraction plant. Cake is soft soil material with a solid content of $60 \%$ and half of the initial volume. In the second step, cake experiences further dewatering by natural processes such as consolidation, desiccation and freeze/thaw in either 1 to 2 meter annual lift or a very thick layer (thickness of 30 meter) in the mined out pits.

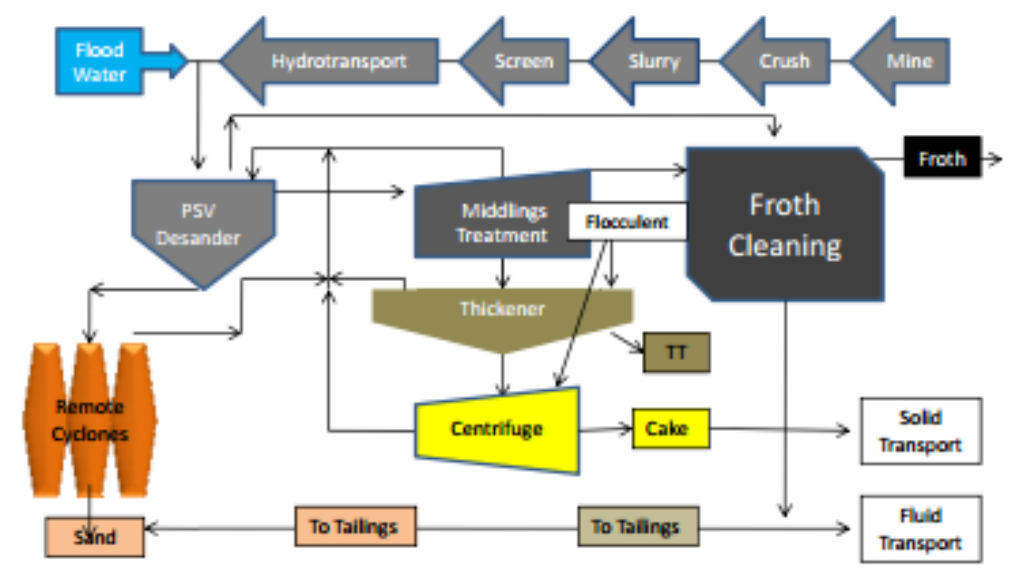

Figure 2-14.MFT centrifuge technique to produce cake and centrate (Devenny, 2010)

\subsubsection{Evaporation}

Evaporation is one of the natural dewatering processes, allowing desiccation of MFT and strength gain deposited in thin lift layers. It is important to distinguish two different concepts, namely Potential Evaporation (PE) and Actual Evaporation (AE). PE is the maximum evaporation of water from surface, while $\mathrm{AE}$ is the actual amount of water removes from soil which is a function of PE.

Non uniform drying of the tailings is one of the undesirable results once AE is lower than PE. As it has shown in Figure 2-15, availability of water at surface for evaporation of freshly deposited layer depends on many factors such as weather condition, albedo, and surface suction (Simms and Grabinsky 2004). Salt precipitation and accumulation at surface lead to increase of osmotic suction which is a result of decrease in water vapor pressure. Presence of salt crust at surface also increases albedo. All these phenomena eventually cause a considerable decrease in evaporation rate at surface (Simms et al. 2007). 
The more water evaporates, the higher suction develops which results in crack formation at surface as tailings undergoes to unsaturated phase. Therefore, crack initiation and crack propagation contribute to further dewatering. However, availability of water at surface from previously deposited layers in a multi-layer deposition depends on hydraulic conductivity, pore size distribution (and therefore capillary force), and water path (tortuosity). The lower hydraulic conductivity, the longer time is required for water to reach surface for evaporation purpose. Also, non-uniform pore size distribution causes non-uniform hydraulic conductivity and matric suction within the tailings.

In a multi-layer fashion deposition, the thickness of each individual layer plays an important role in evaporation. For a thinner layer, downward movement of water to previously desaturated old layers reduces and therefore more water is available at surface for evaporation (Qiu and Sego 1999). On the other hand, time to reach the Air Entry Value (AEV) and therefore dewatering increase for thicker layer. Hence, the thickness of each individual layer is a crucial parameter in designing deposition scheme and determination of evaporation contribution in dewatering of oil sand tailings and shear strength gain.

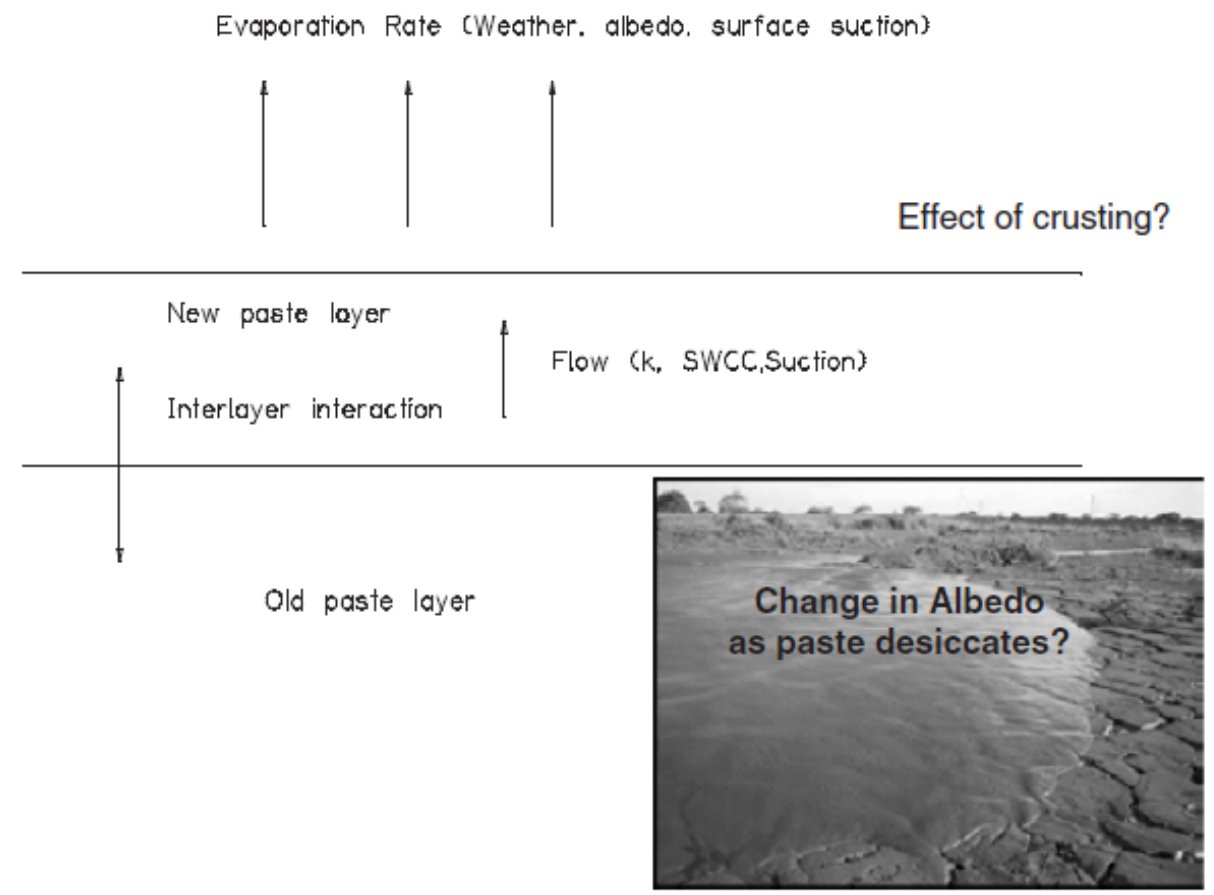

Figure 2-15.Factors affecting drying of a freshly deposited layer (Simms and Grabinsky, 2004) 


\subsubsection{Freeze/Thaw}

This technology involves depositing of MFT in multiple thin lift layers which are freeze in winter and allowed to thaw in the summer. Presence of water and ice and their properties are significant factors affecting the behavior of tailings subjected to freezing and thawing. Soil mineralogy, particle size distribution, and pore fluid chemistry are other factors that affect the freeze-thaw behavior of tailings (Proskin et al. 2012).

Significant thickness of material can be treated by freeze/thaw if the freezing process is repeated on top of a previously frozen layer. The limit of how much MFT can be treated per year is probably related to how much can be thawed in the following summer (BGC Engineering Inc. 2010). As a result, determination of optimum lift thickness is a key factor in successful application of this technique.

Similar to evaporation method, the influence of this technique can be improved by application of chemical amendments prior to freezing.

\subsection{Settling behaviour of oil sand tailings}

Settling of oil sand tailings is a sophisticated process in which a combination of different phenomena such as particle settling, flocculation, segregation, sedimentation, and consolidation, should be take into account (Jeeravipoolvarn 2010).

\subsubsection{Segregated tailings vs. non-segregated tailings}

Non-segregated mixes of whole tailings improve tailings densification and are preferable as far as strength of deposits is concerned. It is known that the initial water content of the tailings is an important factor controlling the settling behaviour. Segregated sediments are formed at very high initial water content when the grain particles are sorted. In contrast, interaction among the particles/flocs results in homogeneous sediments at low initial water content. Grain size distribution of the solids, void ratio and the rheological properties of the fines-water matrix are important factors in determination of whether segregation occurs or not (Jeeravipoolvarn 2010). 
Segregation of fine particles in the tailings can be restricted by removing water and increasing solid content by virtue of natural processes such as sedimentation and consolidation. Azam and Scott (2005) cited some key points that should be considered to generate non-segregated tailings, include "i) The portion of fine content in tailings, higher fine content leads to lower settling and consolidation rates as fine particles in oil sand tailings have a very low hydraulic conductivity (ranging from $10^{-6}$ to $10^{-9} \mathrm{~m} / \mathrm{s}$ ), ii) The quality of released water and its availability for recycling process and iii) The economics of disposal system since higher energy is required for pumping tailings with higher solid content".

\subsubsection{Settling process}

Sedimentation, which is also called hindered settlement, is the process whereby suspended particles in a dilute network, settle by gravity. Kynch's theory (1952) states that "the interface between the dispersion zone and clear water begins to form once dispersed materials aggregate and start to settle". These aggregated particles then form the sediment. The boundary between the dispersion and sediment, called the sediment formation line, moves up as new particles locate on top of the underlying sediment. He also declared this boundary is a straight line if all particles settle uniformly.

In order to find the settling velocity of suspended particles in a very diluted medium, Stokes' law (Equation 2-1) is used by considering three main forces including gravity, buoyancy and drag force (or frictional force; acting on the interface between the fluid and the particle). In fact, Stokes' law is an example of free settling theory assuming uncharged particles settle independently.

$v_{s}=\frac{2}{9} \frac{r^{2} g\left(\rho_{p}-\rho_{f}\right)}{\eta}$

Equation 2-1

Where $v_{s}$ is particle settling velocity, $\mathrm{r}$ is a Stokes radius of particle, $\mathrm{g}$ is gravitational acceleration, $\rho_{p}$ is particle density, $\rho_{f}$ is fluid density and $\eta$ is fluid viscosity.

It should be note that by increasing solid content in the slurry, the behaviour will be different from that predicted by Stokes' law. This is due to the increase in attractions and repulsions caused by Van der Waals forces and charged electric double layers between the solid particles as 
they get closer (Bowden 1988). Bowden also noticed the electrochemical force influences interactions between particles and interaction between particle and medium. However, the influence is more significant in systems of surface active and charged particles.

\subsubsection{Sedimentation}

Similar to Kynch methodology, Imai (1981) examined water content distribution and its variation with time to analyze the sedimentation mechanism. As it has illustrated in Figure 2-16, three distingushed zone can be recongnized during sedimentation of a clay-water mixure namely, flocculation stage, settling stage and consolidation stage. This figure shows the nonuniformity in both settling zone and consolidation zone, segregating by nonlinear sediment formation line where the water content starts to decrease.

In the flocculation stage, dispersed particles accumulated to form flocs and there is no change in water content in comparison to initial value. No settling takes place in the flocculation stage. Electrostatic and electromagnetic forces are the main interparticle forces. The former describes the electrostatic interaction between electrically charged particles. Interparticle forces bring the particles together and form microscopic flocs. As floc size increases, clusters of flocs (also called aggregates) are formed. Further agglomeration of aggregates leads to creation of matrix. As discussed earlier, chemical amendments such as flocculent and coagulants increase solid content of slurries and developing structure by forming flocs and aggregates. Development of structure in turn highlights the influence of effective stress role in compression behaviour from settlement stage to consolidation phase.

In the settling stage the flocs gradually settle and form a layer of a sediment. The onset of settling associated with the occurance of settling and consolidation stages concurrently. However, the sediment formation line is the boundary between these two zones. While water content is increased in the upper zone, it is decreased in the lower zone due to self-weight consolidation of sediment. The settling zone dissappeared once the settling stage is ended. This is followed by consolidation of the whole sediment. A continuoius soil structure is formed once consolidation starts. 


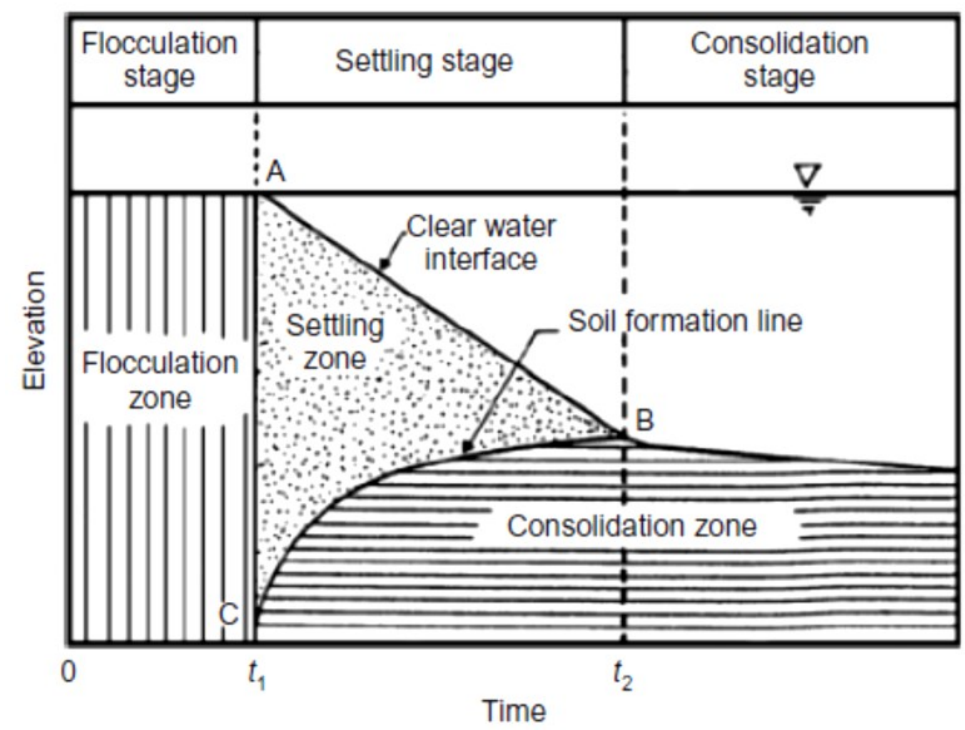

Figure 2-16.The general characteristics of sedimentation of a clay-water mixture (Imai 1981)

It is concluded the settling velocity and in turn settling behaviour of MFT containing considerable amount of charged clay minerals is different from that in Stokes' law and therefore hindered settlement should be taken into account. On the other hand, Terzaghi's model describes one dimensional consolidation behaviour of soils with high density. Therefore, Stokes' law and Terzaghi's equation cannot address contiguous settlement and consolidation stages of slurries with low solid concentration and relatively low density.

Initial void ratio $\left(\mathrm{e}_{\mathrm{i}}\right)$ is an important parameter, usually referred as the boundary between sedimentation and consolidation. It is difficult to distinguish the end of sedimentation and the onset of consolidation as determination of initial void ratio is not straightforward. Carrier et al. (1983) suggested a formula for calculating $e_{i}$ by considering the Liquid Limit (LL) of the material as follow.

$e_{i}=0.07 G_{s}(L L)$

Equation 2-2

Where $G_{s}$ is the specific gravity of the dry solids and LL is the Liquid Limit of the material (\%). However, these authors believed that selection of initial void ratio is somehow arbitrary and in practice the value of $e_{i}$ does not have a significant influence on the storage capacity of the ponds.

Sridharan and Nagaraj (2000) showed the relationship between compressibility and liquid limit is not necessarily reliable, since a soil with lower shrinkage limit compresses more compared to a soil with a higher shrinkage limit, even though their liquid limit are the same. 
Another empirical model is proposed by Stark et al. (2005) for inorganic clays of high plasticity $(\mathrm{CH})$. They observed a correlation between $\mathrm{e}_{\mathrm{i}}$ and Plasticity Index $(\mathrm{PI})$ as equation 2-3:

$e_{i}=8.25+0.02 P I$

Equation 2-3

Hawlader et al. (2008) applied equation 2-4 to find the initial void ratio. It should be note that this equation can be utilized if the initial density of slurry $\left(\rho_{0}\right)$ is more than the structural density $\left(\rho_{s}\right)$. Structural density is the density at which the soil structure is formed within the sedimentation when initiation of consolidation occurs.

$e_{i}=\frac{\left(G_{s}-1\right) \rho_{w}}{\left(\rho_{0}-\rho_{w}\right)}-1$

Equation 2-4

Where $G_{\mathrm{s}}$ is the specific gravity of soil particles and $\rho_{w}$ is the density of water.

\subsubsection{Compression behaviour of tailings}

A full description of compression behaviour involves in a complete understanding of consolidation. The compression is caused by i) expulsion of air/water from the voids, ii) deformation of soil particles, and iii) rearrangements of soil particles. This rearrangement reflects as a volume change leading to compression of saturated fine grained soil resulting in settlement. The rate of volume change is related to the rate at which pore water moves out which in turn depends on the permeability of soil.

\subsubsection{Consolidation}

Consolidation is a time-dependent process by which the volume of soil decreases duo to the applied load. Void ratio and excess pore water dissipation are important parameters to be tracked and measured accurately in this process.

\subsubsection{Terzaghi's consolidation model}

Terzaghi's theory of one dimensional consolidation for saturated soils has been widely accepted as a useful conceptual framework in geotechnical engineering. Based on this theory, when load is applied to the soil, the entire load is immediately $\left(\mathrm{t}=0^{+}\right)$carried by the pore water. Therefore, excess pore water pressure develops and the soil undergoes to an initial settlement. The excess 
pore water pressure dissipates with time due to the drainage and the load is gradually transferred to soil skeleton to form an effective stress. Over time, effective stress increases while excess pore water pressure decreases. Theoretically, at the end of consolidation $(t=\infty)$, the applied load is transferred to soil skeleton and the excess pore water pressure dissipates completely. The mathematical equation of Terzaghi's consolidation theory based on the following assumptions is given in Equation 2-5:

- Clay is homogeneous and saturated

- Strains and drainage are both one dimensional

- Darcy's law is valid

- Strains are small and therefore hydraulic conductivity $(\mathrm{k})$ and coefficient of volume compressibility $\left(\mathrm{m}_{\mathrm{V}}\right)$ remain constant

- Soil grains and water are incompressible

$\frac{\partial u}{\partial t}=c_{v} \frac{\partial^{2} u}{\partial z^{2}}$

Equation 2-5

Where $c_{v}$ is coefficient of consolidation, $u$ is excess pore water pressure, $t$ is time and $z$ is a one dimensional vertical coordinate.

\subsubsection{Davis and Raymond consolidation model}

Unlike Terzaghi's equation in which the pore water pressure is the dependent variable, Davis and Raymond (1965) developed the consolidation theory based on the effective stress as a dependent variable. This model was the first consolidation model considered the variation of permeability as well as compressibility for compressible, normally consolidated clays. The governing equation is as follow:

$-c_{v}\left[\left(\frac{1}{\sigma^{\prime}}\right)\left(\frac{\partial^{2} u}{\partial z^{2}}\right)-\left(\frac{1}{\sigma^{\prime}}\right)^{2}\left(\frac{\partial u}{\partial z}\right)\left(\frac{\partial \sigma^{\prime}}{\partial z}\right)\right]=\left(\frac{1}{\sigma^{\prime}}\right)\left(\frac{\partial \sigma^{\prime}}{\partial t}\right)$

Equation 2-6

The authors concluded dissipation of pore water pressure is much slower than what is predicted by Terzaghi's equation. They also found the degree of settlement identical to Terzaghi's theory. Degree of settlement was found equal to Terzaghi's equation. In spite of considering nonlinear compressibility and permeability variations, the model still assumes very small strains. 


\subsubsection{Finite strain consolidation model}

The main limitations of Terzaghi's theory are considering small strain and constant material properties in addition to neglecting self-weight consolidation. In fact, applicability of Terzaghi's theory is limited to the relatively stiff thin layers undergoes small strains. Assuming constant relationship between effective stress and void ratio and constant hydraulic conductivity is valid only when the final change in effective stress is small in comparison to the preconsolidation effective stress in very soft soils (Cargill 1982). These disadvantages limit the application of this theory for soft materials such as oil sand tailings with nonlinear hydraulic conductivity and compressibility, high initial void ratio at very low effective stress and also large strain and volume change during loading. Therefore, Terzaghi's theory with linear infinitesimal strain is not applicable.

The one dimensional finite strain consolidation theory was introduced by Gibson, England and Hussey (1967). They ended up with the governing equation in terms of void ratio by considering validity of Darcy's law and independency of soil skeleton to effect of time. Equation 2-7 shows Gibson, England and Hussey governing finite strain consolidation equation.

$\pm\left(\frac{\gamma_{s}}{\gamma_{w}}-1\right) \frac{d}{d e}\left[\frac{k(e)}{(1+e)}\right] \frac{\partial e}{\partial z}+\frac{\partial}{\partial z}\left[\frac{k(e)}{\gamma_{w}(1+e)} \frac{d \sigma^{\prime}}{d e} \frac{\partial e}{\partial z}\right]+\frac{\partial e}{\partial t}=0$

Equation

$2-7$

Where $\gamma_{s}, \gamma_{f}$ are the unit weight of solids and water respectively, $\mathrm{k}$ is coefficient of permeability, $\mathrm{t}$ is time, $\mathrm{e}$ is void ratio and $\mathrm{z}$ is a material coordinate.

Unlike conventional consolidation theory, independency of Equation 2-7 to the amount of strain, makes it suitable for thick clay layers susceptible to large settlement. The model also considers a nonlinear void ratio-effective stress relationship as well as permeability as a function of void ratio. In fact, the proposed model is the general form of both conventional consolidation model with linearity properties and small strains and Davis and Raymond consolidation model with nonlinear constitutive equations and small strains. 


\subsection{Assumptions}

Regardless of initial and boundary conditions, the following assumptions should be take into account in order to find the solution of Equation 2-7.

- Homogenous material type

- Compressible soil matrix versus incompressible pore fluid

- Applicability of Darcy's law for flow behaviour description

- Unique relationship between permeability and void ratio $(\mathrm{k}=\mathrm{k}(\mathrm{e}))$

- Unique relationship between effective stress and void ratio $\left(\sigma^{\prime}=\sigma^{\prime}(e)\right)$

There have been attempts made to overcome the limitations of conventional consolidation theory (small strain and linearity behaviour) in different studies. However, there are some differences between solutions of these models resulting from differences in i) the coordinate system used (Euleraian vs. Lagrangian), ii) the dependent variable selected ( void ratio vs. pore water pressure) and iii) the solution methodology (finite difference vs. finite element).

\subsection{Coordinate system}

To solve the Equation 2-7 the best coordinate system should be selected. The Lagransian coordinate system follows the movement of an individual particle as it moves through space and time changes. However, the Eulerian coordinate system considers specific location in the space through which the fluid passes by time. In finite strain consolidation model, the thickness of the consolidating layer is not fixed and the top boundary is moving. Therefore, the top boundary is time dependent and application of fixed coordinate system is not suitable.

\subsection{Permeability and compressibility constitutive relationships}

Solution of Equation 2-7 involves finding appropriate constitutive relationships between void ratio-permeability and void ratio-effective stress (compressibility). In addition, completion of tailings densification over time is highly affected by void ratio-permeability relation. On the other hand, void ratio-effective stress relation influences densification progress within consolidation process. Finding these relations is more challenging in the early stages of consolidation in which void ratio and hydraulic conductivity changes significantly with respect to low effective stresses. The mentioned reasons highlight the fact that constitutive equations 
should be determined accurately to characterize the tailings behaviour more effectively. In other words, failure to find proper constitutive equations particularly at low effective stress range leads to considerable errors in the behaviour predictions.

Carrier et al. (1983) applied Equations 2-8, 2-12 for compressibility and permeability constitutive relationship. Similar to Skempton, they correlated the effective stress with Liquidity Index (LI) as Equation 2-9. They used empirical equations 2-10, 2-11 to find the constant parameters of the compressibility $(\mathrm{A}, \mathrm{B})$. It is shown that $\mathrm{A}$ is proportional to the plasticity index of the waste material. By increasing PI, the A parameter increases, and therefore the void ratio at a given effective stress increases. They finally concluded the conventional consolidation theory predicts a much greater time required for consolidation in comparison to finite strain theory. $e=A \sigma^{\prime B}$

Equation 2-8

$L I=x \sigma^{\prime y}-z$

Equation 2-9

$A=x G \frac{P I}{100}$

Equation 2-10

$B=y$

Equation 2-11

Similarly, permeability can also be correlated to the Liquidity Index (Equation 2-13) and the finite strain parameters $\mathrm{E}$ and $\mathrm{F}$ can be obtained through Equations 2-14, 2-15. Similar to A parameter, E is proportional to PI value but in a more complex manner. It is shown that buy increasing PI values, the E parameter decreases, resulting in the decrease of permeability at a given void ratio.

$k=E \frac{e^{F}}{1+e}$

Equation 2-12

$L I=q[k(1+e)]^{r}-s$

Equation 2-13

$E=\left[q G \frac{P I}{100}\right]^{-\frac{1}{r}}$

Equation 2-14

$F=\frac{1}{r}$

Equation 2-15

Where $\mathrm{A}, \mathrm{B}, \mathrm{E}$ and $\mathrm{F}$ are finite strain parameters and $\mathrm{x}, \mathrm{y}, \mathrm{z}, \mathrm{q}, \mathrm{r}$ and $\mathrm{s}$ are empirical parameters determine from the best fit curve. 
In the literature, different models have been proposed based on the laboratory experimental data

to find constitutive equations. If the tailings or slurry consists of coarse solid particles (sand to silt size), the sedimentation occurs rapidly with no considerable consolidation as deposition progresses. As a result, conducting lab and field tests to determine physical properties is straightforward. Considerable fraction of clay particles and low solid content of tailings such as MFT lead to some critical problems in the laboratory testing. Therefore, laboratory devices should be able of i) accommodating large strains, ii) applying low loads at the early stages of testing as tailings have high initial void ratio which is equivalent to very low range of effective stresses and iii) minimizing the influence of seepage-induced consolidation (Gan et al. 2011). Some researchers, however, applied seepage-induced consolidation test to find the constitutive equations. These models are further described in this chapter.

\subsection{Previous experiments on constitutive relationships determination}

\subsubsection{Self-weight consolidation test}

Cargill (1982) conducted a laboratory study on very soft fine grain soils to analyze the large strain consolidation behaviour by developing a self-weight consolidation apparatus. The testing machine was designed such that pore water pressure was monitored at different levels with respect to depth and stress values were also measured at top and bottom of samples during selfweight consolidation. Contrary to the previous experiments were done before this study, the tests were conducted at controlled rate of strain while loading increased steadily. Finally, void ratioeffective stress and void ratio-permeability constitutive relationships were found.

Another approach is preparation of slurry with sufficient water content to maintain the homogeneity of the mixture. First, the slurry pours into the settling column to form sediment by virtue of settlement. The produced sediment undergoes self-weight consolidation in the next phase. Once equilibrium is achieved, the compression curve at low stress can be obtained by measuring water content and calculating the void ratio with respect to depth by trimming sample at equal intervals. 


\subsubsection{Hydraulic consolidation test}

One of the early attempts in developing laboratory techniques for conducting consolidation test was introduced by Imai (1979). Hydraulic consolidation test (also called seepage-induced consolidation test) is one of the methods for constitutive relationships determination. The most important feature of this approach is the ability to control drainage and to measure pore water pressure during the consolidation test. Several drainage conditions are possible and back pressure can be applied to the sample. The hydraulic consolidation test is suitable for soft soils (clays). Soft soil usually refers to a soil with high water content, high void ratio, high compressibility and low shear strength.

In the Imai's method, preparation of the sediment in the consolidometer of the seepage-induced consolidation test is similar to self-weight consolidation test. Thereafter, a constant head difference across the specimen is created to produce a downward seepage force. The specimen is then consolidated due to the self-weight and the seepage force. As a result, a non-uniform effective stress distribution through the specimen is generated. Due to the fact that water content of the specimen is decreased by increasing effective stress, the water content profile varying with depth can be determined during the experiment. After reaching the steady state flow condition, void ratio distribution is determined based on measured local water content. This is obtained by slicing the sample after its removal from the cell. In fact, after removing the seepage force caused by slicing, the flow rate, the pore water pressure distribution and the water content distribution are measured. Finally, the constitutive relationships, coefficient of consolidation and coefficient of volume change can be determined based on the mentioned measurements.

Abu-Hejleh et al. (1996) proposed an alternative method to the original seepage-induced consolidation test by removing water from the bottom of the specimen at a constant flow rate. In fact in this method controlled flow rate is applied instead of controlled head difference in the original test (Imai 1979, Huerta et al. 1988).

Their experimental methodology consists of three stages i) determination of zero effective stress void ratio $\left(\mathrm{e}_{0}\right)$; this void ratio referred to the boundary between settlement and consolidation, ii) determination of steady state stage of the seepage-induced consolidation and iii) step loading test 
with direct measurement of permeability at high effective stress. The following paragraphs describe these stages in detail as presented by Abu-Hejleh et al. (1996).

In order to determine $\mathrm{e}_{0}$ in stage $\mathrm{i}$, a representative sample close to the field slurry is prepared and allowed to settle in a few days. The supernatant water is then removed and samples from the surface of the sediment is taken. These samples represent the zero effective stress and can be used for calculation of $\mathrm{e}_{0}$.

Once steady state conditions are achieved (no further consolidation and no change in pressure difference) in stage ii, some parameters are determined including, height of solids in the sample ( $\left.H_{s}\right)$, the water flux across the sample $(\mathrm{v})$ and the effective stress at bottom of the specimen $\left(\sigma_{b}^{\prime}\right)$. Equation 2-16 shows how $\sigma_{b}^{\prime}$ can be calculated at the steady state stage. $\sigma_{b}^{\prime}=\sigma_{0}^{\prime}+\gamma_{w} H_{s}\left(G_{s}-1\right)+\Delta p_{s}$ Equation 2-16

Where $\sigma_{b}^{\prime}$ is effective stress produced by the loading piston, $\gamma_{w}$ is the water unit weight, $G_{s}$ is the specific gravity of solids, $H_{s}$ calculated as $\frac{w_{d}}{G_{s} \gamma_{w} A_{s}}$ in which $w_{d}$ is the dry weight of the sample and $\Delta p_{s}$ is the pressure difference across the sample.

After completion of stage ii, step loading and permeability tests are conducted to obtain the compressibility and permeability data at higher effective stresses. In other words, samples undergo consolidation under a large vertical effective stress $\left(\sigma_{c}^{\prime}\right)$. At the end of consolidation, final void ratio and specimen height can be determined. Similar to stage ii, a small downward flow is imposed to determine permeability.

The authors believed less time is required to reach the steady state condition in their proposed technique and that is the main advantage over the conventional method. In fact, for a constant head test, a sufficient amount of water should be accumulated on top of the specimen to determine the accurate flow rate at steady state, whereas detecting steady state is straightforward using the pressure difference transducer in the proposed technique. 
They finally used an extended power function in Equation 2-17 to reach the compressibility constitutive equation.

$e=A\left(\sigma_{v}^{\prime}+Z\right)^{B}$

Equation 2-17

Fox and Baxter (1997) listed all the advantages and disadvantages of Imai hydraulic consolidation test as follow:

Advantages:

- Obtaining compressibility and permeability relationships from a single test and a single hydraulic gradient

- No need for theoretical interpretation of the results as the relationships are measured directly.

- Ability of conducting test for low effective stress range

- Requiring less time to conduct test in comparison to the conventional consolidation test for high compressible materials

Disadvantages:

- Requiring complicated apparatus and highly developed experimental technique to measure local pore pressure

- $\quad$ Slicing the specimen to measure local water content

- Negative effect of sidewall leakage if the effective stress at top of the specimen is zero

To overcome the limitations of the Imai test, Fox and Baxter (1997) proposed another approach to determine the constitutive equations for high compressible materials. Based on their two stage flow procedure, a closed form equations for distribution of pore water pressure, total head, effective stress and discharge velocity were obtained at steady state flow conditions. In their model, void ratio distribution can obtained without measuring the local pore pressures. However, one of the limitations of this method is when the effective stress is zero at top of the specimen.

Hawlader et al. (2008) conducted a number of settling column test to investigate the consolidation behaviour of soft soils at very low effective stress range. They found the compressibility behaviour at low effective stress level (below the threshold stress $\left(\sigma_{c}^{\prime}\right)$ ) is non- 
unique and is very much dependent on the state of the element with respect to its location. However, above the threshold stress level, the compressibility behavior is unique as no changes occur in the soil structure. Therefore, the authors proposed a state-dependent model which involves determination of i) threshold stress $\left(\sigma_{c}^{\prime}\right)$, ii) a soil constant $(\chi)$ and iii) void ratioeffective stress relationship at the end of primary consolidation (EOPCL).

To check validity of the model, comparison was made between predicted and measured $e-\sigma^{\prime}$ paths from the settling column test. EOPCL was determined by drawing the best fit line through all of the end data points with the power function of $e=A \sigma^{\prime B}$. Figure 2-17 is an example shows the ability of the Hawlader et al. model to consider the state dependent compression behaviour below the threshold stress. After constitutive equation was approved, it was implemented in the numerical modeling of the finite strain consolidation model proposed by Gibson, England and Hussey (1967). However, the governing equation was written in terms of effective stress instead of void ratio.

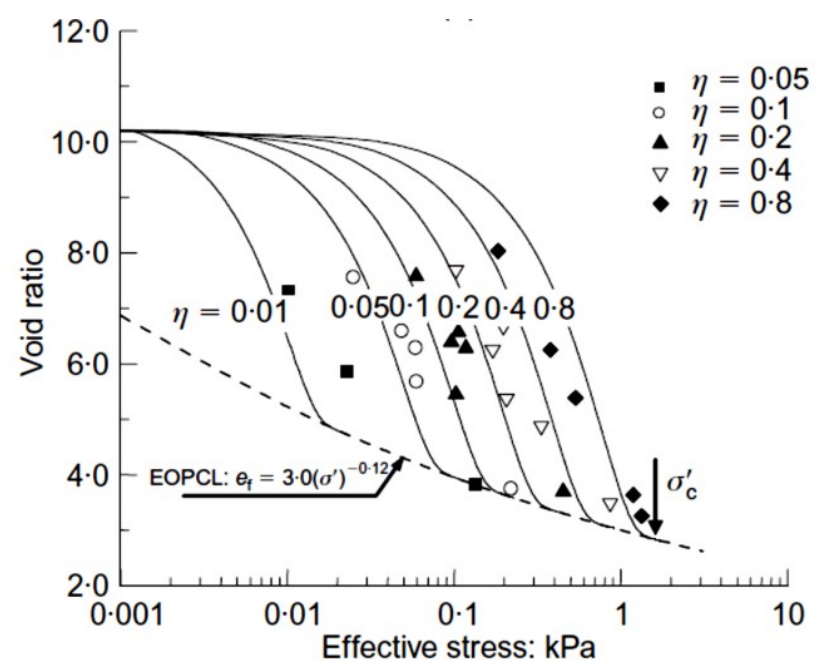

Figure 2-17.Compressibility path followed by soil element during progress of consolidation (solid lines, Hawlader et al. model; data points, Sills, 1995) (2008)

Azam (2011) studied the large strain settling behavior of polymer-amended slurries. He founded the bipower law functions as the best description of constitutive equations. In these equations, the fit parameters resulted from the least-square approach were proportional to the polymer characteristic coefficient $(\mathrm{Cp})$. Equation 2-18 shows the relationship between permeability and void ratio.

$k=10^{(C+e D)}$

Equation 2-18 
Table 2.2 summarizes the proposed permeability and compressibility constitutive equations proposed by different authors.

Table 2.2. Summarized constitutive equations

\begin{tabular}{|l|l|l|l|}
\hline Proposed model & Compressibility & Permeability & Constant \\
\hline Gibson, England and Hussey (1967) & & & $\begin{array}{l}g=-\frac{k}{\gamma w(1+e)} \frac{d \sigma^{\prime}}{d e} \\
\lambda=-\frac{d}{d e}\left(\frac{d e}{d \sigma^{\prime}}\right)\end{array}$ \\
\hline Carrier et al. (1983) & & & $\mathrm{A}, \mathrm{B}, \mathrm{E}, \mathrm{F}$ \\
\hline Huerta et al. (1988) & $e=A \sigma^{\prime B}$ & $k=E \frac{e^{F}}{1+e}$ & $\mathrm{~A}, \mathrm{~B}, \mathrm{C}, \mathrm{D}$ \\
\hline Townsend and McVay (1990) & $e=A \sigma^{\prime B}$ & $k=C e^{D}$ & $\mathrm{~A}, \mathrm{~B}, \mathrm{C}, \mathrm{D}$ \\
\hline Liu and Znidarcic' (1991) & $e=A\left(\sigma^{\prime}+Z\right)^{B}$ & - & $\mathrm{A}, \mathrm{B}$ \\
\hline Abu-Hejleh et al. (1996) & $e=A\left(\sigma^{\prime}+Z\right)^{B}$ & $k=C e^{D}$ & $\mathrm{~A}, \mathrm{~B}, \mathrm{C}, \mathrm{D}$ \\
\hline Hawlader et al. (2008) & $e=A \sigma^{\prime B} *$ & $k=C e^{D}$ & $\mathrm{~A}, \mathrm{~B}, \mathrm{C}, \mathrm{D}$ \\
\hline Azam (2011) & $e=A \sigma^{\prime B}$ & $k=10^{(C+e D)}$ & $\mathrm{A}, \mathrm{B}, \mathrm{C}, \mathrm{D}$ \\
\hline Priestley (2012) & $e=A \sigma^{\prime B}$ & $k=C e^{D}$ & $\mathrm{~A}, \mathrm{~B}, \mathrm{C}, \mathrm{D}$ \\
\hline
\end{tabular}

*Used for the end of primary consolidation

\subsection{Shear strength}

As described earlier, Directive 074 forces the operators to explore new methods as an alternative to a conventional approach for oil sand tailings deposition such that undrained shear strength of tailings should be at least $5 \mathrm{kPa}$ within a year. This highlights the importance of analyzing shear strength of tailings which is one the objectives of this study. However, no studies have been conducted to characterize shearing behaviour of MFT and amended MFT under a monotonic loading using triaxial or simple shear apparatus to date. For example, Jeeravipoolvarn (2010) conducted merely vane shear strength test to characterize the shearing behaviour of oil sand tailings.

The common laboratory tests to find the relationship between a given stress and the corresponding strain, the constitutive relations and shear strength parameters of soils are triaxial test, simple shear test, direct shear test, and hollow cylinder test. Direct shear test is the easiest and fastest test among all techniques, but it is not preferable if accurate shear strength parameters and stress-strain relationship are required. On the other hand, the element test conducting in the 
lab should be representative of the in-situ (field) condition as closely as possible. In fact, direct shear test cannot be an appropriate test to fully simulate field conditions due to the main limitations which are: i) merely total stress can be analyzed, since the device is not mounted to measure pore water pressure. ii) Drainage cannot be controlled. iii) During the test, the area where the vertical and shear load are applied is not constant. iv) A progressive failure from edges to centre occurs due to high stress concentration at the edges. This eventually leads to nonuniform shear stress and deformations.

\subsubsection{Simple shear test}

To overcome the limitations associated with direct shear test, Simple shear test was introduced which is capable of keeping area of sliding constant and imposing more uniform stress distribution. In addition, presence of two porous stones at top and bottom facilitates drainage during consolidation. This configuration is closer to in-situ conditions and the results of the first phase of the testing can be compared to one dimensional $\mathrm{k}_{0}$ consolidation.

Figure 2-18 illustrates a schematic of stress conditions and deformations using Simple shear. As it has shown, a shearing force is applied horizontally with the vertical load perpendicular to it. The direction of the major principal stress is vertical during consolidation and the minor principal stress being horizontal. The principal stresses then rotate during shearing.

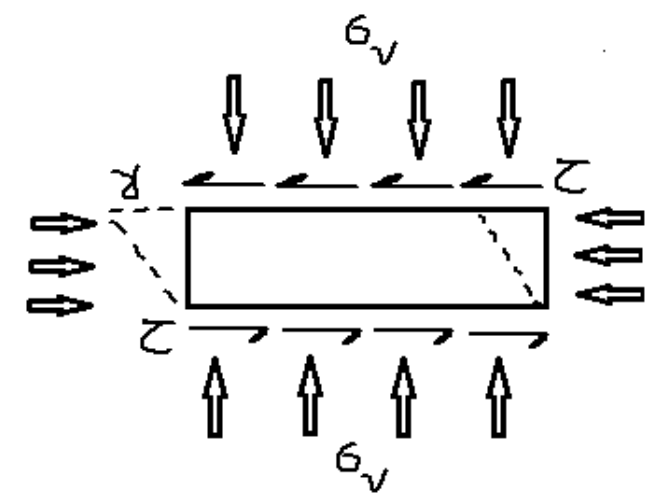

Figure 2-18.Stress conditions and deformation in Simple shear apparatus

Depending on sample, grain size distribution and desired engineering properties, drained or undrained shear strength can be analyzed using a Simple shear device. In order to find drained shear strength the vertical load should remain unchanged during shearing phase. The scenario to 
create or track the undrained conditions for very fine samples such as clay is more complicated, since Simple shear apparatus is not mounted with any pore water pressure measurement or cell pressure. However, the undrained shear strength can be characterized by keeping the volume of sample constant. The configuration of Simple shear apparatus restrains any lateral movement $\left(\varepsilon_{\mathrm{x}}=\varepsilon_{\mathrm{y}}\right)$. Therefore, in order to keep the sample volume constant, the height should be constant. This is facilitated by clamping mechanism at top and bottom of sample (Figure 2-19) and automatic adjustment of vertical load.

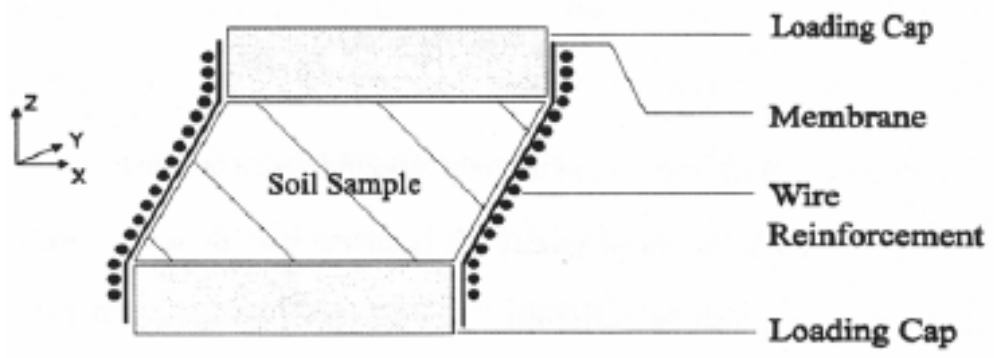

Figure 2-19.Specimen confinement in Simple shear test (Kim 2009)

The hypothesis in constant volume test is that any change in the vertical stress during shearing is equivalent to the change in pore water pressure in truly undrained test. Dyvik et al. (1987) conducted experiments on normally consolidated clays to verify the hypothesis by conducting constant volume shearing tests with pore-water pressure measurement. In fact, samples were enclosed in a pressurized cell to facilitate fully saturation condition. The results of truly undrained test (associated with pore water pressure measurement) and the conventional constant volume test, including stress path and stress-strain relationship on similarly prepared samples were found to be almost identical in saturated form.

There are two Simple shear apparatus available; Norwegian Geotechnical Institute (NGI) apparatus introduced by Kjellman (1951) at the beginning; completed by Bjerrum and Landva (1966) afterward, and Cambridge University (CU) apparatus (Roscoe 1953). Figure 2-20-Figure 2-22 show a schematic of each type of Simple shear device. In the NGI apparatus a circular sample is used and lateral movement is controlled by a wire reinforced rubber membrane. The rubber membrane is stiff enough to facilitate $\mathrm{K}_{0}$ consolidation and keep a constant volume during shearing. On the other hand, Cambridge machine uses a sample with square cross section area and the lateral deformation remains constant using rigid boundaries. 


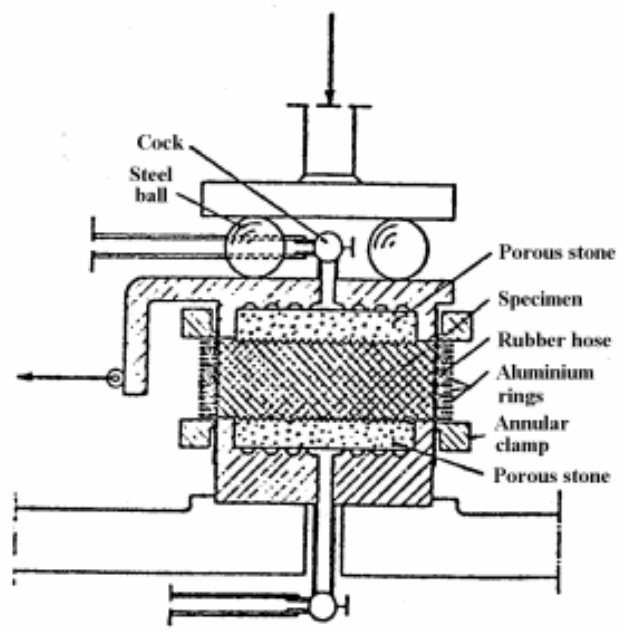

Figure 2-20.NGI simple shear apparatus (Kjellman 1951)

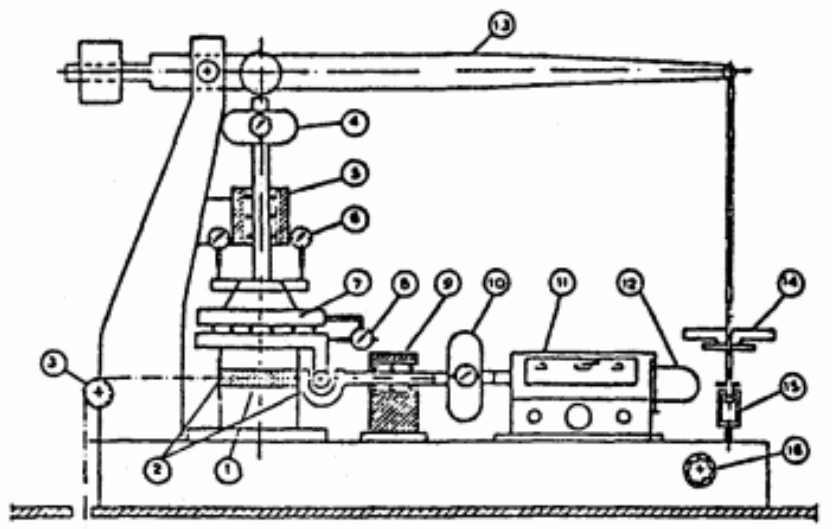

Figure 2-21.NGI Simple shear device (Bjerrum and Landva 1966) 

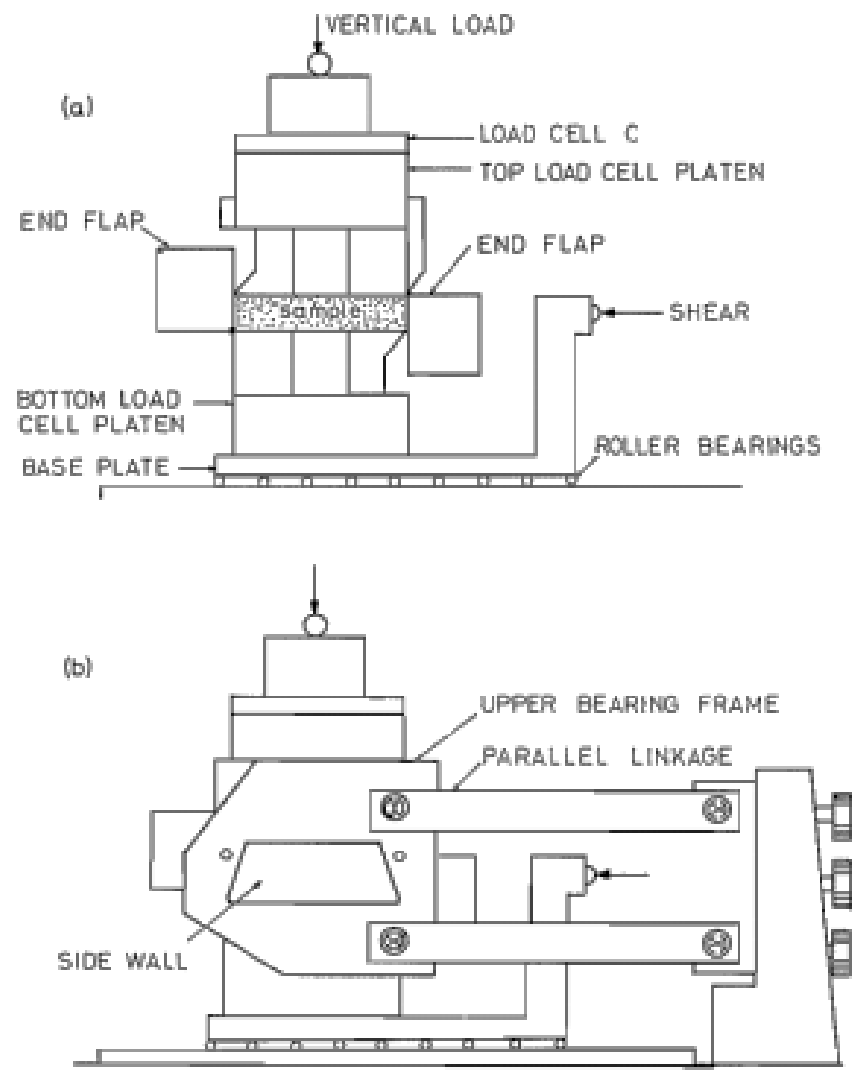

Figure 2-22.The Cambridge University simple shear device- (a) vertical section, (b) side elevation (Roscoe 1953)

One of the limitations associated with Simple shear apparatus is nonuniform distribution of stress and therefore inhomogeneous deformation through the sample. The reason is lack of shear stress at the edge, while normal force is applied in all directions including edges. Figure 2-23 presents shear stress and normal stress distribution in a Simple shear.

Budhu (1983) conducted experiments on similarly prepared sand samples to characterize the behaviour of specimens using NGI and Cambridge apparatus. The results showed nonuniformity development during monotonic loading and more tangibly in cyclic loading. However, some major differences in the results were observed. Budhu believed that "The rigid boundaries of the Cambridge apparatus force the sample to deform in a simple shear configuration, but the 'flexible' vertical boundary of the NGI type apparatus cannot do so except, perhaps, at small shear strains". 
Airey and Wood (1987) investigated the homogeneity of stresses during shearing using the conventional Simple shear device instrumented with load cells at the edges. The results showed that stress distributions are uniform at least in the middle third of the sample and are equal to the average measured stresses in the boundary.

(a)

a)

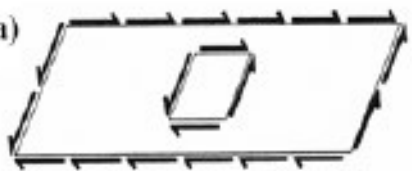

Pure Shear

(b)

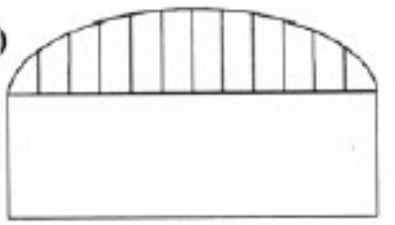

Shear Stress Distribution

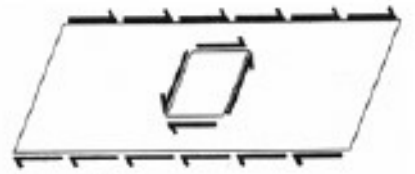

Simple Shear

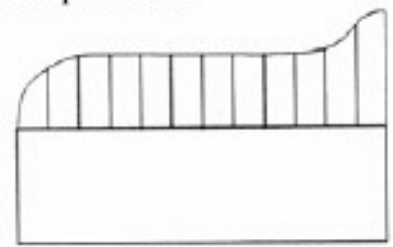

Normal Stress Distribution

Figure 2-23.a) Simple shear and Pure Shear. b) Stress distribution in a Simple shear Airey et al. (1985)

\subsubsection{Undrained monotonic behaviour of sands}

The undrained monotonic behaviour of sands using triaxial test or Simple shear test have been studied in past decades (eg. Ishihara et al. 1975, Vaid and Sivathayalan 1996, Vaid et al. 1999). As it has shown in Figure 2-24 a typical undrained monotonic response of sand categorised within three main groups (after Vaid and Chern 1985). In type 1, the material reaches a peak shear strength at low strain values, followed by contractive (strain softening) behaviour. This characteristic which is called as true liquefaction (Chern 1985) is more common in loose sands. Also, Critical Stress Ratio (CSR) which is defined as the maximum stress ratio at which soil exhibits strain softening can be found in type 1 .

Reaching to CSR is followed by strain softening at a constant stress ratio in type 2. Finally, soil records strain hardening (dilative) by continuing the test (increasing shear strain). Castro (1969) defined this behaviour as limited liquefaction. Quasi-steady state refers to the constant stress ratio at which sand undergoes a steady state-like deformation (Ishahara et al. 1975). Phase Transformation (PT) corresponds to the effective stress ratio at which behaviour of soil changes from strain softening to strain hardening. 
Type 3 only shows strain hardening behaviour in which shear strength of soil is improved even by increasing shear strain (deformation). This behaviour is more common in dense sands.

As described, the behaviour of soil categorized within three behaviour types. In other words, the behaviour of material changes from strain softening to strain hardening by increasing the relative density (corresponds to decreasing void ratio). Previous studies show that initial state variables including fabric, density (or void ratio), loading mode, and confining stress level (consolidation pressure) have a significant effect on monotinic behaviour of soils. The following section describes how monotonic behavior of soils is affected by these parameters.

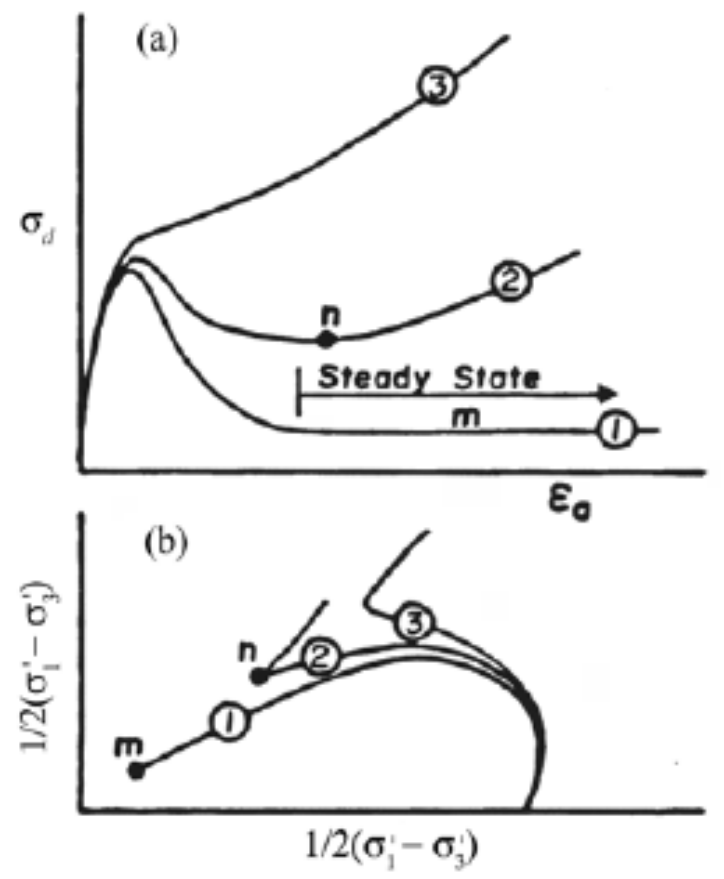

Figure 2-24.Undrained monotonic response of sand at different relative density- a) Stress vs.strain, b) Stress path (after Vaid and Chern 1985).

\subsubsection{Parameters affecting monotonic response of sands}

\subsubsection{Fabric}

Fabric which is influenced by reconstitution method is an important parameter affecting the mechanical behaviour of the soils considerably. Specimens are typically reconstituted by Water Pluviated (WP), Air Pluviated (AP) and Moist Tamped (MT) techniques. Figure 2-25 presents the undrained Simple shear response of two different samples on Syncrude sand and Fraser Delta 
sand respectively. It should be note that the only changing parameter was fabric in all tests and other parameters such as consolidation pressure and initial void ratio were similar for all samples. The graphs clearly indicate that samples prepared with Moist Tamped method experiences a strain softening at the beginning and steady state by increasing deformation. Specimens prepared with AP also showed strain softening at the early stages and followed by quasi-steady state. In contrast, WP samples showed dilative behaviour as shear strain grows up.

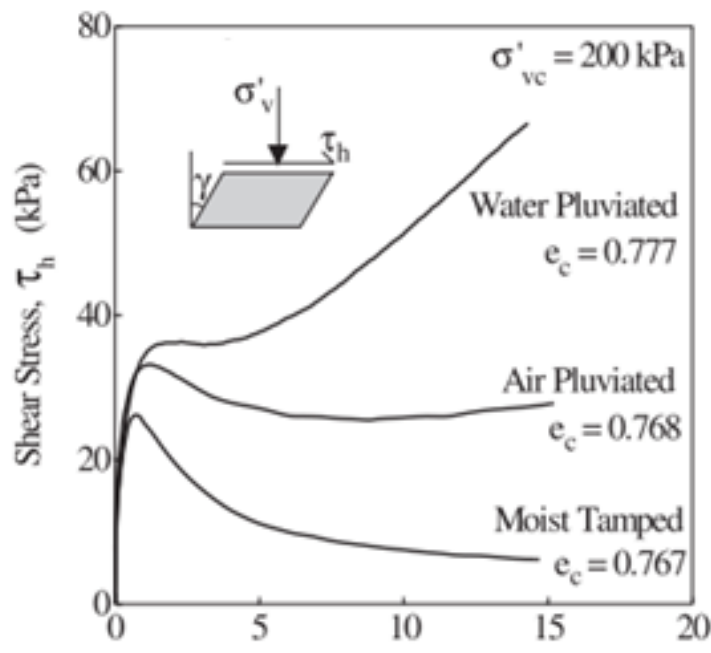

Shear Strain, $\gamma(\%)$

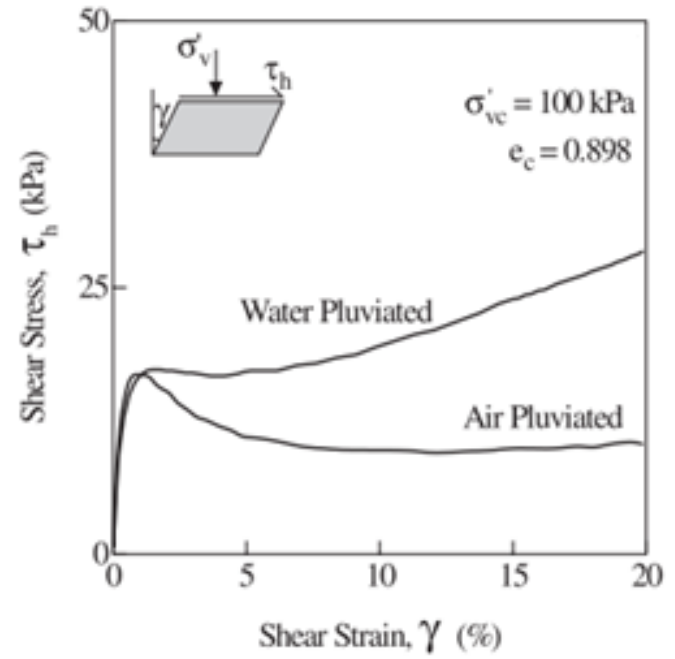

Figure 2-25.Effect of fabric on undrained Simple shear response, a) after Vaid et al. (1995), b) Vaid and Sivathayalan (2000) 


\subsubsection{Loading mode}

It has been reported that for a wide range of void ratio the monotonic response of a given specimen under t riaxial compression test would be different from that in triaxial extension test (Vaid et al. 1990, 2001, Vaid and Sivathayalan 1996). A typical example is shown in Figure 2-26, in which the undrained monotonic behaviour of a given specimen is varied considerably from strain softening in triaxial extension to strain hardening in triaxial compression. The behaviour of soils in Simple shear is somewhere between the behaviours under extension and compression, but closer to the behaviour under triaxail extension. These differences in undrained behaviour probably relates to the fact that $\sigma_{\alpha}$ which is defined as the inclination of $\sigma_{1}$ direction with sand deposition direction is variable for different tests (Vaid and Sivathayalan 1996). While $\sigma_{\alpha}$ is changing from $0^{\circ}$ to $45^{\circ}$ during shearing in simple shear, the value is equal to $0^{\circ}$ and $90^{\circ}$ in triaxial compression and triaxial extension respectively. Another reason for variation in behaviour with loading mode is due to presence of induced anisotropy in particles rearrangement, which is thought to occur differently in the different loading modes (Oda et al. 1978). In other words, particle rearrangement is more difficult when sand is deformed at strain confinement condition.

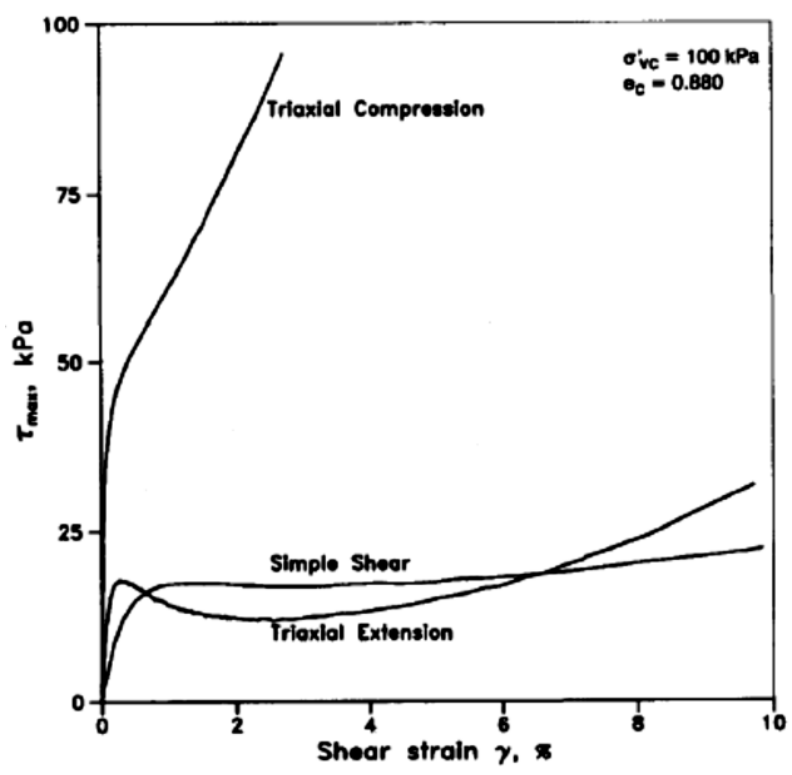

Figure 2-26.Comparison of undrained monotonic behaviour of Fraser Delta sand at different loading modes (Vaid and Sivathayalan 1996) 
Brittleness Index $\left(\mathrm{I}_{\mathrm{B}}\right)$ which is originally introduced by Bishop (1971) can be used to describe the tendency of loose sands to show a contractive behaviour. $\mathrm{I}_{\mathrm{B}}$ defined as: $\frac{\text { Speak-SPT }}{\text { Speak }}$

Where $\mathrm{S}_{\text {peak }}$ is peak shear stress, and $\mathrm{S}_{\mathrm{PT}}$ is the minimum shear stress after peak.

Figure 2-27 shows an example of contractive response and its correlation to $\mathrm{I}_{\mathrm{B}}$. The trend shows that $\mathrm{I}_{\mathrm{B}}$ decreases by increasing consolidation pressure. However, triaxial extension shows more tangible contractiveness compared to Simple shear.

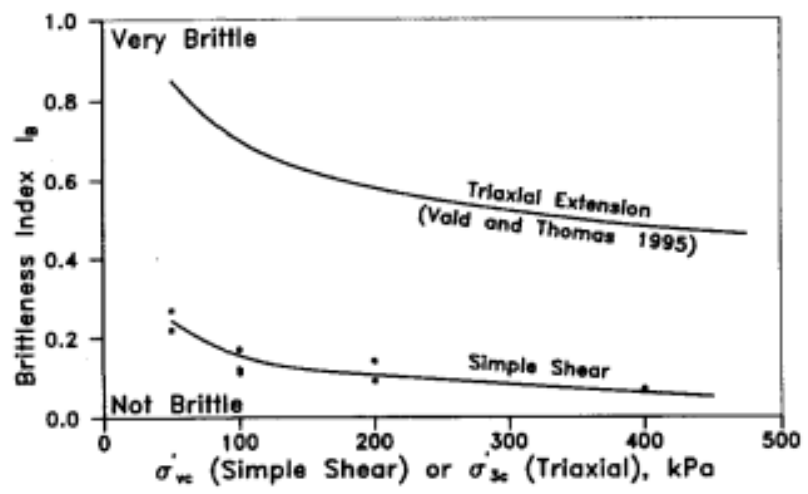

Figure 2-27.The correlation of Brittleness Index and contractiveness tendency (Vaid and Sivathayalan 1996)

Vaid et al. (2001) conducted a series of compression and extension triaxial tests to investigate the influence of initial state variables on monotonic and cyclic response of Fraser River sand. As it has shown in Figure 2-28, it was concluded that increasing $\sigma^{\prime}$ nc (confining stress) at a constant $\mathrm{Kc}\left(\sigma^{\prime}{ }_{1 \mathrm{c}} / \sigma^{\prime}{ }_{3 \mathrm{c}}\right)$ or increasing $\mathrm{K}_{\mathrm{c}}$ at a constant $\sigma^{\prime}{ }_{\mathrm{nc}}$ results in a slight increase of strain softening for compression test. In contrast, tension response was variable from strain softening at steady state to limited liquefaction at quasi steady state by increasing $\sigma^{\prime}$ nc. In addition to the loosest state, denser specimens were also tested. Interestingly, extension response was recorded as strain softening again even though density was increased, whereas the compression response was found to be dilative regardless of $\mathrm{K}_{\mathrm{c}}$ and $\sigma^{\prime}$ nc values. 

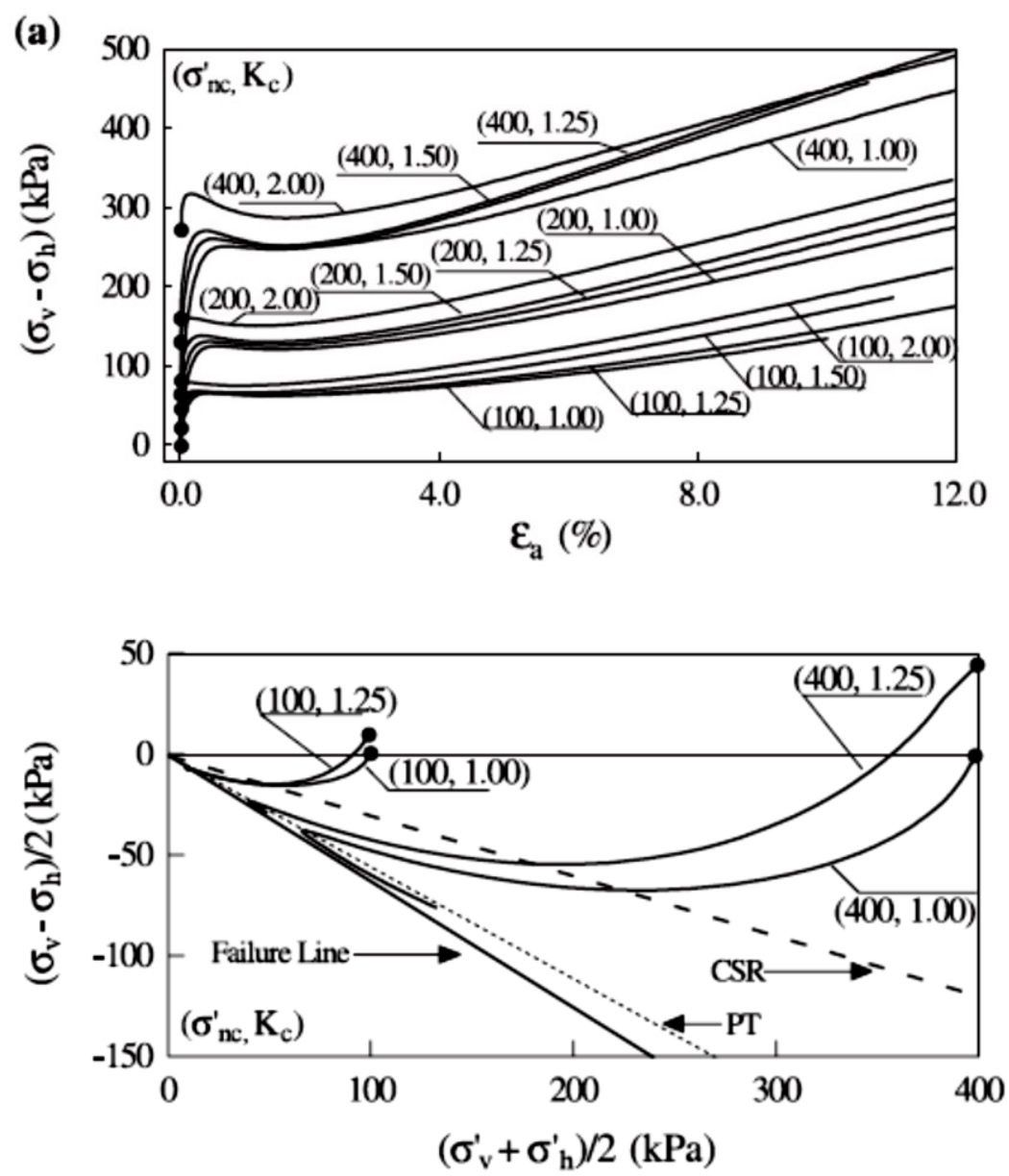

Figure 2-28.Behavior of loosest deposited Frazer River sand in (a) Monotonic triaxial compression loading, and (b) Monotonic extension loading (Vaid et al. 2001)

\subsubsection{Void ratio}

Void ratio is one of the important parameters affecting undrained strength of soils. A wide range of void ratio at a given confining stress should be considered to address the effect of void ratio on behaviour of the soil. Generally, it is expected the undrained response of specimens changes from strain softening to strain hardening as material gets denser as a result of void ratio decrease (Thomas 1992, Vaid and Sivathayalan 1996, Kim 2009).

\subsubsection{Confining stress level}

Different samples with an equal initial void ratio (density) which are similarly prepared should be tested at different stress levels to characterize the effect of confining stress. Generally, the contractiveness tendency decreases with increasing confining stress at a fixed initial void ratio. 
In fact, increasing confining stress level leads to decrease in final void ratio and creation of denser material which is associated with less contractiveness tendency (Thomas 1992, Sivathayalan 1994).

\subsubsection{Shear strength characteristic of clays}

It has been mentioned earlier that the monotonic shear strength characteristic of oil sand tailings in the present study has investigated using Simple shear apparatus. It is known that the fundamental properties of the oil sand tailings are close to engineering properties of very soft clays. Figure 2-29 illustrates an example of monotonic shear response of a clay in a Simple shear apparatus.
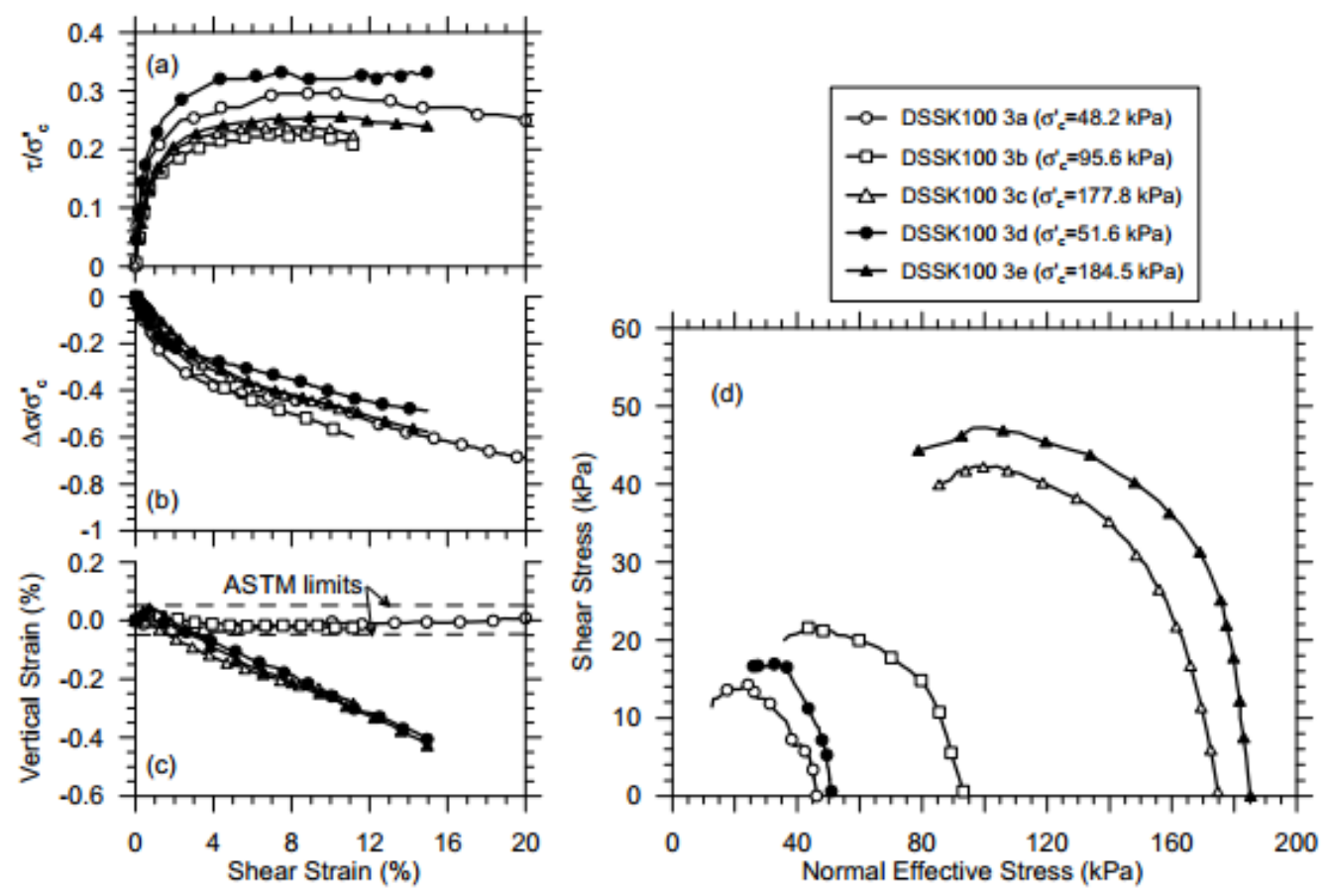

Figure 2-29. Simple shear test results for soft clays (Kaolinite specimens). (Bro et al. 2013)

In the literature, the undrained shear strength of clays has been studied using Simple shear or hollow cylinder equipment. The second approach is beyond the scope of this research; therefore, a brief explanation of affecting parameters on monotonic shear response of clays in a Simple shear has brought herein. 


\subsubsection{Anisotropy of specimens}

The anisotropy of specimens can be caused by either inherent anisotropy or stress-induced anisotropy (Lofroth 2008). Inherent anisotropy occurs during formation of the soil and causes the main differences in soil structures. On the other hand, stress-induced consolidation refers to the condition in which the effective consolidation pressures are not equal in all directions. Larsson (1977) proposed a model for soft clays with ability to estimate undrained shear strength parameters in planes at different orientations to examine the influence of anisotropy on behaviour of clay specimens.

\subsubsection{Sample preparation}

An example of Simple shear response on undisturbed and remoulded specimens at different overconsolidation ratio (OCRs) are presented in Figure 2-30 (Hanzawa et al. 2007). The samples were initially consolidated to $400 \mathrm{kPa}$. As it has shown, the shearing response of both undisturbed and remoulded specimens was found to be equal. The authors believed that the effect of sample disturbance can be overcome at high consolidation pressure.
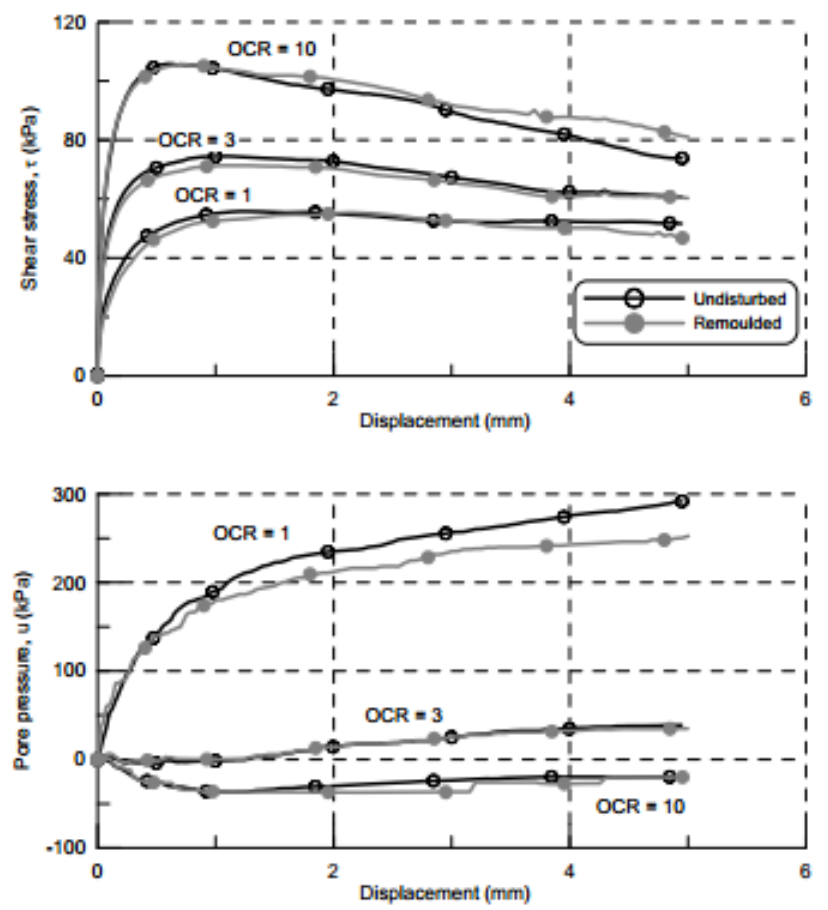

Figure 2-30.Comparison of DST tests on remoulded and undisturbed specimens of plastic Drammen clay (Hanzawa et al. 2007) 


\subsubsection{Stress history and stress state}

It is common that behaviour of specimens be normalized by preconsolidation pressure in order to find the effect of stress history on characteristics of the soil. Ladd and Foot (1974) reported that clay specimens with similar OCR but different consolidation pressure (i.e. different stress history), exhibit a similar stress-strain response when normalized by consolidation pressure. Figure 2-31 shows an example of a clay specimen consolidated at two different consolidation pressures in their studies. However, the shear response graphs are coincided once deviator stress is normalized by consolidation pressure. Similarly, Figure 2-31 shows the normalized shear stress behaviour in Simple shear device. It should be note that small discrepancy in the normalized graphs is not avoidable due to inherent anisotropy of specimens.

Most of available empirical equations to estimate the undrained shear strength of soils using field methods (such as piezocone test and vane shear test) are for normally consolidated or slightly overconsolidated soils from a horizontal ground. Lofroth (2008) investigated the influences of overconsolidation pressure and also the relationship between horizontal effective stress and vertical stress on evaluation of undrained shear strength parameters for both filed tests as well as laboratory test (i.e. Simple shear). The author showed that a correction factor in available empirical equations is required for estimation of undrained shear strength parameters of overconsolidated clays located in a slope for both piezocone test and vane shear test. However, such correction is not required for Simple shear results in the laboratory. 


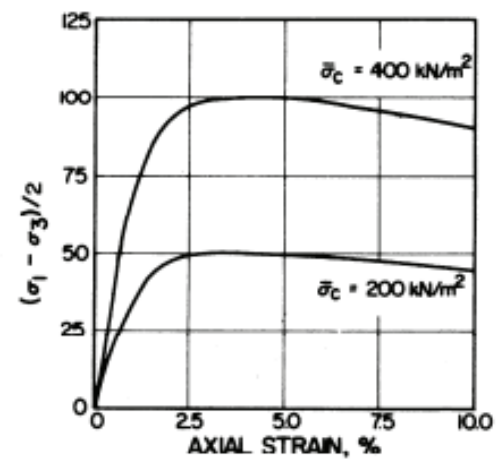

(a) TRIAXIAL COMPRESSION TEST DATA FOR $\bar{\sigma}_{\mathrm{C}}=200$ AND $400 \mathrm{kN} / \mathrm{m}^{2}$

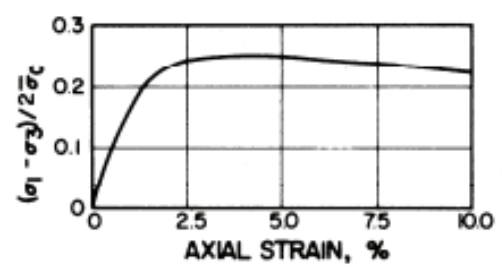

(b) NORMALIZED PLOT OF TRLAXIAL TEST DATA

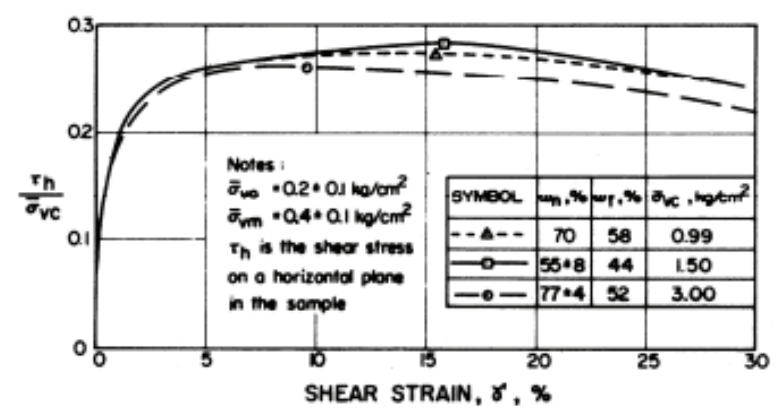

Figure 2-31.Normalised behaviour using idealised triaxial compression test data for homogeneous clay and direct simple shear test data for normally consolidated Maine organic clay (Ladd and Foot, 1974).

\subsubsection{Shearing rate and shearing mechanism}

Hanzawa et al. (2006) published the results of a study conducted on two different clay samples from Norway and Japan using a conventional NGI apparatus and a custom made Simple shear device. The results revealed that second apparatus gives higher strength compared to NGI for all samples consolidated to in situ stress values. Different shearing mechanism, various shear strain rate and specimen anisotropy were found to be the main reasons of discrepancy in the results. The authors indicated that the difference resulting from different shearing mechanism can be quantified using an elasto-plastic model introduced by Ohta et al. (1985). On the other hand, the 
influence of discrepancy of results due to different rates of strain can be overcome using a correction factors from triaxial strain rates.

Bro et al. (2013) investigated the undrained shear strength of various clay specimens by conducting different series of tests at different displacement rates. In first series, the undrained strength of clay specimens was considered at low displacement rates $(1 \% / \mathrm{hr})$ to imply the constant volume test described by ASTM (D6528). In the second approach, the tests were conducted at higher displacement rates in order to facilitate partial drainage. Results showed that at high displacement rates, the undrained strength cannot be estimated accurately, since the height change is relatively large compared to maximum allowable height change recommended by ASTM (less than $0.05 \%$ ). In other words, the volume of sample cannot remain constant due to the change of sample height. The authors concluded that only low displacement rate can meet the requirements of truly undrained shear strength in constant volume Simple shear testing.

\subsubsection{Parameters affecting shear strength of hard rock mine tailings}

The literature reveals undrained behaviour of soils under both monotonic and cyclic loading has been studied from the early 1970s, while a limited attention was given to shear strength characteristic of mine tailings and oil sand tailings. However, recent environmental regulations have forced operators and researchers to investigate the monotonic and cyclic response of mine tailings and oil sand tailings. The following section explains how shear strength of the tailings is affected by different initial state variables.

\subsubsection{Void ratio (density)}

Void ratio or density is a significant parameter influences mechanical properties of the tailings. It has been shown that for reconstituted gold tailings specimens, the behaviour changes from strain softening to strain hardening when void ratio decreases at a fixed consolidation pressure. (AlTarhouni et al. 2011, Daliri 2013). Figure 2-32 shows a typical example of monotonic response of a gold tailings over a range of void ratio. 


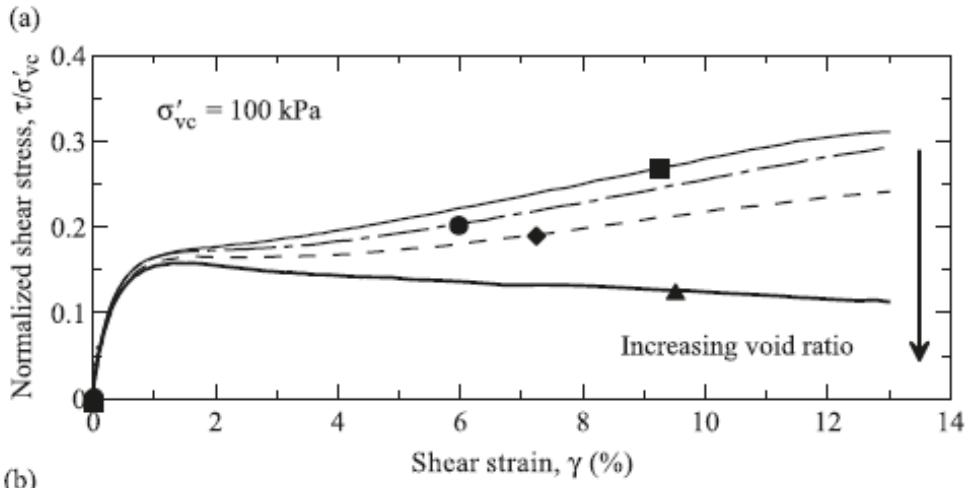

Figure 2-32.Monotonic response of a gold tailings over a range of void ratio (Al-Tarhouni et al. 2011)

\subsubsection{Degree of saturation}

As described earlier, the validity of the assumption that behaviour of a testing material is identical in constant volume test and undrained test was verified by the early studies. Finn et al. (1978) showed the behaviour of a completely dry and completely saturated sand was identical in simple shear. Later on, Dyvik et al. (1987) also verifies the validity of the aforementioned assumption for "saturated" soils. Al-Tarhouni et al. (2011) examined the influence of degree of saturation on behaviour of mine tailings in Simple shear device. Degree of saturation was changing between 0.9 and 1 in their studies. The results are presented in Figure 2-33. As it has shown, the behavior of samples was found to be identical.

Daliri (2013) investigated the effect of degree of saturation on the monotonic response of synthetic silt samples in constant volume test using NGI. Different samples were prepared at the same void ratio but different degree of saturation from completely dry condition to partially saturated. Dry samples were prepared using air pluviation technique. Some dry samples were also used to prepare partially saturated specimens by creating hydraulic gradient and injecting water from a water reservoir which was located higher than specimen. Figure 2-34 is an example of monotonic response of the different synthetic silt samples (Coarse and medium grained soils of low plasticity) in constant volume apparatus at an effective stress of $50 \mathrm{kPa}$. The graph clearly shows that behaviour (Shear stress vs. shear strain and stress path) of samples are identical at a given void ratio regardless of degree of saturation. The author reported that "The monotonic response of dry and partially saturated coarse grained materials at a given density (void ratio), 
effective consolidation stress and fabric under constant volume simple shear is essentially identical". For finer grained soils, it was difficult to separate out the effects of degree of saturation and suction versus possible fabric effects, though the phase transformation and failure angles appeared to be independent of degree of saturation. The author believed the hypothesis that monotonic response in constant volume simple shear are identical at different degree of saturation can be extended for even fine grained materials which produces suction less than 20 $\mathrm{kPa}$ during desiccation.

(a)

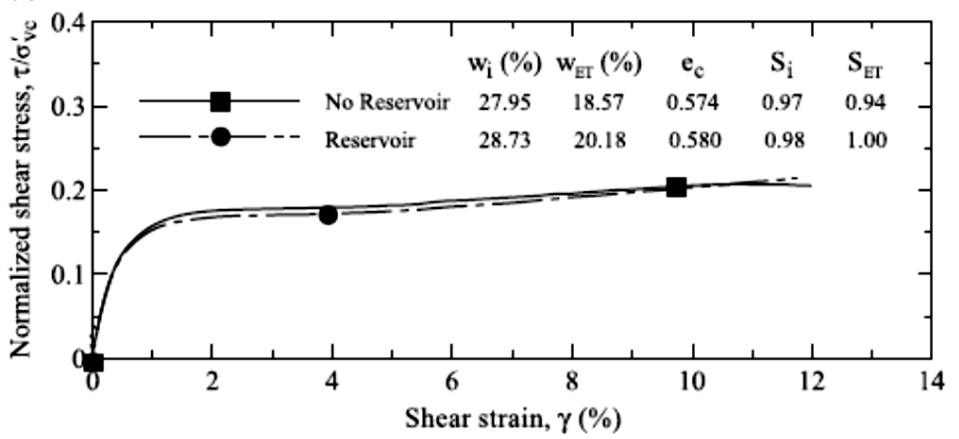

(b)
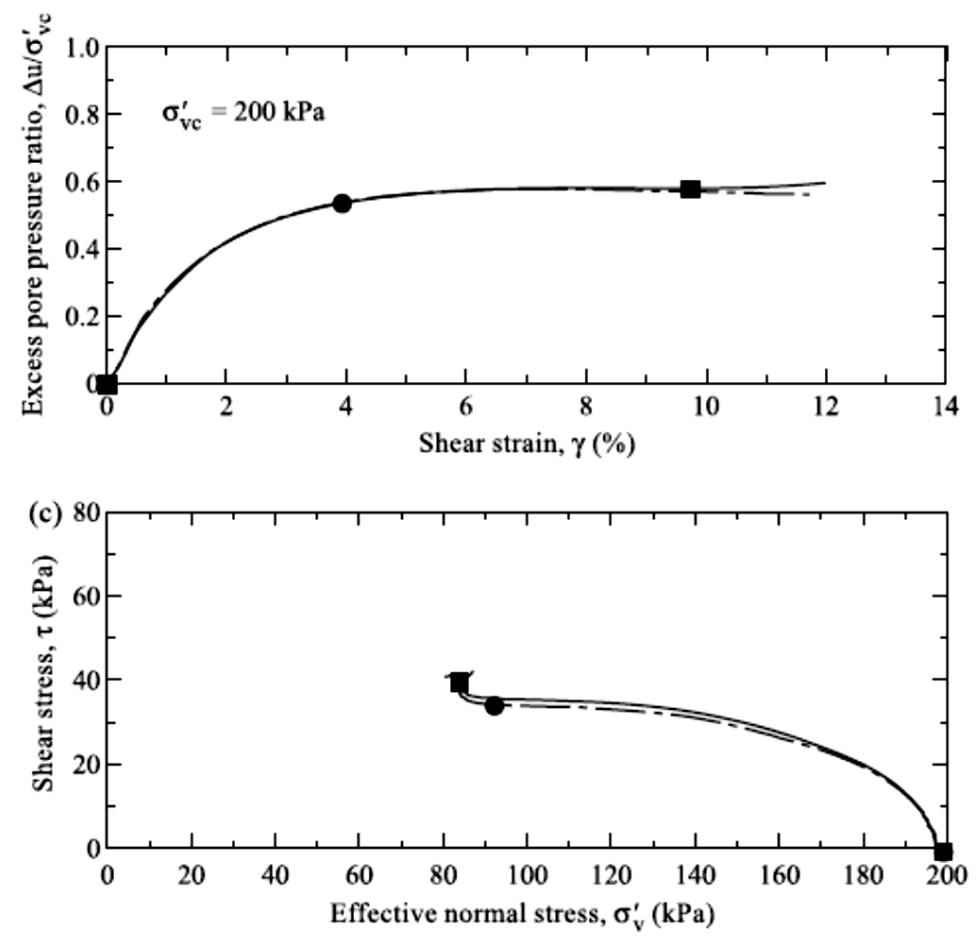

Figure 2-33.Comparison of two samples of similar post-consolidation void ratio (ec), with one of the tests connected to a water reservoir to increase degree of saturation: (a) normalized shear stress versus shear strain; (b) excess pore pressure ratio versus shear strain; (c) stress path. 

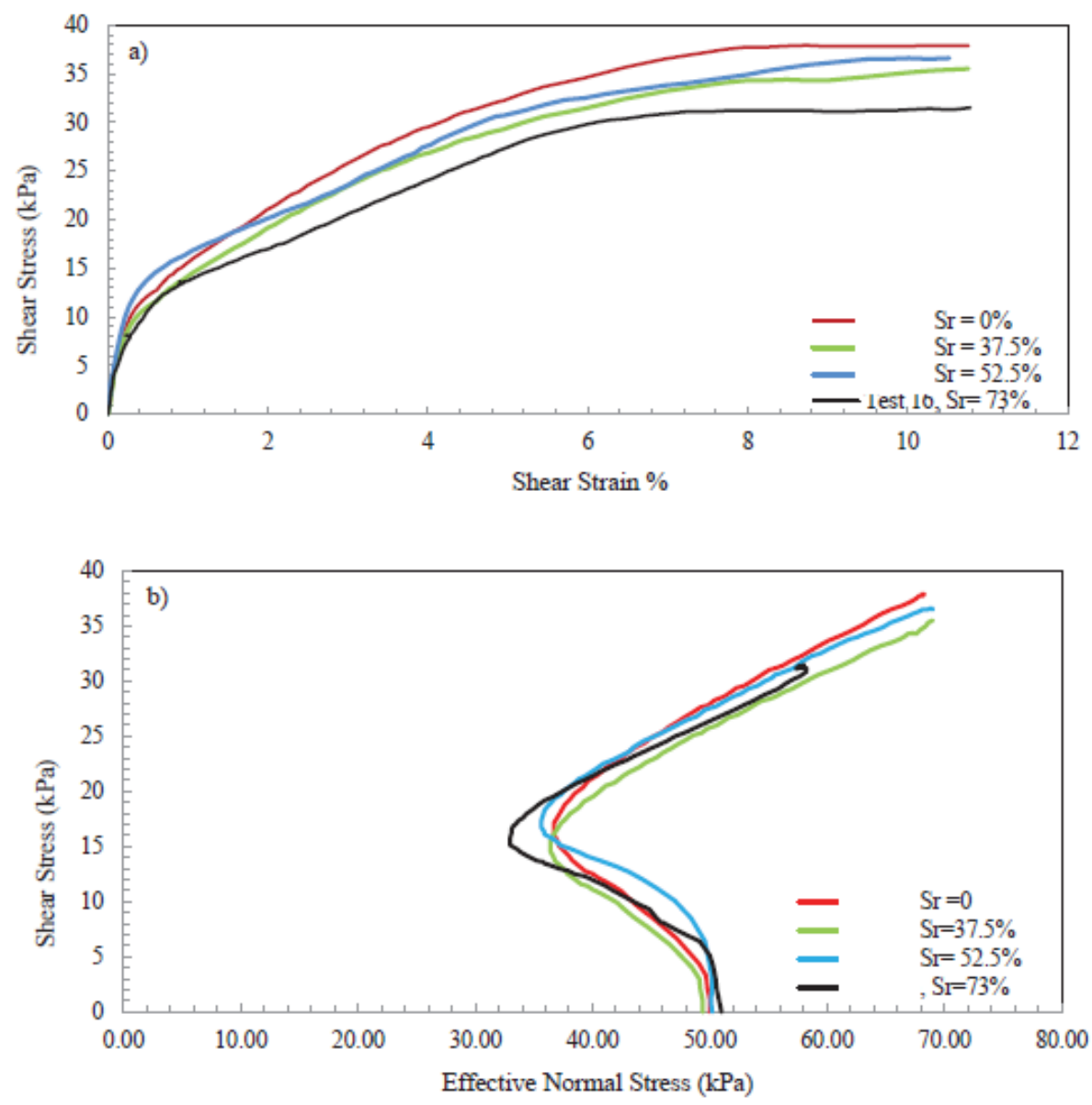

Figure 2-34.Comparison of monotonic response of constant volume tests on synthetic silts under same void ratio (ec $=0.66 \pm 0.01)$ but different degrees of saturation (Daliri 2013)

\subsubsection{Over consolidation pressure}

Some researchers have tried to investigate the monotonic stress-strain response based on normalized shear stress by the effective vertical consolidation pressure (Daliri et al. 2011, AlTarhouni et al., 2011). Kim et al. (2011) applied two different approaches to overconsolidate tailings samples and investigate the shear strength afterwards. The techniques were mechanical loading and dry-wet method. The results of their studies revealed that overconsolidated samples compared to normally consolidated samples show higher shear strength. The monotonic behavior of mechanical overconsolidated samples and desiccated specimens of their study are shown in Figure 2-35. Clearly, the rate of increase in mechanical overconsolidated specimens is more significant compared to desiccated samples. In addition, behavior of desiccated samples was qualitatively different from mechanically overconsolidated samples. While mechanical 
overconsolidated samples showed more pronounced peak strength at phase transformation, desiccated samples exhibited more dilation at larger strains. The authors also showed that increase in over consolidation ratio (OCR) caused by progressive desiccation stress history (equivalent to water content decrease) leads to behavior change from strain softening (positive pore water pressure) to strain hardening (negative pore water pressure). It was also found that the rate of shear strength increase was more significant up to shrinkage limit (which found to be equivalent to air-entry value (AEV) point in SWCC). In other words, no noticeable improvement in shear strength was recorded beyond the shrinkage limit, in spite of considerable increase in OCR and matric suction. This is due to the fact that commencement of desaturation beyond the AEV reduces the contribution of matric suction to total stress and therefore there would be no notable shear strength gain. The results of Kim et al. (2011) study were in good agreement with results of the research conducted by Al-Tarhoini et al. (2011) in which the monotonic response of reconstituted samples consolidated at a given consolidation pressure shows a transition from dilative response for low void ratio values to contractive behavior in high range of void ratios. The results were also compatible with a study conducted by Daliri et al. (2011) within three different laboratory techniques were introduced to simulate stress history of the tailings.

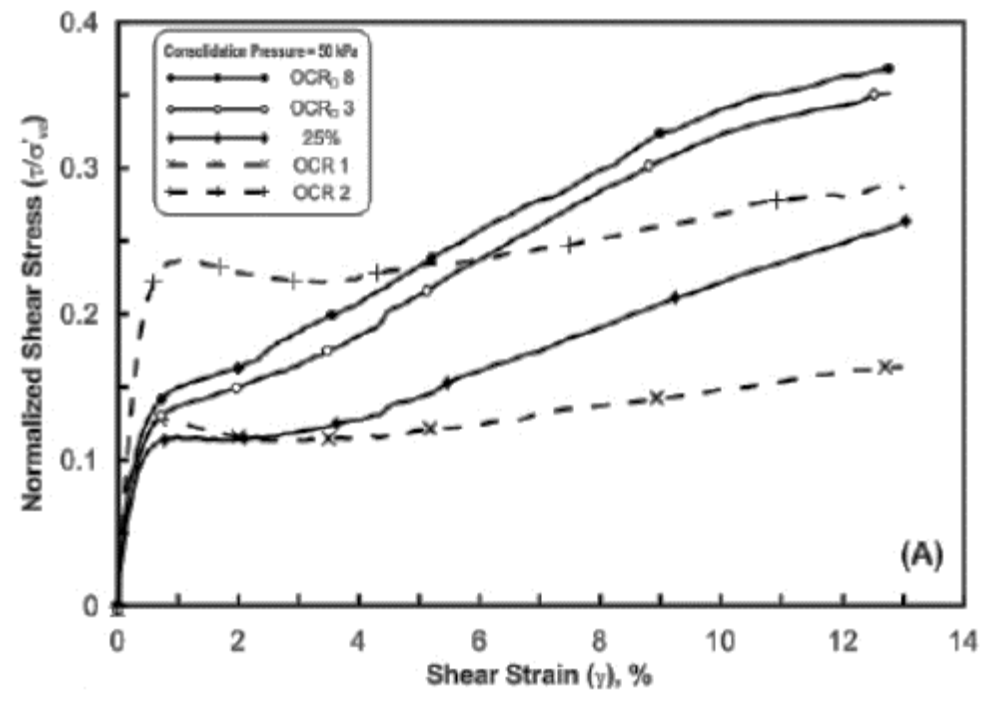

Figure 2-35.The effect of OCR derived by desiccation and mechanical method on monotonic response of thickened gold tailings (Kim et al. 2011) 


\subsubsection{Triaxial test}

Triaxial test is one of the most reliable methodologies to characterize the shear strength behaviour of soils/tailings. This is due to possibility of measuring any changes of stresses, strains and pore pressure values during the test, while controlling drainage conditions. Therefore, a detailed analysis of stress condition and stress-strain relationship can be developed. These results are then applied in constitutive equations to find strength parameters. However, the strength of soil during the testing is highly affected by drainage conditions and also stress condition.

In a conventional triaxial test, a cylindrical sample which is contained in a rubber membrane is placed in a traxial chamber. The specimen is subjected to a desired confining pressure in order to be representative of the in-situ conditions. The axial load is also applied from top of the cell. One-way or two-way drainage can also be controlled by means of connections at top and bottom of sample. Depending on the engineering application, triaxial test is categorized into three different groups as follow:

- Unconsolidated Undrained test (UU)

- Consolidated Drained test (CD)

- Consolidated Undrained test (CU)

The Unconsolidated Undrained (UU) test is the fastest and simplest type of triaxial test. Results of this test are applied to calculate the undrained shear strength of the cohesive specimen (remolded or undisturbed) for a short term. Therefore, this test is merely suitable for a site where the rate of construction is so fast such that pore water pressure does not have enough time to dissipate. As a result, only total stresses are measured and analyzed for stress-strain relationship in a UU test.

The Consolidated Drained (CD) test is suitable for long term analysis by allowing pore water pressure to be dissipated during consolidation. Strength parameters are estimated using effective stress analysis. This test can take a considerable time to be completed, particularly for samples with low hydraulic conductivity.

Similar to CD test, in Consolidated Undrained (CU) test the strength parameters based on the effective stress analysis are found. This test completes within a shorter period as drainage is not 
allowed. Figure 2-36 illustrates typical responses for both drained and undrained conventional triaxial compression tests on loose and dense specimens.
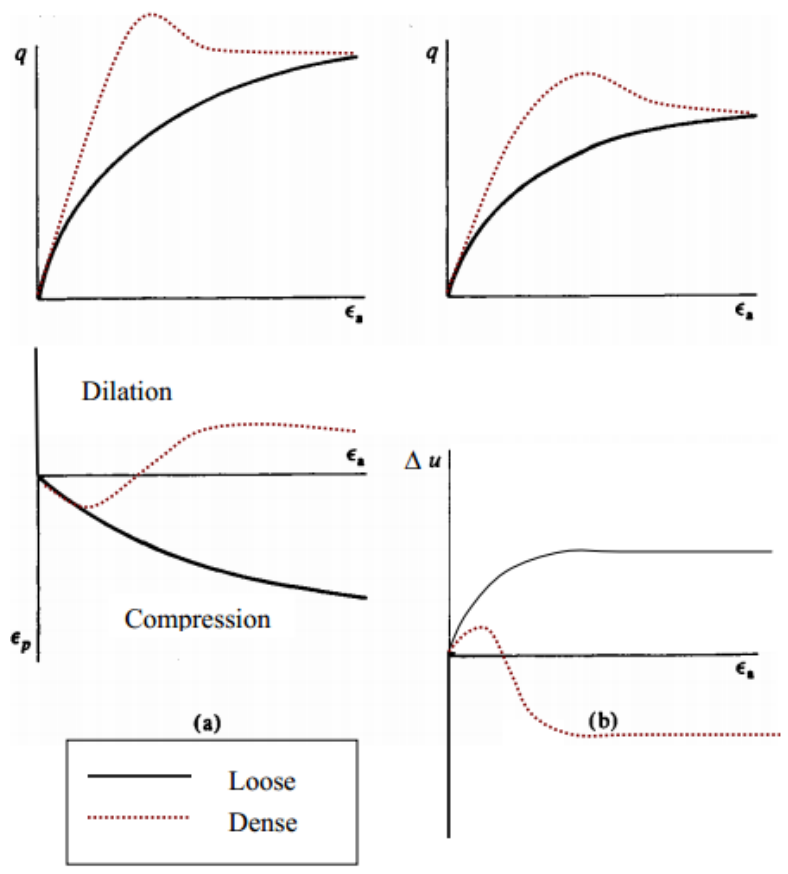

Figure 2-36.Typical results of conventional triaxial

compression tests: (a) drained tests and (b) undrained tests. (Williams 2001)

\subsubsection{Stress state during a triaxial test}

Figure 2-37 summarizes the stress conditions apply to a given specimen in triaxial compression test. $\sigma_{3}$ is the minor principal stress (confining stress) which is applied by pressurizing the water within the cell (surrounding the specimen). q defined as deviatoric stress which is generated by applying the axial load. $\sigma_{1}$ is the major principal stress defining as summation of deviatoric stress and minor stress. The stress state is isotropic once the stress applying in the vertical direction (along the axis of the cylindrical sample) is different from the stresses applied in the horizontal direction (perpendicular to the sides of the cylinder, i.e. the confining pressure). Otherwise, the test is in anisotropic condition. 


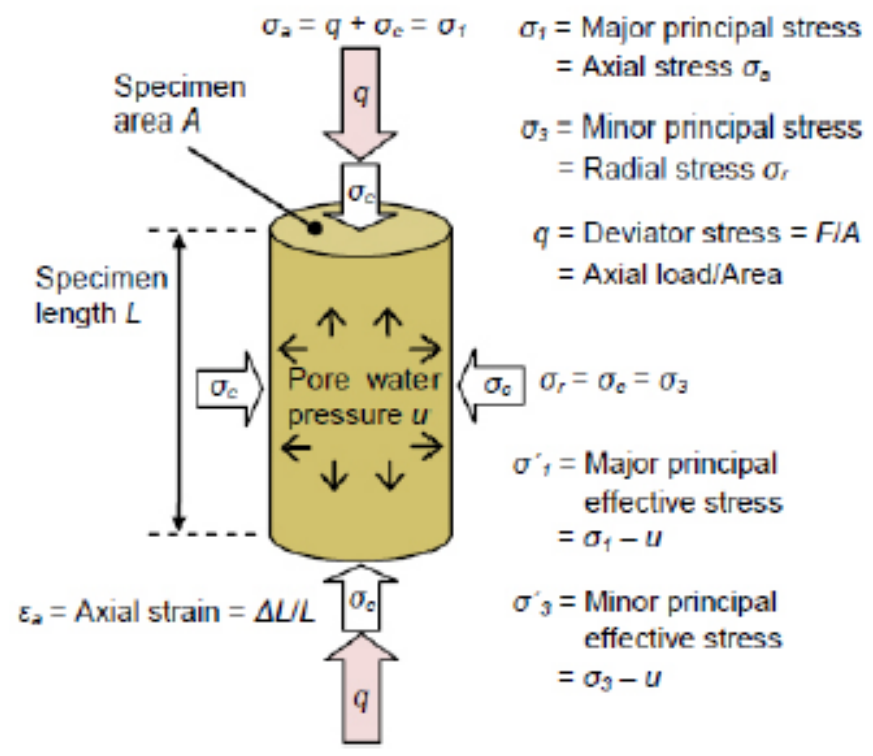

Figure 2-37.Specimen stress state during triaxial compression (GDS 2013)

\subsubsection{Comparison of shearing apparatus and triaxial device}

The main objective of a laboratory testing is simulating the behaviour of a soil similar to the field condition. Therefore, the specimen which is used for laboratory studies should be representative of the field conditions. This is highly influenced by stress and strain distribution within the specimen and their uniformity during testing. The uniformity is highly affected by sample preparation, type and configuration of apparatus (i.e. Simple shear, triaxial, direct shear, hollow cylinder) and measurement of stress and strain during the testing. As an example, differences of triaxial and direct shear approaches can be categorized into three main groups: i) Principal stress conditions including magnitude and orientation, ii) Strain boundary conditions and iii) Failure plane orientation (Castellanos and Brandon 2013).

In the triaxial test, the magnitude of principal stresses is known at the beginning of the test. In contrast, the magnitudes of intermediate and minor principal stresses are not specified in direct shear, since they are governed by the vertical stress. In other words, unlike triaxial test in which the intermediate principal stress is equal to minor principal stress (i.e. $\sigma_{2}=\sigma_{3}$ ), $\sigma_{2}$ is not neither equal to major nor the minor principal stress in simple shear. 
In the triaxial test, the major and minor principal stresses act on vertical and horizontal planes respectively. This orientation is not changing during the shearing. On the other hand, in direct shear, the orientation of principal stresses change during the shearing which is unknown at the end of the test.

In the literature, comparative studies to analyze shear strength characteristics of both sands and clays using various shearing apparatus have been performed. Due to the fact that oil sand tailings have closer behaviour to clayey soils, a brief review of these studies on shear strength of clays is mentioned herein.

Skempton (1964) conducted a series of tests to analyze the shear strength characteristics of clays using direct shear and triaxial devices. The failure was occurred along the pre-existing slip surface within the specimen in triaxial apparatus. Interestingly, shear strength of these specimens were found to be close to the residual strength that were gained in direct shear apparatus for undisturbed clays.

Skempton and Petley (1967) presented the results of direct shear test and triaxial test on clays with pre-existing discontinuities. The residual strength of tested clay specimens from two different testing methodologies were found to be in a good agreement.

Saada and Townsend (1981) evaluated the pros and cons of different laboratory equipment to find the constitutive equations and estimate shear strength parameters of soils. The study considered different apparatus such as triaxial, simple shear, direct shear, torsional shear, and hollow cylinder.

Saada et al. (1983) conducted a laboratory study on both clays and sands using NGI Simple shear, hollow cylinder and triaxial. Both monotonic and cyclic loading were applied to investigate the influence of boundary conditions and distribution of stress and strain during testing. The authors derived three main conclusions: i) Triaxial test is more preferable in axial compression or extension for both monotonic and cyclic loading. ii) Simple shear underestimates the shear strength parameters such as dynamic and static moduli required for landslide and earthquake analysis tangibly. iii) Hollow cylinder overcomes the stress concentration and non- 
uniformities within the sample during testing. Therefore, the hollow cylinder is the most reliable apparatus for cyclic mobility and liquefaction phenomena.

Ahnberg (2006) showed that testing methodology of triaxial test has a considerable effect on the results. Shearing rate of strain and back pressure are important parameters required to be considered in the testing methodology. While low back pressure is preferred for short term stability analysis, high back pressure is used for long term shear strength analysis. Furthermore, high back pressure dissolves any air bubbles within the sample which in turn facilitates saturation process. In some previous studies a back pressure as high as $400 \mathrm{kPa}$ has also reported to ensure saturated condition as closely as possible (Bishop and Henkel 1962, Ahnberg 2006). 


\section{Material and Methods}

\subsection{Introduction}

It is known that compressibility, permeability and shear strength are the most important physical parameters affecting geotechnical bahaviour of the oil sand tailings. This is more challenging for Mature Fine Tailings (MFT) which has low hydraulic conductivity, low water release and low consolidation rate. As mentioned earlier, Directive 074 compels operators to meet certain regulations in terms of shear strength gain after deposition of oil sand tailings.

In the present study, a laboratory investigation was developed to document the consolidation behaviour as well as shearing characteristic of flocculated MFT and raw MFT. To achieve this, thorough test procedures from sample preparation and test methodologies to data collection and results are explained. The results of shearing tests were also analyzed to answer the question of "How polymer amended MFT contributes to faster water release and therefore improving shear strength of oil sand tailings". These results are presented and discussed in this chapter.

\subsection{Testing Materials}

\subsubsection{Raw MFT}

Raw MFT with the average solid concentration of 35.5\% was shipped in $200 \mathrm{~L}$ drums from an oil sands mine in Fort McMurray, Alberta. In most cases, the supernatant water was located on top of the barrel due to the settlement of raw MFT during transportation. In order to get a consistent material, the barrels were re-mixed using a drum mixer. The materials were mixed at an average speed of $200 \mathrm{rpm}$ in both forward and reverse modes for about 24 hours in order to 
reproduce raw MFT similar to initial condition before shipping. The mixed raw MFT were then transferred to smaller buckets for further laboratory tests and investigation.

\subsubsection{Polymer Amended MFT}

As described earlier, flocculation creates aggregates by forming bridges between individual suspended particles or neutralizing particles charges. As a result, water release will be faster and the geotechnical properties of the material will also improve. Therefore, in this study, raw MFT was amended with adding polymer as a flocculant to improve its properties. The amended MFT was then used for further laboratory tests and analysis. To prepare the amended MFT the following steps were conducted:

1. Four (4) grams of high molecular weight anionic polymer is mixed with 996 grams of reclaimed water in a mixing chamber with the average speed of $250 \mathrm{rpm}$ for about 20 minutes. The resulting solution is kept for 24 hours to ensure complete dissolution of polymer in the solvent (reclaimed water).

2. Depending on desired polymer dosage, prepared polymer is added to raw MFT to produce amended MFT in a 3L mixing chamber. The polymer is added in one stage and the material is mixed with the average speed of $250 \mathrm{rpm}$ for 10 seconds. The mixing time is a crucial parameter as if it gets longer, the amended MFT shears and the behaviour of the material changes. The applied mixer is shown in Figure 3-1. 

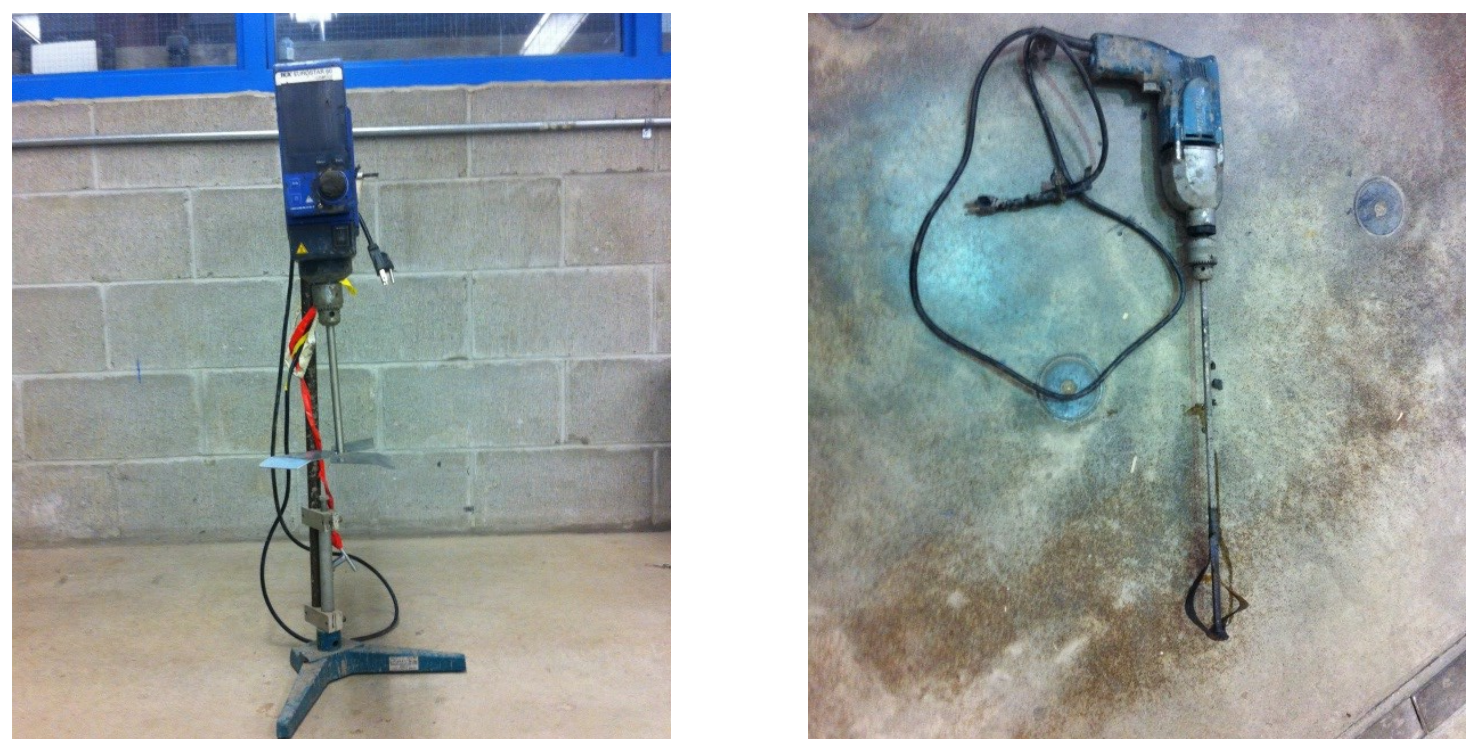

Figure 3-1.Mixer to prepare polymer and amended MFT

The polymer used was an anionic hight molecular weight polymer derived from polyacrylamide.

In order to find the optimum dosage of flocculant to improve water release, jig test (Figure 3-2) was conducted. Flocculated MFT were prepared at different dosages of $600 \mathrm{~g} / \mathrm{T}, 700 \mathrm{~g} / \mathrm{T}, 800$ $\mathrm{g} / \mathrm{T}, 900 \mathrm{~g} / \mathrm{T}$ and $1000 \mathrm{~g} / \mathrm{T}$. One sample was also prepared as raw MFT with no polymer. All samples were mixed simultaneously with the speed of $250 \mathrm{rpm}$ and duration of 10 seconds (similar to the instructions described earlier to prepare the flocculated MFT). The prepared samples were left for 2 weeks for self-weight consolidation while preventing evaporation. Finally, amended MFT with polymer dosage of $700 \mathrm{~g} / \mathrm{T}$ showed better water release compared to other samples. Therefore, polymer dosage of $700 \mathrm{~g} / \mathrm{T}$ was considered to produce amended MFT. 


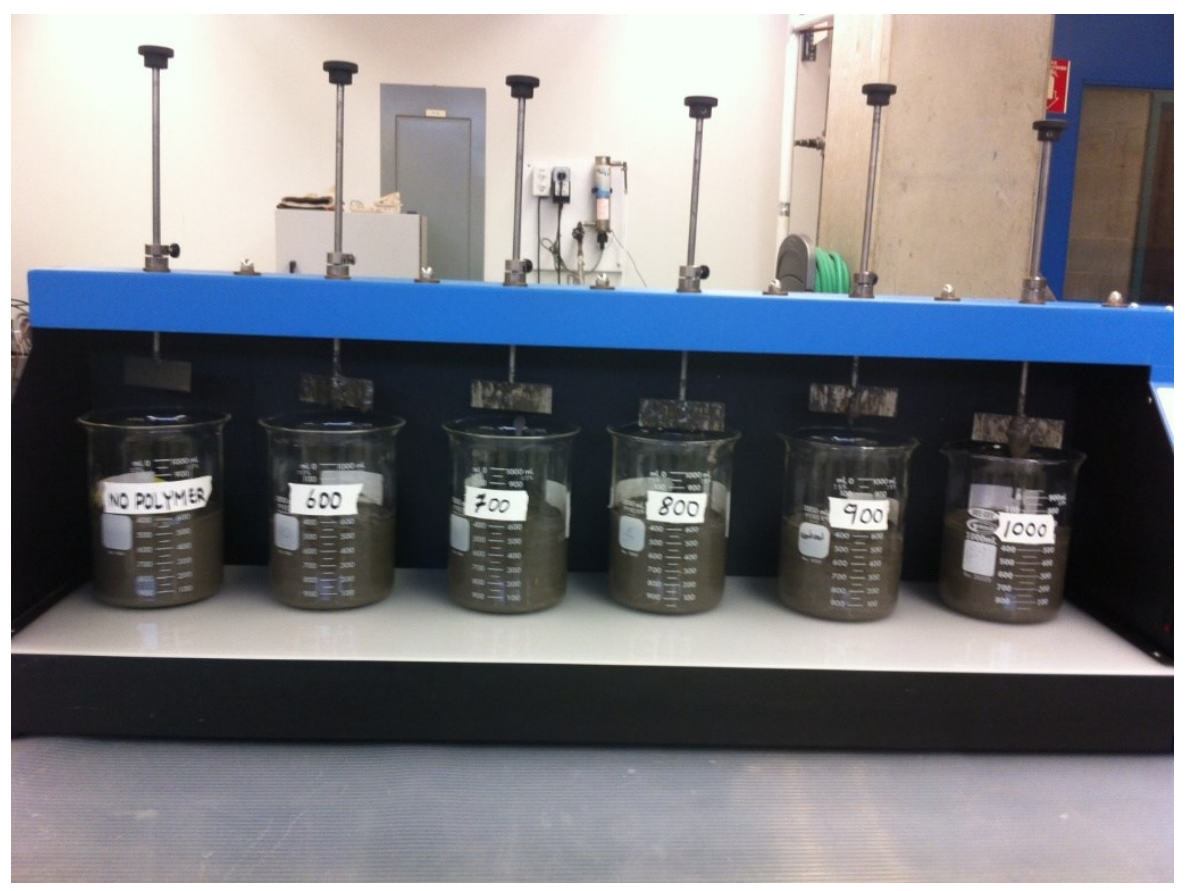

Figure 3-2.Comparison of different dosage of polymer for preparing flocculated MFT (Jig test)

\subsection{Sample preparation for experiments}

In order to analyze load-induced consolidation characteristic and shearing behaviour of polymer amended MFT, two different approaches were applied for sample preparation. Some samples were prepared with merely experiencing drainage from bottom and top without allowing any evaporation, while other samples were undergone both drainage and 3D desiccation. In the first approach, the prepared amended MFT were deposited in a container with initial height and diameter of $25 \mathrm{~cm}$ and $10 \mathrm{~cm}$ respectively (Figure 3-3). After 3.5 months the samples were stable enough that could be transferred to triaxial and simple shear apparatus. After completion of selfweight consolidation, there was no tangible change in diameter, whereas height showed about $8 \mathrm{~cm}$ displacement, reaching to $17 \mathrm{~cm}$. In the second approach, the samples were deposited in lattice mould with similar height as $25 \mathrm{~cm}$ in order to facilitate 3D desiccation while drainage was also allowed from bottom. As a result, the samples were reached stable and appropriate conditions to be tested for further analysis in only 4 days. These latter samples had to be trimmed for about $4 \mathrm{~cm}$ from surface due to the formation of a crust. Below $4 \mathrm{~cm}$ depth, water content was relatively uniform (presented later in Figure 4.2). Figure 3-4 illustrates sample preparation using 3D desiccation technique. 


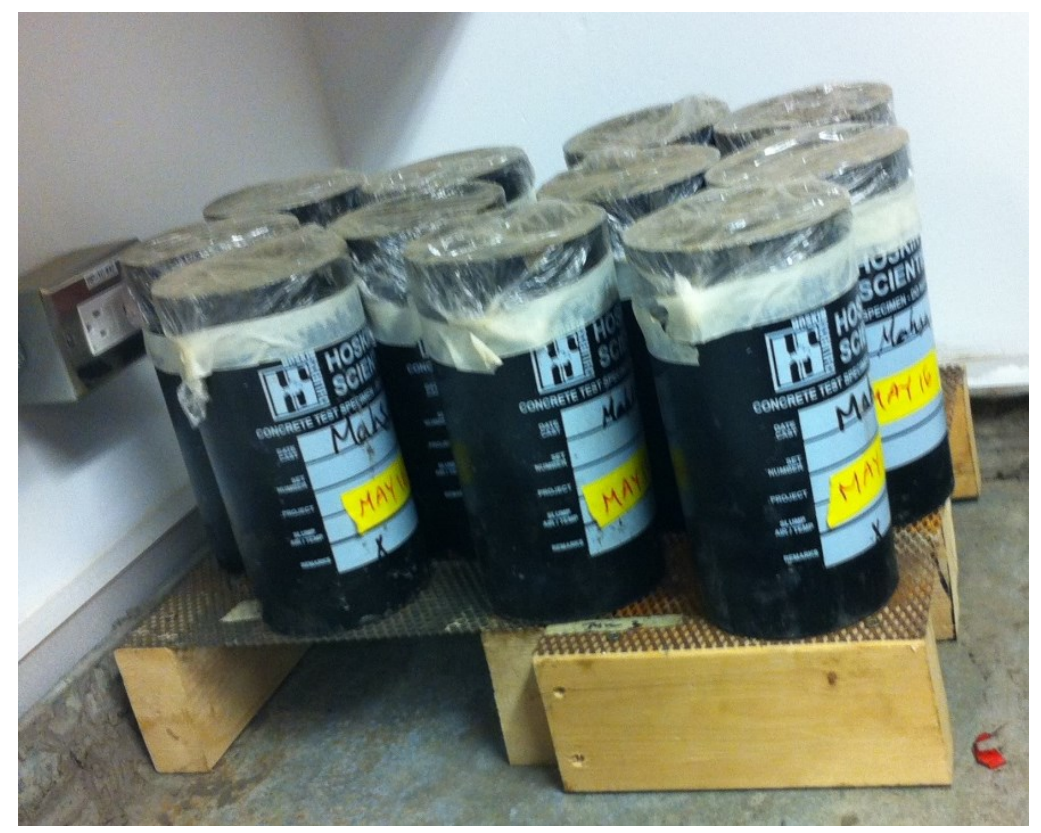

Figure 3-3.Preparation of amended MFT with self-weigth consolidation only

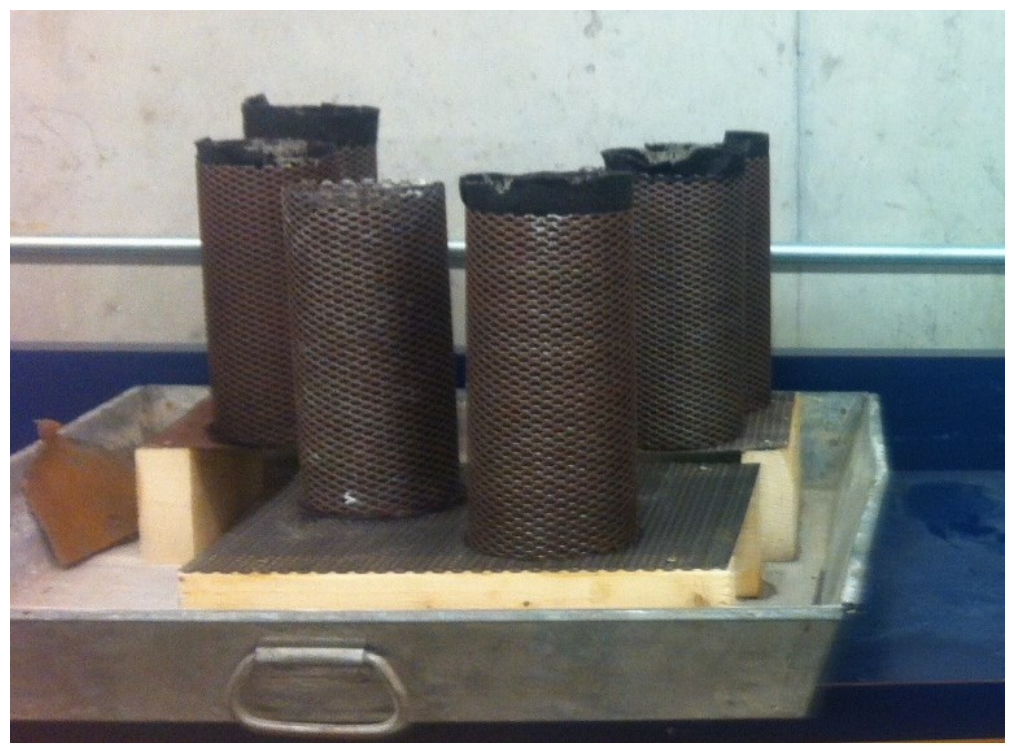

Figure 3-4.Preparation of amended MFT with 3D desiccation 


\subsection{Preliminary geotechnical tests}

\subsubsection{Specific Gravity}

Specific gravity (Gs) is a parameter which is used to determine other geotechnical properties. Specific gravity is the ratio of the mass of unit volume of soil at a stated temperature to the mass of the same volume of gas-free distilled water at a stated temperature. In order to remove air from soil, two approaches can be applied; vacuuming and boiling. In this study, vacuuming method was considered to measure Gs (ASTM D854-00). The required equipment is shown in Figure 3-5. Average specific gravities of 2.2 and 2.5 were measured for raw MFT and amended MFT respectively. This is consistent with data reported in Mizani et al. (2013).
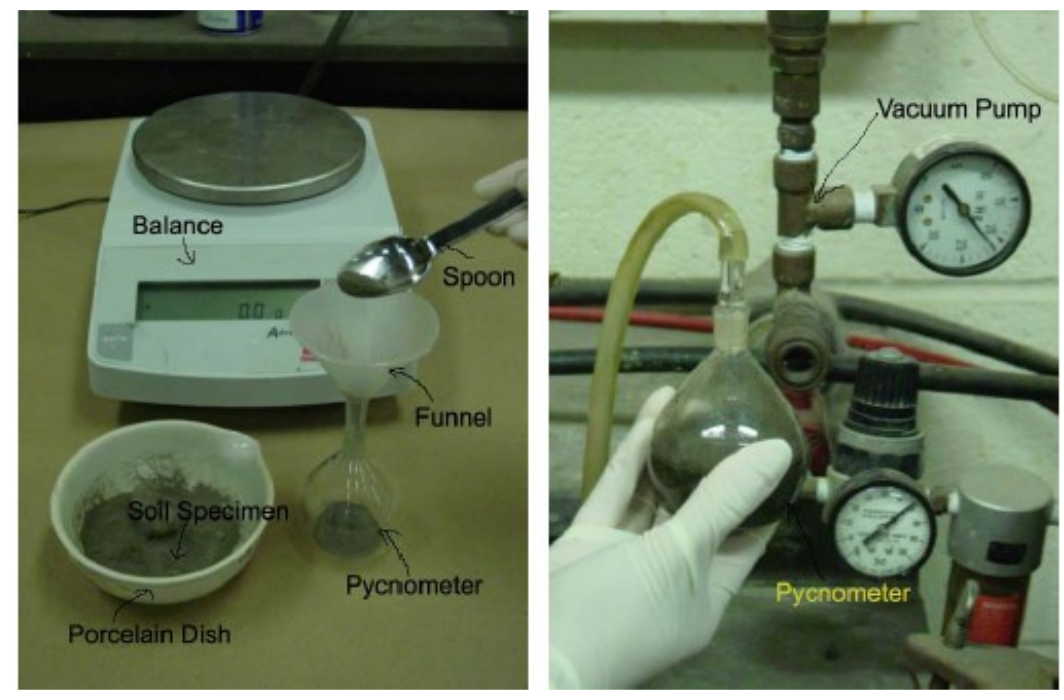

Figure 3-5.Equipment to measure specific gravity

\subsubsection{Grain size distribution}

Grain size distribution is one of the fundamental parameters affecting other soil properties. This can be determined using a sieve analysis (mechanical separation) or hydrometer method. Considering the oil sand tailings is generally classified as a very fine material, hydrometer test was conducted (ASTM D422-63).

Grain size distribution for raw MFT and amended MFT at different dosages of polymer are plotted in Figure 3-6 and Figure 3-7 respectively. It should be note that finding grain size 
distribution for amended MFT is challenging due to two main reasons: i) Using dispersant agent causes dispersion of the aggregates during th test, ii) Conducting hydrometer test requires washing the material through $\# 200$ sieve which break the bridges between the aggregates.

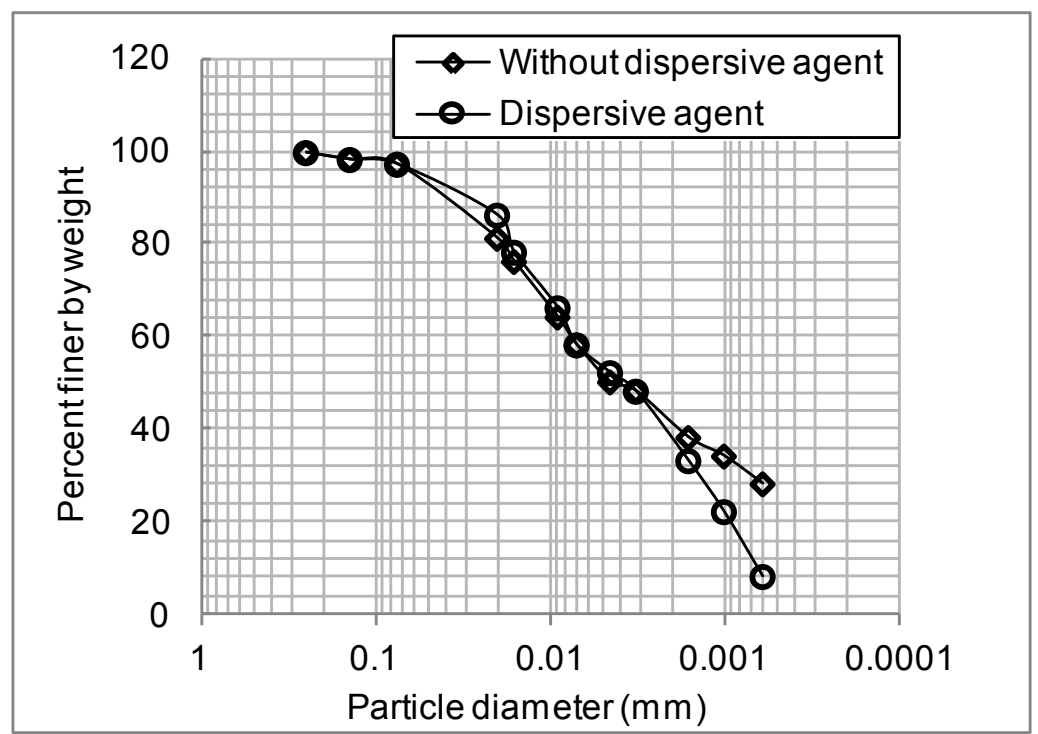

Figure 3-6.Particle size distribution of raw MFT (Bajwa and Simms 2013)

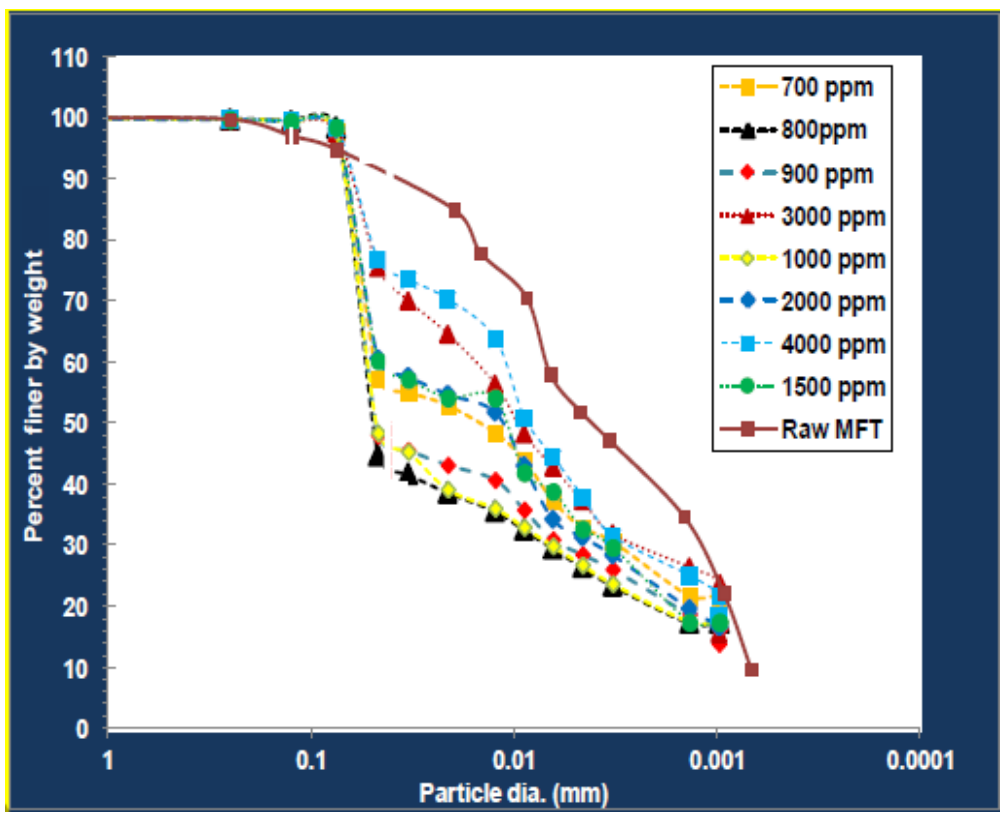

Figure 3-7.Particle size distribution of amended MFT (polymer dosage of 700 g/T) (Bajwa and Simms 2013) 


\subsubsection{Atterberg Limits}

It is known that by increasing water content of the soil, its consistency and behaviour change tangibly which in turn affect other engineering properties. Atterberg Limits include Shrinkage Limit (SL), Plastic Limit (PL), and Liquid Limit (LL). In fact, Atterberg Limits distinguish each boundary change as soil undergoes four stages of solid, semi-solid, plastic and liquid resulting from increasing water content within the soil. These limits provide useful information such as soil identification, classification, settlement characteristics and strength estimation. A Penetrometer was used for the determination of LL and the study followed the procedure as outlined in ASTM standard D 4318 - 10 estimating the plastic limit of MFT.

After conducting Atterberg limit tests, an average liquid limit of 45 and a plasticity index of 26 were found for raw MFT. The activity was also found to be 0.7 . Also, the prepared amended MFT showed the liquid limit and plasticity index of 77 and 34 respectively. The activity of amended MFT was also calculated to be 1.3.

\subsubsection{Hydraulic conductivity}

The saturated hydraulic conductivity of both raw MFT and amended MFT (Sample preparation was explained in section 3.2) were estimated using falling head test. This approach applies Darcy's law to calculate hydraulic conductivity using equation below.

$k=\frac{a l}{A t_{1}} \ln \frac{h_{0}}{h_{1}}$

Where

a is cross sectional area of the stand pipe above the soil column, 1 is length of the soil column, A is cross sectional area of the soil column, $\mathrm{t}_{1}$ is time taken for the total head to reduce from ho to $h_{i}, h_{o}$ is total head loss over the length of the soil column at $t=0$, and $h_{i}$ is total head loss over the length of the column at $\mathrm{t}=\mathrm{t}_{\mathrm{i}}$. Figure 3-8 shows the general set up of measuring hydraulic conductivity. 


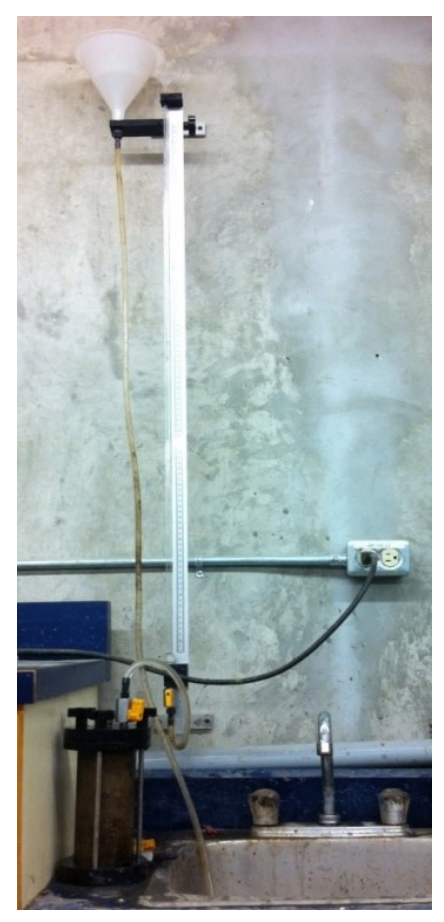

Figure 3-8.Measuring saturated hydraulic conductivity

The initial void ratios for raw MFT and amended MFT at the beginning of the test were 3.9 and 4.5 respectively. The average values of saturated hydraulic conductivity for both raw MFT and amended MFT were calculated as $6.72 \times 10^{-6} \mathrm{~m} / \mathrm{s}$ and $6.6 \times 10^{-5} \mathrm{~m} / \mathrm{s}$ respectively. This clearly indicates adding polymer to raw MFT improves permeability tangibly (up to 10 times). In other words, water release is much faster from tailings due to aggregation of suspended particles and production of flocs.

\subsubsection{Self-weight consolidation test}

Understanding of the self-weight consolidation within the amended MFT involves in recognizing the initial conditions. This can be explained by zero effective stress-void ratio once a fresh material is deposited. The zero effective stress-void ratio refers to the onset of consolidation after completion of sedimentation phase. Generally, sedimentation refers to the conditions when soil particles are descending through the fluid (water) and consolidation is the process when the soil particles are forming a uniform soil matrix. As far as oil sand tailings is concerned, the instant that polymer is added to raw MFT and flocs are created can be considered as the interface 
between sedimentation and consolidation. Therefore, void ratio at the beginning of deposition of amended MFT corresponds to zero effective stress.

\subsection{Principal tests}

\subsubsection{Consolidation test}

\subsection{Concept}

The concept behind consolidation test is measuring deformation (settlement) of the sample by applying loads on it. However, merely one-dimensional deformation (vertical direction) is measured using LVDT. This is facilitated by placing sample in the rigid metal ring which restrains any lateral deformation. Also, locating two porous stones at top and bottom of the sample allows drainage during the test. In fact, oedometer test simulates the loading that sample undergoes in the field, the corresponding vertical deformation and drainage. Figure 3-9 shows the oedometer test used in the present study. A conventional oedometer was used for consolidation tests. However, the rigid metal ring and its belongings were modified for a cylindrical sample with $70 \mathrm{~mm}$ diameter and $40 \mathrm{~mm}$ height.

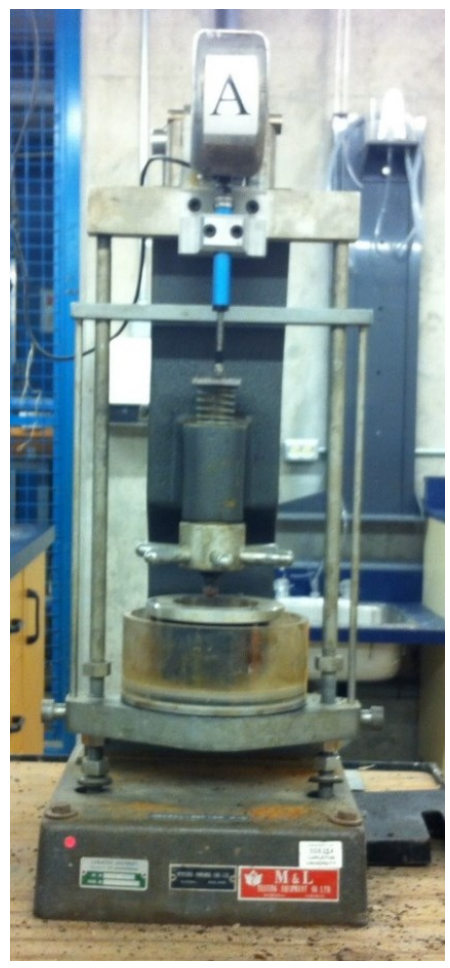

Figure 3-9.Oedometer apparatus used in the present study 


\subsection{Sample set up}

The sample is placed in a rigid metal ring and two porous stones are placed on top and bottom of the sample to allow two-way drainage. The loading cap is then placed on top of the sample and porous stone. The sample is then placed in the consolidation frame and mounted in the apparatus. The rod which is connecting to the loading arm should be sat carefully on top of the top cap. Finally, water is added to the frame to keep the sample saturated during the test. Figure 3-10 illustrates the ring and other parts required for sample set up.

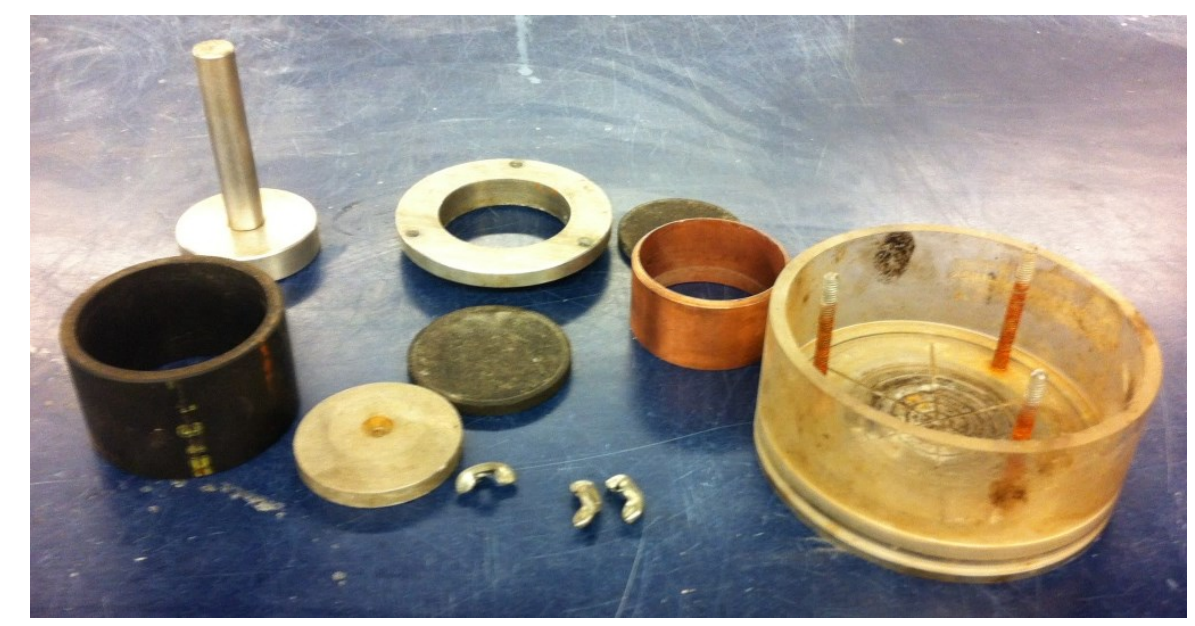

Figure 3-10.The rigid ring and other parts required for sample set up in Oedometer device

\subsection{Test procedure}

For the conventional consolidation test, incremental vertical static load is applied to the sample and the corresponding height change is measured using LVDT. The change in sample height is recorded in data acquisition system during the test. Since sample undergoes more considerable settlement at the beginning of the test, more frequent measurements are required at the early stages of the test. Duration of loading phase depends on consolidation behaviour of the specimen and how long is going to take to reach the equilibrium condition. Equilibrium refers to the state that sample height does not undergo any further change at a given load. In other words, settlement reaches a constant with respect to time. 
Only one-step loading consolidation was used in the present study and the samples were transferred to simple shear device afterward. The height of sample in simple shear should be 20 $\mathrm{mm}$.

\subsection{Results}

Once test is completed, displacement vs. time is plotted. It is also interesting to track void ratio change during consolidation. To characterize the compression behaviour of the specimen, the final void ratio at each loading step is plotted with the corresponding effective stress. The best fit line is also draw to find the constitutive equation of effective stress- void ratio. This equation is used to solve the governing equation of finite strain consolidation model later on. In addition, hydraulic conductivity was estimated using small-strain theory, for comparative purposes only.

\subsubsection{Simple shear test}

\subsection{Concept}

As described earlier, the common laboratory tests to find the relationship between a given stress and the corresponding strain, the constitutive relations and shear strength parameters of soils are triaxial test, simple shear test, direct shear test, and hollow cylinder test.

\subsection{Sample set up}

Different types of Simple shear apparatus has been described in details in chapter two. In NGI simple shear device a cylindrical sample which is placed on a porous stone and covered by a wire reinforced membrane shown in Figure 3-11. The membrane prevents any lateral deformation during consolidation and shearing phase to meet the requirements of plane strain deformation. Another porous stone is also placed on top of sample. Presence of two porous stones at top and bottom facilitates drainage during consolidation. Figure 3-12 presents all required parts for placing sample in the simple shear device. 


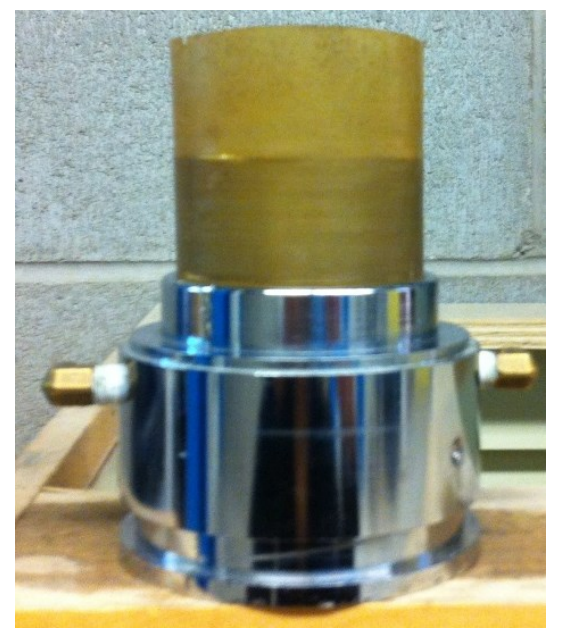

Figure 3-11.The membrane to restrict any lateral movement in NGI device
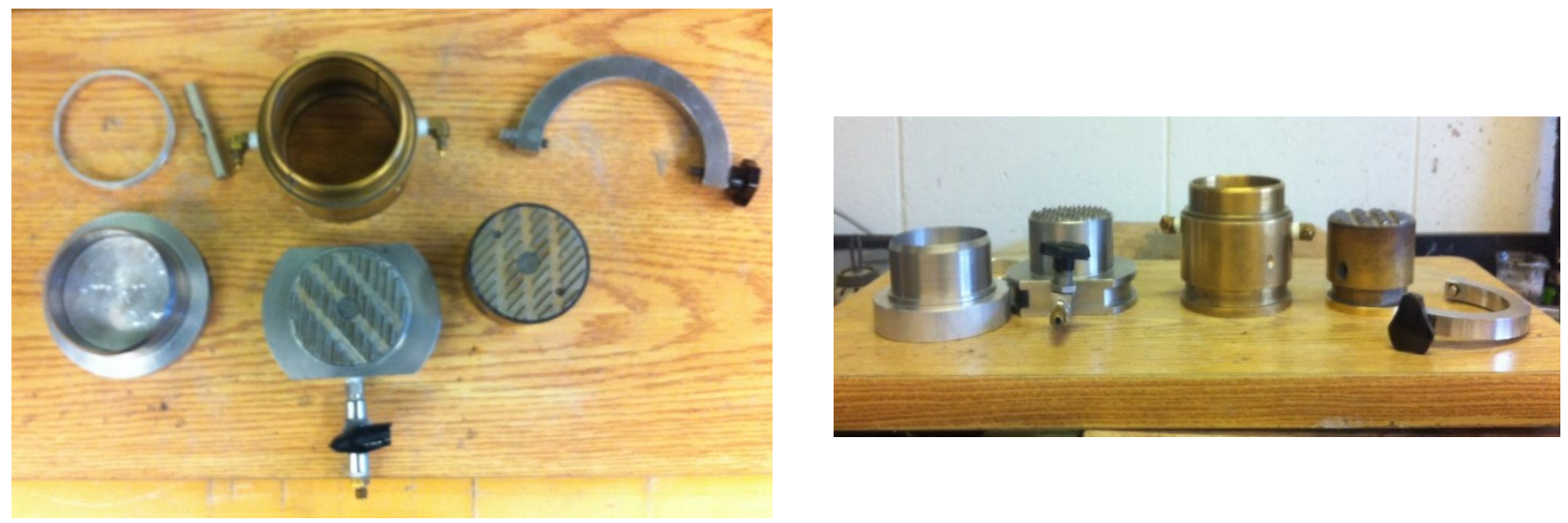

Figure 3-12.Compartments of simple shear apparatus

A cylindrical sample with diameter of $65.5 \mathrm{~mm}$ and height of $20 \mathrm{~mm}$ was used in this research. Figure 3-133 and Figure 3-144 illustrate a configuration and a picture of simple shear device used in the present study respectively. The apparatus consists of a vertical acting air piston, horizontal double acting low friction air piston, simple shear load frame, a constant speed motor drive, load cells, Electronic Pneumatic Transducer (EPT) and Linear Variable Displacement Transducers (LVDT). 


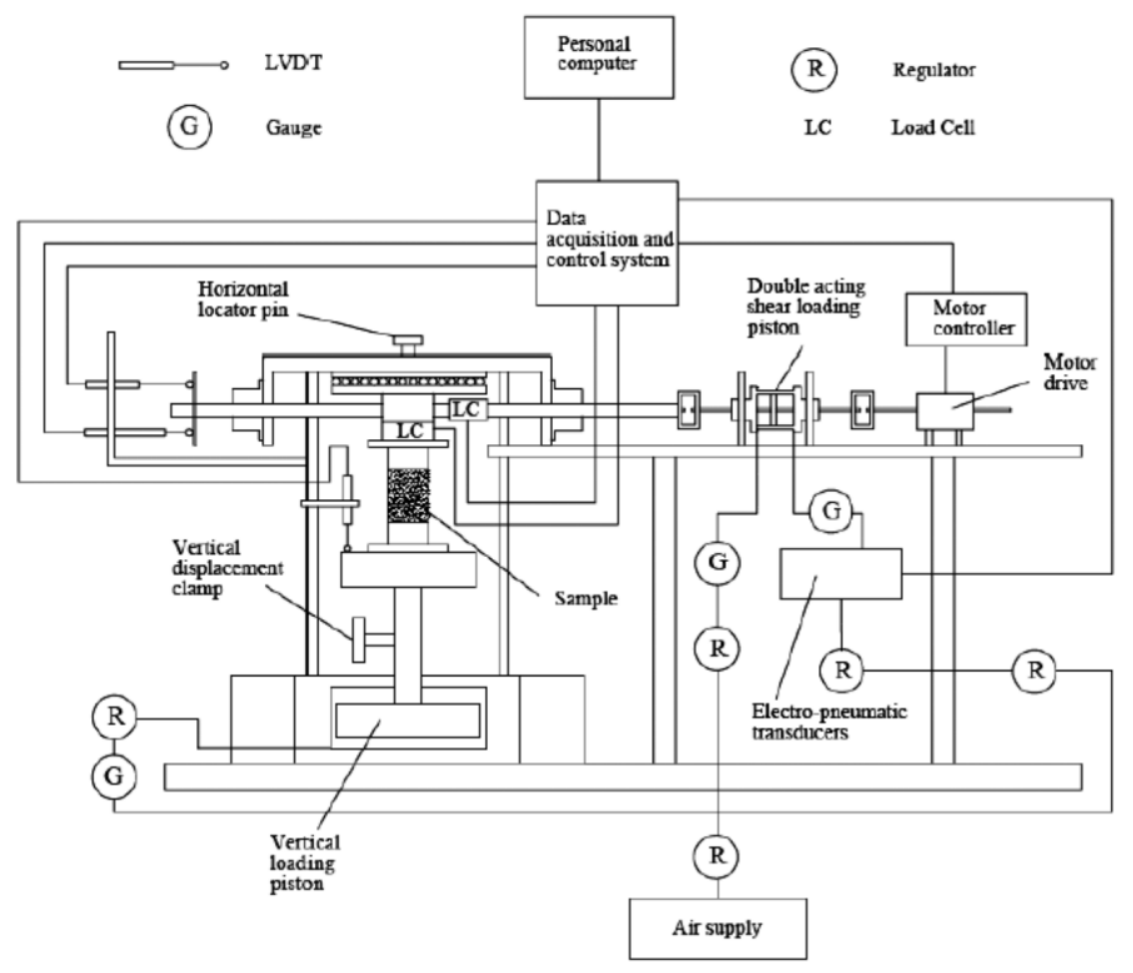

Figure 3-13.Configuration of simple shear apparatus used in the study (Al-Tarhuni 2008)

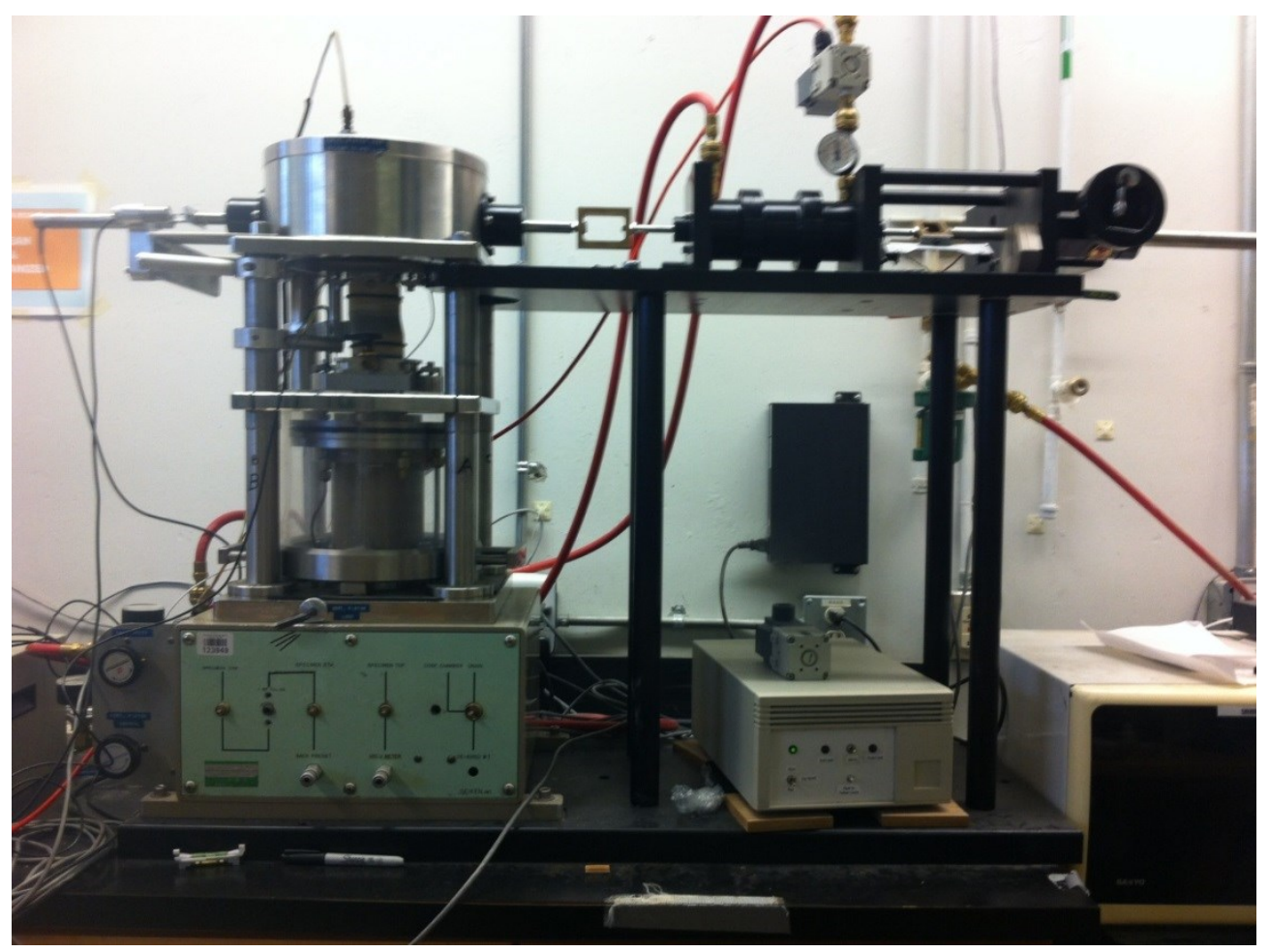

Figure 3-14.simple shear device used in the present study 


\subsection{Consolidation phase}

The vertical load system is located at the bottom of the apparatus and consists of a simple single acting air piston and it is controlled manually by an external pressure regulator. The vertical load is measured using vertical load cells, and the vertical displacements are measured using two Linear Variable Displacement Transducers (LVDTs). In addition, an additional LVDT in the horizontal direction is used to increase the scope of LVDT measurement range.

\subsection{Shearing phase}

Horizontal load can be applied by either double acting low-friction air pistons or a motor driving system connected to a constant speed motor drive.

In a constant volume test, the specimen diameter is constrained by the reinforced membrane and any vertical displacement is restricted by clamping the top and bottom loading cap against vertical movement. The constant volume condition is tracked using the vertical LVDT during each test. As per ASTM D 6528-07, the vertical strain change must be kept to less than $0.05 \%$.

\subsection{Results}

Consolidation phase is usually interpreted by settlement development with respect to time at a given vertical load. Therefore, it is of interest to see how compressibility of testing material and other geotechnical parameters such as void ratio change by increasing consolidation pressure (vertical load).

Stress-strain relationship, pore water pressure build up during undrained shear tests and also stress path are analyzed to find shear strength parameters of testing material.

\subsubsection{Triaxial test}

The triaxial test is one of the most widely performed geotechnical test to analyze the consolidation and shearing characteristics of soil. In this test, a cylindrical specimen with an approximate 2:1 height to diameter ratio is placed within a rubber membrane in a cell which is pressurized later. Each triaxial test contains two phases of consolidation following by shearing under desired conditions to simulate the in situ behaviour of the material. 


\subsection{Specimen set up and system preparation}

Once self-weight consolidation of samples is completed and stable condition is reached, a Shelby tube with $70 \mathrm{~mm}$ diameter and $30 \mathrm{~mm}$ height is used to get undisturbed samples. A rubber membrane is stretched over a mould which placed on the pedestal. The suction is also applied to avoid any wrinkle on the membrane. Then, the sample is pushed gently from the Shelby tube to the membrane and the top cap is placed. Both top and bottom of the sample is secured with Orings in order to have better control on effective stress. Following to the placement of the sample, the cell and other components are also assembled, before filling the cell with water. Finally, LVDT is set to be zero and a given cell pressure is applied to start the test. Figure 3-15 presents a sample after setting up on the triaxial pedestal.
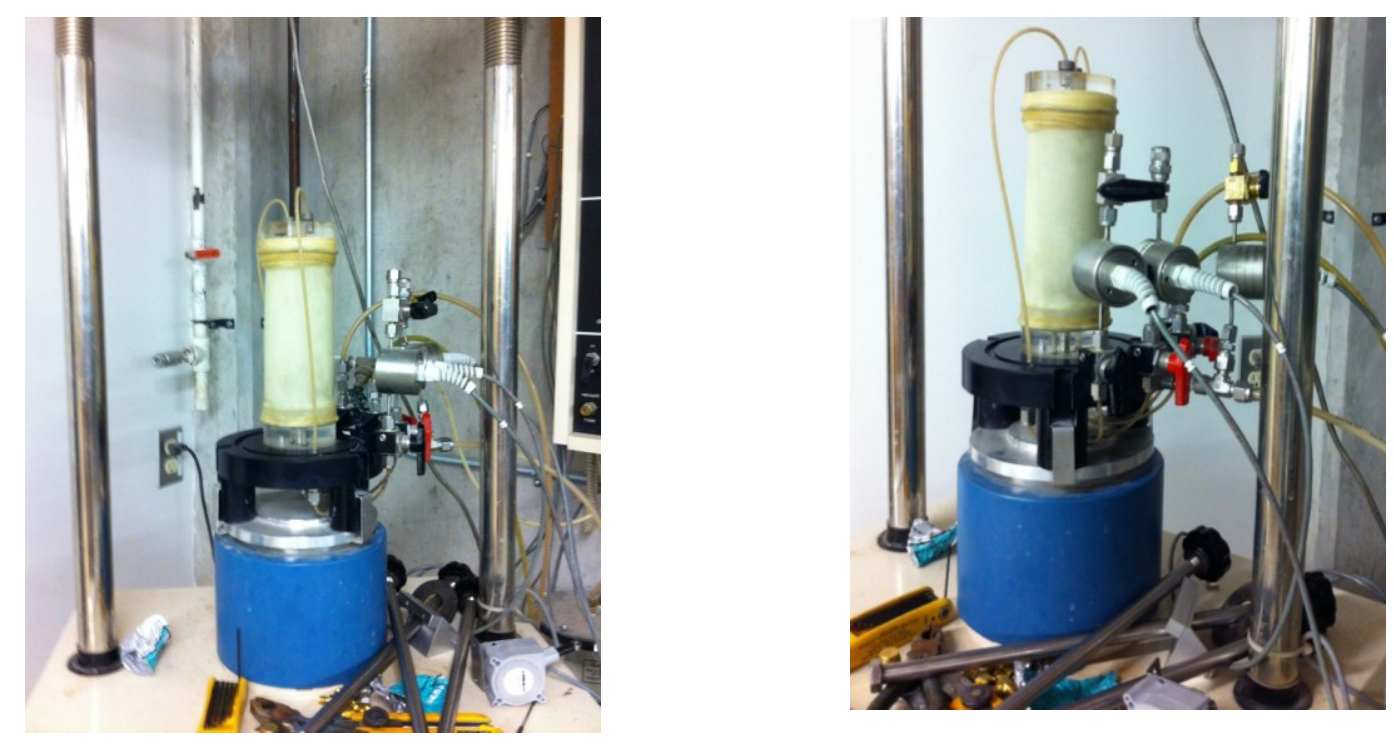

Figure 3-15.Sample set up on the triaxial device

\subsection{Data acquisition system}

In order to record the required data for further analysis, the triaxial apparatus should be mounted with components summarized in Table 3.1. Figure 3-16 illustrates the conventional triaxial test used in the present study. 
Table 3.1.Triaxial data acquisition components

\begin{tabular}{|l|l|}
\hline Component & Function \\
\hline Triaxial cell & Accommodating specimen and water (fluid) \\
\hline $\begin{array}{l}\text { Rubber membrane, O-rings and } \\
\text { porous stones }\end{array}$ & $\begin{array}{l}\text { Seal the specimen from cell fluid, controlling effective stress and } \\
\text { drainage }\end{array}$ \\
\hline Pedestal and top cap & Providing specimen seat and drainage port \\
\hline Cell pressure & Applying confining stress to the specimen \\
\hline Load cell & Measuring axial load change during shearing phase \\
\hline Back pressure & Apply back pressure during sample saturation \\
\hline Velocity controlled load frame & Shearing the specimen through axial movement of a loading platen \\
\hline Pore water pressure transducer & Measuring pore water pressure changes \\
\hline LVDT & Measuring height change \\
\hline Data acquisition unit & Converting analogue reading to digital data \\
\hline Acquisition software & Recording digital data \\
\hline
\end{tabular}

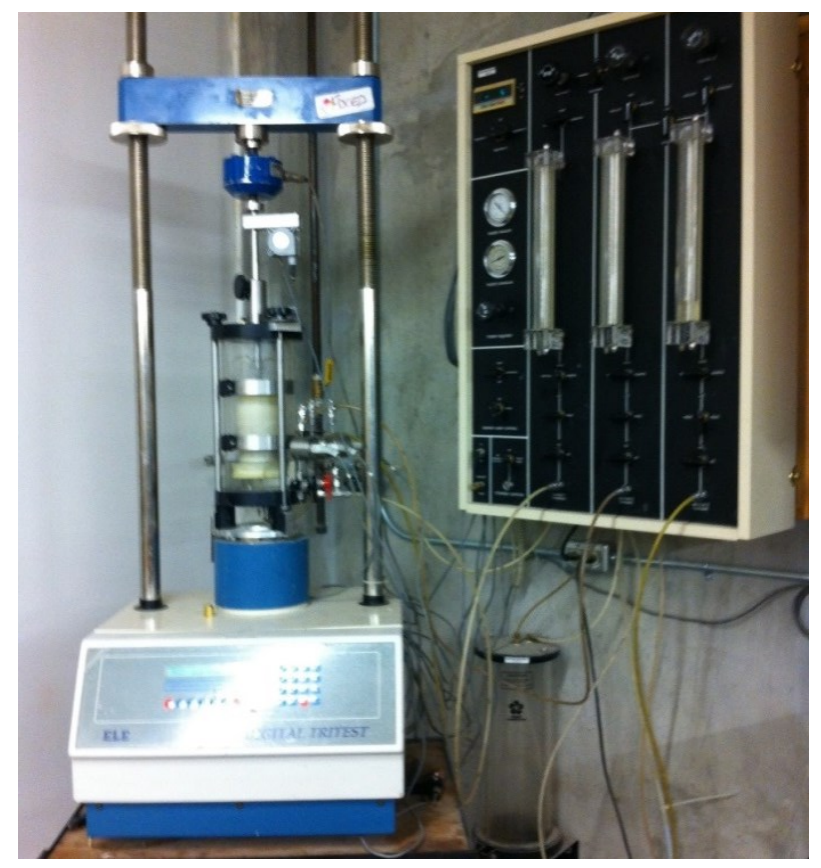

Figure 3-16.Conventional triaxial device used for consolidation and shearing behaviour analysis

\subsection{Saturation phase}

After setting up the sample in the triaxial cell and before starting the consolidation, all drainage lines as well as pore water pressure transducers should be de-aired completely. It is also important to fill all voids in the sample with water. This phase called as saturation. To facilitate saturation of sample two measures may take: i) Using deaired water to fill voids ii) Applying 
back pressure to compress the air within the sample. Second approach is considered in the present study.

After removing air form all drainage connections and pore pressure transducers, cell pressure and back pressure are linearly increased such that effective stress remains constant. Effective stress is difference of cell pressure and back pressure. The sample over-consolidates if the effective stress at this stage gets larger than value required during shearing.

In order to check saturation of sample, Skepmton`s B value $(\Delta u)$ should be calculated. To achieve this, drainage valves are closed and cell pressure is increased. Following to increase in cell pressure, pore pressure also rises. B value is the change of pore water pressure over change of cell pressure before and after closing drainage valves. Theoretically, B value equals to 1 represents fully saturated condition. However, according to ASTM standard (1995), "Specimens shall be considered to be saturated if the value of $\mathrm{B}$ is equal to or greater than 0.95 , or if $\mathrm{B}$ remains unchanged with addition of back pressure increments.

\subsection{Consolidation phase}

In the triaxial apparatus consolidation starts at a given cell pressure and sample is allowed to be consolidated under this pressure. In fact, the consolidation stage is used to reach a desired effective stress before onset of shearing. When cell pressure is applied to the soil, the entire pressure is immediately $\left(\mathrm{t}=0^{+}\right)$carried by the pore water. Therefore, excess pore water pressure develops and the soil undergoes to an initial consolidation. The excess pore water pressure dissipates with time due to the drainage and the load is gradually transferred to specimen to form an effective stress. Over time, effective stress increases while excess pore water pressure decreases.

The consolidation stage is stopped once equilibrium is reached which is equivalent to no longer significant change in volume of the specimen. During this phase, the sample height is tracked by recording the sample displacement using LVDT. This height is then used to find the void ratio at each time at a given effective stress during consolidation. The pore water pressure is also recorded using pore pressure transducers. 


\subsection{Shearing phase}

The specimen is sheared by applying a given axial strain to the sample at a constant rate. This is facilitated by upward movement of the load frame platen in compression test or downward movement in extension mode. Depending on the engineering application, drainage can be facilitated. The undrained shear strength of amended MFT was considered in this study and the rate of shearing was set as $1 \mathrm{~mm} / \mathrm{min}$.

The relationship between deviatoric stress and axial strain is one the main graphs which is used to characterize the shearing response of the specimen. The shearing continues until failure is reached to determine the maximum deviatoric stress or the test can be stopped after reaching a certain amount of axial strain (15\% as an example).

In this study, the Consolidated Undrained (CU) triaxial test was conducted on polymer amended MFT as well as raw MFT to investigate the consolidation and shearing behaviour. 


\section{Results of consolidation, simple shear, and triaxial tests}

\subsection{Introduction}

Testing material, sample preparation, and test methodologies have been described in Chapter 3 . This chapter documents result of consolidation and shearing tests conducted on raw MFT and polymer amended MFT using oedometer, simple shear, and triaxial apparatus. Comparison is also made for different sets.

\subsection{Self-weight consolidation test}

In Chapter 3 sample preparation for consolidation, simple shear and triaxial tests was described in detail. Some samples were prepared such that only drainage was allowed after deposition (consolidated samples). Sample preparation was about 3.5 months in this method. As described earlier, the material undergoes self-weight consolidation right after deposition and before starting other load-induced test. Therefore, it is important to track the void ratio change with respect to depth during deposition time.

In order to keep consistency prepared material was split to two portions; one for self-weight consolidation test and the other for load-induced consolidation test

In order to track the self-weight consolidation and the associated changes in the tailings properties, a device was designed to allow incremental sampling (Figure 4-1). As it has shown, the device was a cylinder consisting of moveable rings with height of $1 \mathrm{~cm}$ each. An extension part was also placed on top of the rings to mimic a similar height of consolidated samples at the 
beginning of the deposition. Grease was applied at bottom of each ring to avoid any leakage of material or water.

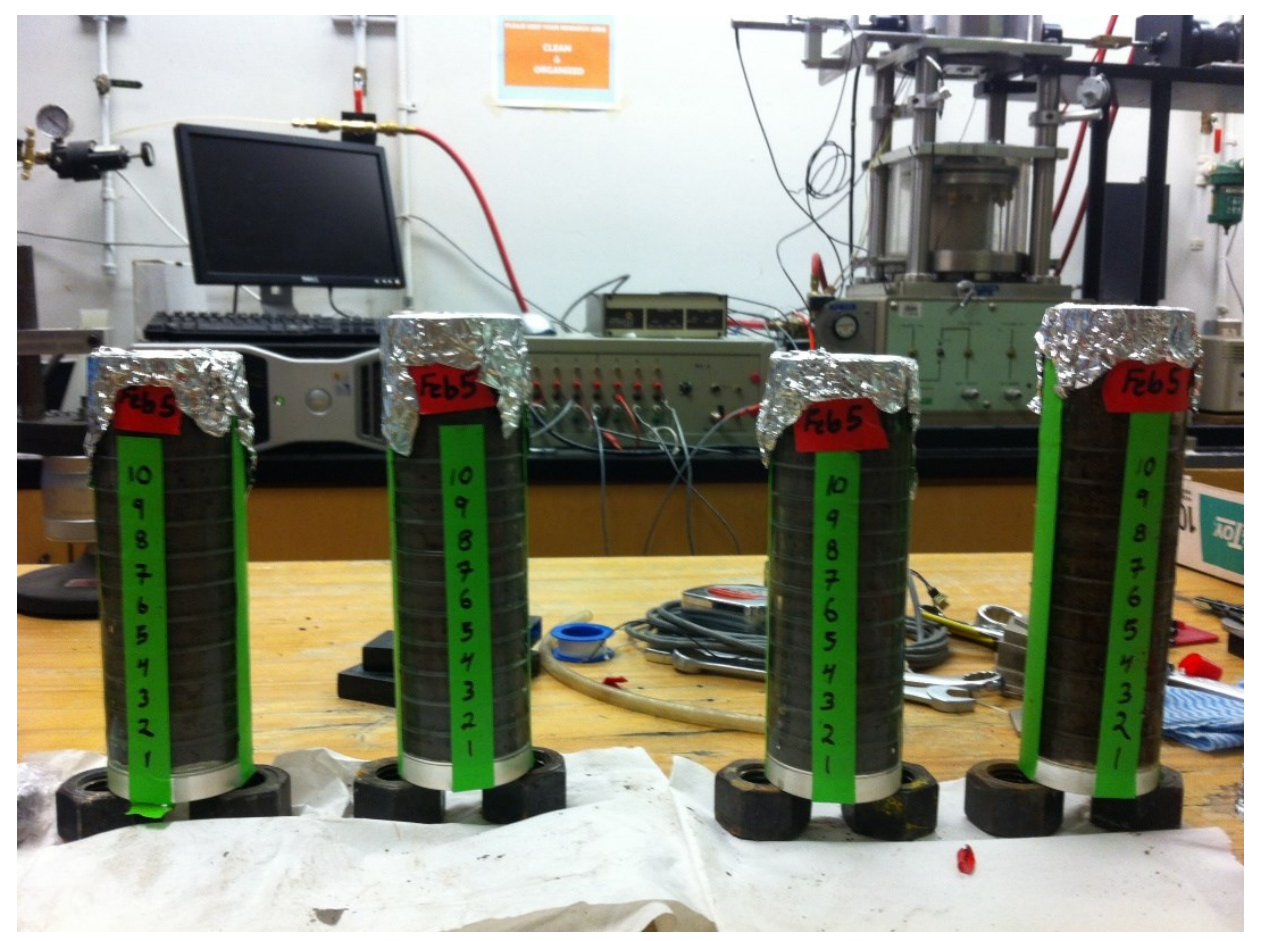

Figure 4-1.Moveable rings to track self-weight consolidation

After deposition, the materials in the cylinder were left from 1 week to 4 weeks to allow selfweight consolidation to be completed. During the test, evaporation was prevented by covering the cylinder from top. Once self-weight consolidation was finished, supernatant water was collected and the material was taken from each ring for water content measurement, and void ratio calculation (or density).

The results of void ratio at bottom of each increment are plotted with respect to elevation in Figure 4-2. The initial void ratio of deposited tailings at the beginning of each test and before any consolidation was 3.9. In fact, this void ratio corresponds to zero effective stress. In addition, due to the fact that samples settled over time, nine measurements were taken for the first week, while there were eight for the rest of the tests. The results revealed that void ratio decreased over time for all four tests. However, the rate of drop was more tangible within the first week such that void ratio decreased from 3.9 to 1.7 . 


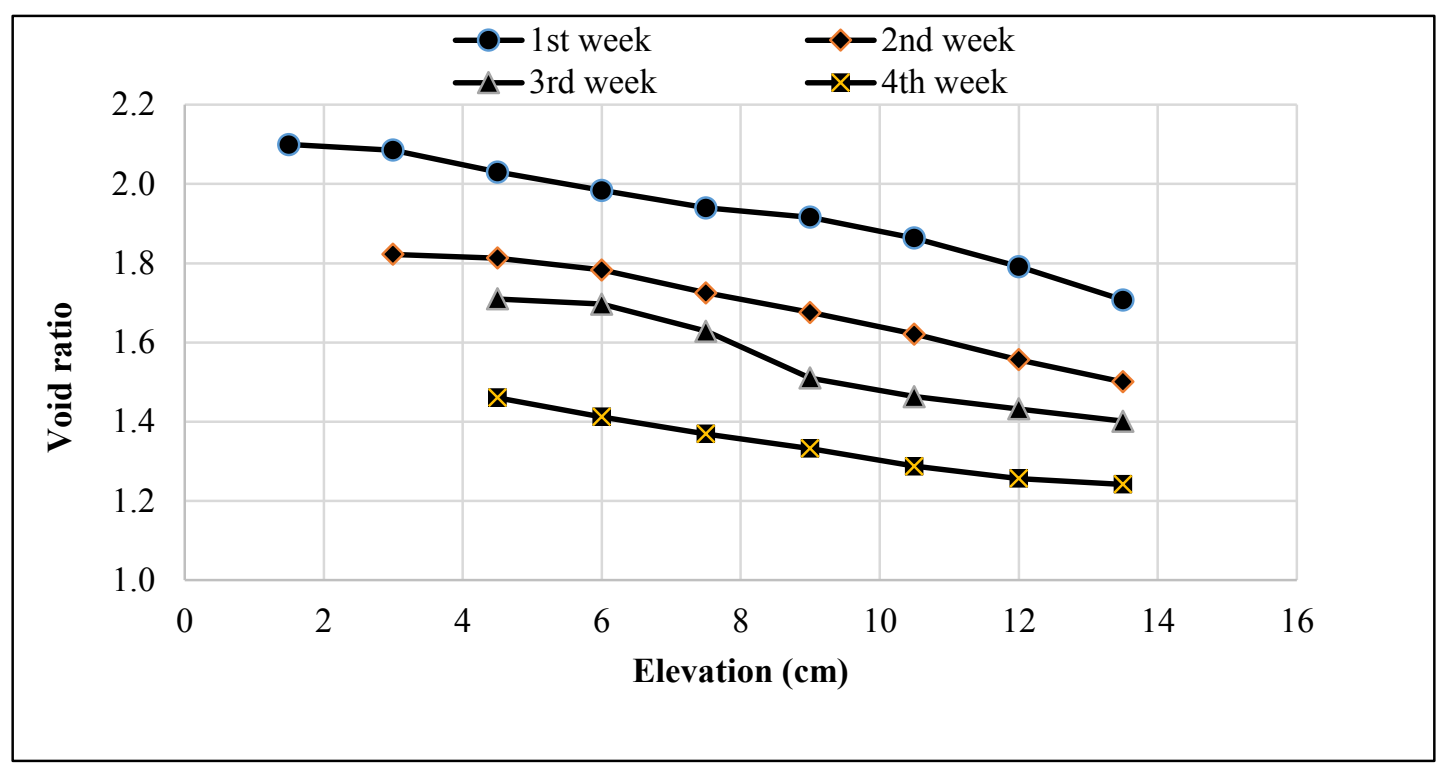

Figure 4-2.Void ratio change with respect to depth during self-weight consolidation

\subsection{Load-induced consolidation results}

$\mathrm{K}_{0}$ consolidation was performed on raw MFT, desiccated amended MFT and consolidated amended MFT. Preparation of samples was explained in details in chapter 3.

One step loading tests were conducted at consolidation pressure of $25 \mathrm{kPa}, 50 \mathrm{kPa}, 75 \mathrm{kPa}$, and $100 \mathrm{kPa}$ using a modified oedometer apparatus explained in chapter 3. It should be note that initial water content of raw MFT specimen was lower compared to two other categories. In fact, absence of any amendment agent to keep the MFT particles together leads to instability of the sample in the oedomter apparatus. As a result, the maximum water content of raw MFT to be technically suitable for consolidation test was found to be $43 \%$, while it was roughly $60 \%-65 \%$ for the amended MFT. Also, the lower value of water content leads to lower initial void ratio for raw MFT samples.

\subsubsection{Raw MFT}

The results of total displacement and settlement at the end of one step loading consolidation for raw MFT are shown in Figure 4-3. A similar trend was found for each test, as the rate of increase in displacement was more tangible within first 5 hours, followed by reaching a constant value 
(equilibrium condition) after 24 hours. In addition, the rate of displacement rise was recorded higher as the consolidation pressure increased. The total displacement was found to be $5.5 \mathrm{~mm}$, $6.22 \mathrm{~mm}, 6.99 \mathrm{~mm}$, and $7.76 \mathrm{~mm}$ for samples consolidated from $25 \mathrm{kPa}$ to $100 \mathrm{kPa}$.

Figure 4-3 illustrates void ratio changes for each raw MFT test. As it has shown, all tests were started at fairly equal void ratio and reached the constant value after 24 hours. As it was expected, the rate of void ratio change was higher at higher loads.

\subsubsection{Desiccated MFT}

The results of desiccated amended MFT after completion of consolidation are summarized in Figure 4-4. As far as displacement is concerned, all samples showed a considerable rise within 6 hours, continued by reaching the equilibrium condition after 24 hours. Surprisingly, the behaviour of specimens experiencing loading of $25 \mathrm{kPa}$ and $50 \mathrm{kPa}$ were almost similar. In other words, the characteristic of desiccated amended MFT start to change considerably at consolidation pressure higher than $75 \mathrm{kPa}$.

Similarly, the rate of decrease in void ratio was almost similar for samples consolidated at 25 $\mathrm{kPa}$ and $50 \mathrm{kPa}$. On the other hand, void ratio dropped significantly as the loading increased from $75 \mathrm{kPa}$ to $100 \mathrm{kPa}$. The total void ratio change was recorded as 0.776 for a sample consolidated at $75 \mathrm{kPa}$, while it was found to be 0.918 for specimen underwent consolidation pressure of $100 \mathrm{kPa}$.

\subsubsection{Consolidated amended MFT}

Figure 4-5 shows a general characteristic of consolidated amended MFT after consolidation. A similar trend was recorded for development of displacement within the specimens; a tangible increase up to 5 hours which was followed by reaching steady state condition after 24 hours. The figure also clearly shows the sample consolidated at $100 \mathrm{kPa}$ revealed steeper trend compared to lower consolidation pressures especially $25 \mathrm{kPa}$.

The void ratio graph reveals a significant reduction as the consolidation pressure was increased. For instance, the final void ratio of samples consolidated at $25 \mathrm{kPa}$ and $100 \mathrm{kPa}$ were recorded as 0.722 and 0.343 respectively, while the initial void ratio was similar for both (1.26). 

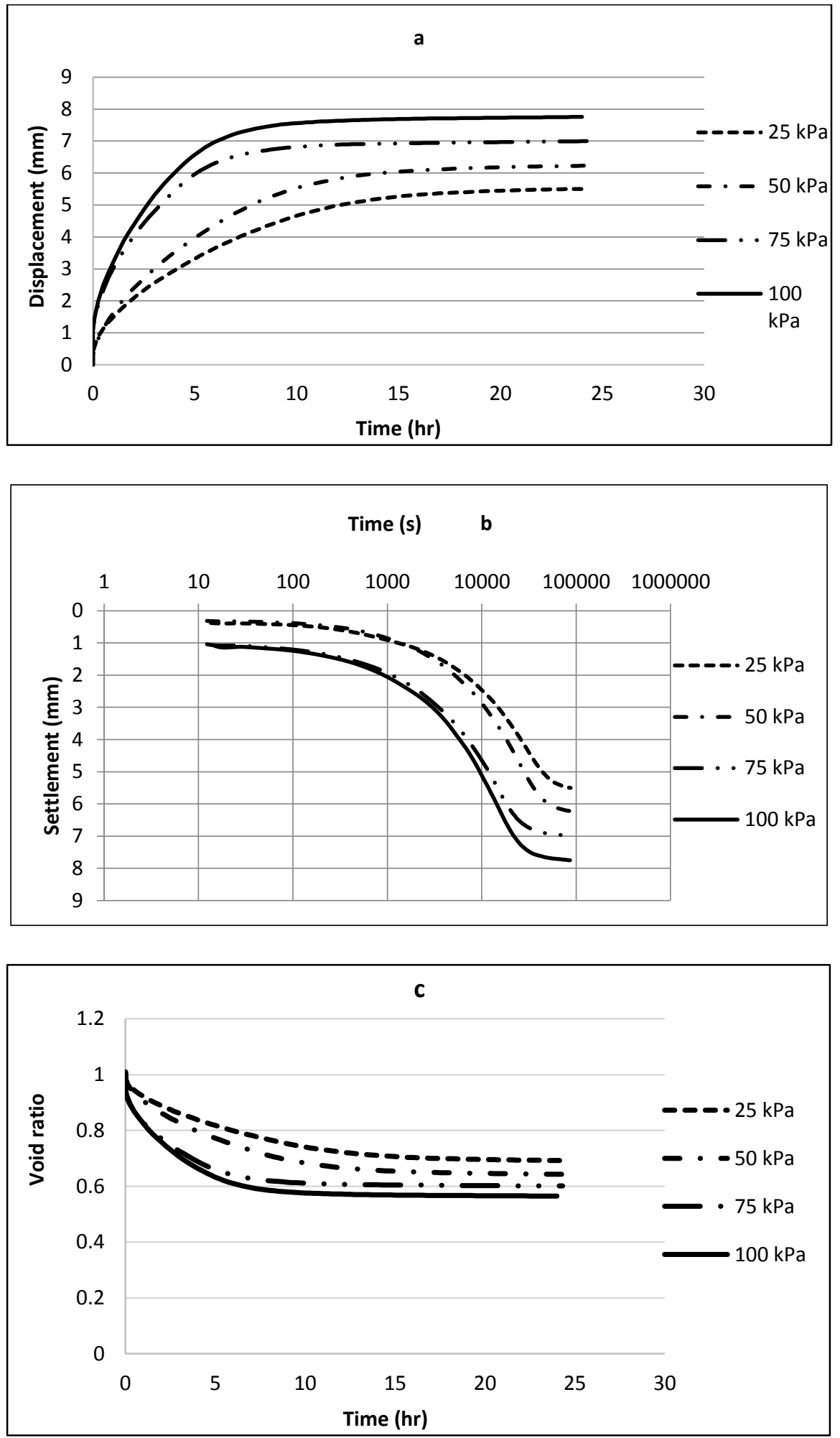

Figure 4-3.Behaviour of Raw MFT during consolidation. a) Displacement, b) Settlement, c) Void ratio changes 

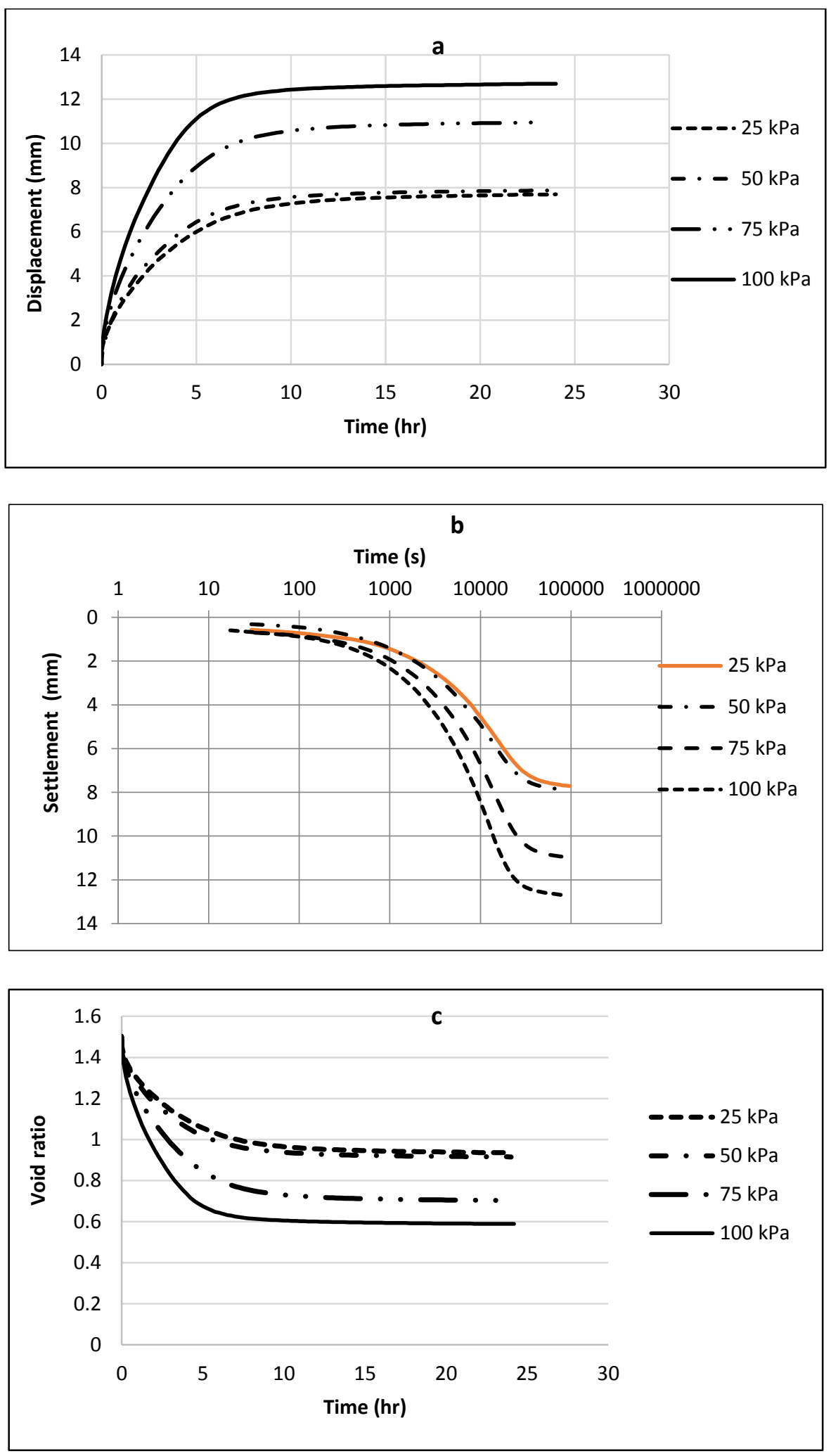

Figure 4-4.Behaviour of desiccated amended MFT during consolidation. a) Displacement, b) Settlement, c) Void ratio changes 

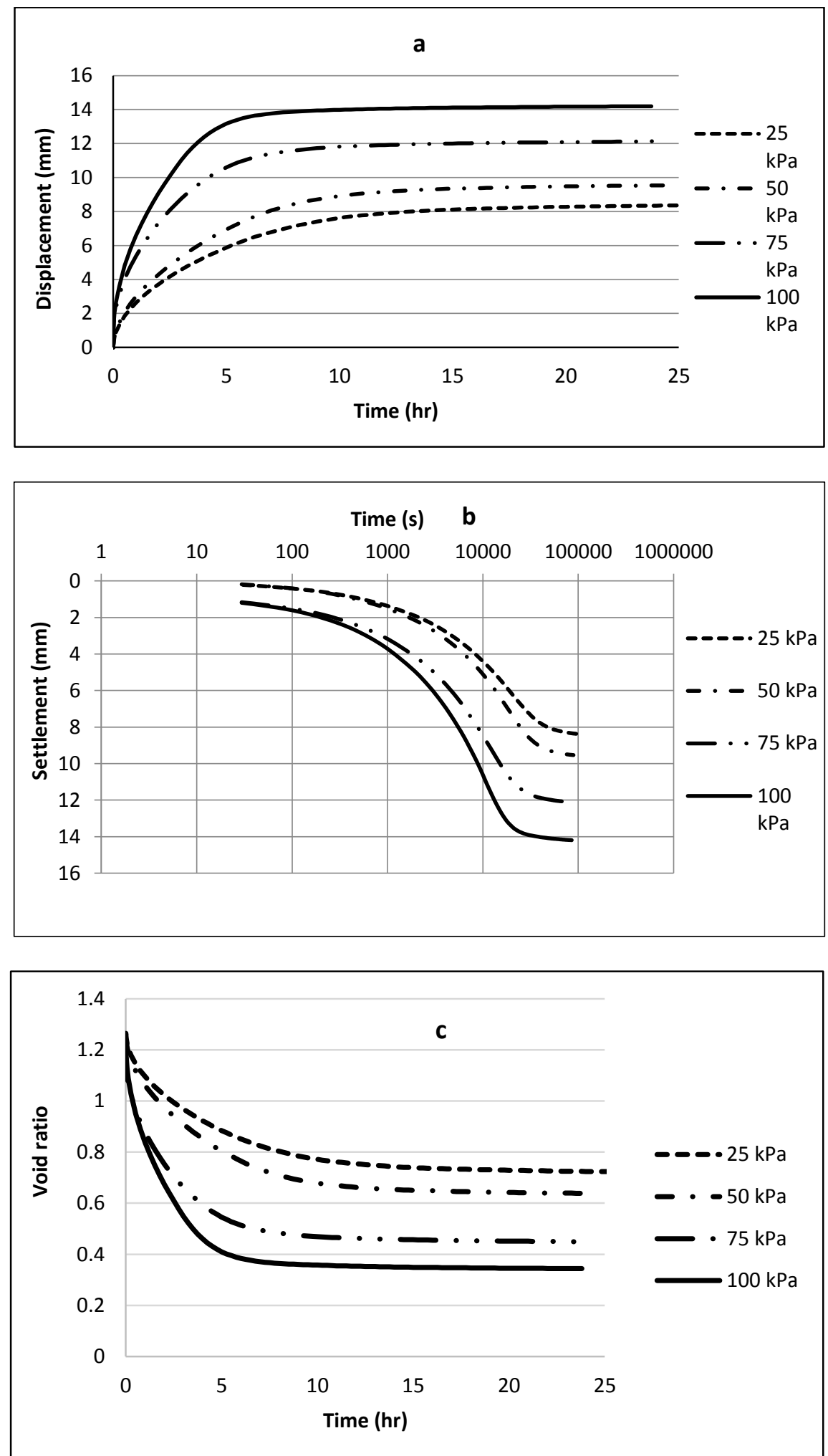

Figure 4-5.Behaviour of consolidated amended MFT during consolidation. a) Displacement, b) Settlement, c) Void ratio changes 


\subsubsection{Compressibility constitutive equation}

In order to determine the compressibility characteristic of each material, the relationship between final void ratio at the end of consolidation and effective stress is plotted. The results of compressibility behaviour are summarized in Figure 4-6. The constitutive equation of each category is also found by fitting the power trend line in each graph.

The rate of decrease and final void ratio values are both affected by initial water content (or solid content) and initial void ratio. Therefore, the compressibility behaviour is also affected by initial properties of sample. Interestingly, the final void ratio of raw MFT and consolidated samples are coincident at lower consolidation pressure (i.e. $25 \mathrm{kPa}$ and $50 \mathrm{kPa}$ ), in spite of having different initial solid content.

\subsubsection{Permeability constitutive equation}

After completion of consolidation, permeability was calculated using Equation 4.1.

$k=C_{v} \cdot \gamma_{w} \cdot m_{v}$

Equation 4-1

Where

$\mathrm{C}_{\mathrm{v}}$ is the coefficient of consolidation, $\gamma_{\mathrm{w}}$ is unit weight of water, $\mathrm{m}_{\mathrm{v}}$ is volume coefficient of compressibility.

$C_{v}=\frac{T_{v} \cdot H^{2}}{t}$

Equation 4-2

Where

$\mathrm{T}_{\mathrm{V}}$ is time factor, $\mathrm{H}$ is length of average drainage path, and $\mathrm{t}$ is time.

$m_{v}=\frac{\Delta e}{\Delta \sigma(1+e)}$

Equation 4-3

$\Delta \mathrm{e}$ is change of void ratio for incremental loading, $\Delta \sigma$ is incremental pressure applied, and $\mathrm{e}$ is initial void ratio.

Another important constitutive relationship is the correlation between hydraulic conductivity and average void ratio at the end of consolidation. This correlation and constitutive equations are plotted in Figure 4-7. It should be note that permeability changes as the void ratio changes during the test. Therefore, the estimated permeability with respect to average void ratio is shown in each 
graph. As expected, permeability increases by increasing void ratio. However, the rate of change in permeability is less than order of a magnitude in all tests due to small rate of change in void ratio. The reason is that all three categories of samples were experienced self-weight consolidation before applying any load-induced consolidation, and therefore, a considerable part of void ratio change occurred before load-induced consolidation.

It should be noted that these relationships use small-strain theory for samples experienced a large strain. The consolidation data are presented here for comparative purposes, but should not be used for consolidation modelling. 

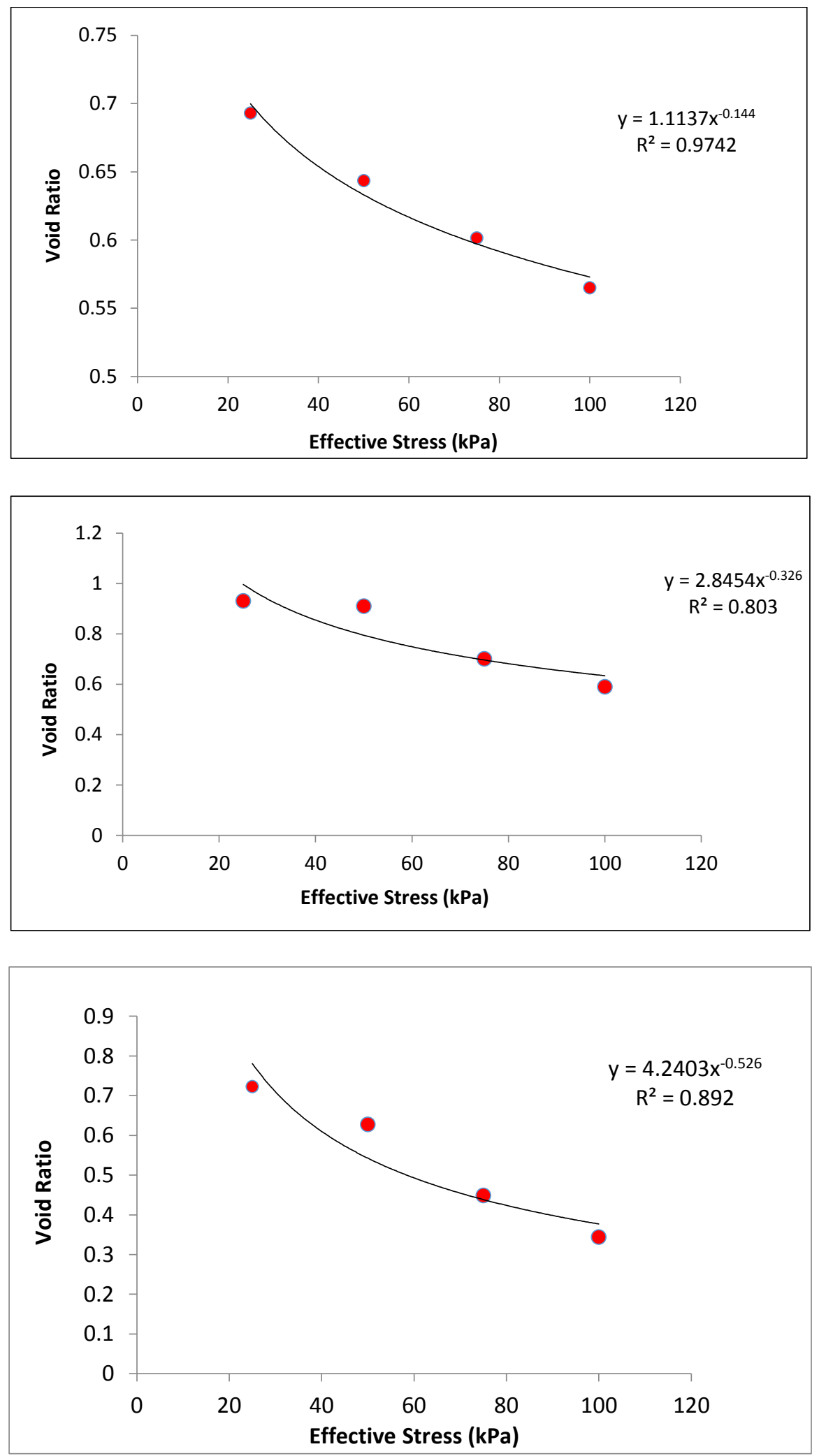

Figure 4-6.Compressibility behaviour- a) Raw MFT, b) Desiccated amended MFT, c) consolidated amended MFT 

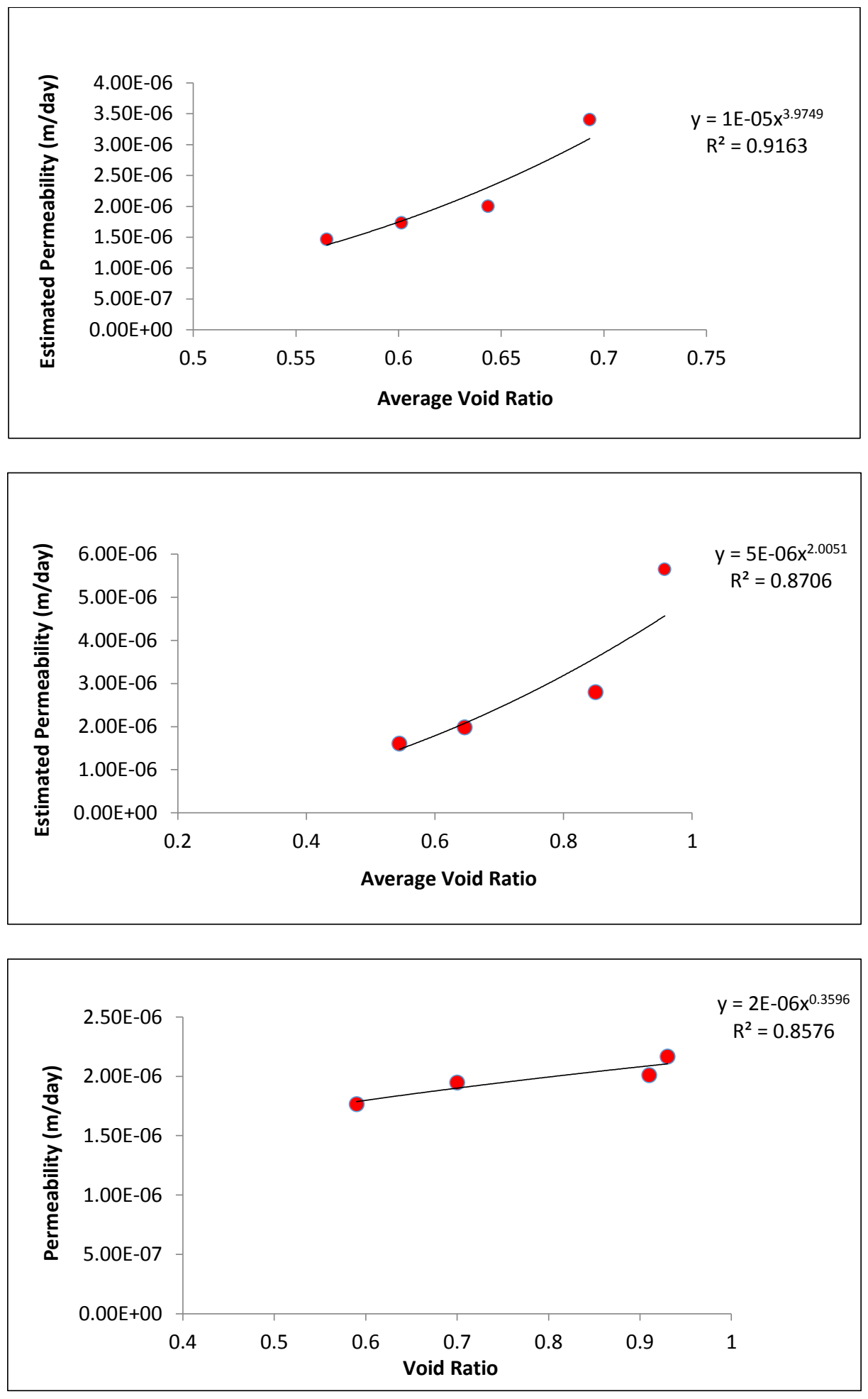

Figure 4-7.Calculated permeability at the end of consolidation- a) Raw MFT, b) Consolidated amended MFT, c) Desiccated amended MFT 


\subsection{Simple shear results}

The samples were removed from oedometer apparatus after completion of consolidation. Water content samples were obtained and the total weight was measured. The samples were then placed in the simple shear reinforced membrane. Each sample was reloaded with a vertical stress similar to the consolidation pressure in oedometer device for about 10 minutes.. A monotonic shear loading was then applied to a given sample. A constant rate of strain equal to $20 \%$ per hour was chosen in the data acquisition system.

A wide range of strain was considered due to softness of oil sand tailings. Therefore, each shearing test was ceased at $25 \%$ strain. Figure $4-8$ shows a specimen before and after shearing while the effective normal stress was $50 \mathrm{kPa}$.
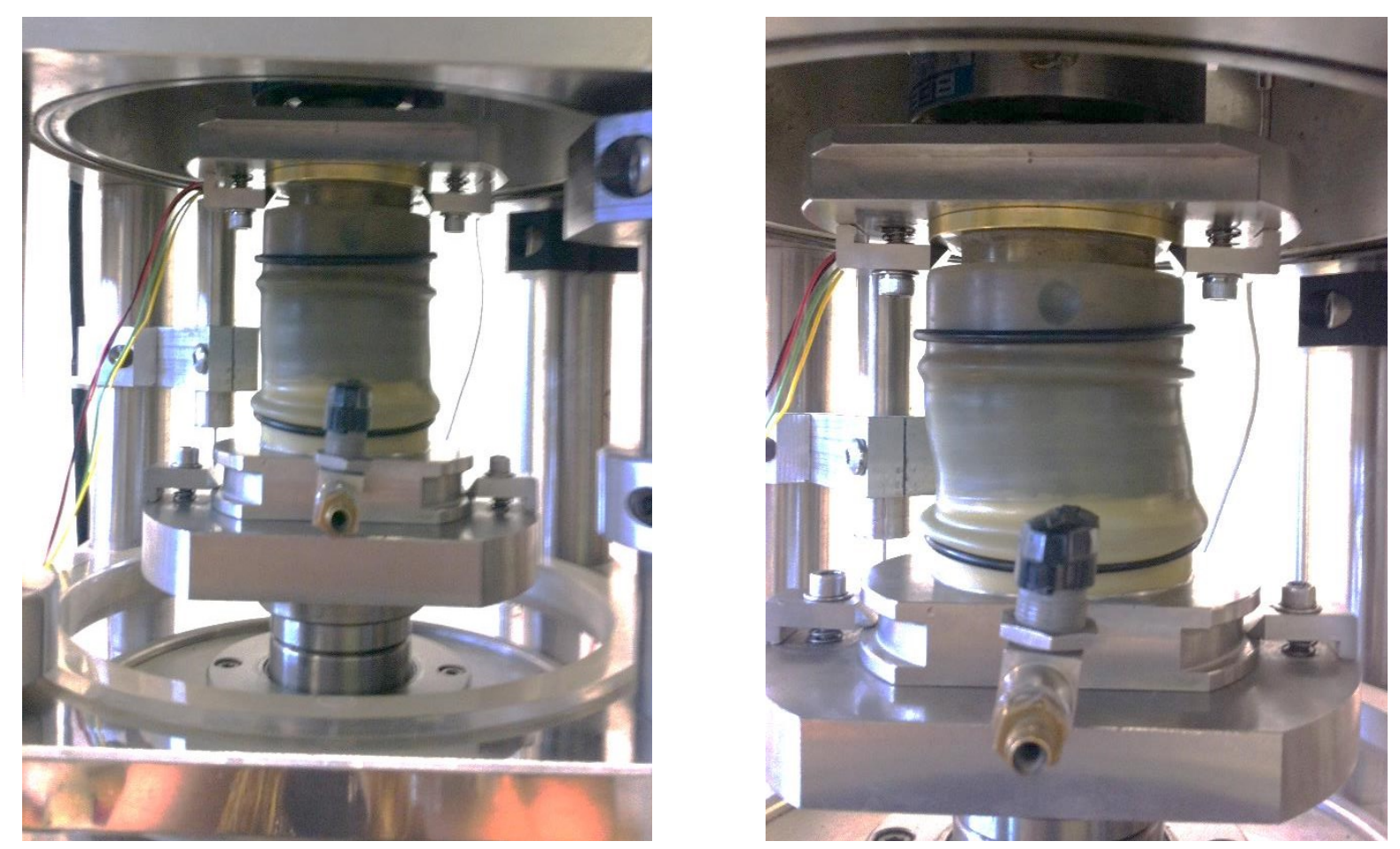

Figure 4-8.A sample within the simple shear device before and after shearing

\subsubsection{Shear stress vs. shear strain}

The results of shear stress vs. shear strain for raw MFT, consolidated amended MFT and desiccated MFT are presented in Figure 4-9-Figure 4-11 respectively. It can be seen that all tests 
achieved a steady value of shear strength, despite continuously increasing pore-water pressure. Also, no tangible shear strength was gained after reaching peak value, although shearing continued to even $25 \%$.

On the other hand, consolidated samples showed different characteristics at different vertical loading. While pore water pressure developed smoothly from the beginning until the end of shearing at vertical load of $25 \mathrm{kPa}$, it increased dramatically for both tests at vertical load of 50 $\mathrm{kPa}$ and $75 \mathrm{kPa}$. Interestingly, the shearing test conducted at vertical load of $100 \mathrm{kPa}$ displayed a completely different behaviour compared to other tests, in which pore water pressure increased initially to reach the maximum value at strain equals to $5 \%$, and dropped continuously to reach a constant value at the end of shearing (i.e. shear strain equal to $25 \%$ ).

\subsubsection{Stress path}

Shear stress vs. vertical stress (stress path) of raw MFT, consolidated MFT and desiccated MFT are illustrated in Figure 4-9-Figure 4-11 respectively. In order to analyze the behaviour more accurately, two phases were determined in each graph by considering a specific point, where the material response was changed before and after reaching this point.

Raw MFT displayed similar behaviour at all vertical loads such that vertical stress was decreasing while shear stress was increasing until reaching a specific point. Beyond this point, vertical load continued to decrease, whereas shear stress was remained almost constant.

Similar to raw MFT, desiccated samples exhibited two different trends before and after a specific point. In fact, a simultaneous drop in vertical load and raise in shear strength at first stage, followed by a continuous decrease in vertical load and slight increase in shear stress. Nonetheless, the second stage was more considerable for raw MFT in comparison to desiccated samples.

Characteristics of consolidated samples were recorded similar to desiccated specimens at all vertical loads. However, consolidated sample experienced smoother trend in the second phase at vertical load of $50 \mathrm{kPa}$. The stress path for consolidated sample at vertical load of $100 \mathrm{kPa}$ was similar in the first phase but very different at the second stage in which shear stress started to increase dramatically. 


\subsubsection{Shear stress-void ratio}

The relationship between shear strength and final void ratio at the end of shearing for amended MFT and raw MFT are compared in Figure 4-12. Similar to stress-strain graph, it was found that desiccated MFT give slightly higher strength compared to consolidated amended samples, but at

higher void ratio (lower densities). Both polymer amended tailings gave substantially higher strengths at a given void ratio than MFT. 

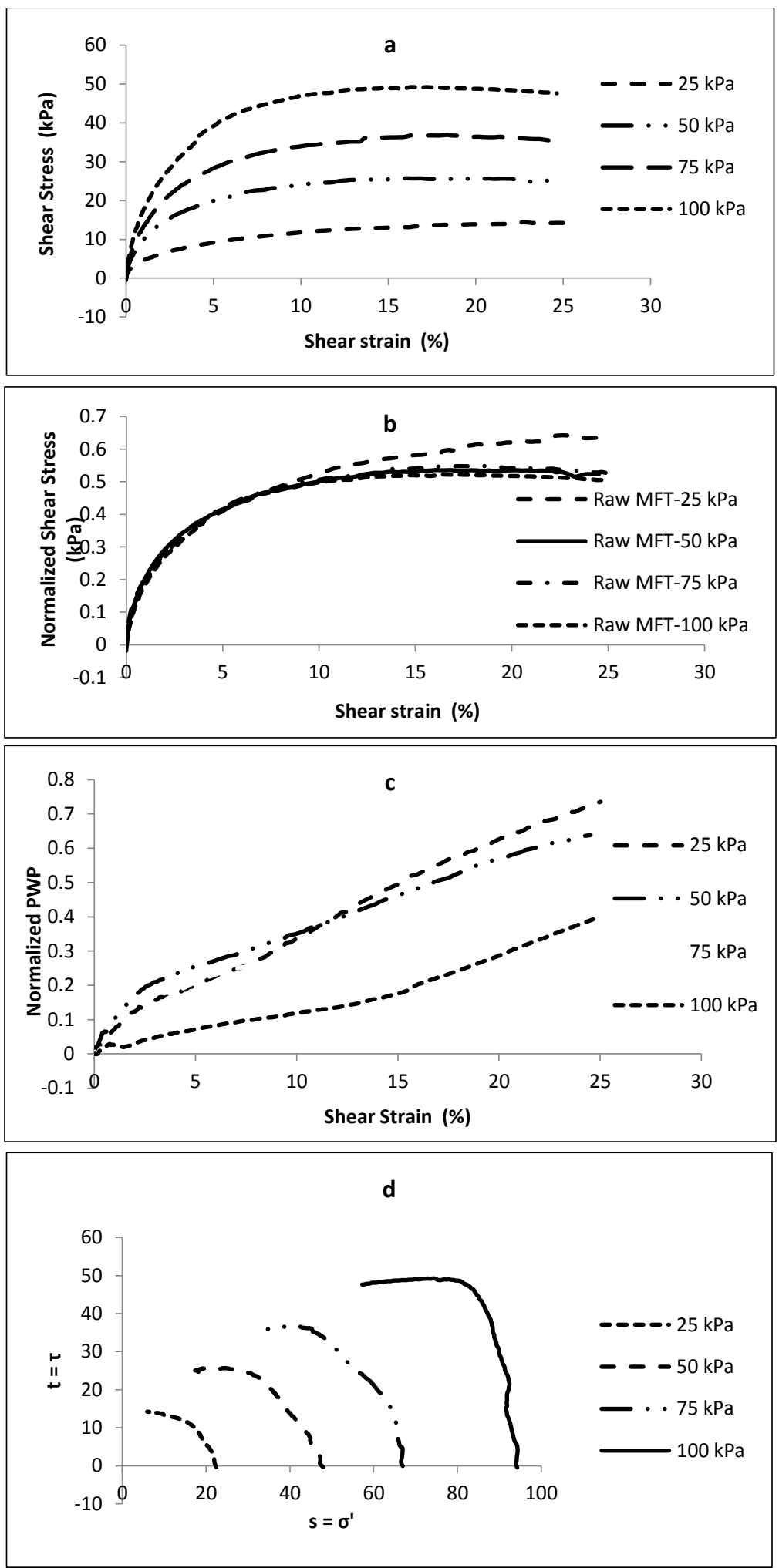

Figure 4-9.Comparison of Raw MFT behaviour during shearing- a) shear stress vs. shear strain, b) Normalized shear stress vs. shear strain, c) Normalized pore water pressure, d) stress path 

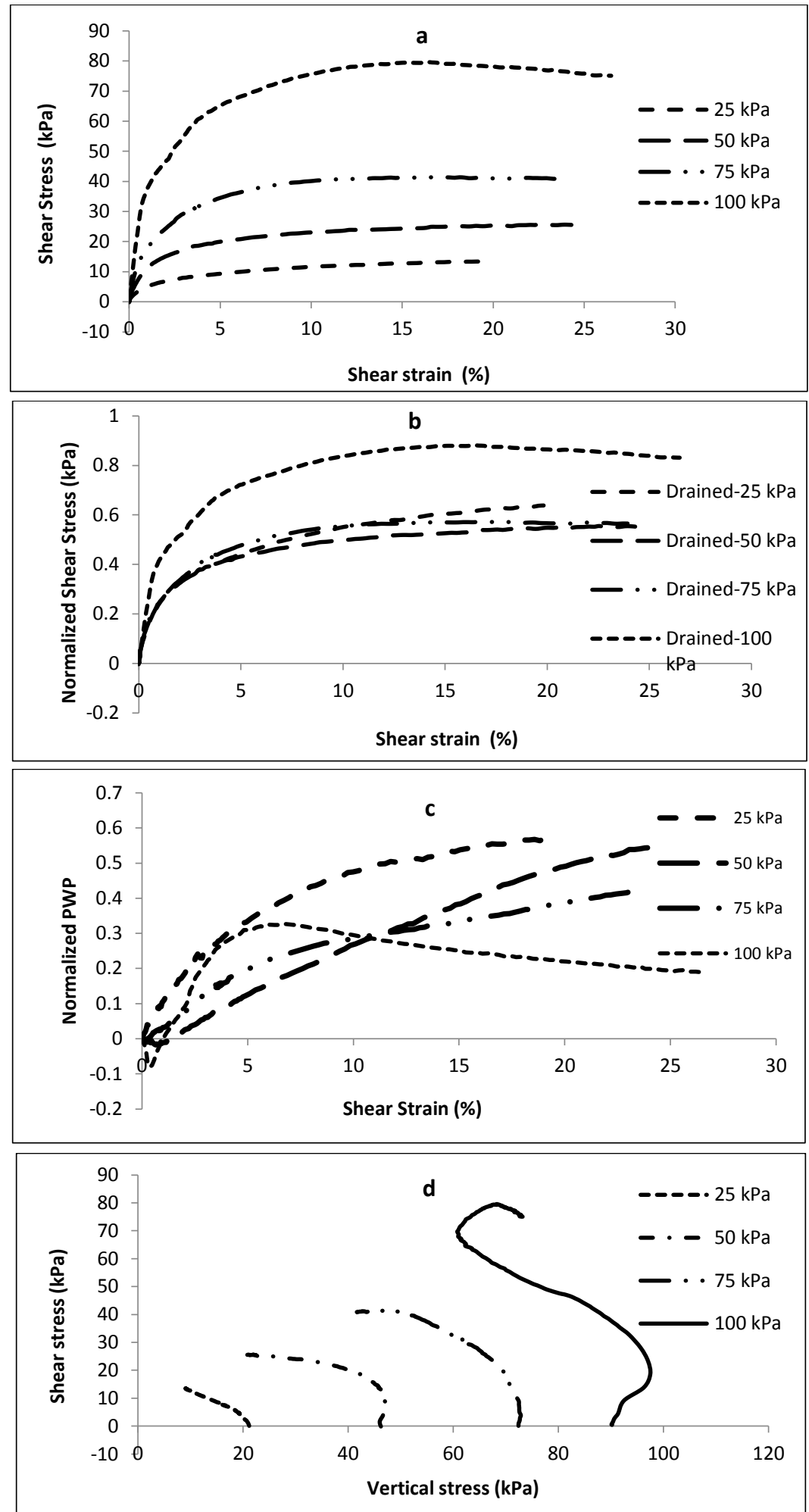

Figure 4-10.Comparison of consolidated amended MFT behaviour during shearing- a) shear stress vs. shear strain, b) Normalized shear stress vs. shear strain, c) Normalized pore water pressure, d) stress

path 

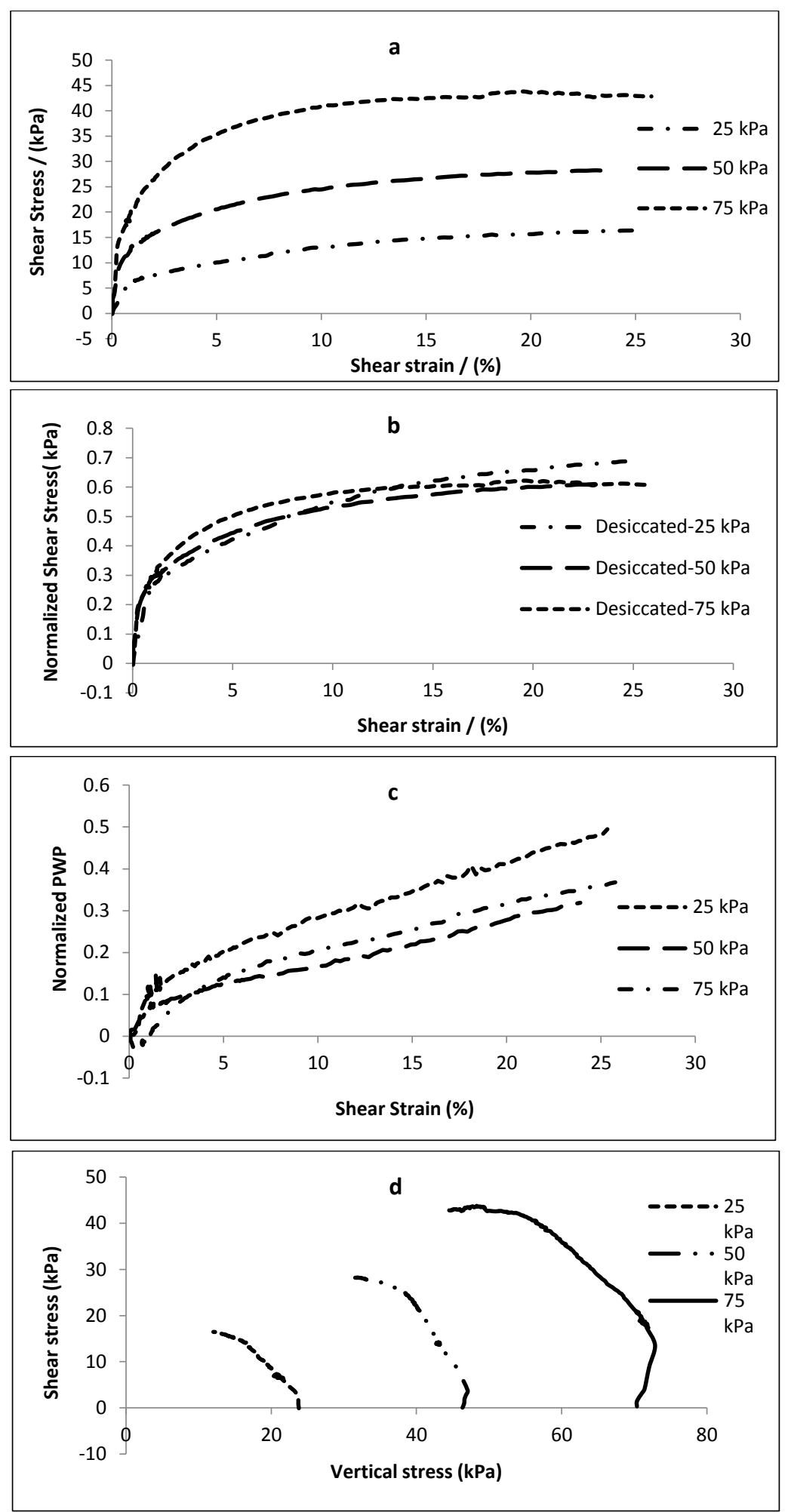

Figure 4-11.Comparison of desiccated MFT behaviour during shearing- a) shear stress vs. shear strain, b) Normalized shear stress vs. shear strain, c) Normalized pore water pressure, d) stress path 


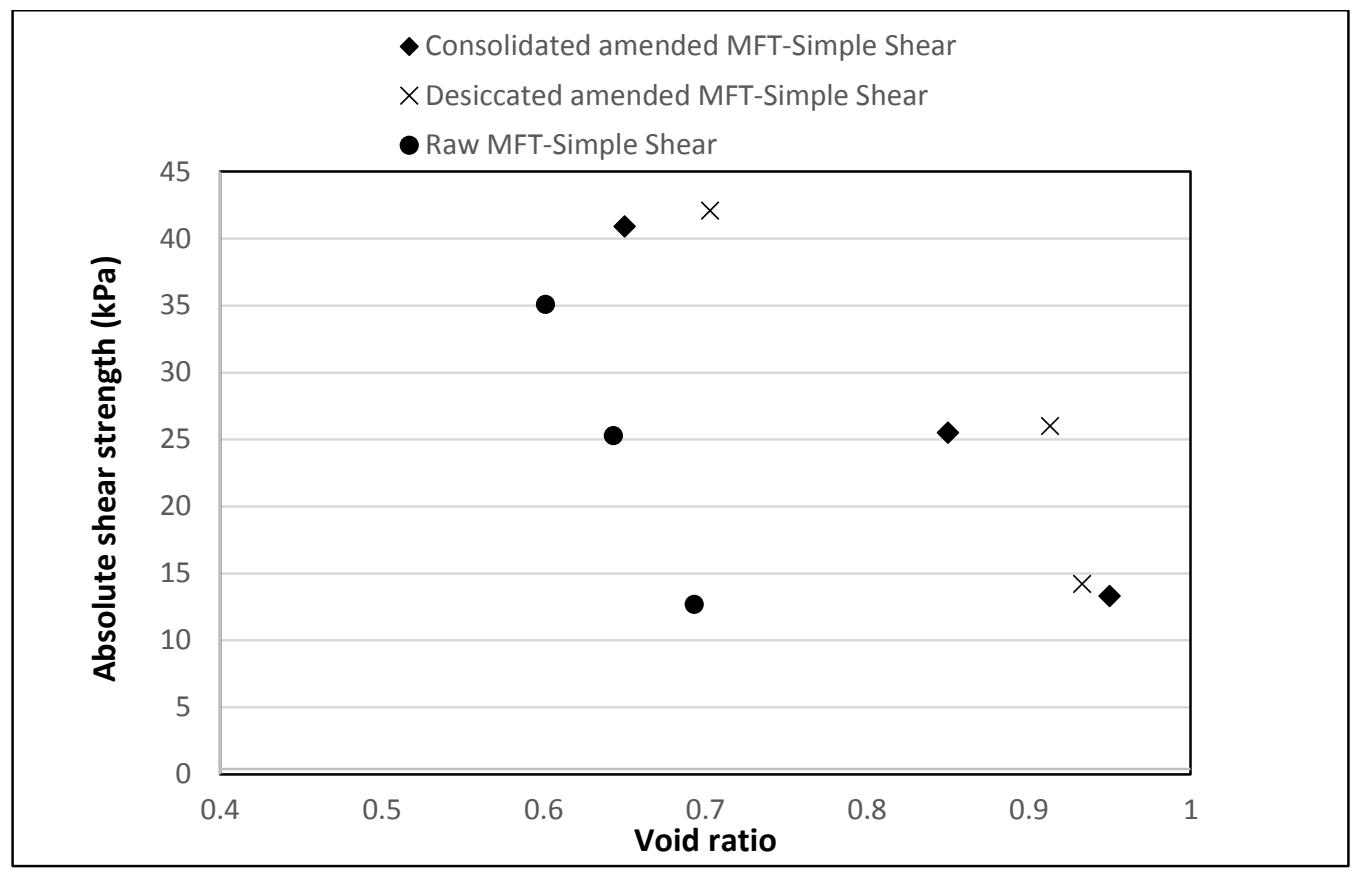

Figure 4-12. Shear strength-void ratio relationship 


\subsection{Triaxial results}

Sample preparation is described in section 3.2 chapter 3. The Consolidated Undrained (CU) triaxial compression test was conducted on polymer amended MFT to investigate the shearing behaviour. All samples have $135 \mathrm{~mm}$ height and $75 \mathrm{~mm}$ diameter before starting the test. Each test was conducted in three main phases, including saturation, consolidation, and shearing. In order to compare the results of triaxial test with simple shear, the effective stress of $25 \mathrm{kPa}$ to $100 \mathrm{kPa}$ was considered in each series of test.

To achieve a sufficient degree of saturation back pressure was applied to the specimen. A back pressure of $100 \mathrm{kPa}$ was considered to start the saturation process. Depending on the desired effective stress, four-five days were required to get the B value higher than 0.95 in each test. Once the saturation process was completed, the isotropic consolidation was applied, while the drainage valves were kept open at top and bottom of sample to facilitate two-way drainage. The time required for completion of consolidation was found to be 24-48 hours. During consolidation, the water drained from top and bottom of sample were collected into two different reservoirs. The amount of collected water was recorded every day. Reaching a constant water level within reservoirs in addition to reaching constant sample height were indications of consolidation termination. After consolidation, shear deviator stress was applied to the specimen. The shearing speed was set at $1 \mathrm{~mm} / \mathrm{min}$ by controlling the axial deformation rate. The shear test was terminated once the axial strain reached $15 \%$. During the shearing phase, stress-strain relationship and pore water pressure build up at top and bottom of sample were recorded. 

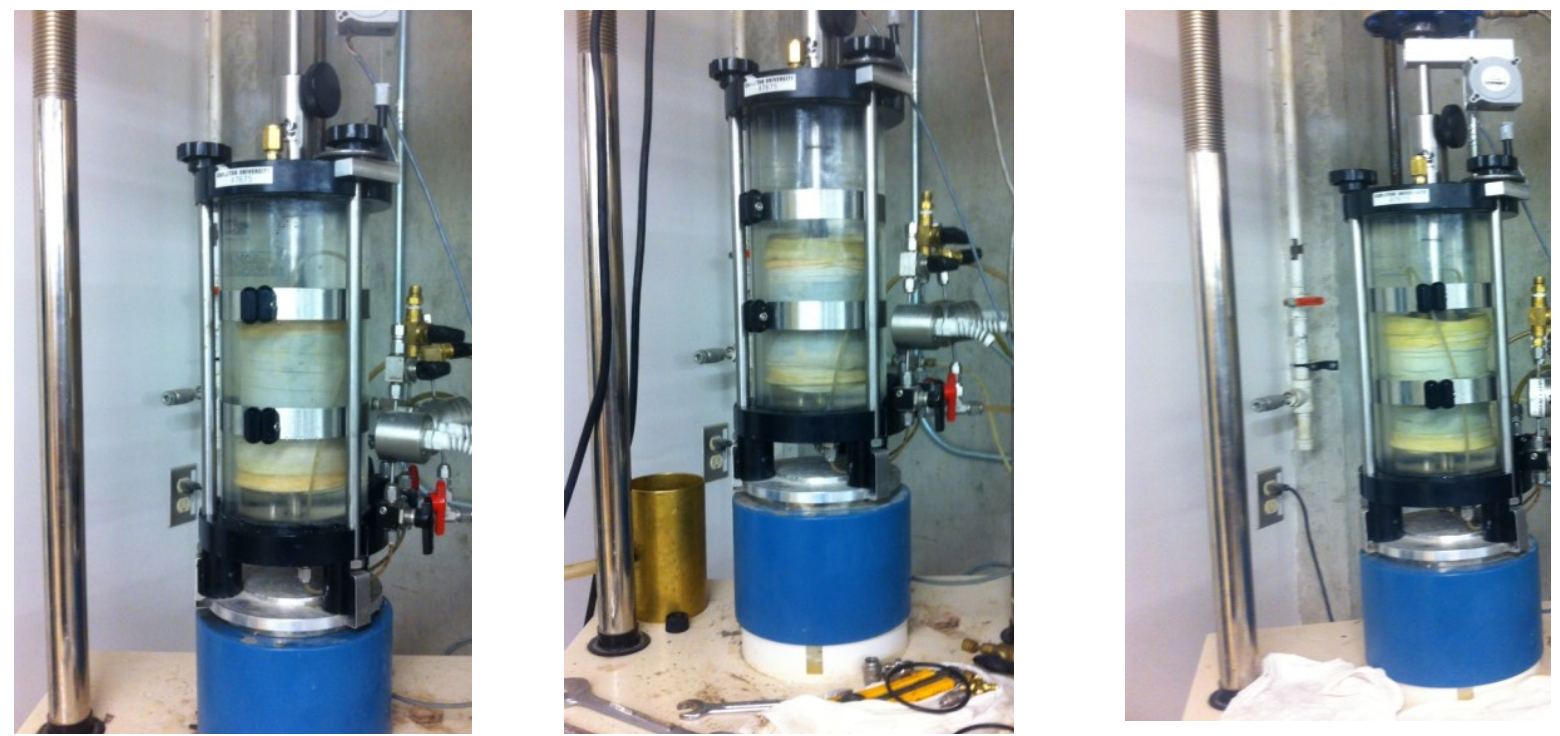

Figure 4-13 illustrates a sample before and after consolidation and after shearing while effective stress was $100 \mathrm{kPa}$ As it has shown, necking was observed after consolidation, since the specimen was softer (lower water content) at the middle compared to top and bottom.
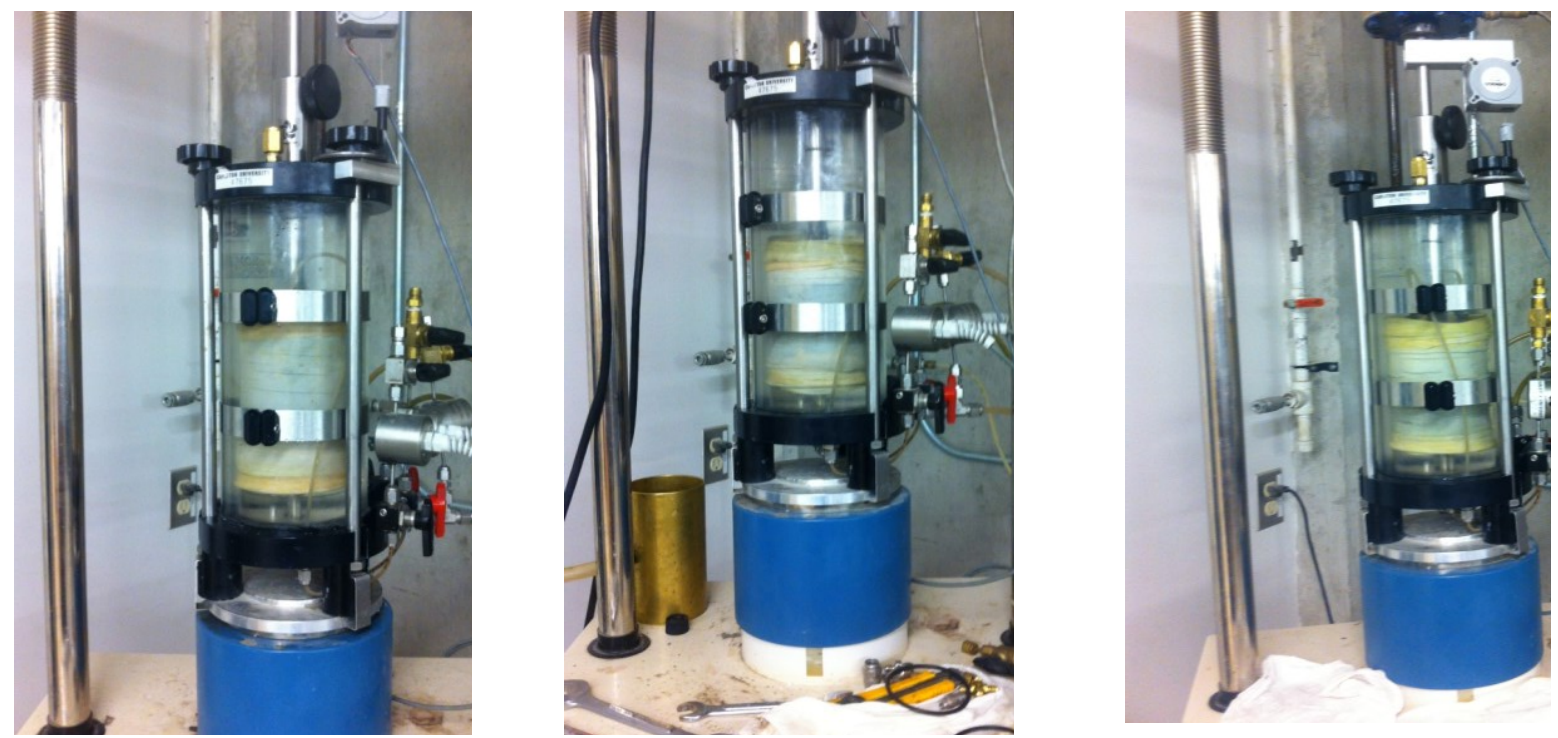

Figure 4-13. Figure 4-14.Sample within triaxial apparatus from left to right-before consolidation-after consolidation- after shearing

\subsubsection{Monotonic shearing results}

\subsubsection{Deviator stress vs. axial strain}

The results of deviator stress vs. axial strain during shearing for consolidated amended samples are plotted in Figure 4-15. As it was expected, shear strength of samples increased by increasing 
the vertical effective stress. The maximum deviator stress was jumped from $8.23 \mathrm{kPa}$ to 33.46 $\mathrm{kPa}$ as the effective stress increased from $25 \mathrm{kPa}$ to $100 \mathrm{kPa}$. On the other hand, all samples approached a constant value of shear strength at all stress levels. It should be note that all triaxial tests were ceased at axial strain of $15 \%$ while the simple shear tests were stopped at shear strain of $25 \%$. Therefore, it was expected that behaviour of samples within triaxial apparatus would approach steady state condition by continuing the test.

Stress-strain relationship for desiccated amended MFT is illustrated in Figure 4-17. Similar to consolidated amended MFT, samples approached a constant value of shear strength. In addition, shear strength increased dramatically from $5.4 \mathrm{kPa}$ to $24.4 \mathrm{kPa}$ as the effective stress increased from $25 \mathrm{kPa}$ to $100 \mathrm{kPa}$. Also, stress-strain graphs were found to be smoother at higher effective stress levels.

\subsubsection{Pore water pressure}

Since the shearing phase was conducted under undrained conditions, it was important to track pore water pressure build up. Two pressure transducers at top and bottom of sample were used to record the pore water pressure change. The results of pore pressure development at top and bottom of consolidated samples are summarized in appendix (Figure 7-12-Figure 7-15). The similar graphs for desiccated specimens are illustrated in Figure 7-16-Figure 7-18. Pore water pressure development was recorded similar with an increasing trend at top and bottom of all consolidated and desiccated samples, except consolidated sample at effective stress of $25 \mathrm{kPa}$ and desiccated sample at effective stress of $50 \mathrm{kPa}$.

It should be note that both pressure transducers should showed similar trends, but as it has shown in all figures, pore water pressure graph at bottom of sample was smoother compared to pore water pressure at top even though all transducers were calibrated couple of times using the pressure calibrator. To find the reason, one test was repeated while the transducers at top and bottom were switched. For that test pore pressure graph was found fluctuated at bottom, whereas pore pressure trend was smooth at top. So, it was concluded that transducer for top pore water pressure picks up some noises during the test which results in fluctuated graph. It should be note that although pore pressure graph at top was not as smooth as pore pressure graph at bottom, the general increasing trend was clear within all tests. 


\subsubsection{Stress path}

Figure 4-15-Figure 4-18 illustrate $\mathrm{p}^{\prime}\left(\left(\sigma_{1}^{\prime}{ }_{1}+\sigma_{3}^{\prime}\right) / 2\right)$ vs. $\mathrm{q}^{\prime}\left(\left(\sigma_{1}^{\prime}{ }_{1}-\sigma_{3}^{\prime}\right) / 2\right)$-known as stress path- for consolidated amended and desiccated amended specimens respectively. Both pore water pressure at top and bottom were considered to find $\mathrm{p}^{\prime}$ and $\mathrm{q}^{\prime}$ values. Therefore, two different stress paths with respect to pore water pressures were found. Stress path graphs from bottom pore water pressure were almost linear with similar trend. In fact, decrease in $\mathrm{p}^{\prime}$ and increase in $\mathrm{q}^{\prime}$ was occurred simultaneously until termination of the test. The only exception was experienced for consolidated sample at effective stress of $25 \mathrm{kPa}$ and desiccated sample at effective stress of 50 $\mathrm{kPa}$. On the other hand, stress path graphs from top pore water pressure showed a contractive behaviour for both consolidated amended MFT and desiccated amended MFT.

\subsubsection{Water content distribution}

At the end of each test, the sample removed carefully from triaxial apparatus and trimmed into 10 equal sections for water content measurement. The water content distribution for polymer amended and desiccated samples are summarized in Table 4.1 and Table 4.2 respectively. It is shown that samples have more uniform water content distribution with respect to depth at higher effective stress levels, although a completely uniform sample was not achieved in any test.

\subsubsection{Shear strength-void ratio}

The relationship between shear strength and final void ratio at the end of shearing for consolidated MFT and desiccated MFT are compared in Figure 4-19. It was found that desiccated MFT give slightly higher strength compared to consolidated samples, even at lower void ratio (higher densities). 

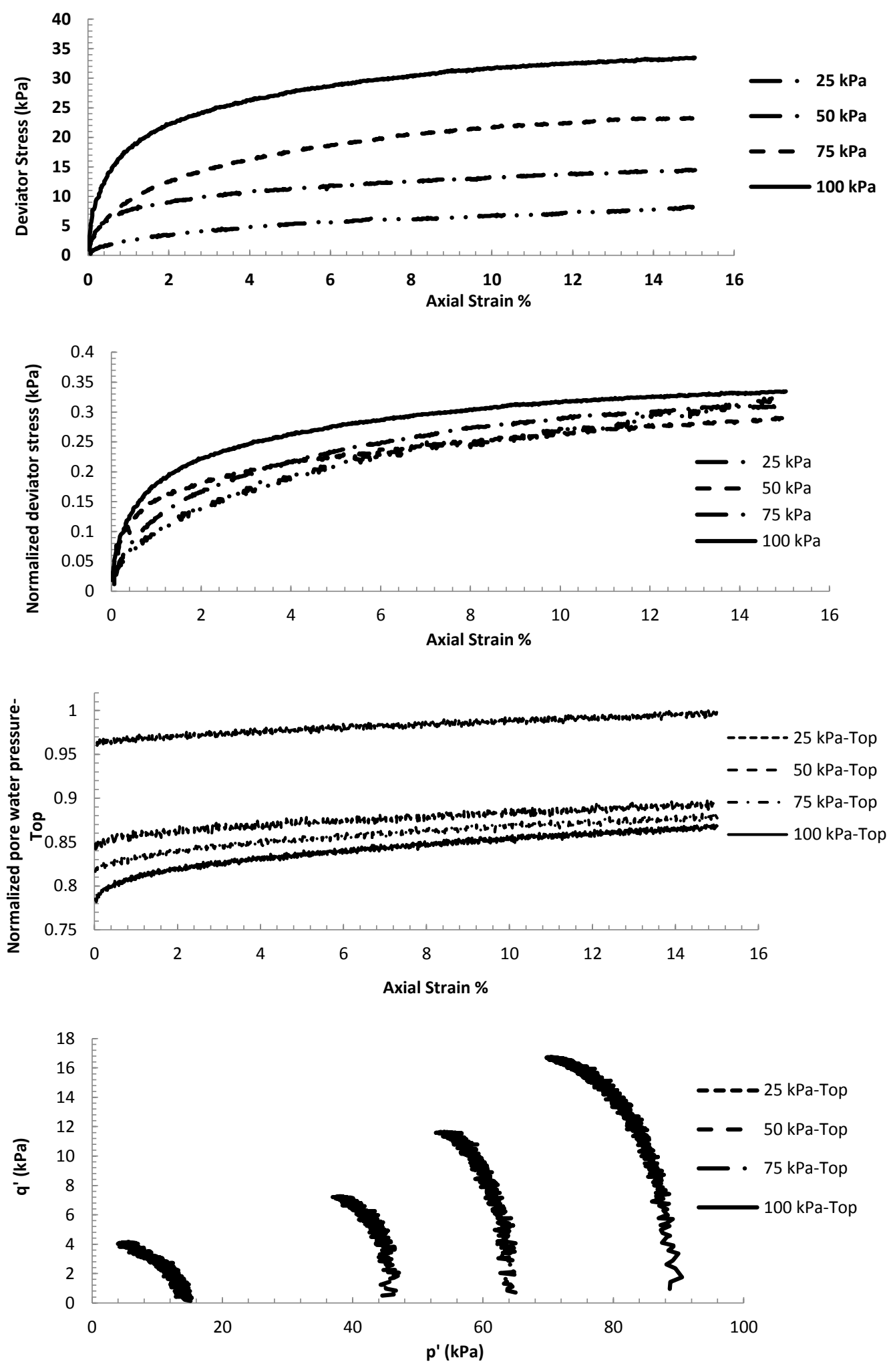

Figure 4-15.Comparison of consolidated amended MFT behaviour during shearing a) Deviator stress vs. strain, b) Normalized stress, c) Normalized pore water pressure (top) d) Stress path (top) 

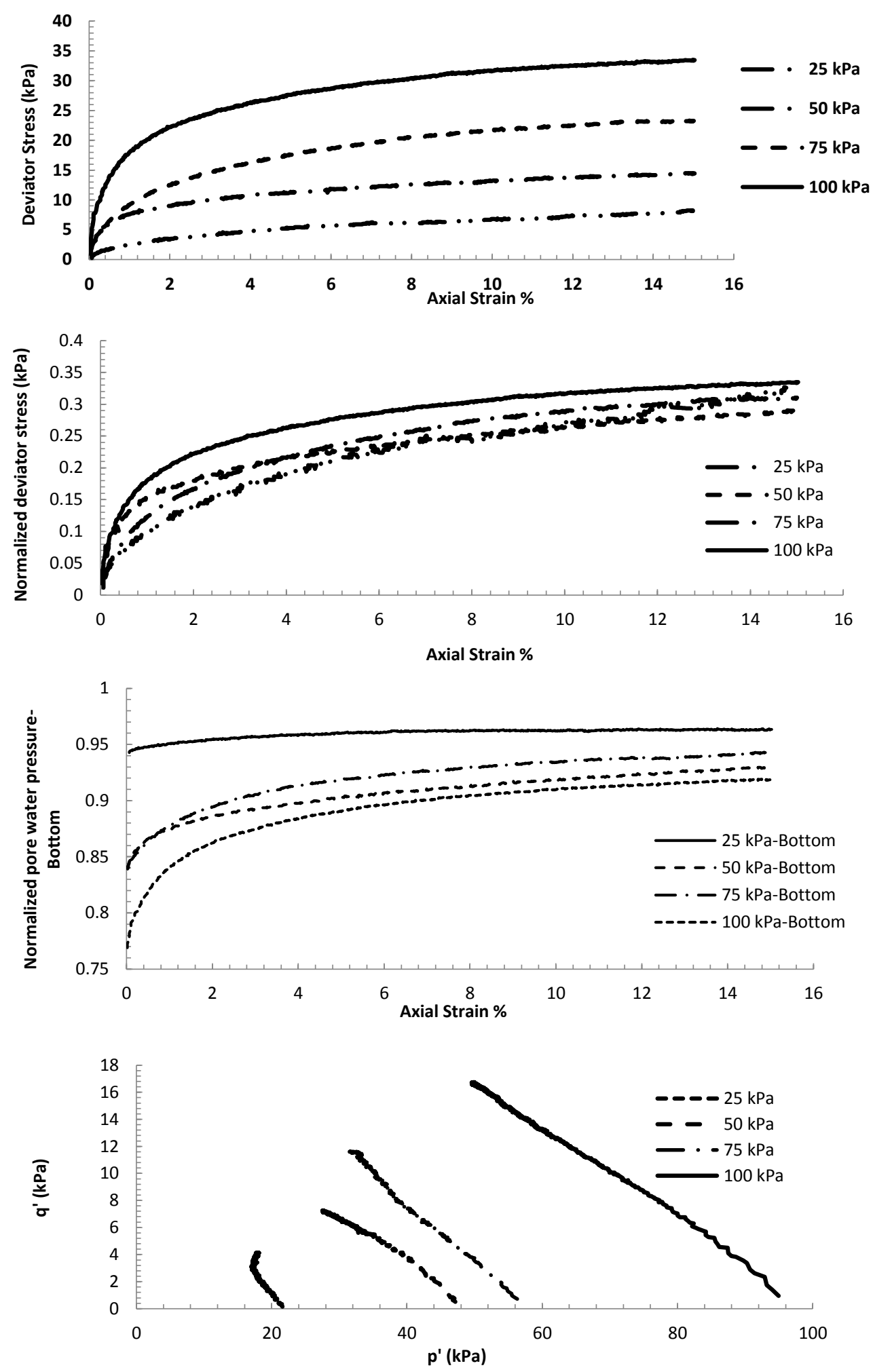

Figure 4-16.Comparison of consolidated amended MFT behaviour during shearing a) Deviator stress vs. strain, b) Normalized stress, c) Normalized pore water pressure (bottom) d) Stress path (Bottom) 

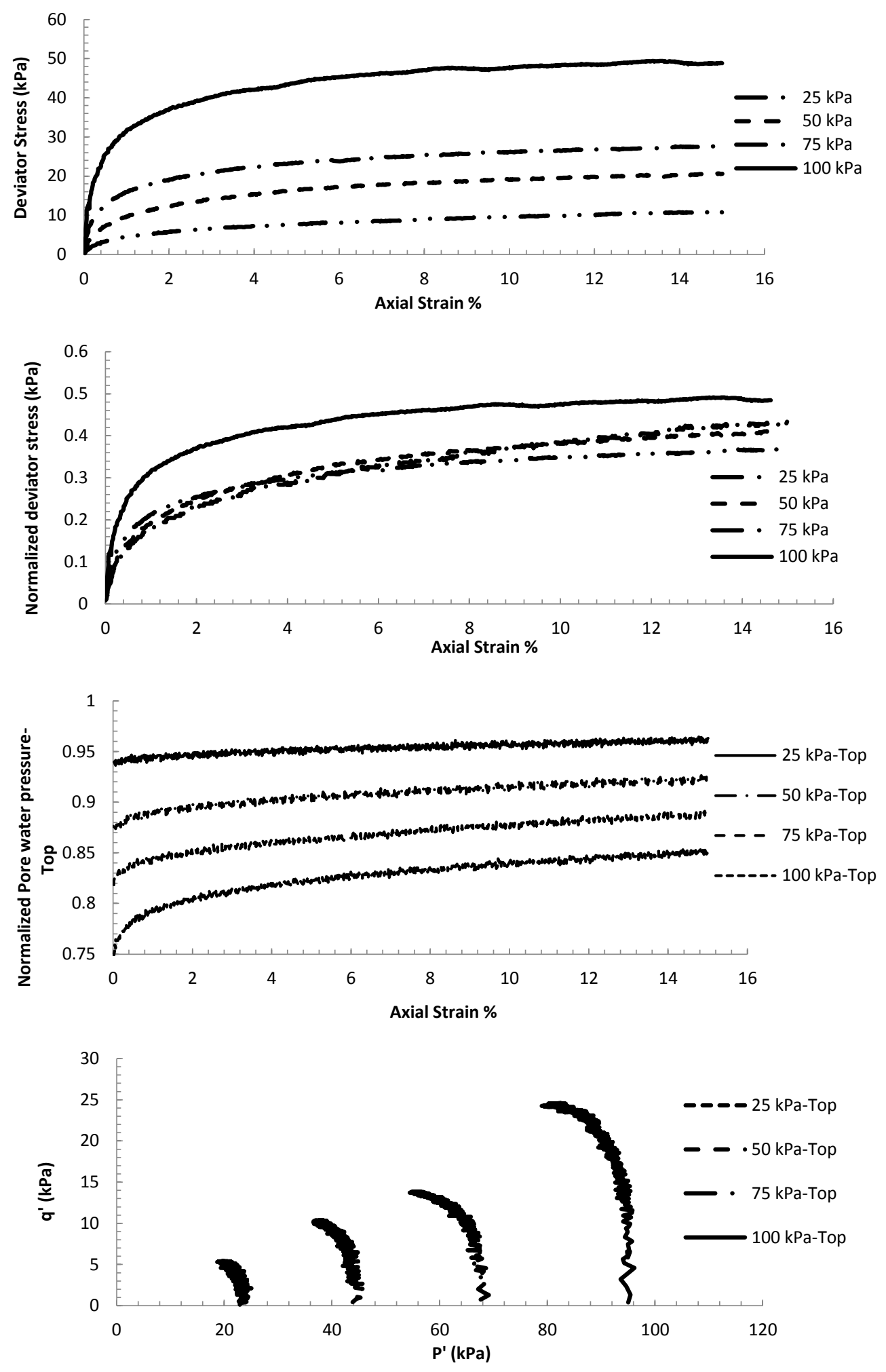

Figure 4-17.Comparison of desiccated amended MFT behaviour during shearing a) Deviator stress vs. strain, b) Normalized stress, c) Normalized pore water pressure (Top) d) Stress path (Top) 

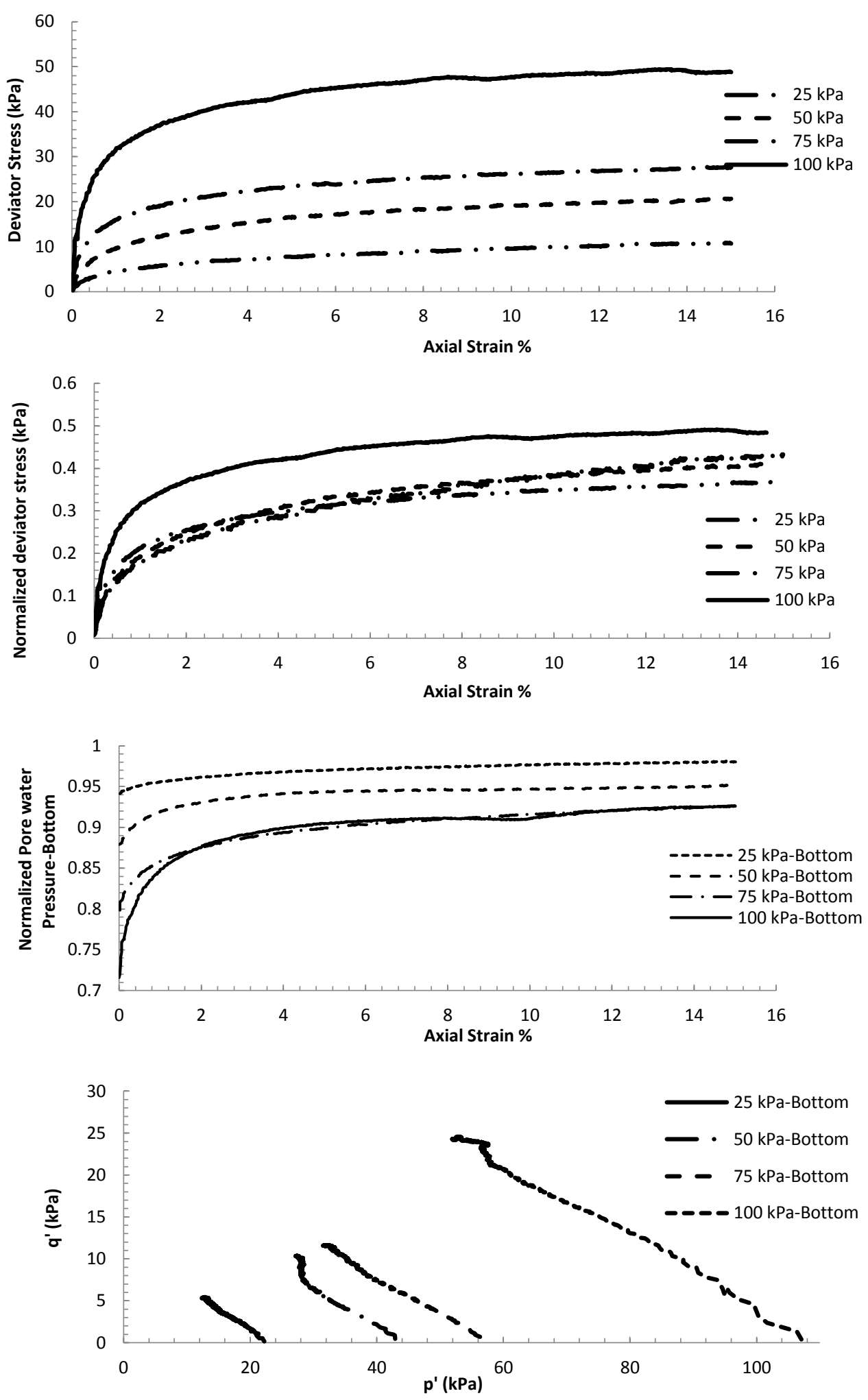

Figure 4-18.Comparison of desiccated amended MFT behaviour during shearing a) Deviator stress vs. strain, b) Normalized stress, c) Normalized pore water pressure (Bottom) d) Stress path (Bottom) 
Table 4.1. Water Content and Solid Content distribution after shearing in the triaxial apparatusconsolidated amended samples

\begin{tabular}{|l|l|l|l|l|l|l|l|l|}
\hline & \multicolumn{2}{l}{$\mathbf{2 5} \mathbf{~ k P a}$} & \multicolumn{2}{l}{$\mathbf{5 0} \mathbf{~ k P a}$} & $\mathbf{7 5} \mathbf{~ k P a}$ & \multicolumn{2}{l|}{$\mathbf{1 0 0} \mathbf{~ k P a}$} \\
\cline { 2 - 9 } & Ww & Ws & Ww & Ws & Ww & Ws & Ww & Ws \\
\hline $\begin{array}{l}l \\
\text { (Bottom) }\end{array}$ & 0.397 & 0.716 & 0.385 & 0.722 & 0.332 & 0.751 & 0.317 & 0.759 \\
\hline 2 & 0.423 & 0.703 & 0.387 & 0.721 & 0.348 & 0.742 & 0.322 & 0.756 \\
\hline 3 & 0.442 & 0.693 & 0.388 & 0.720 & 0.352 & 0.740 & 0.320 & 0.757 \\
\hline 4 & 0.455 & 0.687 & 0.394 & 0.717 & 0.352 & 0.740 & 0.320 & 0.757 \\
\hline 5 & 0.450 & 0.690 & 0.398 & 0.715 & 0.341 & 0.745 & 0.311 & 0.763 \\
\hline 6 & 0.433 & 0.698 & 0.394 & 0.717 & 0.332 & 0.751 & 0.309 & 0.764 \\
\hline 7 & 0.415 & 0.707 & 0.376 & 0.727 & 0.322 & 0.756 & 0.299 & 0.770 \\
\hline 8 & 0.382 & 0.724 & 0.369 & 0.731 & 0.318 & 0.759 & 0.295 & 0.772 \\
\hline 9 & 0.358 & 0.736 & 0.348 & 0.742 & 0.315 & 0.760 & 0.291 & 0.775 \\
\hline 10 (Top) & 0.336 & 0.748 & 0.335 & 0.749 & 0.318 & 0.759 & 0.291 & 0.775 \\
\hline
\end{tabular}

$\mathbf{W}_{\mathrm{w}}=$ Water content, $\mathbf{W}_{\mathrm{s}}$ :Solid Content

Table 4.2.Water Content and Solid Content distribution after shearing in the triaxial apparatusDesiccated amended samples

\begin{tabular}{|l|l|l|l|l|l|l|l|l|}
\hline & \multicolumn{2}{|l}{$\mathbf{2 5} \mathbf{~ k P a} \mathbf{5 0} \mathbf{~ k P a}$} & $\mathbf{7 5} \mathbf{~ k P a}$ & \multicolumn{2}{l|}{$\mathbf{1 0 0} \mathbf{k P a}$} \\
\cline { 2 - 9 } & Ww & Ws & Ww & Ws & Ww & Ws & Ww & Ws \\
\hline $\begin{array}{l}\text { (Bottom) } \\
\text { (B) }\end{array}$ & 0.392 & 0.719 & & & 0.364 & 0.733 & 0.314 & 0.761 \\
\hline 2 & 0.413 & 0.708 & 0.374 & 0.728 & 0.361 & 0.735 & 0.311 & 0.763 \\
\hline 3 & 0.411 & 0.709 & 0.367 & 0.732 & 0.361 & 0.735 & 0.306 & 0.765 \\
\hline 4 & 0.416 & 0.706 & 0.362 & 0.734 & 0.356 & 0.737 & 0.306 & 0.766 \\
\hline 5 & 0.403 & 0.713 & 0.355 & 0.738 & 0.346 & 0.743 & 0.300 & 0.770 \\
\hline 6 & 0.399 & 0.715 & 0.347 & 0.742 & 0.333 & 0.750 & 0.291 & 0.774 \\
\hline 7 & 0.383 & 0.723 & 0.341 & 0.745 & 0.316 & 0.760 & 0.289 & 0.776 \\
\hline 8 & 0.372 & 0.729 & 0.341 & 0.746 & 0.318 & 0.759 & 0.278 & 0.782 \\
\hline 9 & 0.373 & 0.728 & 0.338 & 0.748 & 0.304 & 0.767 & 0.285 & 0.778 \\
\hline 10 (Top) & 0.346 & 0.743 & 0.318 & 0.759 & 0.292 & 0.774 & 0.277 & 0.783 \\
\hline
\end{tabular}

$\mathrm{W}_{\mathrm{w}}=$ Water content, $\mathrm{W}_{\mathrm{s}}$ :Solid Content 


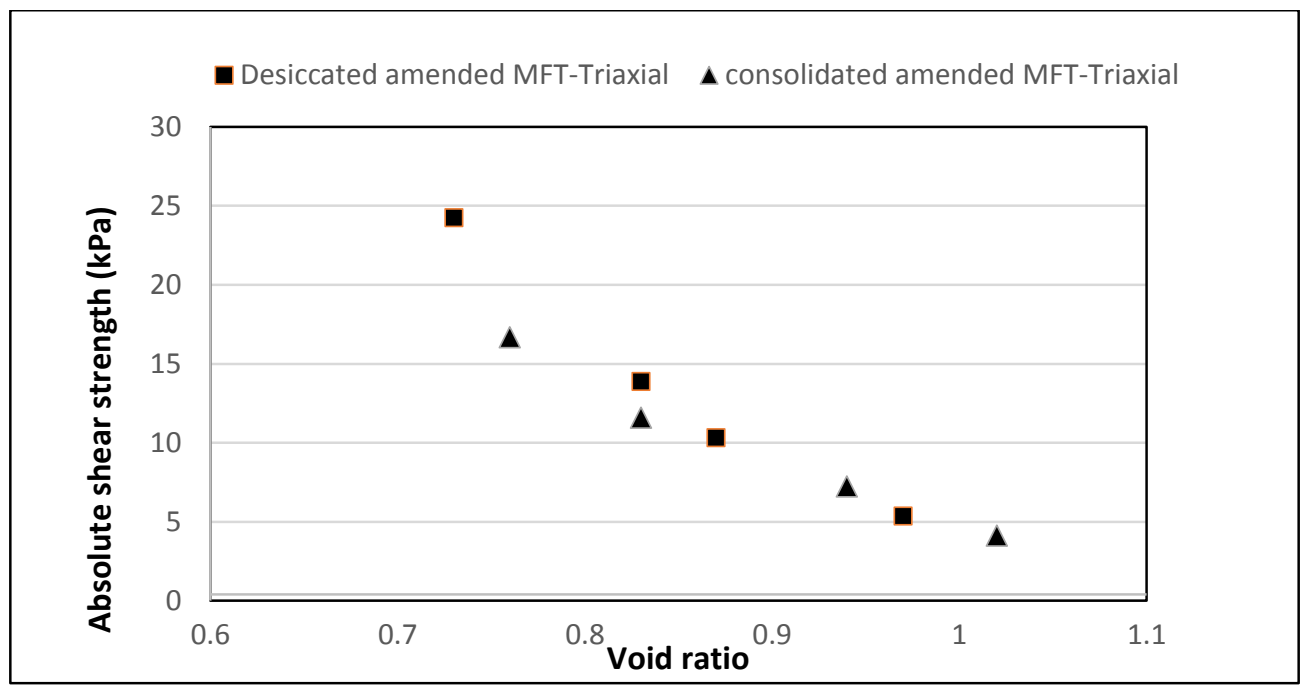

Figure 4-19. Shear strength-void ratio relationship 


\section{Discussions and conclusions}

\subsection{Introduction}

This chapter summarizes all observations and results from the present study. A comparison was made between the results of consolidation tests, simple shear tests and triaxial tests to investigate any change in behaviour of consolidated amended MFT that may arise at different testing methodologies. Also, the main conclusions from the analytical and experimental approaches have been brought. At the end, recommendations for further studies are given.

\subsubsection{Compressibility constitutive relationship}

As described in the previous chapter, the constitutive equations between void ratio and permeability as well as void ratio and effective stress are required to solve the general equation of large strain consolidation model. The results of compressibility as well as constitutive equation for all samples are summarized in Figure 5-1. Comparison can be made at two different stress levels: i) Low effective stress levels (i.e. $25 \mathrm{kPa}$ or $50 \mathrm{kPa}$ ), ii) High effective stress levels $(75 \mathrm{kPa}$ and $100 \mathrm{kPa})$.

As far as general trends are concerned, the compressibility of amended MFT compared to raw MFT was more tangible. In other words, raw MFT experienced lower compressibility at a given effective stress. This might relate to different initial properties such as lower water content/void ratio of these specimens compared to amended MFT at the beginning of the test. Furthermore, consolidated amended MFT recorded slightly higher compressibility compared to desiccated amended samples at all effective stress levels. 
On the other hand, the void ratio decreased gradually as effective stress increased for raw MFT. In contrast, void ratio decrased more considerable for amended MFT, when effective stress increased from $50 \mathrm{kPa}$ to $75 \mathrm{kPa}$ and from $75 \mathrm{kPa}$ to $100 \mathrm{kPa}$. In fact, compressibility increased markedly as the effective stress transmitted from lower levels to higher levels.

It has been shown that desiccation history affects the compressibility of hard rock tailings such that higher degree of desiccation associated with lower compressibility of tailings (Daliri 2013). Compressibility results on oil sand tailings are in a good agreement with hard rock tailings

compressibility results, as desiccated MFT showed lower compressibility compared to consolidated MFT even though the difference was not as high as hard rock tailings

\subsubsection{Permeability constitutive relationship}

The permeability-void ratio relationships for all samples are compared in Figure 5-2. A general trend was achieved for all samples such that permeability decreased following to void ratio drop. Nonetheless, the trend was clearer for consolidated MFT, since a wider range of permeability was found with respect to void ratio. Furthermore, the graph exhibits that consolidated amended MFT are more permeable compared to desiccated amended MFT up to void ratio of 0.65 and tends to be coinciding beyond this void ratio.

Also, the graph exhibits that permeability range was narrow for all samples, although a good fit line (constitutive equation) with acceptable $\mathrm{R}^{2}$ was found for each specimen. As described earlier, the samples underwent self-weight consolidation before transferred to testing apparatus. Therefore, a considerable part of permeability and void ratio changes occur during self-weight consolidation, and the change becomes less tangible at the end of loaded consolidation test.

Furthermore, results of falling head permeability tests in chapter 3 showed that consolidated amended MFT have higher permeability compared to raw MFT (at least 10 times). However, Figure 5-2 reveals that such difference is not appreciable at the end of loaded consolidation tests. In other words, addition of polymer improves dewatering of Raw MFT at the beginning of selfweight consolidation, but any positive or negative influence of polymer on permeability of raw MFT disappears gradually during load-induced consolidation process. 


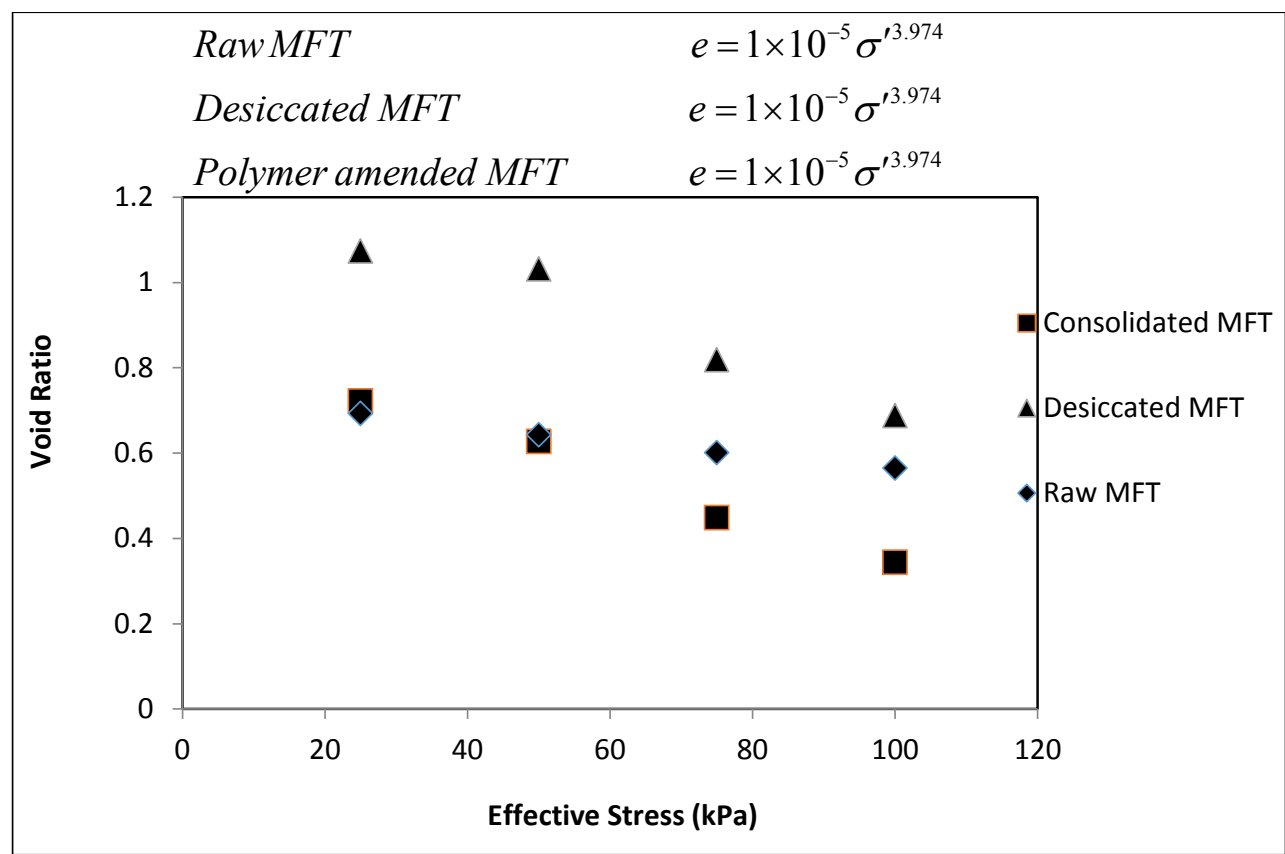

Figure 5-1 Combined compressibility behaviour of all samples

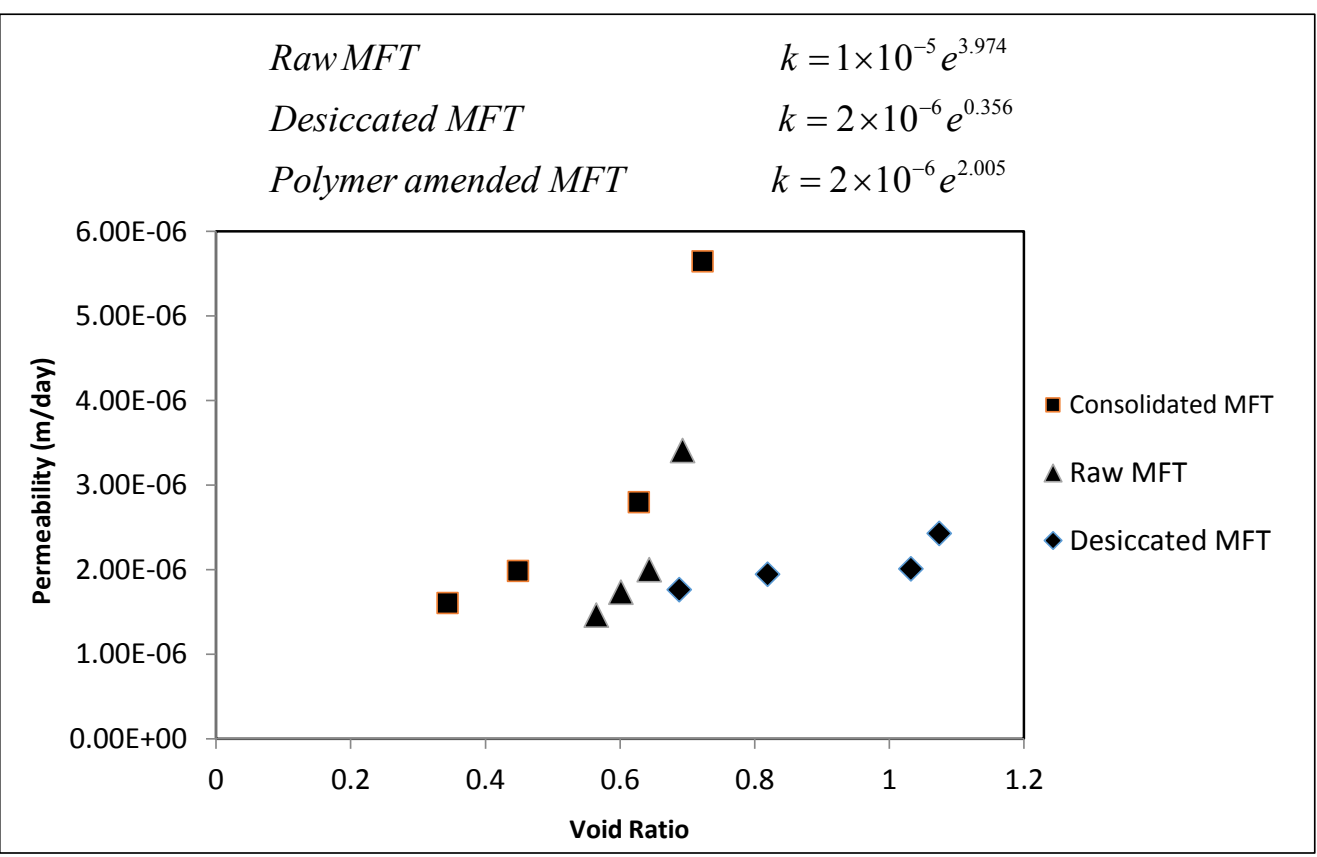

Figure 5-2 Combined permeability results 


\subsection{Comparison of simple shear results}

\subsubsection{Shear stress vs. Shear strain}

Comparison of shear stress vs. shear strain response for different samples at various effective stress levels of $25 \mathrm{kPa}$ to $100 \mathrm{kPa}$ are presented in Figure 5-3. The comparison can be categorised into two groups with respect to vertical effective stress level: i) Low effective stress levels, i.e. $25 \mathrm{kPa}$ and $50 \mathrm{kPa}$, ii) High effective stress levels, i.e. $75 \mathrm{kPa}$ and $100 \mathrm{kPa}$.

At lower effective stress levels, shear strength behaviour of raw MFT and polymer amended MFT were similar during the test. In other words, the graphs were coincident at all strains and therefore, the maximum shear strength was found almost equal for both samples. On the other hand, desiccated samples had somewhat higher strength at a given consolidation stress, although the increasing trend was more tangible after shear strain of $7.5 \%$ after consolidation to $25 \mathrm{kPa}$ and shear strain of $12 \%$ after consolidation to $50 \mathrm{kPa}$. This difference shows the contribution of desiccation on shear strength gain, although the difference was not very noticeable.

A different scenario was experienced at higher effective stress levels. Unlike lower effective stress levels, shear strength trend was not coincident for raw MFT and polymer amended MFT. At effective stress of $75 \mathrm{kPa}$, both amended MFT (desiccated and consolidated) samples exhibited higher shear strength than raw MFT during the test, although the difference was more tangible after shear strain of 3\%. In addition, shear strength of desiccated MFT was considerably higher than raw MFT at all strain levels especially after consolidation to $100 \mathrm{kPa}$. For example, shear stress was recorded $79 \mathrm{kPa}$ for amended MFT in comparison to $42 \mathrm{kPa}$ for raw MFT at strain level of $15 \%$. This indicates a considerable shear strength gain by polymer amended MFT compared to raw MFT.

The relationship between shear strength and final void ratio at the end of shearing for amended MFT are compared in Figure 5-4. Similar to stress-strain graph, it was found that desiccated MFT give slightly higher strength compared to amended samples, but at higher void ratio (lower densities). Daliri (2013) showed that even small degree of desiccation leads to change the behaviour of hard rock tailings from contractive to dilative in simple shear, which in turn improves shear strength gain. In other words, degree of dilative behaviour increased with degree 
of desiccation. Results of simple shear test on oil sand tailings showed that desiccation contributes to shear strength gain to some extent, especially at higher effective stress levels. . 

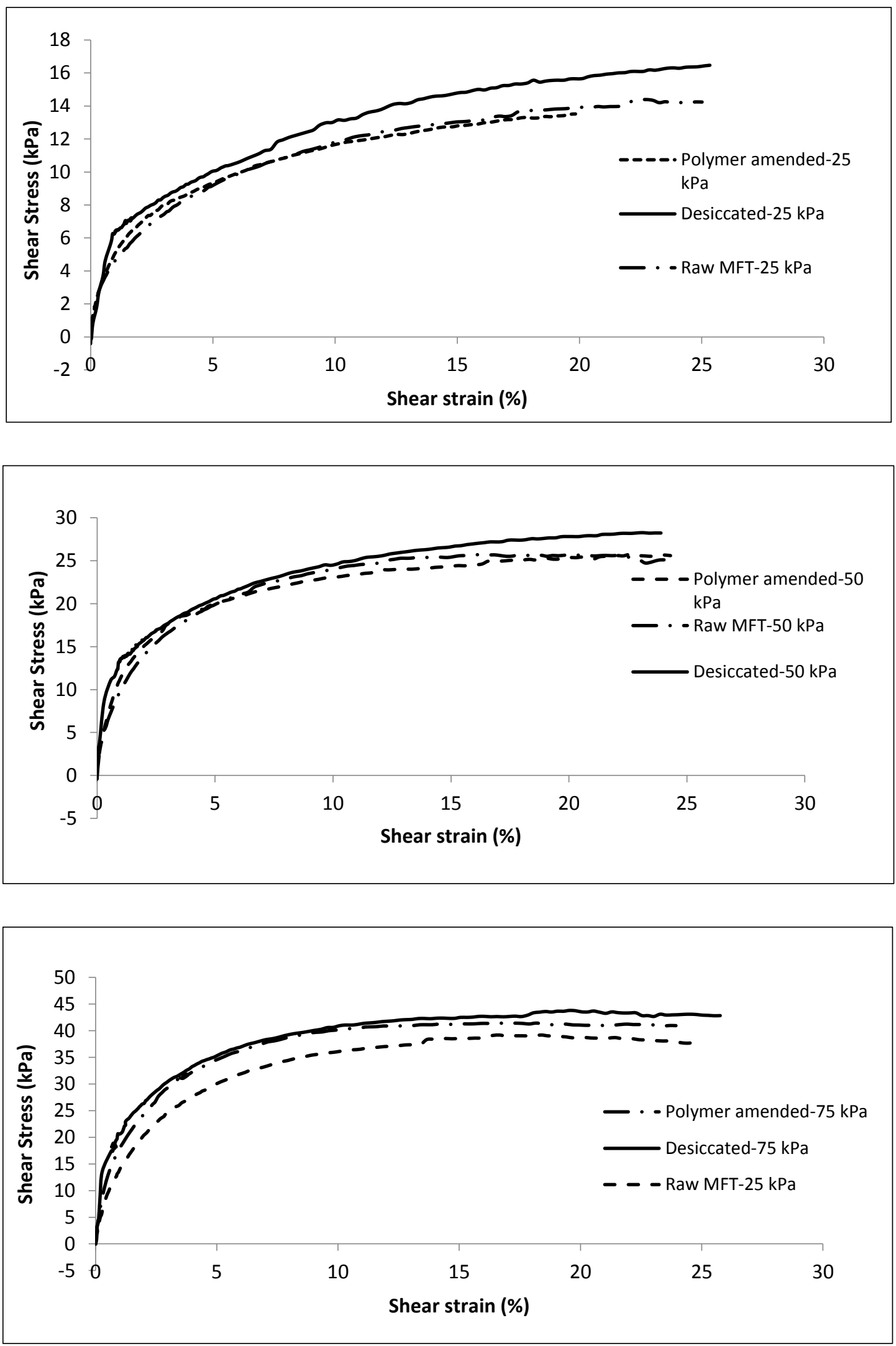


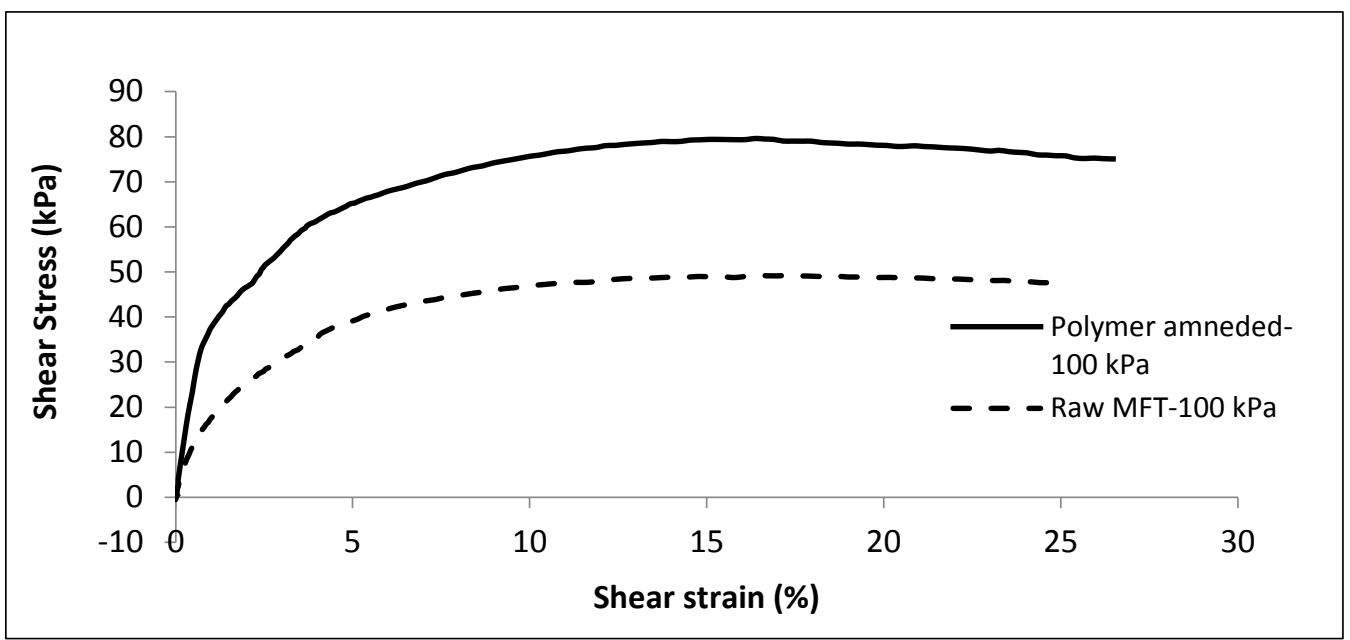

Figure 5-3. Simple shear results comparison between consolidated amended MFT and raw MFT at effective stress level of a) $25 \mathrm{kPa}$, b) $50 \mathrm{kPa}$, c) 75 kPa, d) $100 \mathrm{kPa}$

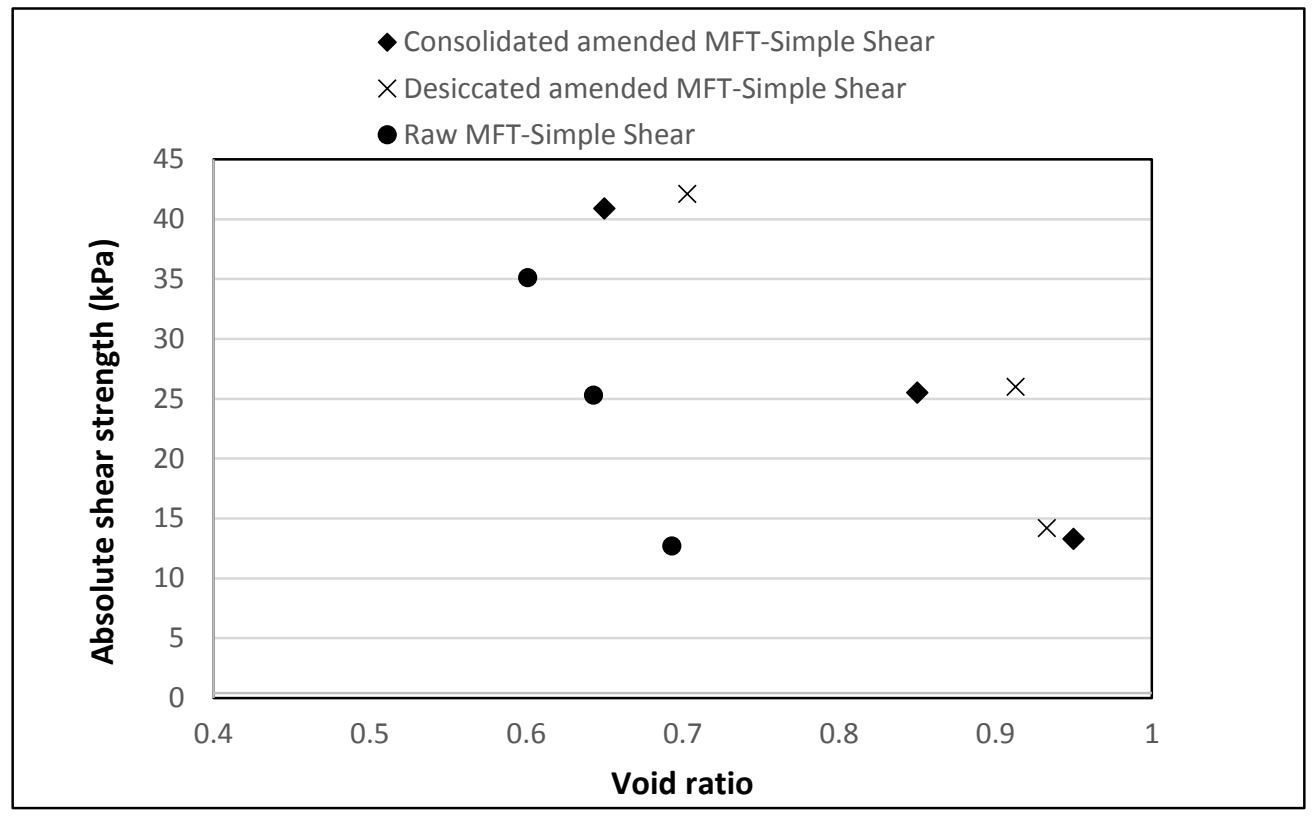

Figure 5-4. Shear strength-void ratio relationship

\subsubsection{Stress path}

Figure 5-5 presents comparison of stress path at all stress levels for amended MFT as well as raw MFT. Regardless of sample type, the general trend for stress path was found similar at a given effective stress level. The only exception was found for consolidated sample at effective stress level of $100 \mathrm{kPa}$. 
It should be note that stress path pattern of oil sand tailings are not following the common stress path pattern in previous studies for sands or even hard rock tailings (Vaid and Chern 1985, Daliri 2013)). However, oil sand tailings stress path are similar with those conducted on soft clay specimens by Bro et al. (2013), although those samples were stiffer (Figure 5-6).
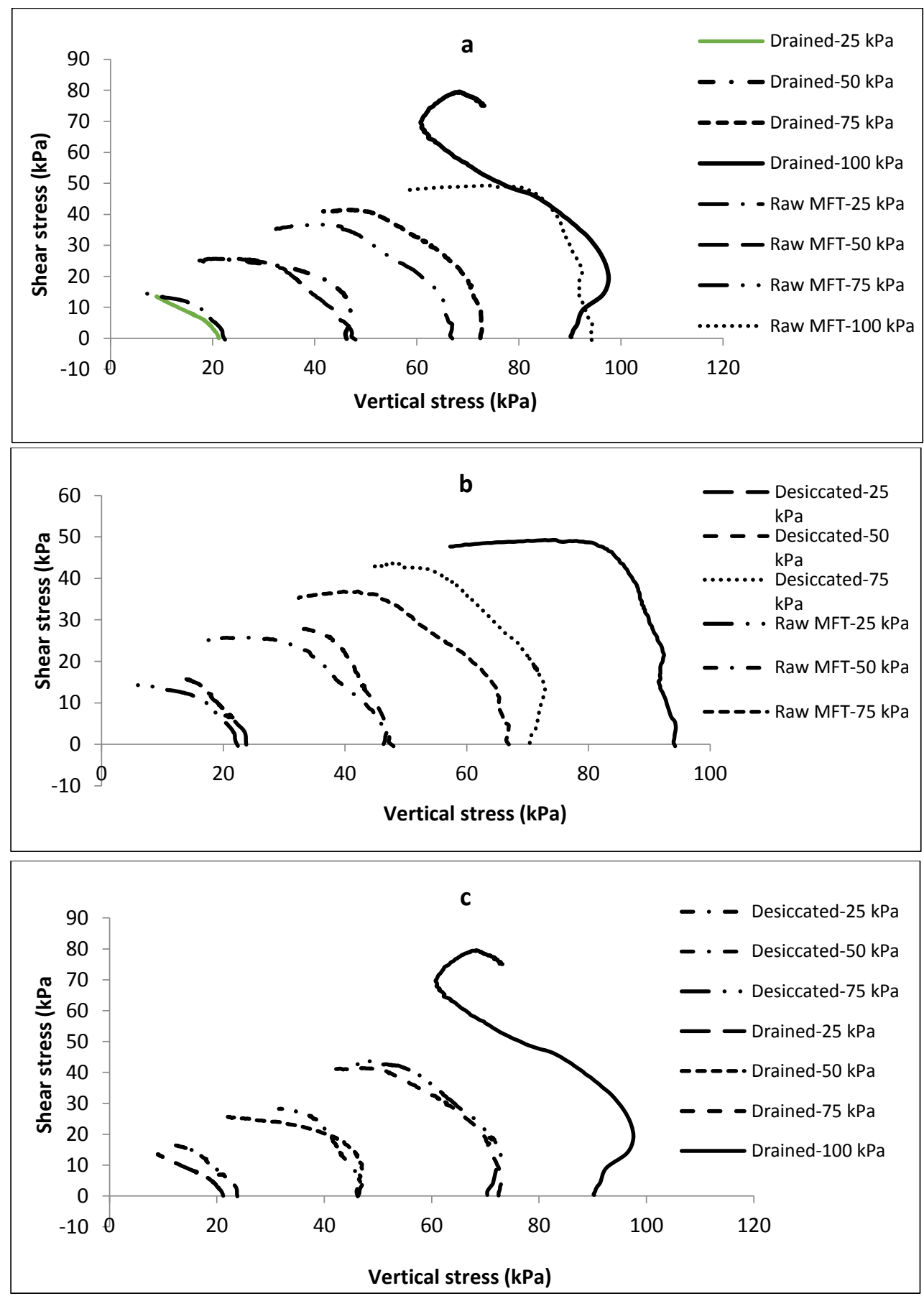

Figure 5-5.Stress Path comparison- a) Raw MFT and polymer amended MFT, b) Raw MFT and desiccated amended MFT, c) Polymer amended desiccated MFT 


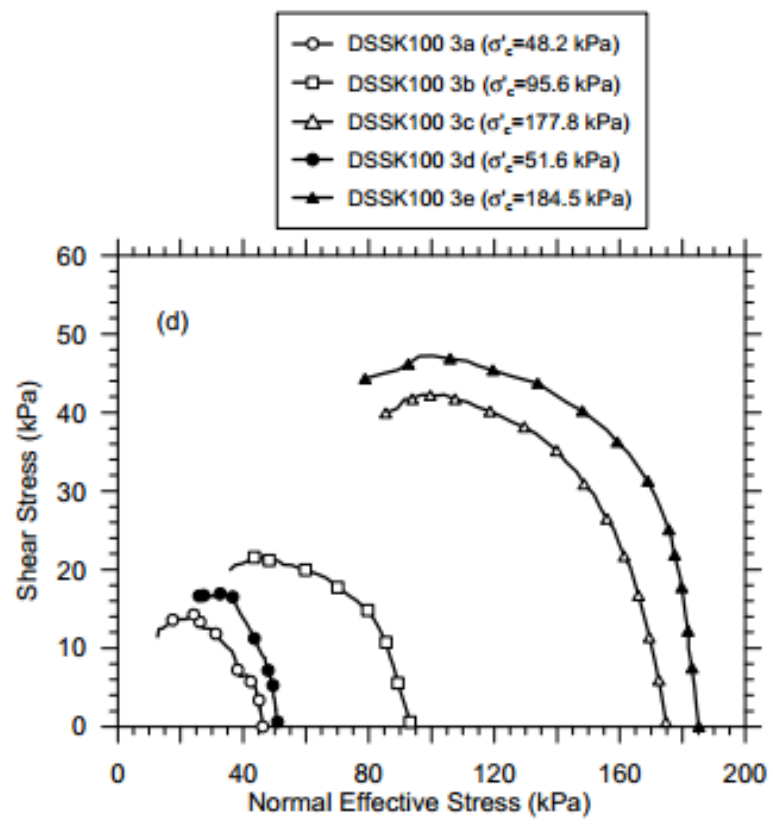

Figure 5-6. Simple shear test results for soft clays (Kaolinite specimens) (Bro et al. 2013).

\subsection{Comparison of triaxial results}

\subsubsection{Deviator stress vs. axial strain}

Comparison of deviator stress vs. axial strain response between consolidated amended MFT and desiccated MFT at various effective stress levels from $25 \mathrm{kPa}$ to $100 \mathrm{kPa}$ are presented in Figure $5-7$.

Regardless of effective stress level, desiccated amendedsamples showed higher shear strength compared to consolidated amended specimens at all strain values. However, the difference was more tangible at effective stress of $100 \mathrm{kPa}$ compared to lower effective stress levels. For instance, the maximum shear strength for desiccated sample and consoldiated sample at shear strain of $15 \%$ were $24 . \mathrm{kPa}$ and $16.68 \mathrm{kPa}$ at effective stress of $100 \mathrm{kPa}$, whereas the values found to be $5.35 \mathrm{kPa}$ and $4.12 \mathrm{kPa}$ at effective stress of $25 \mathrm{kPa}$. The results highlight the fact that desiccation contributes to shear strength gain for amended MFT.

Rate of shear strength gain is another important factor to take into account. Table 5.1 and Table 5.2 summarize the results of shear strength development for consolidated and desiccated samples respectively. The first column presents the maximum shear strength at the end of the test which 
corresponds to axial strain of $15 \%$. The second column presents $50 \%$ of maximum shear strength and the corresponding axial strain. The last column also shows the shear strength value at axial strain of 7.5\%. The results of all amended MFT show that rate of shear strength gain is tangible within the beginning of the test, such that $50 \%$ of maximum shear strength was gained while the axial strain was less than $3 \%$. Thereafter, the rate of shear strength development decreased gradually until the axial strain of $15 \%$ was reached.

The influence of desiccation on shear strength development of amended MFT in triaxial apparatus is in good agreement with the previous study conducted on hard rock tailings by Daliri (2013). The author concluded that desiccated specimens have higher strength compared to desiccated-rewetted samples in triaxial test. Furthermore, samples with higher degree of desiccation showed a pronounced peak shear strength for hard rock tailings, whereas no noticeable peak was recorded for amended MFT even though a considerable part of shear strength gain was occurred within the very beginning of the test.

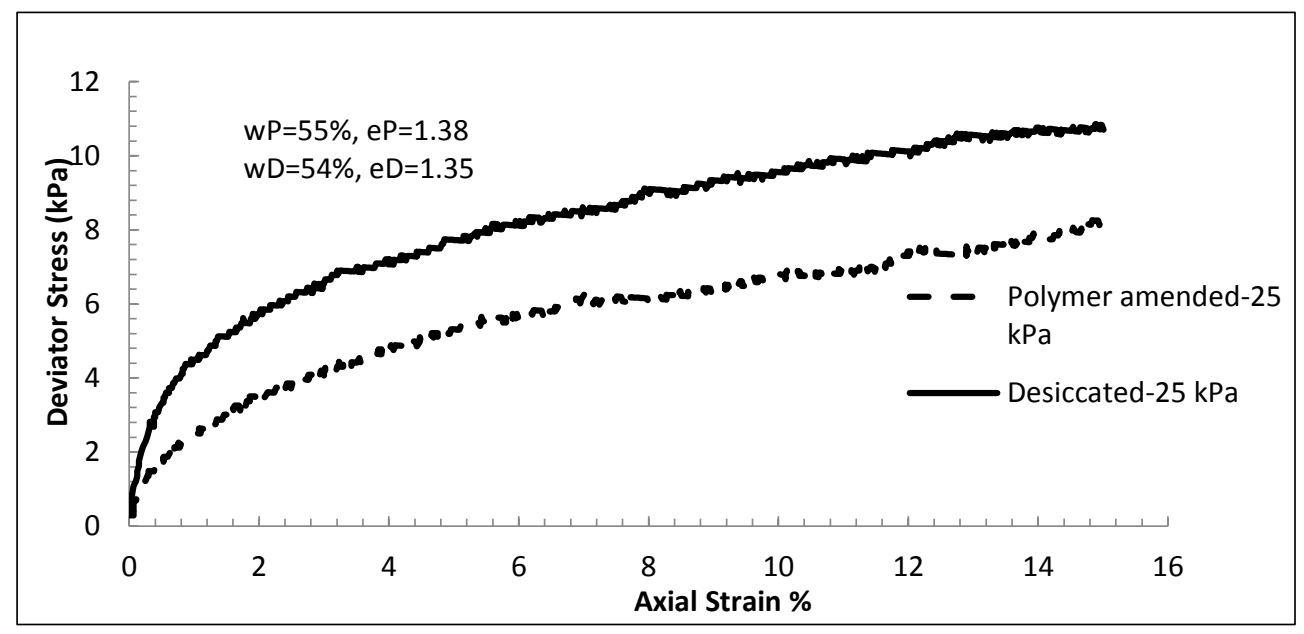



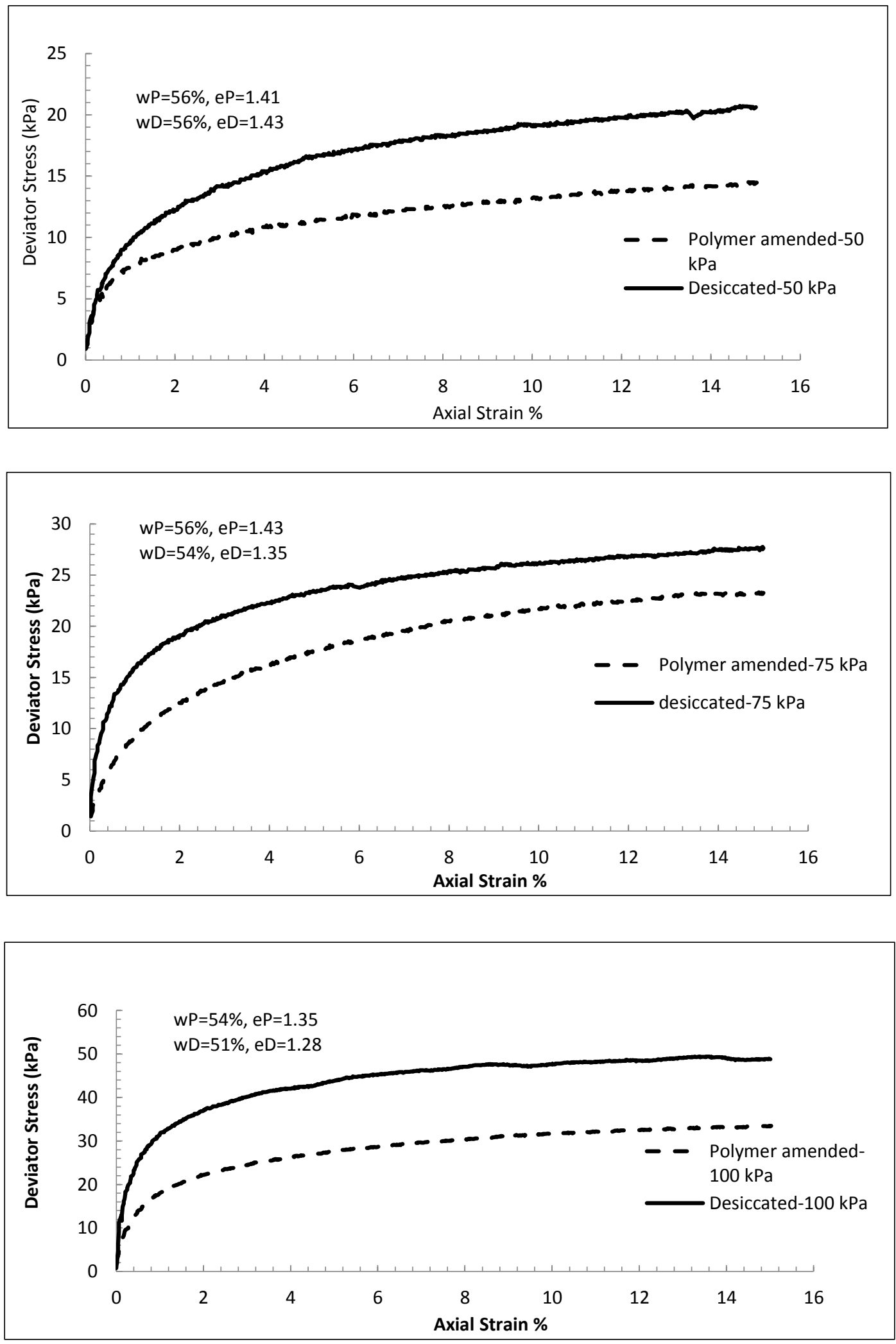

Figure 5-7. Comparison of triaxial results at effective stress level of a) $25 \mathrm{kPa}$, b) $50 \mathrm{kPa}, \mathrm{c}$ ) $75 \mathrm{kPa}$, d) $100 \mathrm{kPa}$ 
Table 5.1. Shearing characteristic-consolidated amended MFT

\begin{tabular}{|l|l|l|l|}
\hline Stress Level & $\begin{array}{c}\text { Shear } \\
\text { strength } \\
\mathbf{( k P a )}\end{array}$ & $\begin{array}{l}\mathbf{5 0 \%} \text { of shear srength (kPa) } \\
\text { and the corresponding strain }\end{array}$ & $\begin{array}{l}\text { Shear strength }(\mathbf{k P a}) \text { at } \\
\text { axial strain of 7.5\% }\end{array}$ \\
\hline 25 & 4.1 & $2.1 @ 3 \%$ & 3.1 \\
\hline 50 & 7.2 & $3.6 @ 0.8 \%$ & 6.2 \\
\hline 75 & 12.4 & $6.2 @ 0.6 \%$ & 10 \\
\hline 100 & 16.5 & $8.3 @ 0.8 \%$ & 14.5 \\
\hline
\end{tabular}

Table 5.2. Shearing characteristic-Desiccated amended MFT

\begin{tabular}{|c|c|c|c|}
\hline Stress Level & $\begin{array}{c}\text { Shear } \\
\text { strength } \\
\text { (kPa) }\end{array}$ & $\begin{array}{l}50 \% \text { of shear srength }(\mathrm{kPa}) \\
\text { and the corresponding strain }\end{array}$ & $\begin{array}{c}\text { Shear strength }(\mathrm{kPa}) \text { at } \\
\text { axial strain of } 7.5 \%\end{array}$ \\
\hline 25 & 5.4 & $2.7 @ 1.71 \%$ & 4.3 \\
\hline 50 & 10.3 & $5.1 @ 1.2 \%$ & 9.1 \\
\hline 75 & 13.5 & $6.2 @ 1.98 \%$ & 10 \\
\hline 100 & 24.4 & $12.2 @ 0.4 \%$ & 23.2 \\
\hline
\end{tabular}

\subsection{Comparison of tariaxial and simple shear results}

\subsubsection{Stress-strain relationship}

The results of stress-strain relationship from triaxial tests and simple shear tests for all desiccated and consolidated amended MFT are compared in Figure 5-9 and Figure 5-10. In order to make the comparison, the shear strain from simple shear test converted to axial strain. It is shown that those specimens that were tested in simple shear had higher strength compared to samples from triaxial tests at a given effective stress level (consolidation pressure). Nonetheless, the disperancy in the shear strength value were more tangible at higher effective stress levels. To quantify and illustrate the difference, Table 5.3 summarizes the maximum devitor stress at a given consolidation pressure for triaxial tests as well as the shear strength of samples at shear strain of $12 \%$ from simple shear.

Beier et al. (2013) analyzed shear strength behaviour of oil sand fine tailings using undrained shear strength filed data from vane shear tests. The author showed that polymer ameneded MFT might exhibit characteristics of sensitive, metastable deposits, even if regulatory strength requirements are met. In fact, sensivity arised due to considerable differences in peak and residual shear strength values in undrained strength graph (Figure 5-8). Nonetheless, results of 
the current study show that polymer amended MFT achieving/approaching steady value of shear strength in simple shear and triaxial at least after consolidation process.

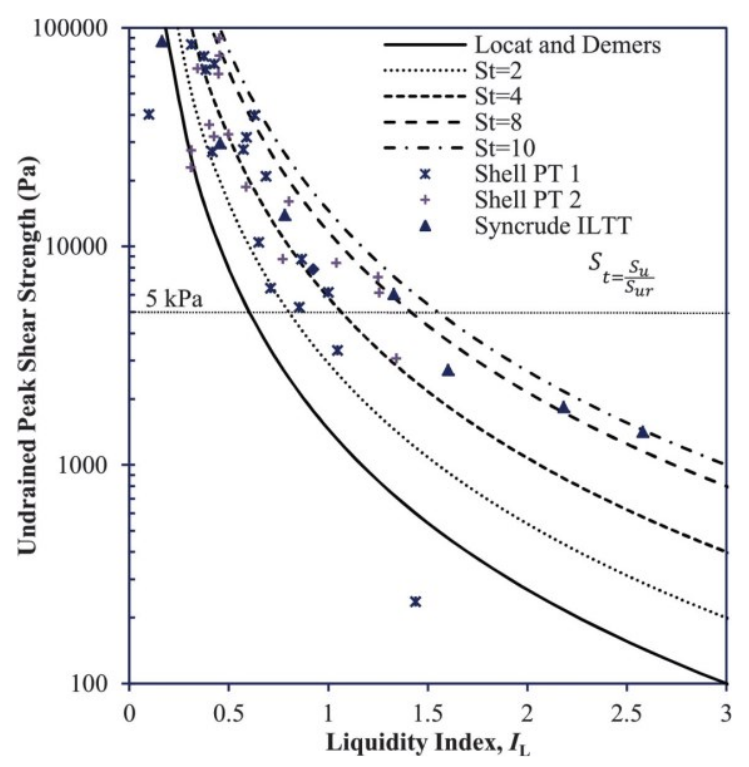

Figure 5-8-Su-sensitivity of oil sands fine tailings.

\subsubsection{Shear stress-void ratio}

Shear stress-void ratio relationship for both triaxial and simple shear are compared in Figure 511. Simple shear showed stronger response compared to triaxial at a given void ratio. However, void ratio values are different at a given stress level. This may be due to the difference in consolidation process. In fact, samples experience $\mathrm{K}_{0}$ consolidation within simple shear while undergo isotropic consolidation within triaxial. It should be note that differences between simple shear and triaxial might be due to non-uniformity of the triaxial samples. Furthermore, as the desiccated samples from both triaxial and simple shear are more similar, the differences may be due to the variation in density in the consolidated amended samples.

This same data is compared with field measurements of vane tests on MFT samples and peak undrained strength measured in polymer amended tailings shown in Beier et al. (2013). The comparison is shown in Figure 5-12. Interestingly, all the laboratory results plot relatively close to the MFT line rather than the polymer amended line. This indicates that the element tests measure closer to the residual or innate strength of the material. This may have to do with the shear rate in the element tests versus the field vane measurements - this issue deserves further investigation. 

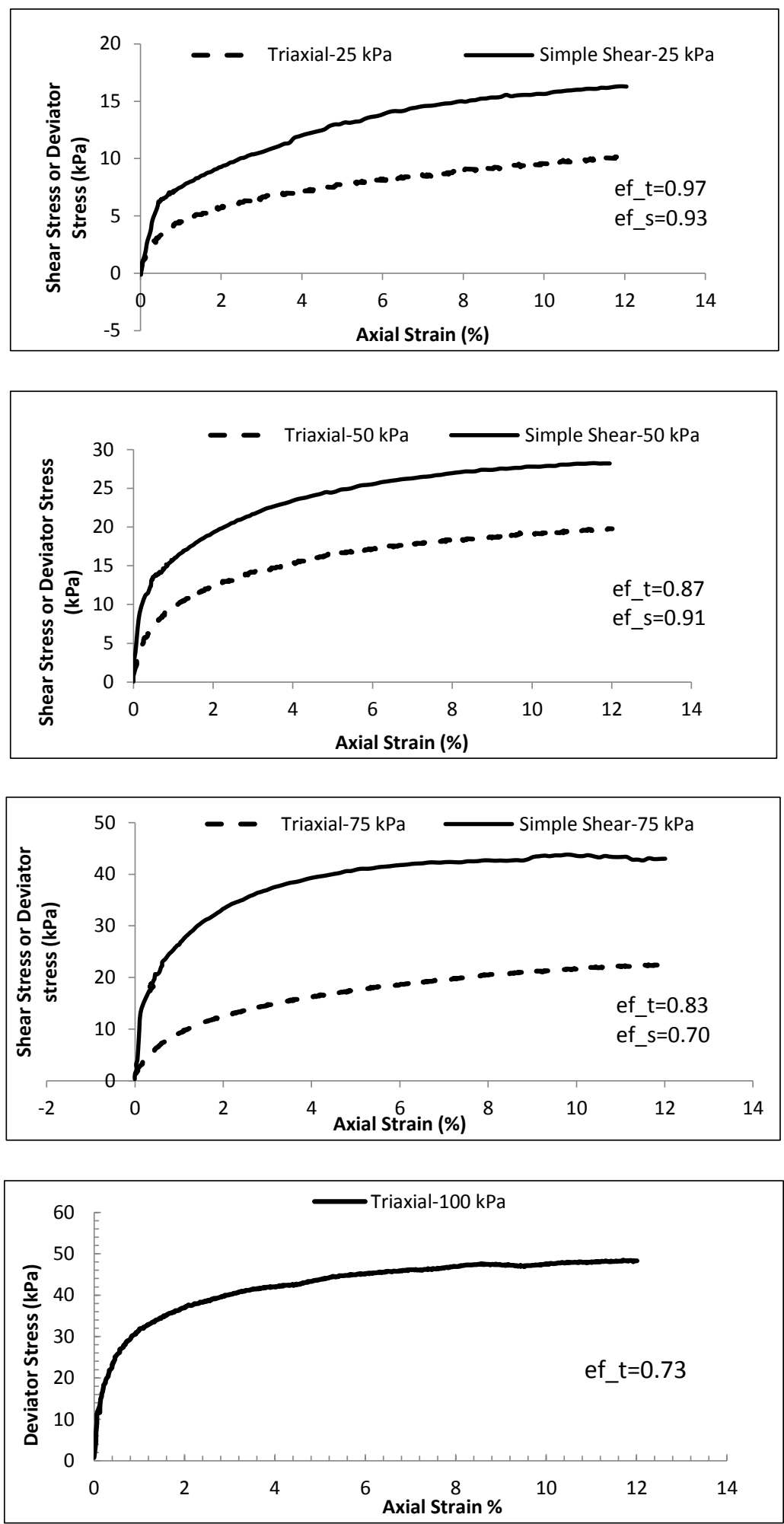

Figure 5-9. Stress-Strain comparison in simple shear and triaxial Desiccated amended MFT 

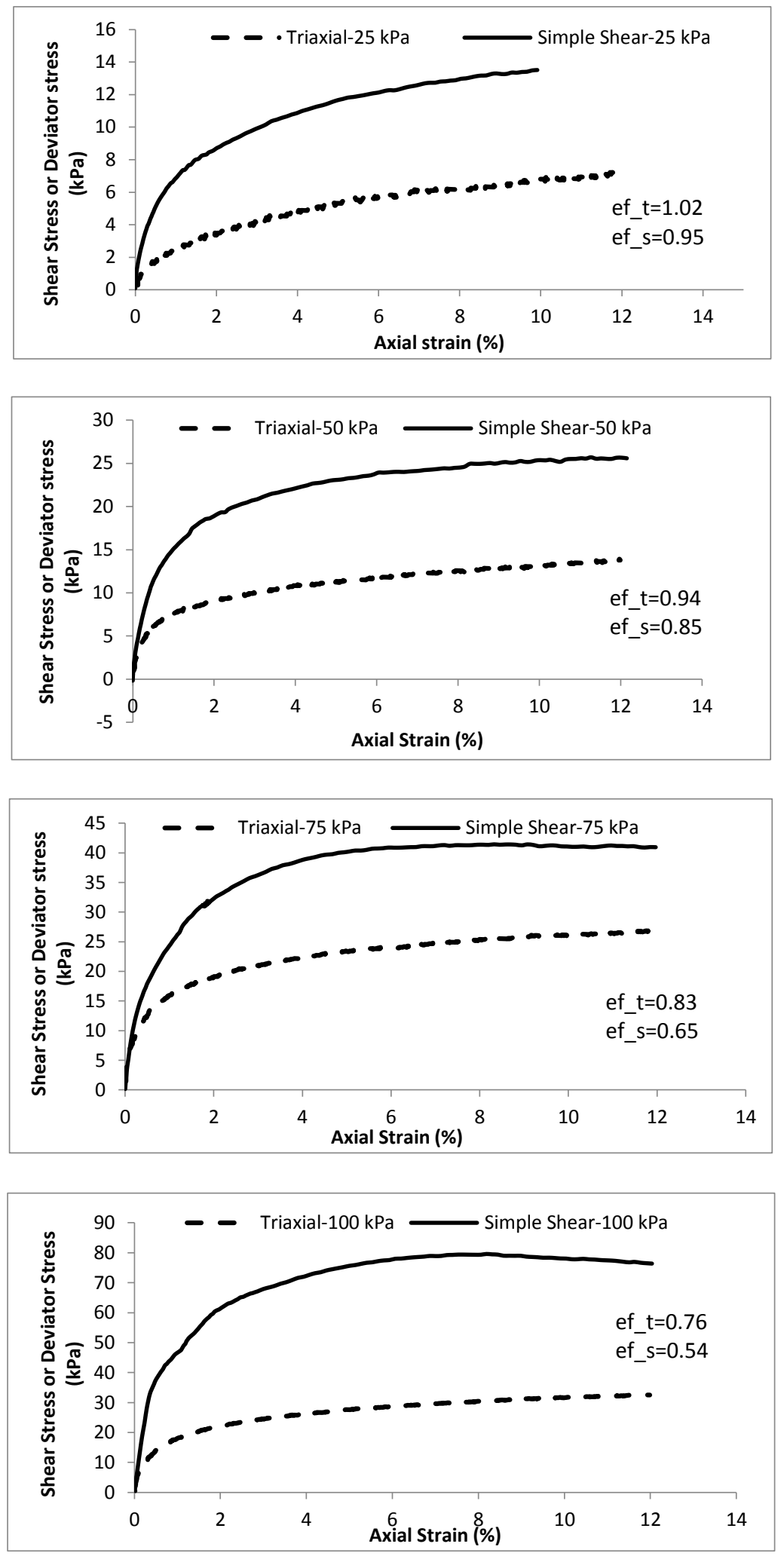

Figure 5-10. Stress-Strain comparison in simple shear and triaxial consolidated amended MFT 
Table 5.3.Comparison of Shear stress values-Consolidated amended samples

\begin{tabular}{|c|c|c|c|c|}
\hline & \multicolumn{4}{|c|}{ Consolidation Pressure (kPa) } \\
\hline & 25 & 50 & 75 & 100 \\
\hline Shear stress (12\%) & 4.12 & 7.2 & 11.5 & 16.6 \\
\hline$\tau(12 \%)$ & 13.5 & 25.7 & 40.9 & 76.4 \\
\hline
\end{tabular}

$\tau(12 \%)$ : Shear strength at shear strain of $12 \%$

Table 5.4.Comparison of Shear stress values-Desiccated amended samples

\begin{tabular}{|l|l|l|l|l|}
\hline & \multicolumn{4}{|c|}{ Consolidation Pressure (kPa) } \\
\hline & 25 & 50 & 75 & 100 \\
\hline Shear stress $(12 \%)$ & 5.3 & 10.3 & 13.8 & 24.2 \\
\hline$\tau(12 \%)$ & 16.3 & 28.2 & 43.0 & - \\
\hline
\end{tabular}

$\tau(12 \%)$ : Shear strength at shear strain of $12 \%$

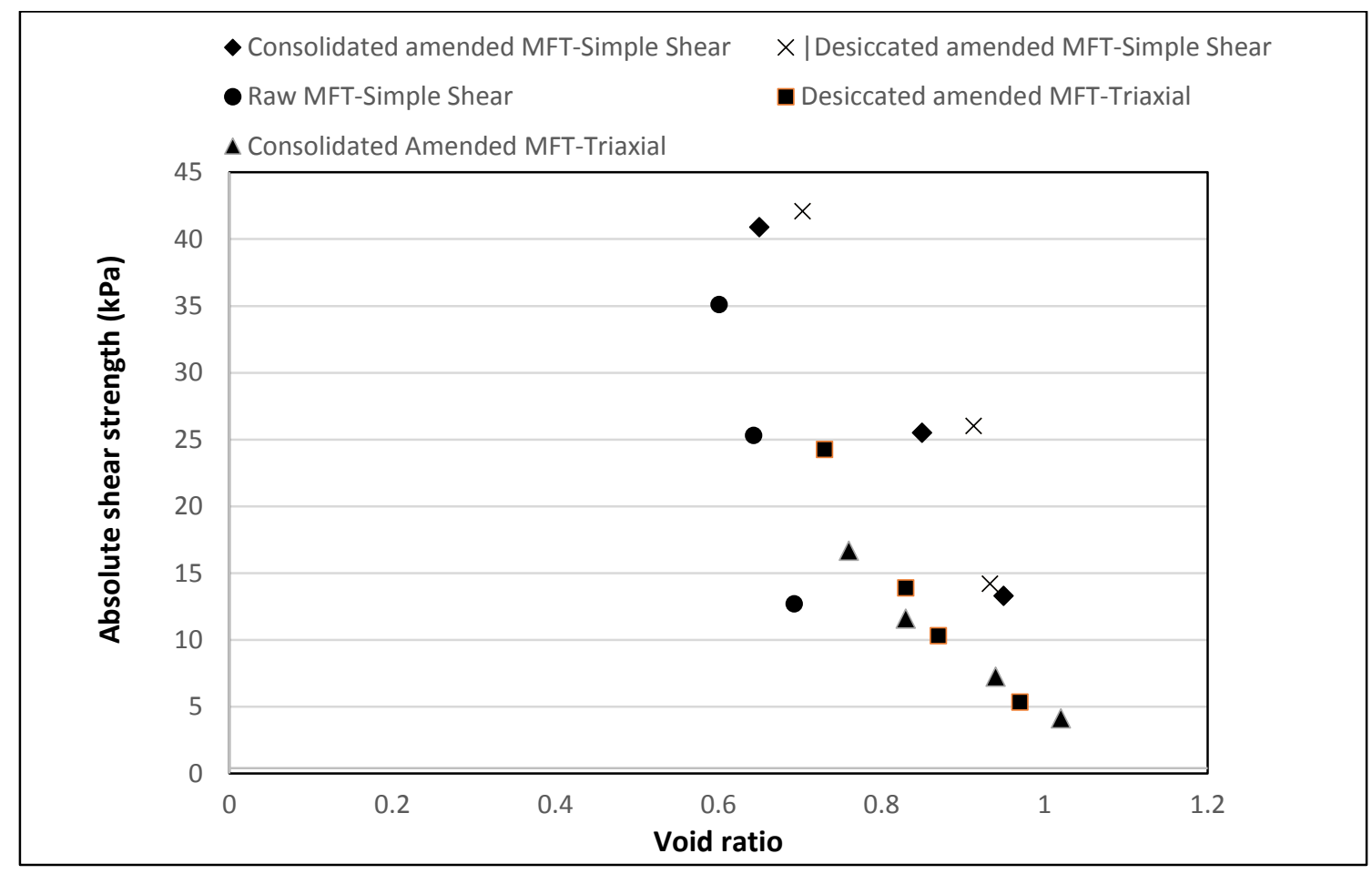

Figure 5-11- Comparison of shear stress-void ratio for triaxial and simple shear 


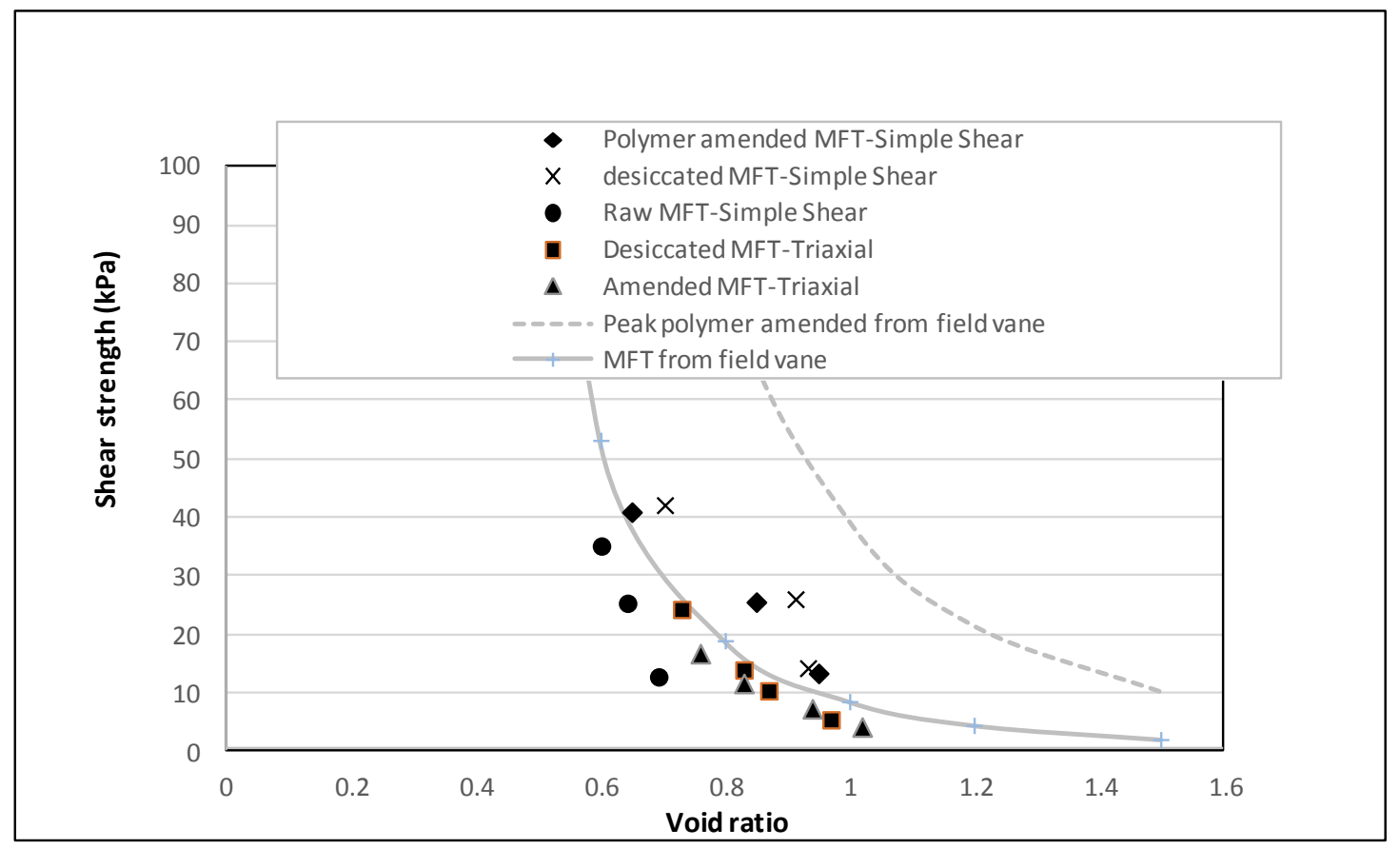

Figure 5-12- Comparison of element test shear strength to field vane data - lines best fits to data presented in Beier et al. (2013). 


\subsection{Conclusions}

Consolidation, simple shear and triaxial were conducted on polymer amended MFT, desiccated MFT as well as raw MFT. The following conclusions are obtained:

- In simple shear, raw MFT, consolidated polymer amended MFT, and desiccated polymer amended MFT samples all reached a constant value of shear stress, despite continuously increasing pore-water pressure.

- In simple shear, polymer amended tailings exhibited the same ratio of strength to consolidation pressure as raw MFT, but exhibited higher strength on a void ratio basis

- Similar to simple shear, the shear strength of amended MFT increased with increasing consolidation pressure in triaxial apparatus. However, amended MFT samples approached a constant value of shear strength rather than reaching a constant shear stress value.

- Triaxial samples exhibited substantial heterogeneity, even after consolidation. This probably cast significant doubt on the validity of the triaxial measurements.

- Simple shear showed stronger response compared to triaxial at a given void ratio. However, different values of void ratio were found in simple shear and triaxial at a given consolidation pressure. This might be due to different consolidation history that samples experienced ( $\mathrm{K} 0$ consolidation vs. isotropic consolidation).

\subsection{Recommendations for future study}

The main focus of this research was on experimental investigation including consolidation and shear strength of raw MFT as well as polymer amended MFT. The following measures are recommended for future studies:

- Investigating rate effects in both field vane and element test measurements for raw MFT and polymer amended MFT 
- Preparing and testing desiccated amended MFT at different degree of desiccation in order to investigate the influence of desiccation history on shear strength behaviour of oil sand fine tailings.

- $\quad$ Trying to find a better way to prepare more uniform triaxial samples

- Conducting simple shear and triaxial tests at effective stress levels higher than 100 $\mathrm{kPa}$ to examine if the influence of polymer on consolidation characteristic and shear strength improvement changes.

- Probing the sensitivity of the material further using cyclic tests.

- Conducting vane shear strength measurements in the field and in controlled laboratory experiments and comparing the results with laboratory shear strength findings from element tests. 


\section{References}

Abu-Hejleh, A., Znidarčić, D., and Barnes, B. 1996. Consolidation Characteristics of Phosphatic Clays. Journal of Geotechnical Engineering, 122(4): 295-301.

Åhnberg, H. 2006. Effects of consolidation stresses on the strength of some stabilised Swedish soils. Ground Improvement, Vol. 10, No. 1, pp. 1-13.

Airey, D. W., Budhu, M., and Wood, D. M., 1985. Some aspects of behaviour of soils in simple shear, Developments in Soil Mechanics and Foundation Engineering 2, Elsevier, London, England.

Airey, D.W., and Wood, D.M. 1987. An evaluation of direct simple shear tests on clay. Géotechnique, 37(1): 25-35.

Al-Tarhuni, M., 2008. Liquefaction and Post-liquefaction behavior of gold mine tailings under simple shear loading”, M.Sc. Thesis, Carleton University.

American Society for Testing and Materials, 1995. Designation: D4767, Standard test method for consolidated undrained triaxial compression test for cohesive soils. Annual Book of ASTM Standards, Vol 4 (8).

American Society for Testing and Materials, 2007. "Designation: D 6528-07, Standard Test Method for Consolidated Undrained Direct Simple shear Testing of Cohesive Soils," Annual Book of ASTM Standards, Vol. 4.09.

Azam, S., and Scott, J.D. 2005. Revisiting the Ternary Diagram for Tailings Characterization and Management. Geotechnical News. 43-46.Azam, 2011. Large Strain Settling Behavior of Polymer-Amended Laterite Slurries. International Journal of Geomechanics, 11(2): 105-112.

Bajwa, T., Simms, P., 2013. Influence of dewatering and desiccation on microstructure and vane strength of polymer amended oil sand mature fine tailings. In proceeding of 66th Canadian Geotechnical Conference (GeoMontreal). 
Beier, N., Wilson, W., Dunmola, A., and Sego, D., 2013. Impact of flocculation-based dewatering on the shear strength of oil sands fine tailings. Canadian Geotehnical Journal. 50: 1001-1007.

BGC Engineering Inc., 2010. Oil Sands Tailings Technology Review. Oil Sands Research and Information Network, University of Alberta, School of Energy and the Environment, Edmonton, Alberta. OSRIN Report No. TR-1. 136 pp

Bishop, A.W., 1971. Shear strength parameters for undisturbed and remolded soil specimens. Roscoe memorial Symposium, Cambridge University.

Bishop, A.W. and Henkel, D.J. 1962. The measurements of soil properties in the Triaxial tests. Second edition. Edward Arnold Ltd, London 1962.

Bjerrum, L., Landva, A., 1966. Direct simple shear tests on a Norwegian quick clay. Geotechnique, 16(1). 1-20.

Bowden, R. K. 1988. Compression behaviour and shear strength characteristics of a natural silty clay sedimented in the laboratory. Ph.D. thesis, Oxford University.

Bro, A.D., Stewart, J.P., Pradel, D., 2013. Estimating Undrained Strength of Clays from Direct Shear Testing at Fast Displacement Rates, Proceedings of ASCE Geocongress.

Budhu, M. 1984. Nonuniformities imposed by simple shear apparatus. Canadian Geotechnical Journal, 21(1). 125-137.CAPP. 2012. Crude oil forecast, markets and pipelines. Canadian Association of Petroleum Producers (CAPP), Calgary, Alberta. http://www.capp.ca/forecast/Pages/default.aspx. [Last accessed May 22, 2013].

Cargill, K.W. 1982. Consolidation of Soft Layers by Finite Strain Analysis. U.S. Army Engineer Waterways Experimentation Station. Vicksburg, Mississippi, Miscellaneous Paper GL-82-3.

Carrier, W. D. III, Bromwel, L. G., and Somogyi, F. 1983. Design capacity of slurried mineral waste ponds. ASCE Journal of Geotechnical Engineering, 109(5): 699-716. 
Castellanos, B.A. and Brandon, T.L. (2013) "A Comparison between the Shear Strength Measured with Direct Shear and Triaxial Devices on Undisturbed and Remolded Soils," Proceedings of the 18th International Conference on Soil Mechanics and Geotechnical Engineering, Paris, 317-320.

Castro, G. 1969, Liquefaction of sands. PhD Thesis, Harvard University, Cambridge, Massachusetts.

Canada's Oil Sands Innovation Alliance (COSIA), 2014. Guidelines for Performance Management of Oil Sands Fluid Fine Tailings Deposits to Meet Closure Commitments.

Daliri, F., 2013. The influence of desiccation and stress history on monotonic and cyclic shear response of thickened gold tailings. Ph.D. Thesis, Department of Civil and Environmental Engineering, Carleton University.

Davis, E. H. and Raymond, G. P. 1965. A Non-Linear Theory of Consolidation, Geotechnique, 15(2):161-173.

Devenny.D.W. 2010. A screening study of oil sand tailings technologies and practices. Prepared for Alberta energy research institute.

Dyvik, R., Berre, T., Lacasse, S., and Raadim, B., (1987), Comparison of truly undrained and constant volume direct simple shear tests, Geotechnique, Vol. 37(1), 3-10.

ERCB. 2011. A report on Regulatory Action in Alberta's Oil Sand. The Energy Resources Conservation Board of Alberta (ERCB), Calgary, Alberta. www.ercb.ca/reports/RegulatoryActioninAlbertasOilSands. [Last accessed May 22, 2013].

ERCB. 2009. Directive 074 Tailings Performance Criteria and Requirements for Oil Sands Mining Schemes. The Energy Resources Conservation Board of Alberta (ERCB), Calgary, Alberta. http://www.ercb.ca/regulations-and-directives/directives/directive074. [Last accessed May 22, 2013].

Fox, P. and Baxter, C. 1997. Consolidation Properties of Soil Slurries from Hydraulic Consolidation Test. Journal of Geotechnical Engineering, 123(8): 770-776. 
GDS. 2013. Introduction to Triaxial testing. GDS instuments. http://www.gdsinstruments.com. [Last accessed May 22, 2013].

Government of Alberta, 2011. Facts about Alberta's oil sands tailings management, Calgary, Alberta. http://www.oilsands.alberta.ca/facts.html. [Last accessed May 22, 2013].

Government of Alberta, 2012. Oil sands environmental management, Calgary, Alberta. http://www.oilsands.alberta.ca/facts.html. [Last accessed May 22, 2013].

Government of Alberta, 2012. Facts about Alberta's oil sands and its industry, Calgary, Alberta. http://www.oilsands.alberta.ca/facts.html. [Last accessed May 22, 2013].

Gan, J., Ebrahimi, B. N., and Haug, M. D. 2011. Consolidation and Hydraulic Conductivity Testing of Slurries. In Proceeding of Tailings and Mine Waste, Vancouver, BC, Canada.

Gibson, R. E., England, G. L., and Hussey, M. J. L. 1967. The theory of one-dimensional consolidation of saturated clays. Geotechnique, 17(3): 261-273.

Hanzawa, H., Nutt, N., Lunne, T., Tang, Y.X., and Long M. (2007). “A comparative study between the NGI direct simple shear apparatus and the Mikasa direct shear apparatus," Soils and Foundations, 47 (1), 47-58.

Hawlader, B. C., Muhunthan, B., and Imai, G., 2008. State-dependent constitutive model and numerical solution of self-weight consolidation. Ge'otechnique 58(2): 133-141

Huerta, A., Kriegsmann, G. A., and Krizek, R. J. 1988. Permeability and compressibility of slurries from seepage-induced consolidation. Journal of Geotechnical Engineering, ASCE, 114(5), 614-627.

Imai, G. 1979. Development of a new consolidation test procedure using seepage force. Soils and Foundations. 19(3): 45-59.

Imai, G. 1981. Experimental studies on sedimentation mechanism and sediment formation of clay materials. Soils and Foundations. 21(1): 7-20. 
Jeeravipoolvarn, S., 2008. Deposition of In-Line Thickened Fine Tailings. $1^{\text {st }}$ International Oil Sands Tailings Conference, Edmonton, Alberta.

Jeeravipoolvarn, S., 2010. Geotechnical Behavior of In-Line Thickened Oil Sands Tailings. Ph.D. Thesis, Department of Civil and Environmental Engineering, University of Alberta.Kim, Y., 2009. Static Simple shear characteristics of Nak-dong River clean sand. KSCE Journal of Civil Engineering. 13(6):389-401. DOI 10.1007/s12205-009-0389-9.

Kim H., F., Simms P. and Sivathayalan S., 2011. The influence of desiccation and overconsolidation on monotonic and cyclic shear response of thickened gold tailings. Proceedings of the 64th Canadian Geotechnical Conference, Toronto, Canada.

Kynch, G. J. 1952. A theory of sedimentation. Transactions of Faraday Society, 48, 166-176.

Ladd, CC. and Foot, R. (1974). New design procedure for stability of soft clays. ASCE Journal of the Geotechnical Engineering Division. Vol 100, No GT7, pp 763-786.

Lahaie, R., 2008. Syncrude Canada Ltd. - New tailings concepts. $1^{\text {st }}$ International Oil Sands Tailings Conference, Edmonton, Alberta.

Larsson, R., 1977. Basic behaviour of Scandinavian soft clays. Swedish Geotechnical Institute, Report No 4. Linköping.

Liu J.C., AND Znidarčić, D., 1991. Modeling one dimensional compression characteristics of soils. Journal of Geotechnical Engineering.117 (1):162-169.

Lofroth, H., 2008. Undrained shear strength in clay slopes; Influence of stress conditions. Ph.D. Thesis. Department of Civil and Environmental Engineering, Chalmers University of Technology.

Masliyah, J., 2009. Course notes of fundamentals of oil sands extraction, University of Alberta.

Matthews, J.G., Shaw, W.H., MacKinnon, M.D. and Cuddy, R.G., 2000. Development of composite tailings technology at Syncrude Canada. Environmental Issues and Management of Waste in Energy and Mineral Production, Calgary, Alberta. A.A. Balkema, Rotterdam. 
Mizani, S., Soleimani, S., Simms, P. (2013) Effects of polymer dosage on dewaterability, rheology, and spreadability of polymer-amended mature fine tailings, in Proceedings 16th International Seminar on Paste and Thickened Tailings (Paste 13).

Powter, C., 2012. Oil sands tailings: A liquid problem or a solids problem. 3rd International Oil Sands Tailings Conference, Edmonton, Alberta, Canada.

Priestley, D., 2012. Modeling multidimensional large strain consolidation of tailings. M.Sc. Thesis, Department of Mining Engineering, University of British Columbia.

Proskin, S., Sego, D., and Alostaz, M., 2012. Oil Sands MFT Properties and Freeze-Thaw Effects. Journal of Cold Regions Engineering, 26 (2): 29-54.

Qiu, Y., and Sego, D.C., 1999. Behaviour of sub-aerial deposited tailings and design of subaerial deposition in arid regions. In the Proceeding of Sixth annual tailings and mine waste conference, Colorado State University, Colorado, USA.

Roscoe, K. H. 1953. An apparatus for the application of simple shear to soil samples. Proceedings, 3rd International Conference on Soil Mechanics and Foundation Engineering, Zurich.

Saada, A.S., Townsend, F.C., 1981. State of the art: Laboratory strength testing of soils, American Society for Testing Materials, ASTM STP, 740 (1981), pp. 7-77.

Saada, A. S. , Fries, G. , and Ker, C. C. 1982. "An evaluation of laboratory testing techniques in soil mechanics."Soils and Found. , 23 (2 ), 381-395.

Simms, P.H, and Grabinsky, M.W. 2004. A simple method for estimating rates of drying and desaturation of paste tailings during surface deposition. Proceedings of the 11th annual conference on Tailings and Mine Waste: 287-292.

Simms, P.H., Grabinsky, M.W., and Zhan, G. 2007. Modelling evaporation of paste tailings from the Bulyanhulu mine. Canadian Geotechnical Journal, 44(12): 1417-1432. Sivathayalan, S., 
1994. Static, cyclic and liquefaction simple shear response of sands. M.A.Sc. Thesis. University of British Columbia.

Skempton, A. W., 1964. Long-term stability of clay slopes. Géotechnique, 14(2), 77-102.

Skempton A. W., Petley D. J., 1967., The shear strength along structural discontinuities in stiff clays, In Proceedings of the Geotechnical Conference, Oslo, pp 29-46.

Sobkowicz, J., 2012. Oil sands tailings technology deployment roadmap. Alberta InnovatesEnergy and Environment Solutions. Project Report, Volume 2, component 1 results.

Sridharan, A., Nagaraj, H.B., 2000. Compressibility behaviour of remoulded, fine-grained soils and correlation with index properties. Canadian Geotechnical Journal, 37 (3): 712-722.

Stark, T. D., Choi, H., and Schroeder, P. R. 2005. Settlement of dredged and contaminated material placement areas. II: Primary consolidation, secondary compression, and desiccation of dredged fill input parameters. Journal of Waterway, Port, Coastal, Ocean Engineering, 131(2): $52-61$.

Sworska A., Laskowski, J.S., and Cymerman, G., 2000. Flocculation of the Syncrude fine tailings: Part I. Effect of $\mathrm{pH}$, polymer dosage and $\mathrm{Mg}^{2+}$ and $\mathrm{Ca}^{2+}$ cations. International Journal of Mineral Processing, 60: 143-152.

Thomas, J., 1992. Static, cyclic and post liquefaction undrained behaviour of Fraser River sand. M.A.Sc Thesis, University of British Columbia.

Townsend, F. and McVay, M. 1990. SOA: Large Strain Consolidation Predictions. Journal of Geotechnical Engineering, 116(2), 222-243.

Williams, H.S., 2001. Development of a true Triaxial apparatus for soil testing. M.Sc. Thesis, Department of Civil and Environmental Engineering, Louisiana State University.

Yuan, S. and Shaw, W. 2007. Novel Processes for Treatment of Syncrude Fine Transition and Marine Ore Tailings. Canadian Metallurgical Quarterly, 46(3): 265-272. 
$\mathrm{Xu}$, Y., T. Dabros and J. Kan, 2008. Filterability of oil sands tailings. Process Safety and Environmental Protection 86(4): 268-276. 
7 Appendix 


\subsection{Simple shear results}
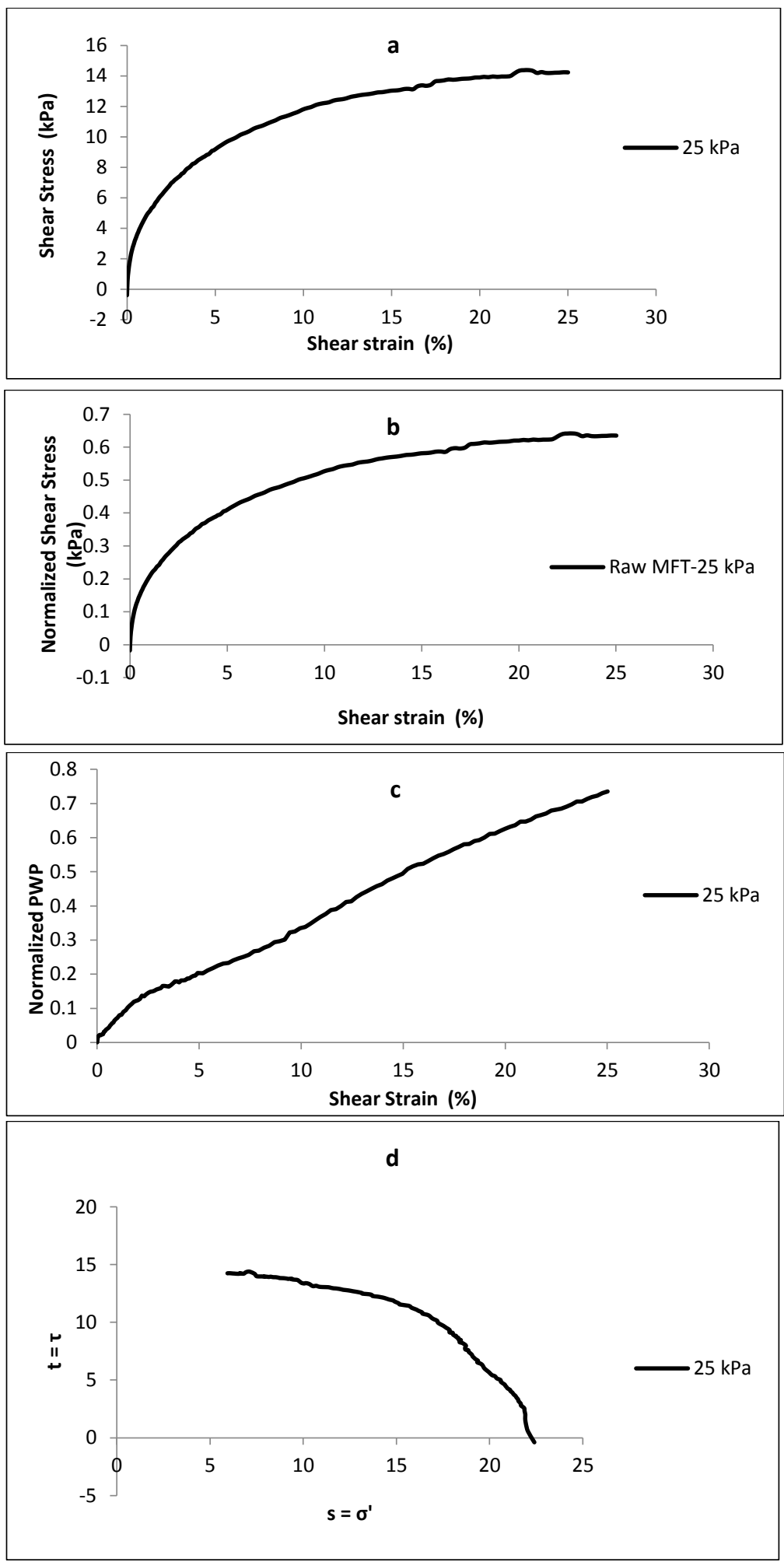

Figure 7-1.Raw MFT behaviour during shearing ( $25 \mathrm{kPa})$ - a) shear stress vs. shear strain, b) Normalized shear stress vs. shear strain, c) Normalized pore water pressure, d) stress path 

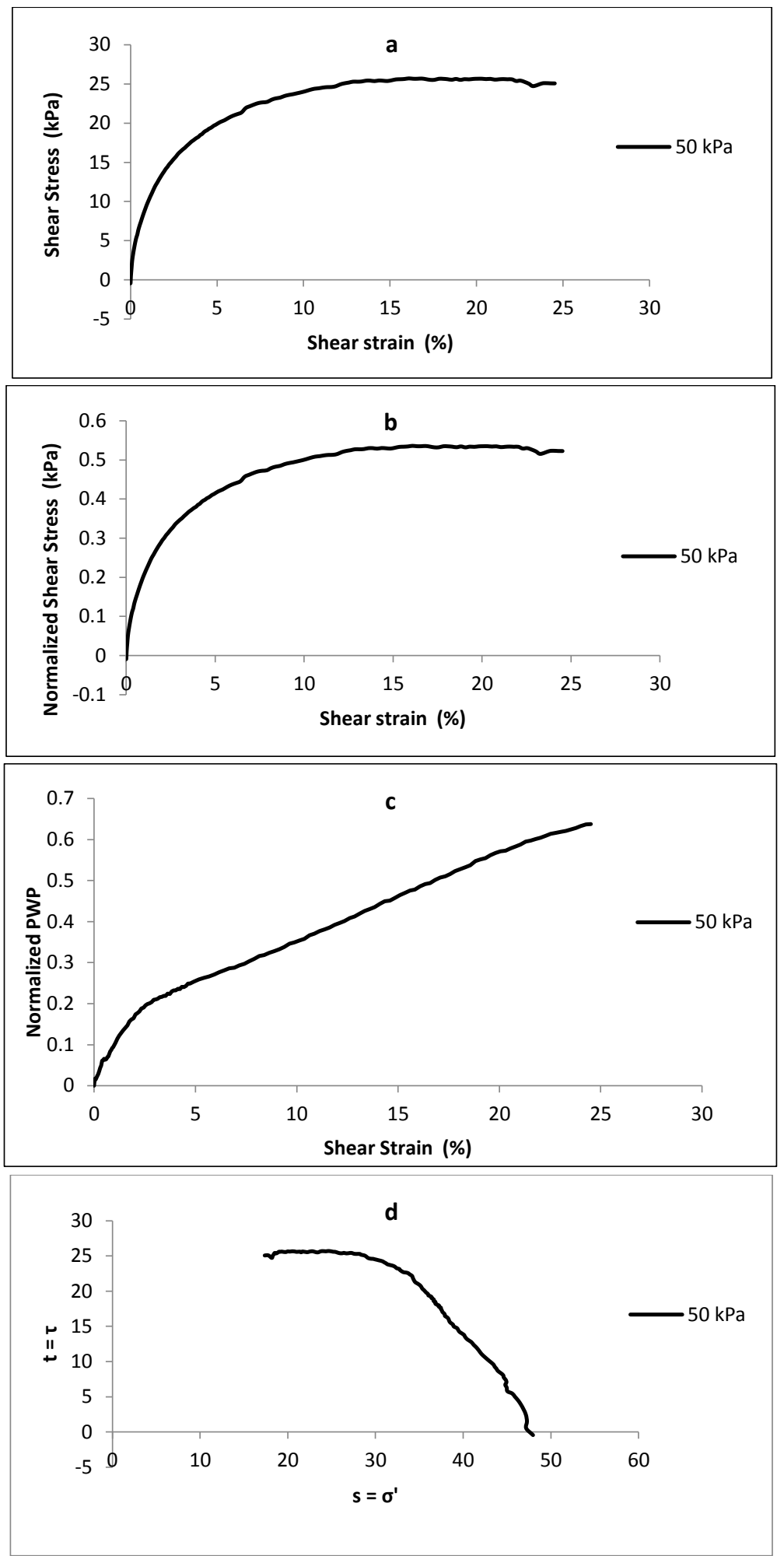

Figure 7-2.Raw MFT behaviour during shearing (50 kPa)- a) shear stress vs. shear strain, b) Normalized shear stress vs. shear strain, c) Normalized pore water pressure, d) stress path 

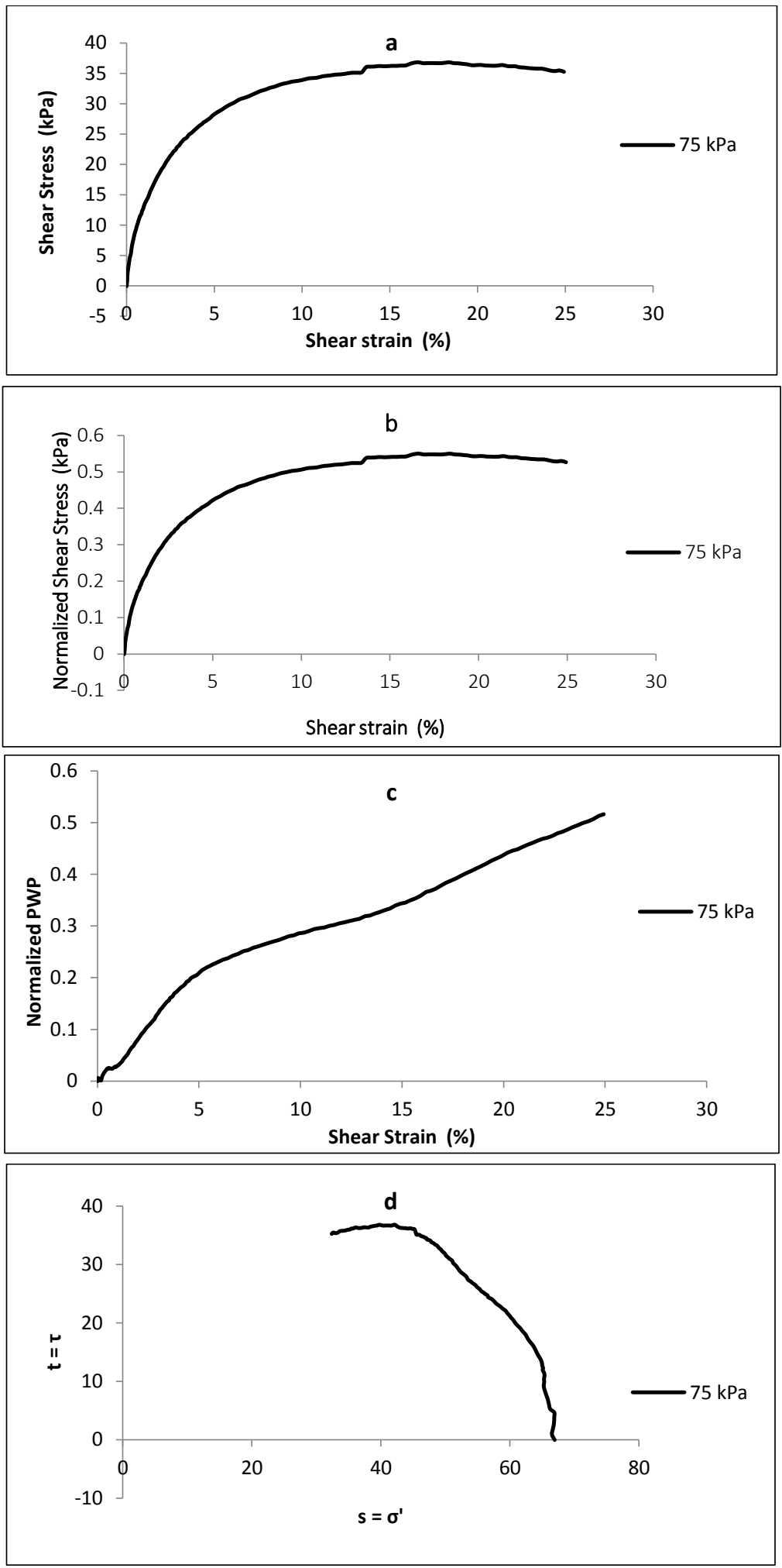

Figure 7-3.Raw MFT behaviour during shearing ( $75 \mathrm{kPa})$ - a) shear stress vs. shear strain, b) Normalized shear stress vs. shear strain, c) Normalized pore water pressure, d) stress path 

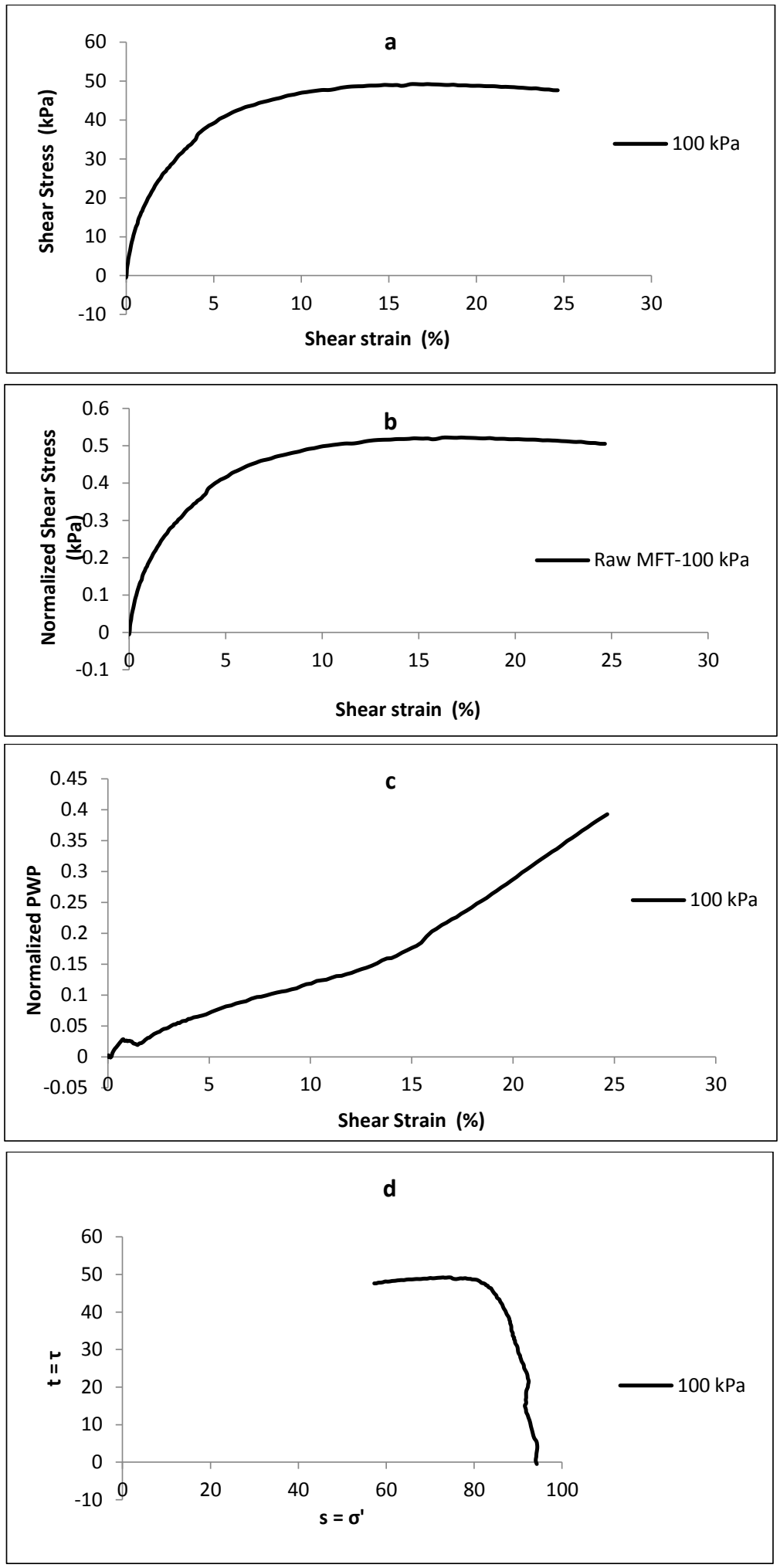

Figure 7-4.Raw MFT behaviour during shearing (100 kPa)- a) shear stress vs. shear strain, b) Normalized shear stress vs. shear strain, c) Normalized pore water pressure, d) stress path 

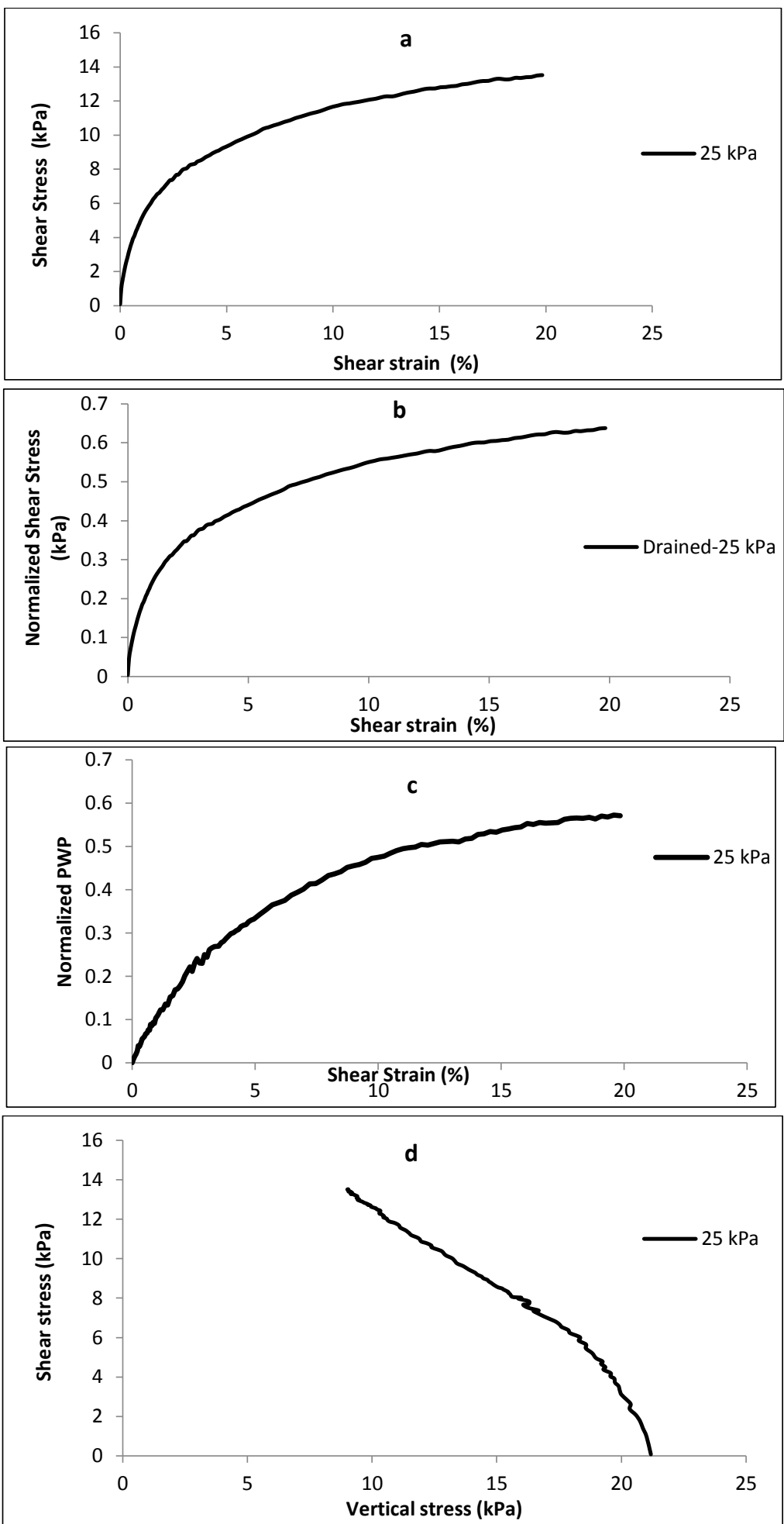

Figure 7-5.Consolidated amended MFT behaviour during shearing (25 kPa)- a) shear stress vs. shear strain, b) Normalized shear stress vs. shear strain, c) Normalized pore water pressure, d) stress path 

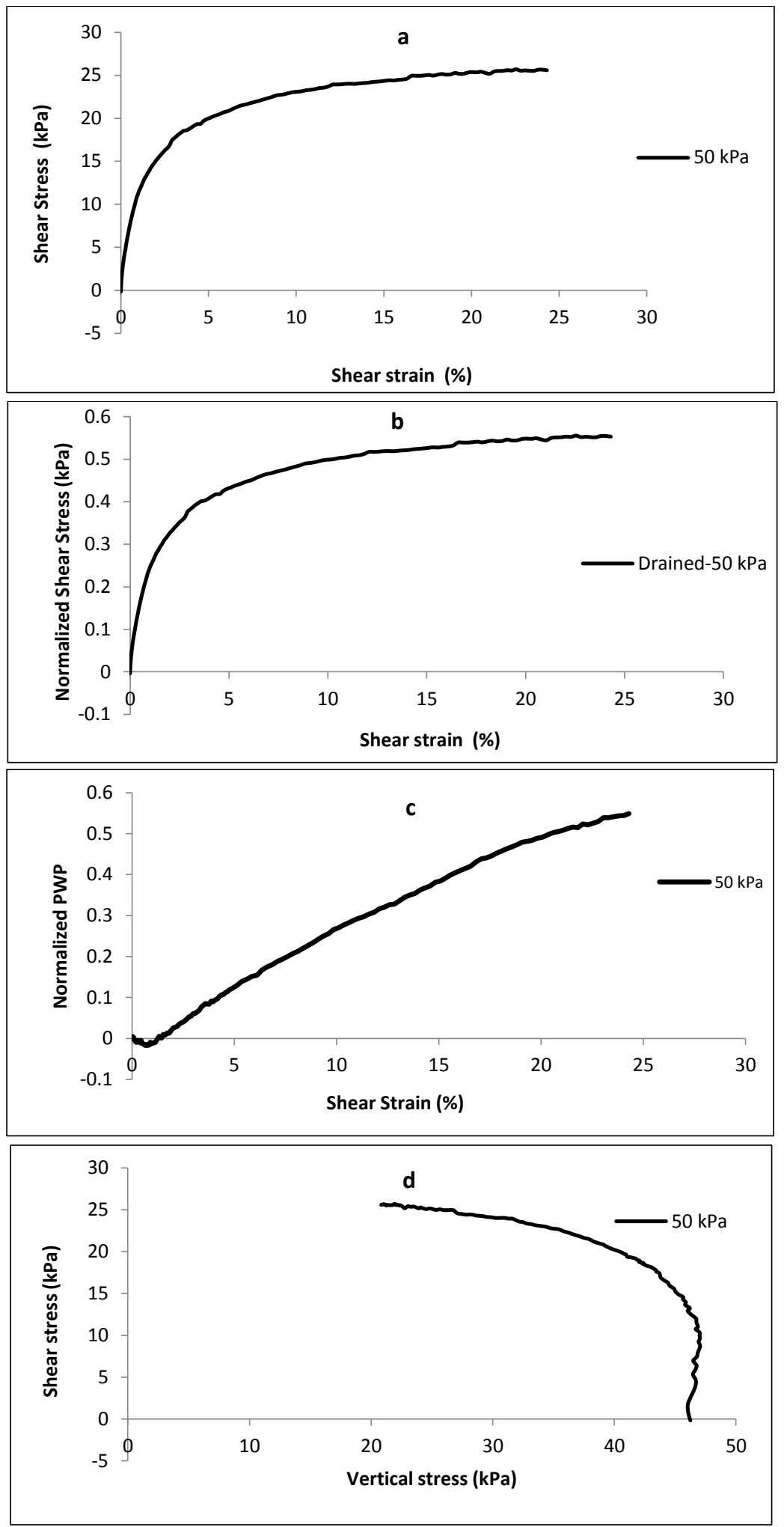

Figure 7-6. Consolidated amended MFT behaviour during shearing (50 kPa)- a) shear stress vs. shear strain, b) Normalized shear stress vs. shear strain, c) Normalized pore water pressure, d) stress path 

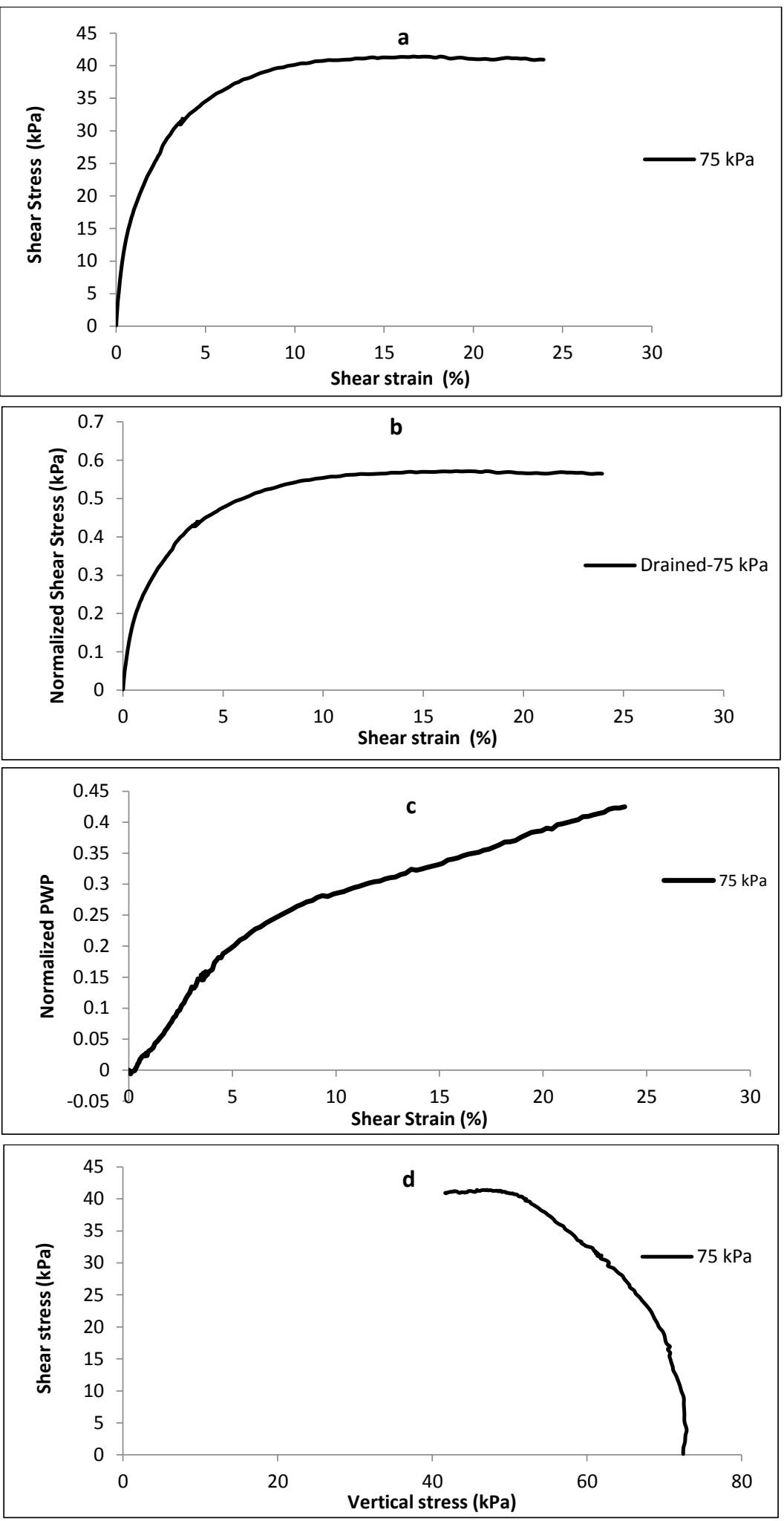

Figure 7-7. Consolidated amended MFT behaviour during shearing (75 kPa)- a) shear stress vs. shear strain, b) Normalized shear stress vs. shear strain, c) Normalized pore water pressure, d) stress path 

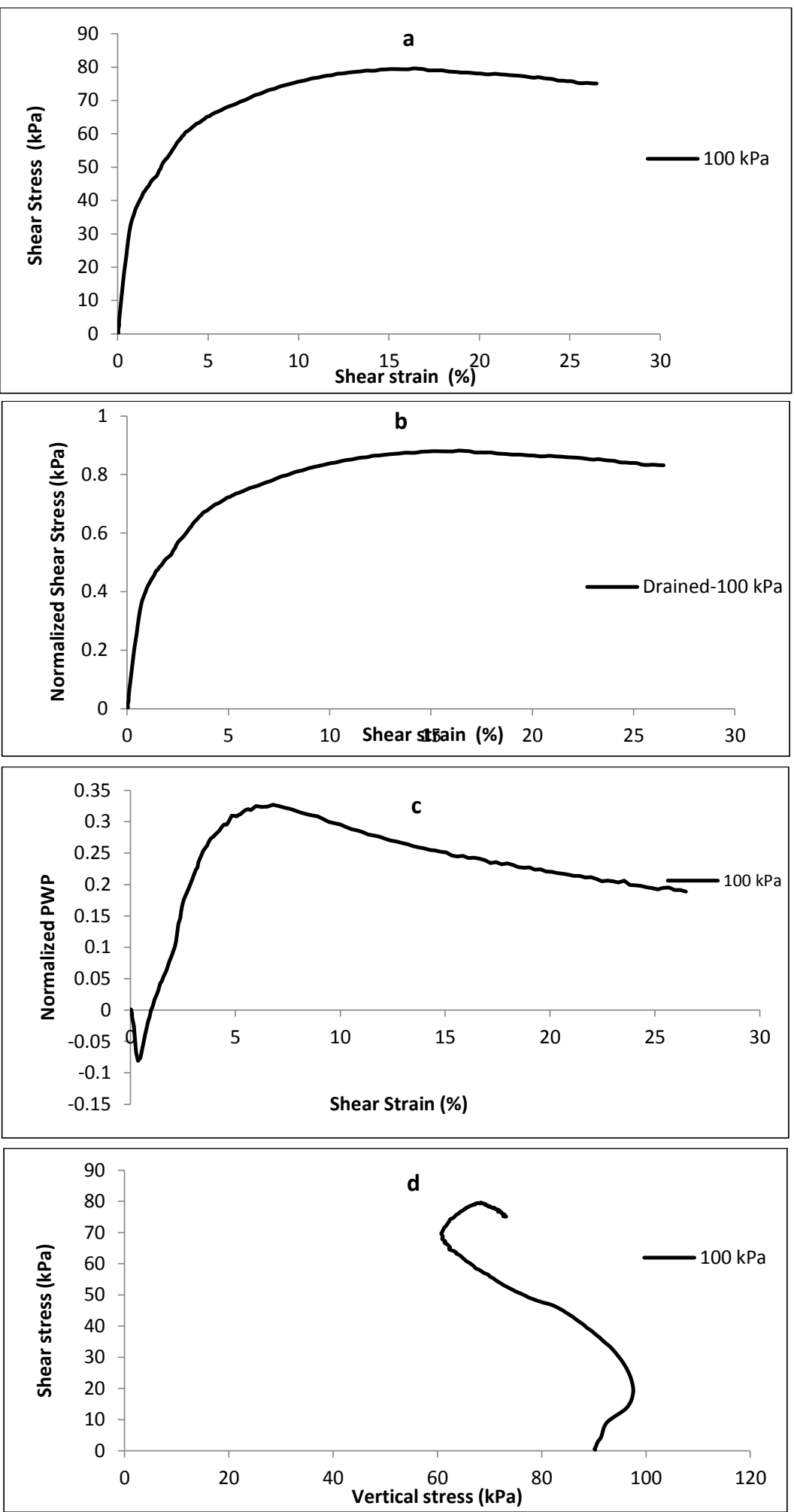

Figure 7-8. Consolidated amended MFT behaviour during shearing (100 kPa)g- a) shear stress vs. shear strain, b) Normalized shear stress vs. shear strain, c) Normalized pore water pressure, d) stress path 

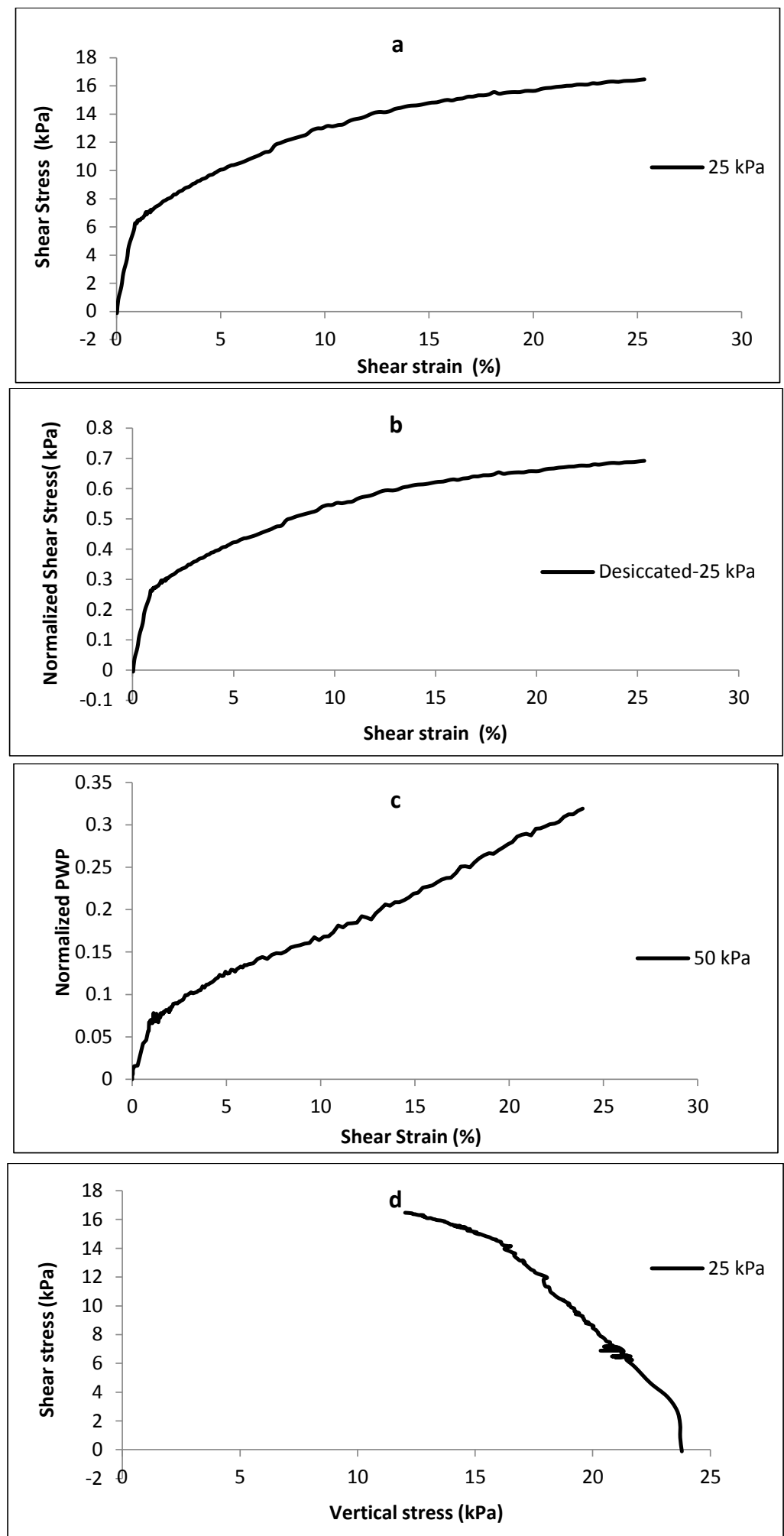

Figure 7-9.Desiccated MFT behaviour during shearing (25 kPa)- a) shear stress vs. shear strain, b) Normalized shear stress vs. shear strain, c) Normalized pore water pressure, d) stress path 

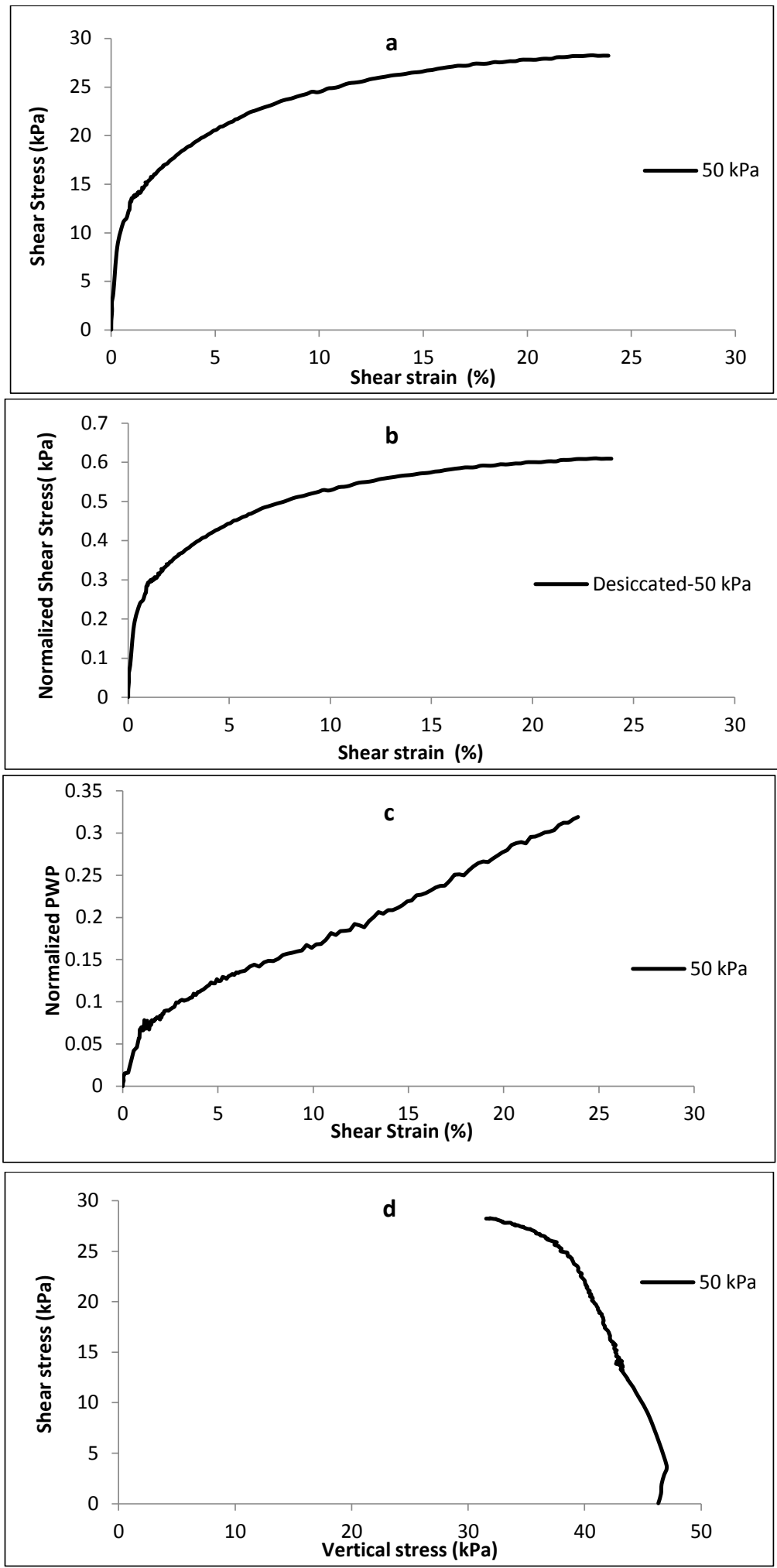

Figure 7-10.Desiccated MFT behaviour during shearing(50 kPa)- a) shear stress vs. shear strain, b) Normalized shear stress vs. shear strain, c) Normalized pore water pressure, d) stress path 

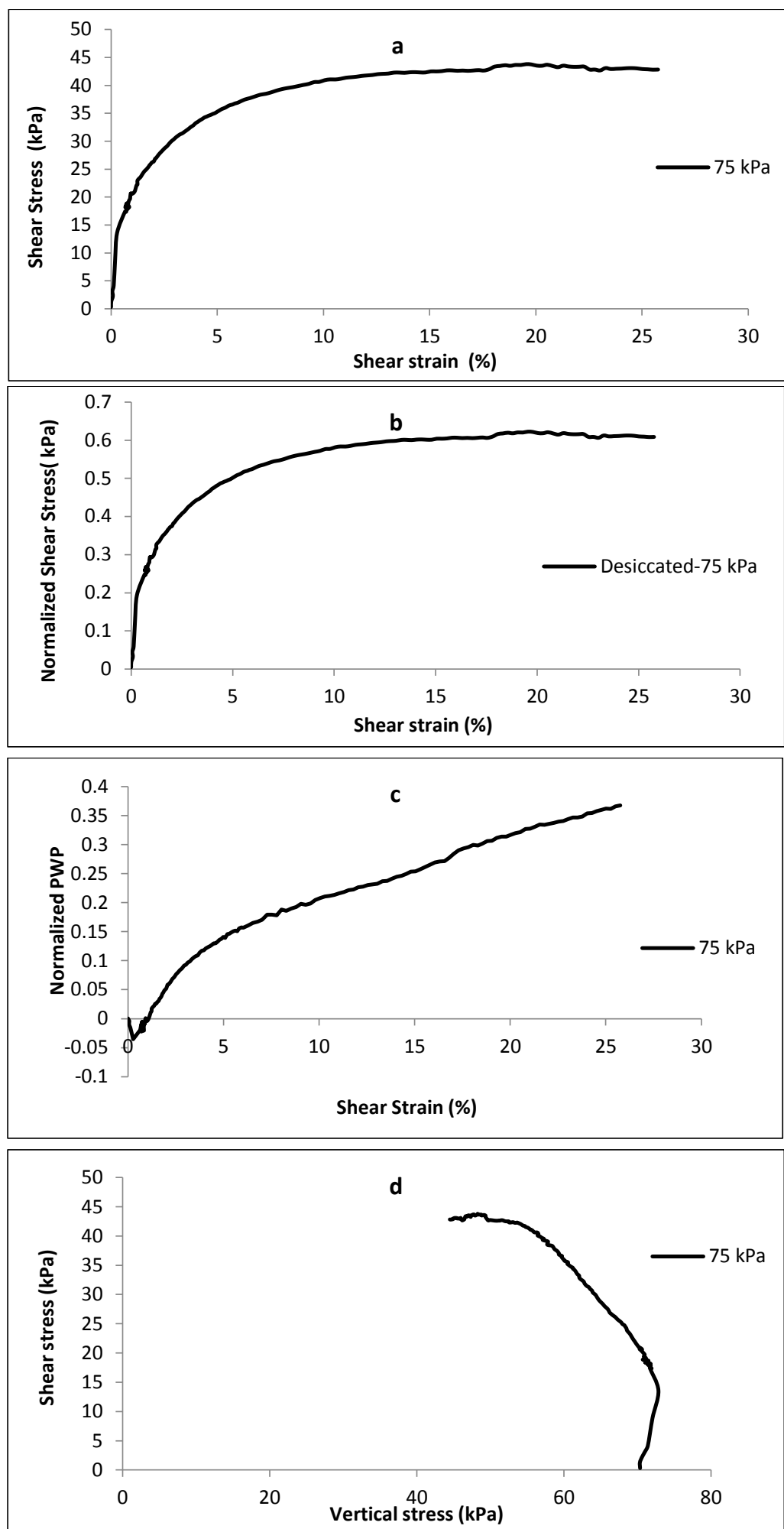

Figure 7-11.Desiccated MFT behaviour during shearing ( $75 \mathrm{kPa})$ - a) shear stress vs. shear strain, b) Normalized shear stress vs. shear strain, c) Normalized pore water pressure, d) stress path 


\section{2 triaxial results}
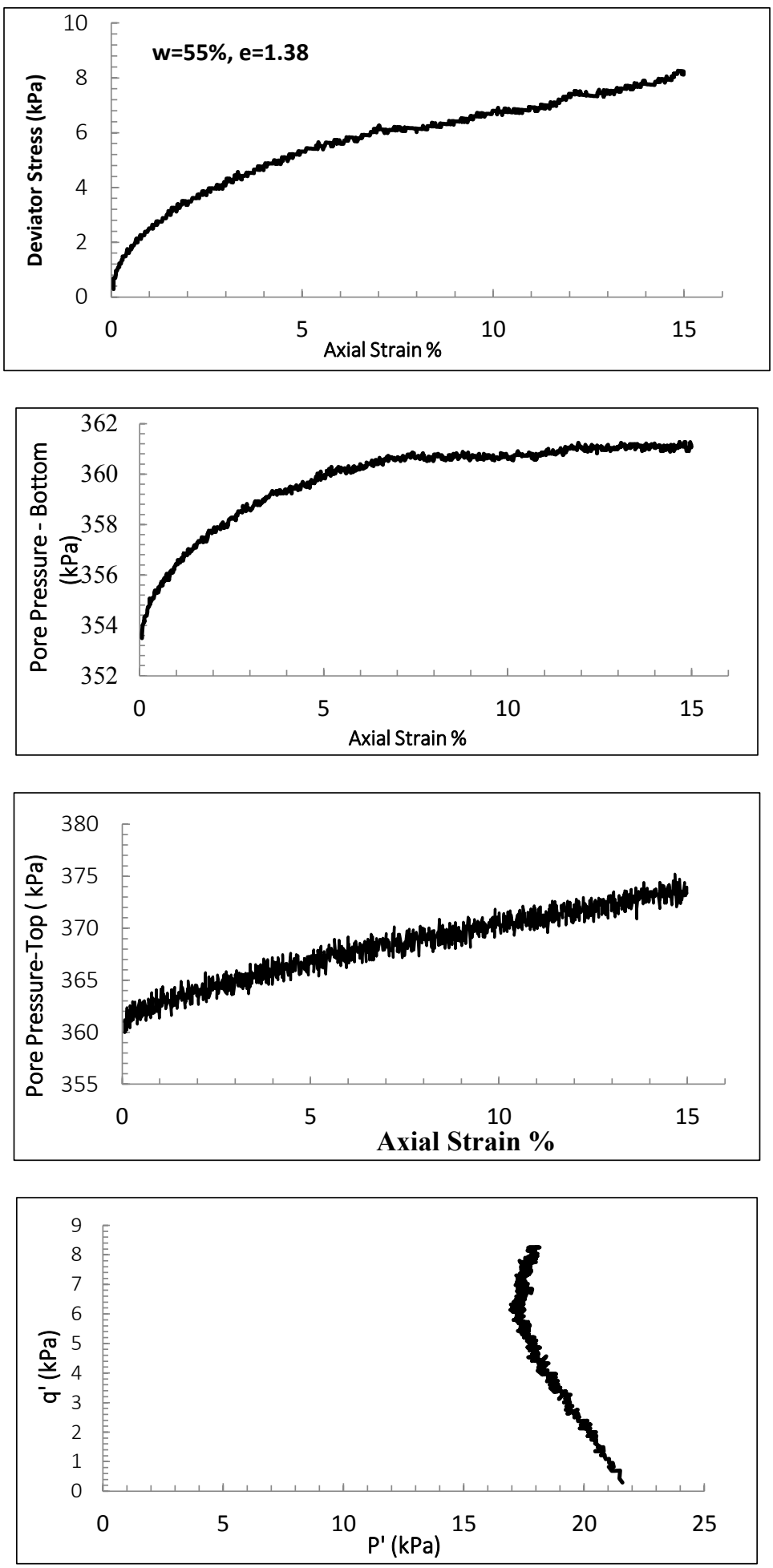

Figure 7-12. consolidated amended MFT behaviour during shearing(25 kPa)- a) Deviator stress vs. shear strain, b) Pore water pressure-Bottom c) Pore water pressure-Top, d) stress path (bottom) 

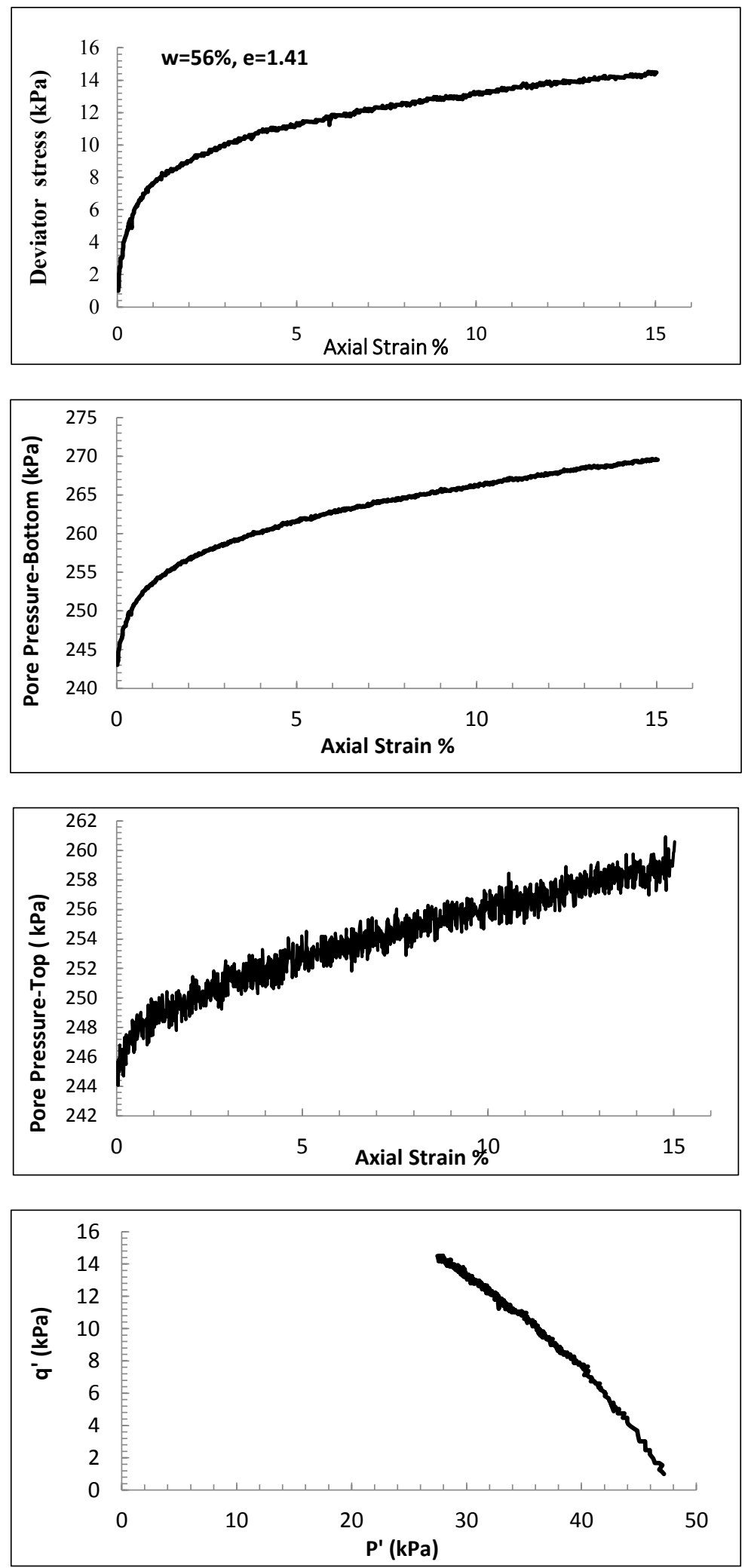

Figure 7-13.Consolidated amended MFT behaviour during shearing(50 kPa)- a) Deviator stress vs. shear strain, b) Pore water pressure-Bottom c) Pore water pressure-Top, d) stress path (bottom) 

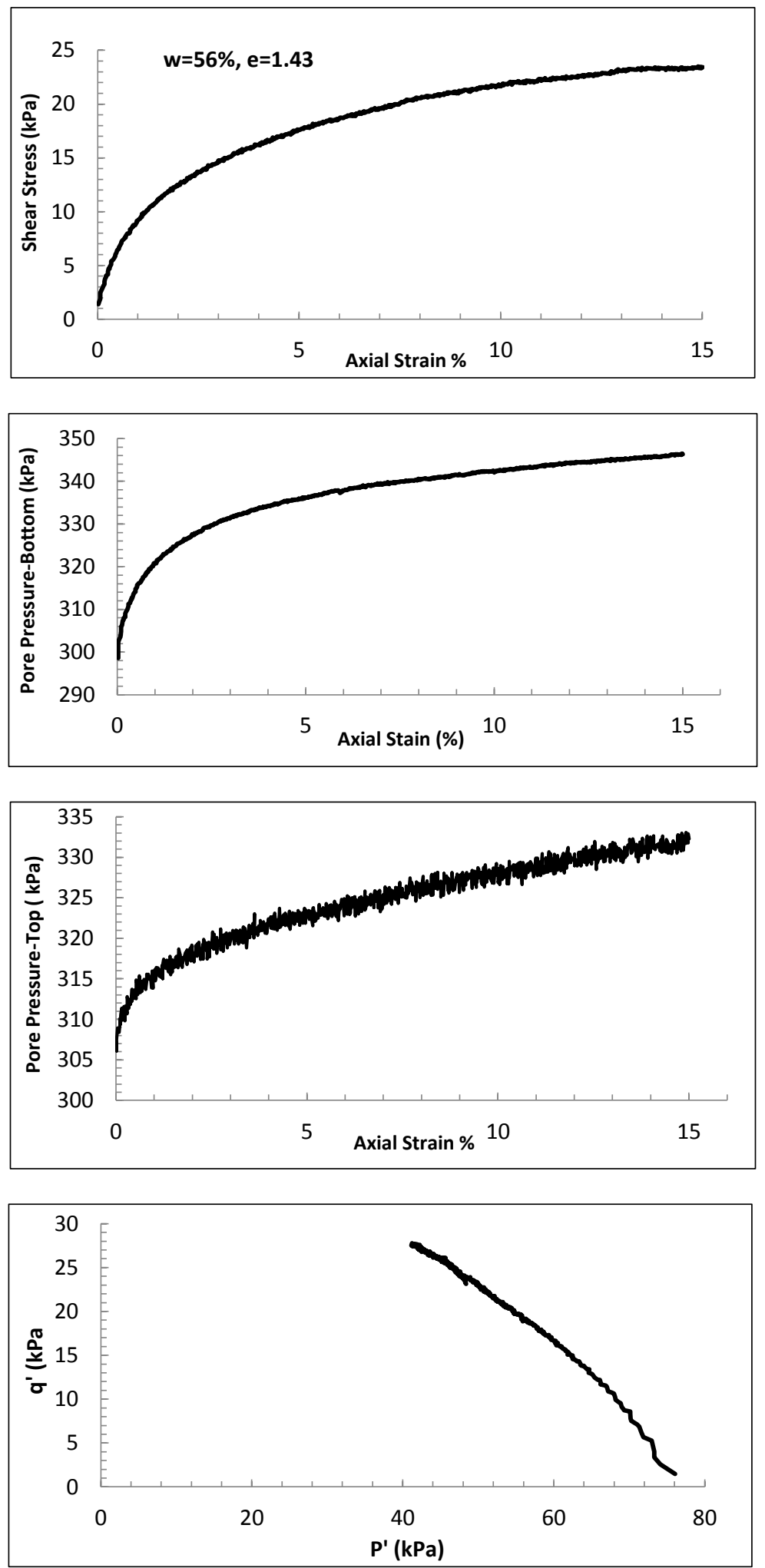

Figure 7-14.Consolidated amended MFT behaviour during shearing(75 kPa)- a) Deviator stress vs. shear strain, b) Pore water pressure-Bottom c) Pore water pressure-Top, d) stress path (bottom) 

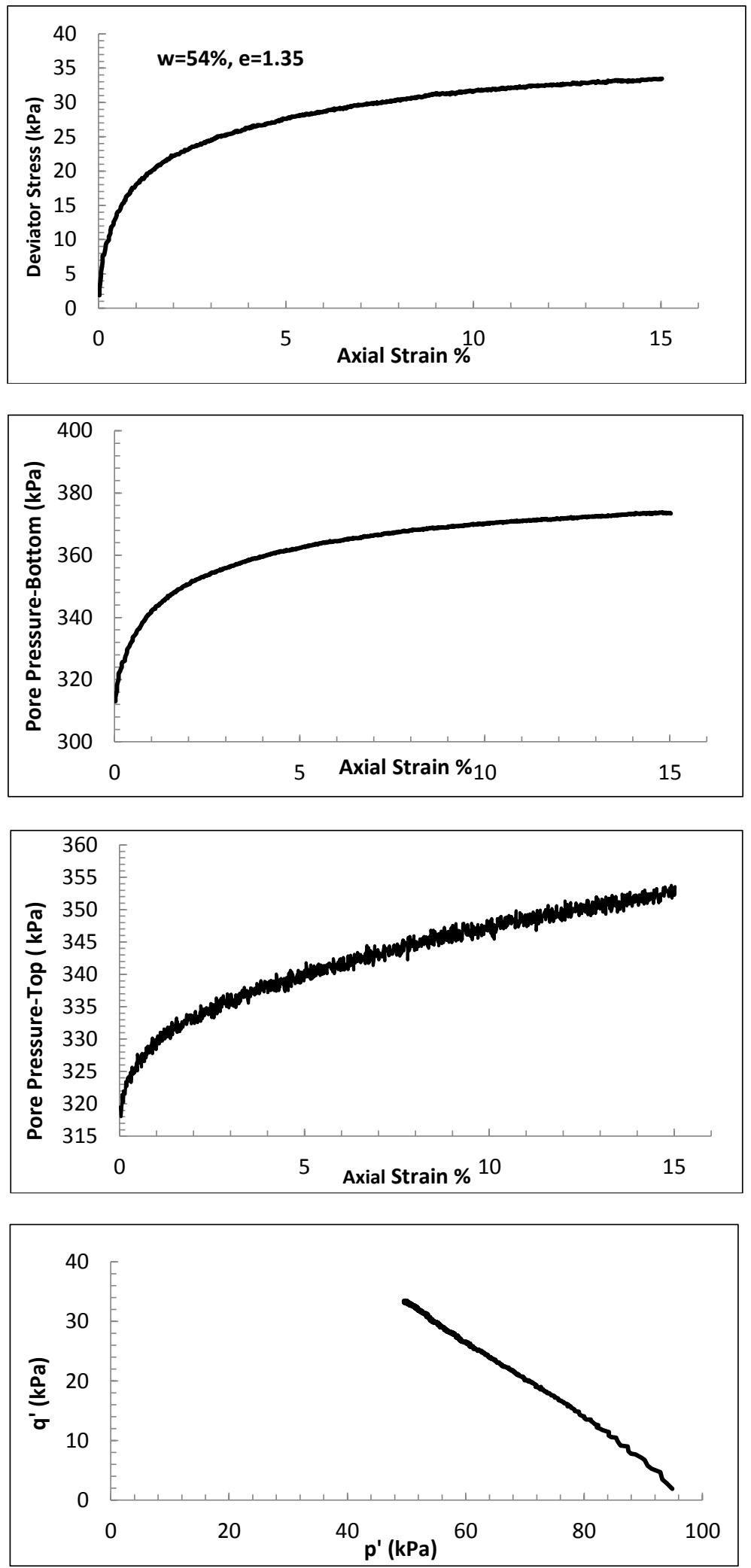

Figure 7-15.Consolidated amended MFT behaviour during shearing(100 kPa)- a) Deviator stress vs. shear strain, b) Pore water pressure-Bottom c) Pore water pressure-Top, d) stress path (bottom) 

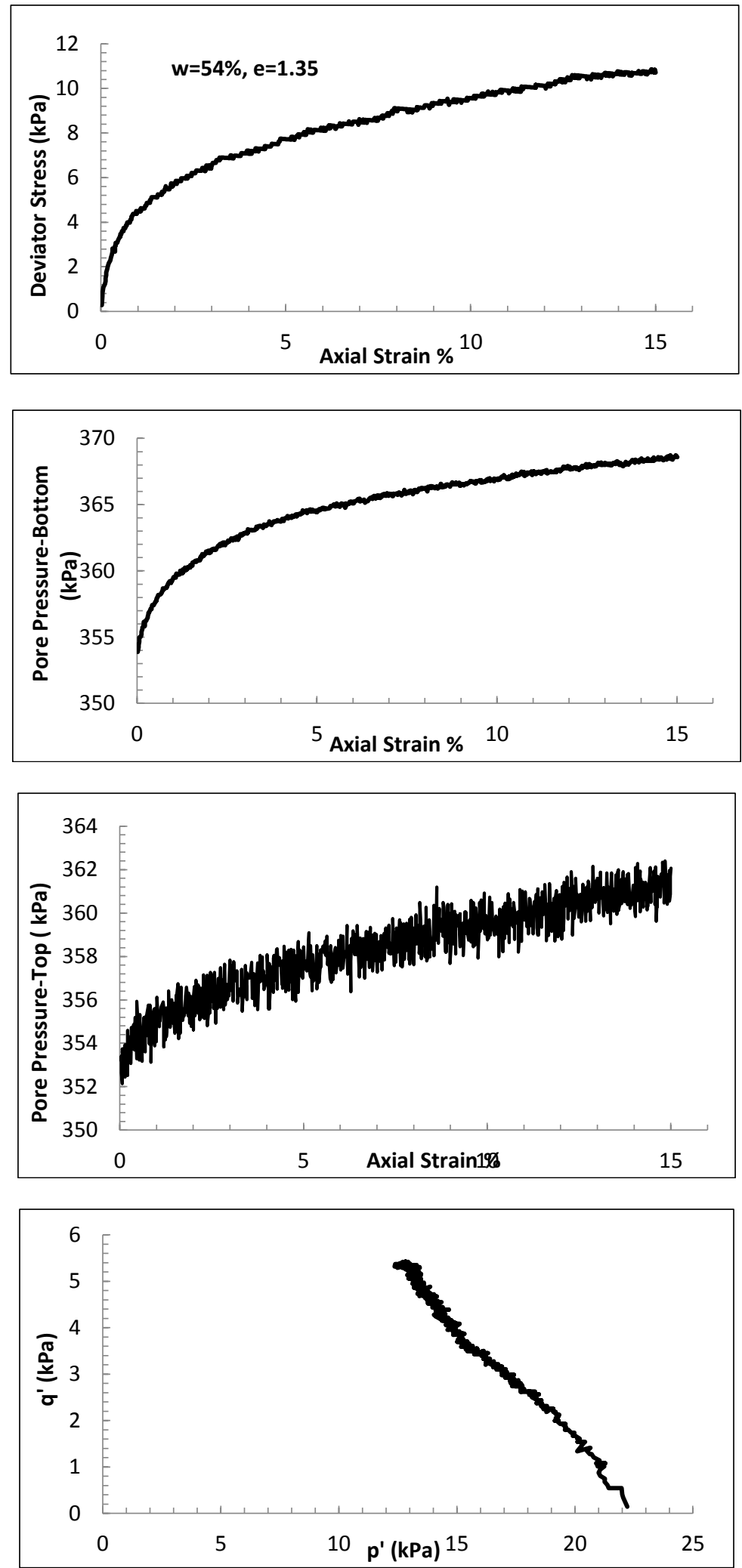

Figure 7-16.Desiccated MFT behaviour during shearing(25 kPa)- a) Deviator stress vs. shear strain, b) Pore water pressure-Bottom c) Pore water pressure-Top, d) stress path (bottom) 

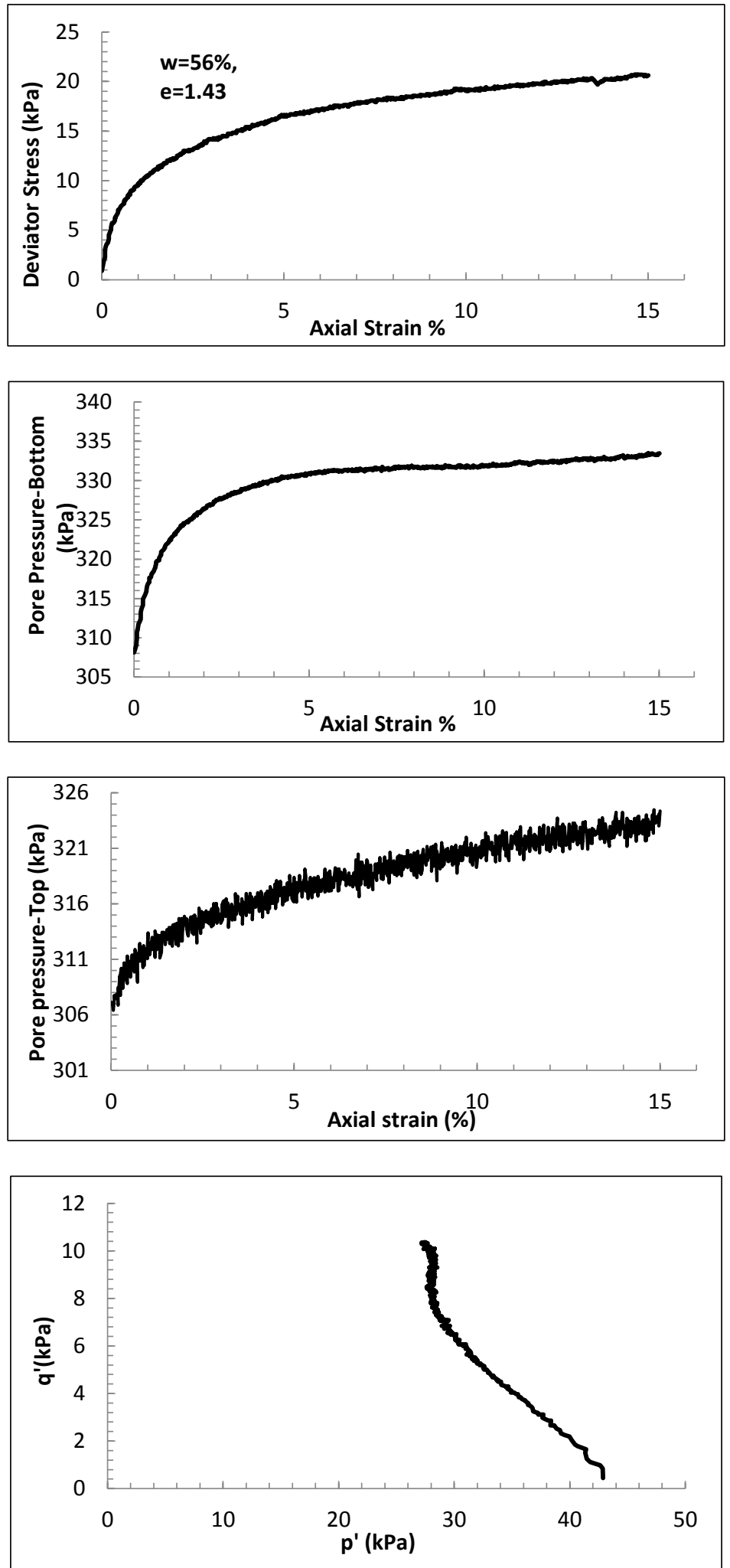

Figure 7-17.Desiccated MFT behaviour during shearing(50 kPa)- a) Deviator stress vs. shear strain, b) Pore water pressure-Bottom c) Pore water pressure-Top, d) stress path (bottom) 

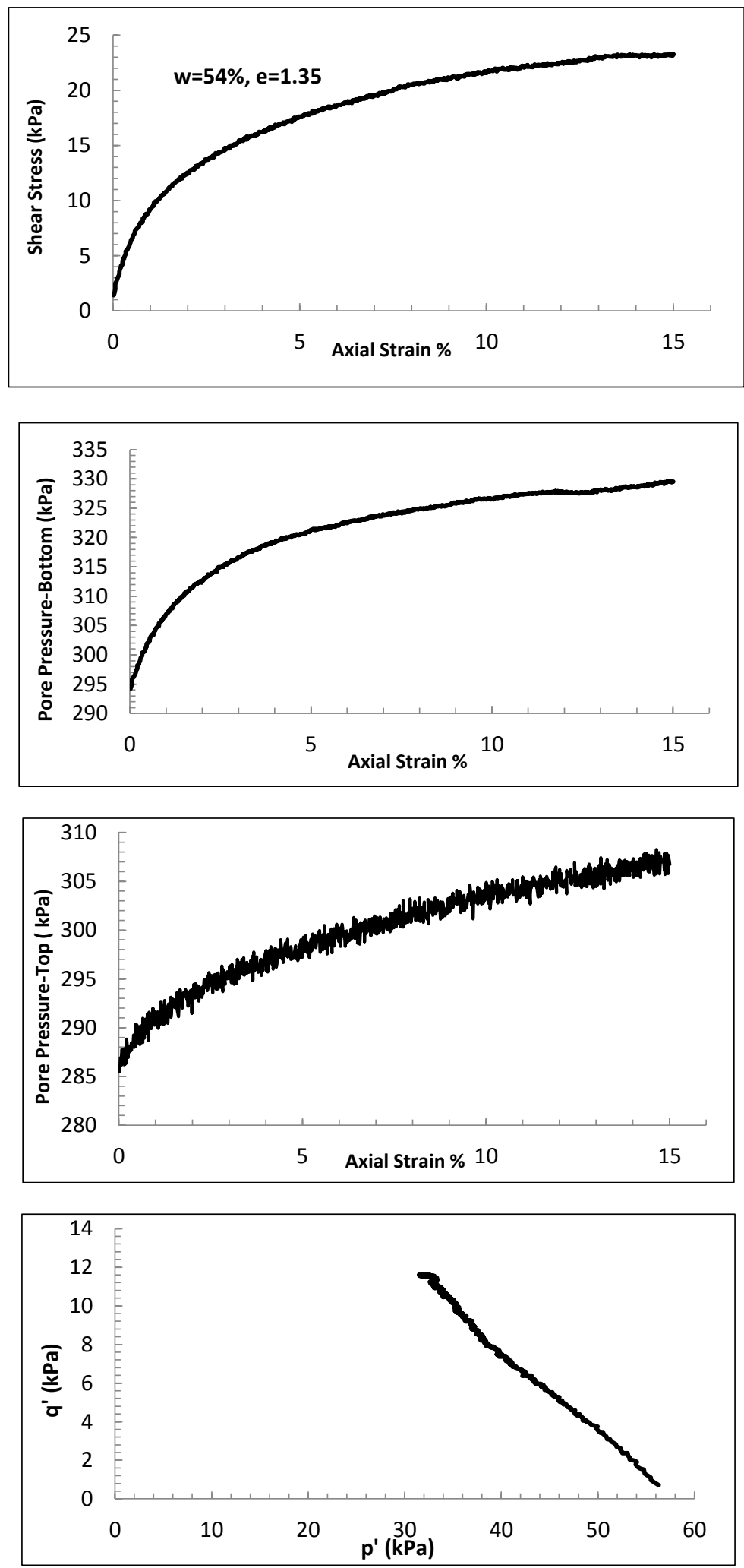

Figure 7-18.Desiccated MFT behaviour during shearing(75 kPa)- a) Deviator stress vs. shear strain, b) Pore water pressure-Bottom c) Pore water pressure-Top, d) stress path (Bottom) 

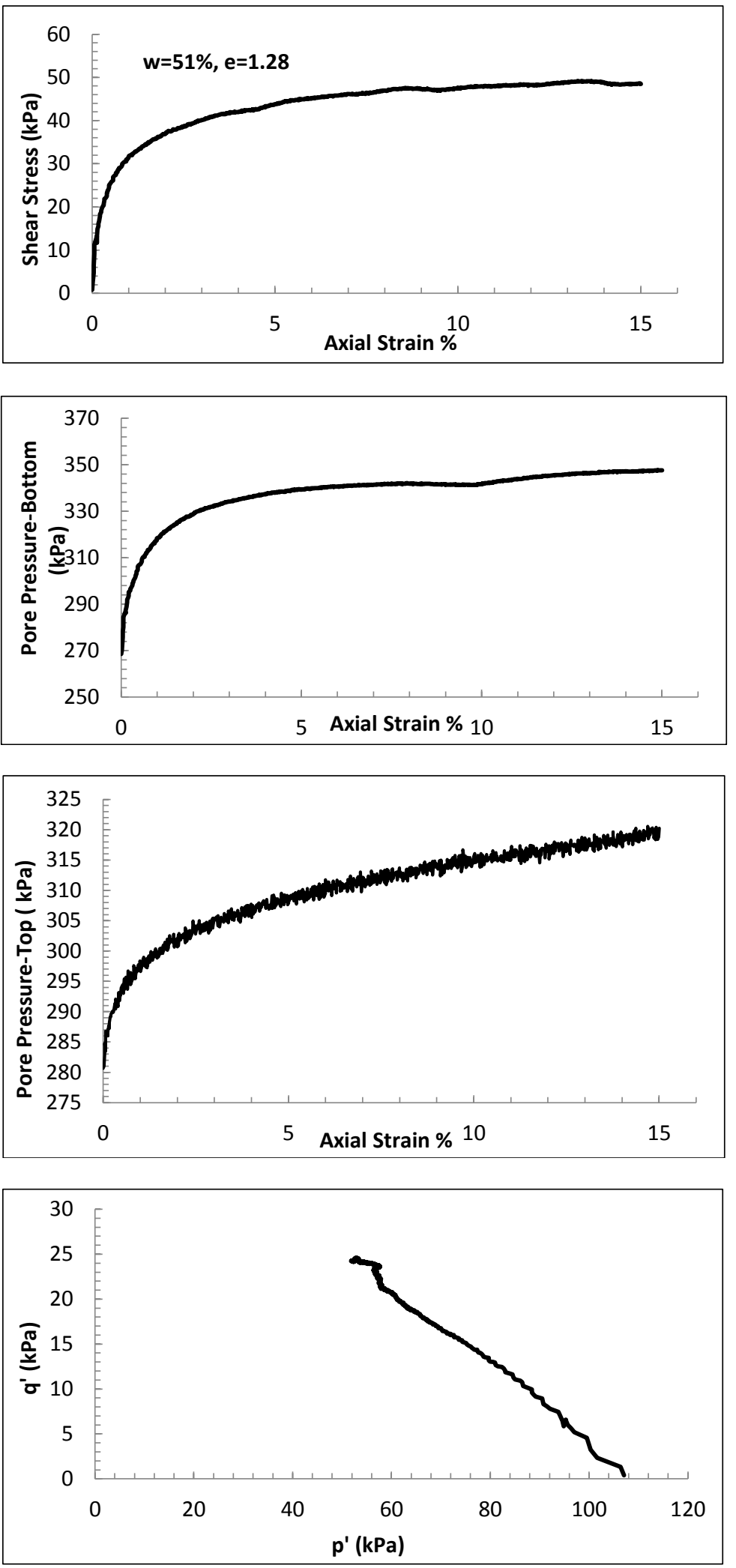

Figure 7-19.Desiccated MFT behaviour during shearing(100 kPa)- a) Deviator stress vs. shear strain, b) Pore water pressure-Bottom c) Pore water pressure-Top, d) stress path (Bottom) 